\title{
La educación terapéutica en los pacientes con EPOC
}

TESIS DOCTORAL

Programa de doctorado en Ciencias de la Enfermería

ANA FOLCH AYORA

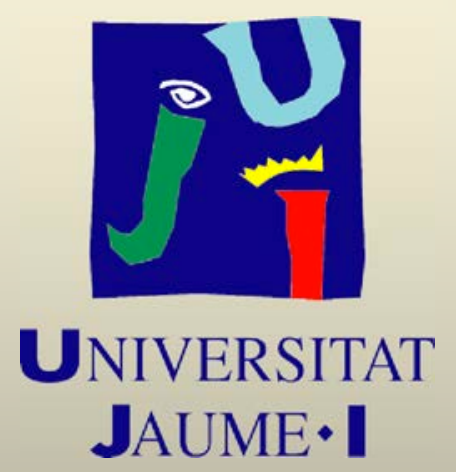

Directoras: María Loreto Macia Soler, María Isabel Orts Cortés 


\section{Agradecimientos}

Por fin ha llegado el momento. Después de tantos meses en los que había que saltar las barreras que se iban sumando para la realización del proyecto, las mismas, barreras me han hecho conocer personas que lo han hecho posible. Así que es difícil empezar los agradecimientos de esta tesis, ya que son muchas las personas que tiene un trocito de cada una de las páginas que la componen.

Voy a empezar agradecer en las primeras personas que confiaron en mí para llevarla a cabo, Isabel y Loreto. Intentando motivarme cuando la captación no era buena y orientándome con sus conocimientos en cada uno de los apartados. Así que solo puedo decir gracias.

A mis compañeros de la UJI por compartir y escuchar en mis momentos de agobio y desesperación. Pero sin duda a mi compañera, Vicky, que sin conocerme decido ayudarme en todo lo necesario, por qué sin ti esto no hubiera sido posible, he podido dejar pocos o muchos conocimientos a la ciencia pero sin duda, me llevo una amiga, gracias Vicky.

Como no, a todos los pacientes que han, confiado en mí, pensando que yo les estaba aportando mucho, pero eran ellos los que me han enseñado todo lo que se de esta enfermedad. Así que siempre os estaré agradecida.

Y a otros que aunque no se vean de forma física han aportado grandes granitos como mi novio y compañero de viaje en el camino de la vida, Carlos, por estar ahí cuando te he necesitado y siempre me has sabido comprender, muchas gracias, por ser tan bueno conmigo.

A todos mis amigos, en especial a Raquel e Idoya, que aunque los he dejado un poco de lado los últimos meses siempre han estado motivando, como lo prometido es deuda por fin podré irme al viaje que me regalasteis para mi cumpleaños.

A mis padres y hermana, solo me queda decirlos que prometo estar más tiempo con vosotros, ya no me volverá a quedar la excusa de que tengo que hacer tesis, a ti Belén prometo visitarte en Barcelona que hace un año que te fuiste y no he ido ni a ver tu casa, perdón.

$\mathrm{Y}$ a tantas personas que no recuerdo en este momento pero sin duda tienen mucho que ver con estas páginas. 


\section{Abreviaturas por orden alfabético}

ATS American Thoracic Society

AAT Alfa-1-antitripsina

ACV Accidente Cerebro Vascular

BMRC British Medical Research Council

BODE Body mass index airflow obstruction dyspnea and exercise capacity index

CAT Cuestionary Assesment Test

cc Centímetros Cúbicos

CVRS Calidad de Vida Relacionada con la Salud

CVF Capacidad Vital Forzada

CIE Clasificación Internacional de Enfermedades

CO Monóxido de Carbono

$\mathrm{CO}_{2} \quad$ Dióxido de Carbono

DAAT Deficiencia de Alfa-1-antitripsina

dl Decilitros

DLCO Capacidad de difusión del monóxido de carbono

EFQM European Foundation Quality Management

EPOC Enfermedad Pulmonar Obstructiva Crónica

ET Educación Terapéutica

EVA Escala de Valoración Analógica

FEF Capacidad espiratoria forzada

FEV $_{1} \quad$ Flujo espiratorio en el primer segundo

FVC Capacidad Vital Forzada

GC Grupo Control 
GI Grupo Intervención

GOLD Chronic Obstructive Lung Disease

GRD Grupos Relacionados con el Diagnóstico

HAD Hospital anxiety and depression scale

HR Hazard Ratio

IC Intervalo de Confianza

INE Instituto Nacional de Estadística

IgE Inmunoglobulina $\mathrm{E}$

IMC Índice de Masa Corporal

IR Insuficiencia Respiratoria

ISHLT International Society for Heart and Lung Transplantation Registry

Kg Kilogramos

LABA Beta adrenérgicos de larga duración

LAMA Anticolinérgicos de larga duración

m Metros

mg Milígramos

mm Milímetros

ml Mililitros

mmHg Milímetros de mercurio

MRC Medical Resoult Council

NHLBI National Heart, Lung, and Blood Institute

$\mathrm{NO}_{2} \quad$ Dióxido de nitrógeno

$\mathbf{O}_{2} \quad$ Oxígeno

OMS Organización Mundial de la Salud

$\mathbf{P a O}_{2} \quad$ Presión arterial de Oxígeno

$\mathrm{PaCO}_{2}$ Presión arterial de Dióxido de Carbono 
SEPAR Sociedad Española de Enfermedades Respiratorias

SGRQ St. George Respiratory Questionnaire

$\mathrm{SpO}_{2} \quad$ Saturación Arterial de Oxígeno

SNS Sistema Nacional de Salud

$\mathbf{S O}_{2} \quad$ Dióxido de Sulfuro

TAC Tomografía Axial Computerizada

TACAR Tomografía Axial Computerizada de tórax de Alta Resolución

TBC Tuberculosis Pulmonar

TSN Tratamiento Sustitutivo de Nicotina

UE Unión Europea

UCE Unidad de Corta Estancia

UHD Unidad de Hospitalización Domiciliaria

UCI Unidad de Cuidados Intensivos

UJI Universitat Jaume I

VIH Virus de la Inmunodeficiencia Humana 


\section{RESUMEN}

Introducción: la EPOC es prevenible y tratable. En el curso de la misma aparecen uno o dos periodos de agudizaciones o exacerbaciones anuales, suponiendo un elevado coste sanitario. Por lo tanto la prevención de las exacerbaciones es un objetivo prioritario recogido en las principales guías de consenso. La educación terapéutica (ET) forma parte del tratamiento en la prevención secundaria y terciaria.

Objetivo: Determinar y evaluar la efectividad de un programa estructurado de ET, en comparación con la atención tradicional, trascurridos tres meses del alta, en base al uso de recursos sanitarios utilizados, calidad de vida, conocimiento de la enfermedad y la adherencia al tratamiento.

Material y métodos: revisión integradora de los ensayos clínicos que apliquen programas de ET, estudio descriptivo de la población EPOC en el Hospital Universitario General de las historias clínicas de los últimos 5 años para llevar a cabo un ensayo clínico aleatorizado y controlado (simple ciego: enmascaramiento en el análisis de los datos y ocultación de la asignación) de un 1 año y 6 meses de duración. En el Hospital Universitario General de Castellón. Población y muestra: selección de forma consecutiva a pacientes que ingresen con diagnóstico de exacerbación de EPOC que den su consentimiento informado ingresen y tengan teléfono de contacto, se excluyeron pacientes con esperanza de vida $<6$ meses de vida o sin capacidad de seguir un programa educativo. Análisis de los datos, descripción e inferencia, comparación de variables mediante pruebas paramétricas o no paramétricas en función de la naturaleza de las variables y las condiciones de aplicación de los test. Nivel de significación bilateral $\mathrm{p}<0.05$.

Resultados: de los 77 pacientes incluidos en el estudio 60 finalizaron el mismo, con un perfil mayoritario de varón de 73,2 años con estudios básicos, que vive con su esposa en su domicilio familiar. Si atendemos a los ingresos hospitalarios, la media de ingresos anuales se situó en 1 ingreso por causa respiratoria y 2 visitas a urgencias anuales. Siendo el grupo control el que presento una mayor reducción de los mismos, siendo sus diferencias significativas. Todos los pacientes mejoran sus conocimientos tanto de sus signos y síntomas de exacerbación como la medicación de rescate en caso de necesidad, siendo esta mejoría más notoria y significativa en el conocimiento del nombre de su patología. El uso de los dispositivos de inhalación mejora el uso del cartucho presurizado de forma significativa, pero no lo hace al comprarla entre los grupos al inicio y al final del estudio. La adherencia al tratamiento se mantuvo muy homogénea al principio y al final del mismo.

Conclusiones: la ET no disminuye el uso de recursos sanitarios, no mejora la calidad de vida, ni la adherencia al tratamiento, solo mejorando la realización de la técnica de uso del cartucho presurizado.

Palabras clave: Enfermedad Pulmonar Obstructiva Crónica, Educación en Salud, Educación del Paciente como Asunto

Proyecto subvencionado por SEPAR, Área enfermería (191) 


\section{ABSTRACT}

Introduction: COPD is preventable and treatable. During the same one or two periods of exacerbations or annual exacerbations, assuming a high health care costs appear. Therefore prevention of exacerbations is a priority reflected in the major consensus guidelines. Therapeutic education (ET) is part of treatment in secondary and tertiary prevention.

Objective: To identify and assess the effectiveness of a structured ET, compared to traditional care program, three months elapsed discharge, based on the use of health resources used, quality of life, knowledge of the disease and treatment adherence.

Methods: integrative review of clinical trials apply ET programs, descriptive study of COPD population at the University General Hospital of the medical records of the past five years to carry out a (single-blind randomized controlled clinical trial: masking the data analysis and allocation concealment) of a 1 year and 6 months. General University Hospital of Castellon. Population and sample: selection of consecutive patients admitted with a diagnosis of COPD exacerbation give their informed consent to enter and have telephone contact, excluded patients with or without ability to follow an educational program life expectancy $<6$ months of age . Data analysis, description and inference, comparing variables mediantes parametric or non-parametric tests depending on the nature of the variables and conditions of application of the test. Sided significance level of $\mathrm{p}<0.05$.

Results: Of the 77 patients included in the study 60 completed it with a male majority profile of 73.2 years with only basic education, who lives with his wife in their family home. If we look at hospital admissions, the average annual income rose to 1 admission for respiratory causes and 2 annual visits to the emergency room. As the control group which presented a greater reduction thereof, with their significant differences. All patients improve their knowledge both of the signs and symptoms of exacerbation as rescue medication if necessary, with the most noticeable and significant knowledge of the name of their condition improved. The use of inhalation devices improves the use of pressurized cartridge significantly, but it does buy between groups at the beginning and end of the study. Adherence remained very homogeneous at the beginning and end.

Conclusions: ET does not diminish the use of health resources, does not improve the quality of life and adherence to treatment, only improving the performance of the technique of using pressurized cartridge.

Keywords: Chronic Obstructive Pulmonary Disease, Health Education, Patient Education as Topic

Project subsidized by SEPAR, nursing Area 


\section{Índice de contenidos}

\section{Marco teórico}

1. Introducción..................................................... 11

1.1 Enfermedad pulmonar obstructiva crónica.......................11

1.2 Signos y síntomas de la EPOC................................11

1.3 Fenotipos clínicos de la EPOC .............................. 12

1.4 Epidemiologia................................................14

$\mathbf{1 . 5}$ Historia de la EPOC ...........................................16

1.6 Diagnóstico...............................................17

1.7 Historia natural de la EPOC ...................................20

1.7.1 Exacerbaciones......................................... 21

1.7.2 Gravedad de las exacerbaciones...........................22

$\mathbf{1 . 8}$ Etiología de la EPOC.........................................23

1.9 Comorbilidades asociadas a la EPOC ...........................29

1.10 Prevención de la EPOC ....................................32

1.11 Tratamiento del paciente con EPOC..........................36

1.11.1 Cirugía..................................................36

1.11.2 Tratamiento farmacológico...............................37

1.11.3 Tratamiento no farmacológico..........................40

1.12 Educación terapéutica ....................................41

1.12.1 Contenido de los programas de educación terapéutica en pacientes EPOC.....................................42

1.12.2 Recomendaciones generales de los programas de educación terapéutica............................................42

1.13 Justificación...........................................45

\section{Hipótesis y objetivos}

2.1Hipótesis.......................................................46

2.2 Objetivos................................................46

2.2.1 Objetivo secundarios................................46

2.2.2 Objetivos principales...................................46

\section{III.Metodología}

3.1 Metodología Revisión Integradora 
3.1.1 Diseño...............................................48

3.1.2 Criterios de selección..................................48

3.1.3 Identificación de los estudios...........................49

3.1.4 Valoración de la calidad metodología......................49

3.1.5 Análisis de los datos...................................50

3.2 Metodología del análisis de las características de la población con diagnóstico de exacerbación de la EPOC catalogada con el GRD088 y que ingresan en el Hospital Universitario General de Castellón desde 2008 hasta 2013

3.2.1 Diseño............................................... 51

3.2.2 Población y muestra...................................51

3.2.3 Variables estudiadas....................................51

3.2.4 Procedimiento de recogida de datos....................52

3.2.5 Consideraciones éticas...............................52

3.3 Metodología para determinar y evaluar la efectividad de un programa estructurado de educación terapéutica

3.3.1 Diseño................................................

3.3.2 Ámbito.............................................54

3.3.3 Población y muestra.................................56

3.3.4 Duración................................................57

3.3.5 Variables

3.3.5.1 Variables sociodemográficas.....................57

3.3.5.2 Variable explicativa...............................58

3.3.5.3 Variables de resultado principal..................60

3.3.5.4 Variables de control..............................62

3.3.6 Recogida de datos..................................66

3.3.7 Análisis estadístico....................................67

3.3.7.1 Estadística descriptiva general.....................67

3.3.7.2 Estadística homogeneidad de los grupos al inicio....67

3.3.7.3 Estadística bivariante de contraste de hipótesis.......68

3.3.7.4 Tamaño muestral................................68

3.3.8 Aleatorización

3.3.8.1 Generación de la secuencia.......................68

3.3.8.2 Mecanismo de ocultación de la asignación............68 
3.3.9 Consideraciones éticas .69

\section{IV.Resultados}

4.1 Resultados de la Revisión Integradora..............................71

4.1.1 Participantes/reclutamiento...........................72

4.1.2 Intervenciones.......................................73

4.1.3 Medidas de resultado..................................74

4.1.4 Resultados de los programas educativos..................74

4.1.5 Calidad metodología..................................75

4.2 Resultados del análisis de las características de la población con diagnóstico de Exacerbación de la EPOC catalogado con GRD088 y que ingresan en el Hospital Universitario General de Castellón desde 2008 hasta 2013

4.2.1 Variables sociodemográficas..........................76

4.2.2 Variables clínicas.......................................76

4.2.2.1 Ingresos hospitalarios..........................76

4.2.2.2 Ingresos por año.................................77

4.2.2.3 Número de ingresos por mes.....................77

4.2.3 Variables de control....................................78

4.2.3.1 Comorbilidades................................78

4.2.3.2 Hábitos tóxicos.................................80

4.2.3.3 Procedimientos diagnósticos utilizados.............80

4.2.3.4 Tratamientos terapéuticos utilizados...............81

4.3 Resultados de la efectividad de un programa estructurado de educación terapéutica (ET), durante el ingreso, en comparación con la atención tradicional

4.3.1 Participantes en el estudio...............................82

4.3.2 Descriptivo general..................................84

4.3.2.1 Variables sociodemográficas.....................84

4.3.2.2 Resultados principales.............................86

4.3.2.3 Resultados de las variables de control................94

4.3.3 Resultados homogeneidad entre grupos.................102

4.3.3.1 Variables sociodemográficas......................102

4.3.3.2 Variables principales...........................103 
4.3.3.3 Variables de control .108

4.3.4 Determinar y evaluar la efectividad de un programa estructurado de educación terapéutica (ET), a los 3 meses, en comparación con la atención tradicional

4.3.4.1 Uso de los servicios hospitalarios..................116

4.3.4.2 Calidad de vida.................................117

4.3.4.3 Conocimiento de la enfermedad..................119

4.3.4.4 Adherencia al tratamiento.

4.3.5 Resultados evaluación de la efectividad del tipo de atención en el grupo de pacientes asignados al grupo intervención

4.3.5.1 Uso de los servicios hospitalarios.

4.3.5.2 Calidad de vida

4.3.5.3 Conocimiento de la enfermedad. 123

4.3.5.4 Adherencia al tratamiento. 125

4.3.6 Resultados evaluación de la efectividad del tipo de atención en el grupo de pacientes asignados al grupo control

4.3.6.1 Uso de los servicios hospitalarios. 126

4.3.6.2 Calidad de vida .127

4.3.6.3 Conocimiento de la enfermedad 128

4.3.6.4 Adherencia al tratamiento

\section{Discusión}

5.1 Revisión Integradora 131

5.2 Discusión del análisis de las características de la población con diagnóstico de exacerbación de la EPOC catalogado con el GRD088 y que ingresan en el Hospital Universitario General de Castellón desde 2008 hasta 2013 .134

5.3 Discusión de la determinación y evaluación de la efectividad de un programa estructurado de educación terapéutica, durante el ingreso, en comparación con la atención convencional

5.3.1 Descripción de la población 136

5.3.2 Homogeneidad de los grupos.........................138

5.3.3 Recursos sanitarios utilizados........................... 138

5.3.4 Calidad de vida......................................138

5.3.5 Conocimientos en la EPOC..........................................139 
5.3.6 Adherencia al tratamiento. 141

\section{VI.Limitaciones}

6.1 Limitaciones en la Revisión Integradora. 143

6.2 Limitaciones de la determinación y evaluar la efectividad de un programa estructurado de educación terapéutica, durante el ingreso, en comparación con la atención convencional. 143

6.3 Limitaciones de la determinación y evaluar la efectividad de un programa estructurado de educación terapéutica, durante el ingreso, en comparación con la atención convencional.....................................143

VII. Conclusiones.......................................................... 145

VIII. Recomendaciones..................................................... 147

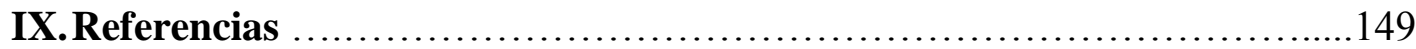

X. Anexos

Anexo I. Contenido de las sesiones de educación..........................180

Anexo II. Definiciones clave............................................201

Anexo III. Cuestionario al ingreso......................................202

Anexo IV. Cuestionario a los 3 meses....................................219

Anexo V. Recomendaciones para la implementación de los cuestionarios...236

Anexo VI. Hoja de información y consentimiento informado. ... 


\section{Índice de tablas}

Tabla 1. Escala de clasificación GOLD de la EPOC ................................. 18

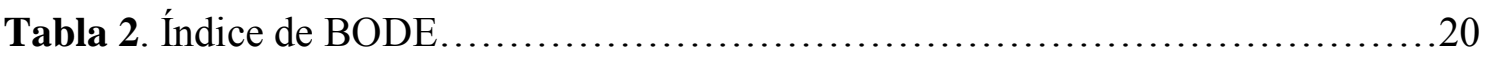

Tabla 3. Clasificación de la gravedad de las exacerbaciones.......................23

Tabla 4. Factores de riesgo................................................. 28

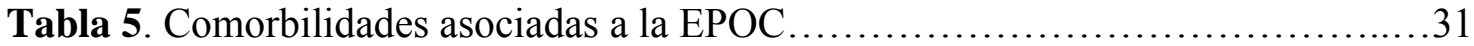

Tabla 6. Tratamiento para la deshabituación tabáquica.............................35

Tabla7. Agentes infecciosos causantes en mayor medida de las exacerbaciones........39

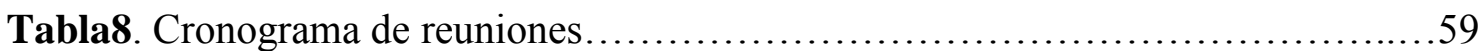

Tabla 9. Puntuaciones escala calidad de vida CAT .................................60

Tabla10. Puntuación escala de calidad de vida St. George.........................61

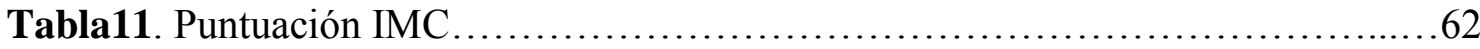

Tabla12. Estadíos de la EPOC...................................................63

Tabla 13. Valores normales de la gasometría arterial..............................63

Tabla14. Grado de disnea MRC ................................................64

Tabla15. Puntuación índice de Chalson..........................................64

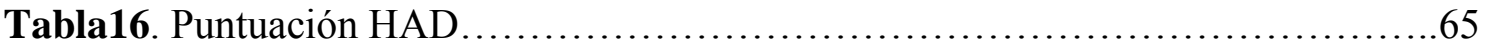

Tabla 17. Puntuación Barthel................................................66

Tabla 18. Efecto de los programas educativos en las principales variables de resultado .75

Tabla19.Frecuencias de hospitalizaciones por unidad hospitalaria..................76

Tabla 20. Frecuencias de ingresos por año....................................... 77

Tabla 21. Frecuencia de comorbilidades.......................................... 71

Tabla 22. Procedimientos diagnósticos más utilizados............................. 80

Tabla 23. Procedimientos terapéuticos utilizados.................................. 81

Tabla 24. Sexo y edad.......................................................... 84

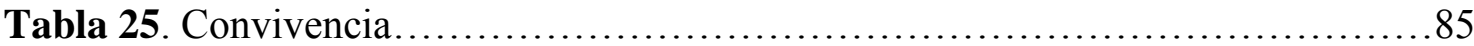

Tabla 26. Apoyo social percibido.............................................. 85

Tabla 27. Uso de los servicios hospitalarios..................................... 87

Tabla 28. Calidad de vida CAT ................................................ 88

Tabla 29. Calidad de vida St.George síntomas.................................. 89

Tabla 30. Exacerbaciones................................................ 90 
Tabla 31. Calidad de vida St. George: Limitaciones y molestias percibidas............91

Tabla 32. Calidad de vida St. George calidad de vida total.........................92

Tabla 33. Conocimiento de la enfermedad....................................92

Tabla 34. Uso de los dispositivos de inhalación.................................93

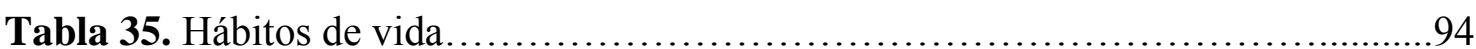

Tabla 36. Estado nutricional......................................................... 95

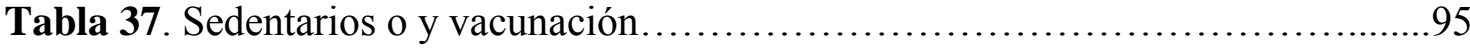

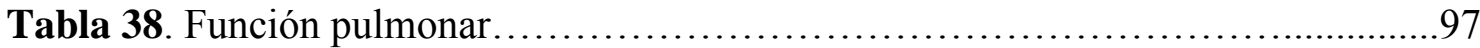

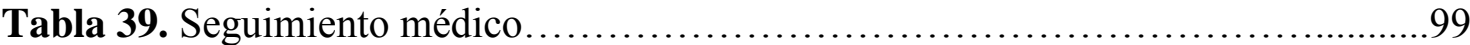

Tabla 40. Estado psicológico................................................... 101

Tabla 41. Dependencia en las actividades de la vida diaria........................101

Tabla 42. Variables sociodemográficas al ingreso................................ 102

Tabla 43. Uso de los servicios hospitalarios al ingreso.......................... 103

Tabla 44. Calidad de vida CAT al ingreso.................................... 104

Tabla 45. Calidad de vida St. George al ingreso.................................105

Tabla 46. Conocimiento de la enfermedad al ingreso...........................106

Tabla 47. Uso de los dispositivos de inhalación al ingreso.........................107

Tabla 48. Adherencia al tratamiento al ingreso.................................. 107

Tabla 49. Hábitos de vida al ingreso........................................... 109

Tabla 50. Función pulmonar al ingreso.................................... 111

Tabla 51. Seguimiento médico al ingreso........................................ 113

Tabla 52. Estado psicológico al ingreso...................................... 115

Tabla 53. Dependencia en las actividades de la vida diaria al ingreso...................115

Tabla 54. Uso de los servicios hospitalarios a los 3 meses........................117

Tabla 55. Calidad de vida CAT 3 meses.......................................... 118

Tabla 56. Calidad de vida St. George 3 meses...................................118

Tabla 57. Conocimiento de la enfermedad a los 3 meses............................119

Tabla 58. Uso de los dispositivos de inhalación a los 3 meses.......................120

Tabla 59. Adherencia al tratamiento a los 3 meses.............................. 120

Tabla 60. Uso de los servicios hospitalarios grupo intervención....................121

Tabla 61. Calidad de vida CAT grupo intervención....................................122

Tabla 62. Calidad de vida St. George grupo intervención........................... 123

Tabla 63. Conocimiento de la enfermedad grupo intervención....................123

Tabla 64. Uso de los dispositivos de inhalación grupo intervención.................124 
Tabla 65. Adherencia al tratamiento grupo intervención........................... 125

Tabla 66. Uso de servicios hospitalarios grupo control........................... 126

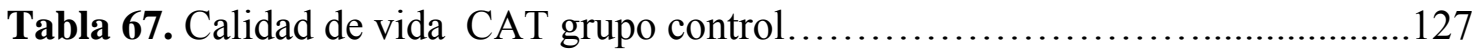

Tabla 68. Calidad de vida St.George grupo control...................................127

Tabla 69. Conocimiento de la enfermedad grupo control..........................128

Tabla 70. Uso de los dispositivos de inhalación grupo control....................129

Tabla 71. Adherencia al tratamiento grupo control.................................129 


\section{Índice de gráficos}

Gráfico 1. Frecuencia de exacerbaciones por año............................. 77

Gráfico 2. Frecuencia de los tumores........................................... 78

Gráfico 3. Nivel de estudios.................................................... 84

Gráfico 4. Calidad de vida CAT valores totales................................. 88

Gráfico 5. Adherencia terapéutica............................................. 93

\section{Índice de imágenes}

Imagen 1. Hospital Universitario General de Castellón..............................54

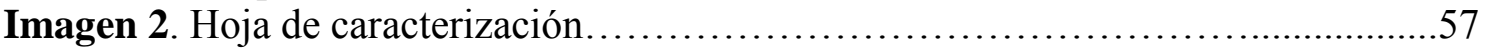

\section{Índice de diagramas}

Diagrama 1. Diagrama de flujo............................................66

Diagrama 2. Diagrama de flujo Revisión Integradora............................ 72

Diagrama 3. Diagrama de flujo de los participantes del estudio....................83 


\section{MARCO TEÓRICO}




\section{MARCO TEÓRICO}

Los antecedentes de esta tesis se dividen en dos partes diferenciadas, una parte comprendida por las definiciones anatomofisiopatologicas de la Enfermedad Pulmonar Obstructiva Crónica de acuerdo a la evidencia científica más reciente, incluyendo el tratamiento de la enfermedad.

Una segunda parte donde se describen los tratamientos preventivos más avanzados, haciendo un especial énfasis en la educación terapéutica como objetivo clave del trabajo de investigación que se presenta.

\section{Introducción}

\subsection{Enfermedad pulmonar obstructiva crónica}

La Enfermedad Pulmonar Obstructiva Crónica (EPOC) se define como una enfermedad respiratoria caracterizada por una limitación crónica no reversible al flujo aéreo, con un diagnóstico precoz difícil, que se presenta entre la franja de edad de los 40 y los 69 años, dependiendo de países y regiones(1)

Tiene un comienzo silente y la manifestación más evidente es la presencia de disnea no progresiva.

El origen de la enfermedad se atribuye como consecuencia de una respuesta inflamatoria a partículas nocivas y gases, principalmente derivados del humo de tabaco.

Caracterizada por la aparición de agudizaciones frecuentes y asociada a comorbilidades que contribuyen el agravamiento progresivo de la enfermedad(2).

\subsection{Signos y síntomas de la EPOC}

Los principales signos y síntomas de la EPOC son:

Disnea, objetiva o subjetiva se trata del principal síntoma de la enfermedad, siendo causante de una pérdida progresiva de la calidad de vida de las personas, apreciada de forma distinta en función de la edad. Se manifiesta en etapas avanzadas, es progresiva y su presencia dificulta la tolerancia al ejercicio hasta limitar las actividades de la vida diaria. Existiendo varios instrumentos para medirla, el instrumentos más fácil, extendido y recomendado es el Medical Resoult Council (MRC)(3).

Tos crónica, aparece de forma lenta y progresiva hasta la aparición de forma diaria, teniendo mayor prevalencia en horario matutino, no está relacionada con el grado de obstrucción ni con la gravedad de la misma. 
Expectoración, de contenido mucolítico, tiene mayor espesor durante las primeras horas de la mañana y siendo de gran relevancia el aspecto del mismo, como los cambios en el color. Estando relacionados con la aparición de una exacerbación. Así como un volumen excesivo (>30 ml/día) la presencia de bronquiectasias. O la expectoración hemoptoica que sería indicativa de otro diagnóstico como el carcinoma (4).

Otros síntomas, como sibilancias, opresión torácica, pérdida de peso, ansiedad y depresión, osteoporosis, disfunción muscular e inflamación sistémica crónica, que afecta a las vías aéreas, parénquima y arterias pulmonares estarían también relacionadas con la EPOC (4).

\subsection{Fenotipos clínicos de la EPOC}

En la EPOC las formas de presentación son muy heterogéneas y por ello no es posible tener un único parámetro en consideración. La denominación de fenotipo se utiliza para referirse a las formas clínicas de los pacientes con EPOC, que se han definido como "aquellos atributos de la enfermedad que solos o combinados describen las diferencias entre individuos con EPOC en relación a parámetros que tienen significado clínico". Por tanto el fenotipo es capaz de clasificar a los pacientes en subgrupos con valor pronóstico y permite determinar la terapia más adecuada para lograr mejores resultados clínicos (5).

La actual clasificación clasifica a los pacientes en subgrupos en base a su valor pronóstico y permite determinar el tratamiento más adecuado para lograr mejores resultados $(6,7)$. Existen otras clasificaciones, pero la guía GesEPOC española clasifica a los pacientes en cuatro grandes grupos:

1. Fenotipo no agudizador con enfisema o bronquitis crónica

2. Fenotipo mixto EPOC-asma

3. Fenotipo agudizador con enfisema

4. Fenotipo agudizador con bronquitis crónica

Se han propuesto otros posibles fenotipos: declinador rápido(8), bronquiectasias $(9,10)$ y sistémico $(11)$, pero su trascendencia a la hora de dirigir el tratamiento no está establecida, y otros que se han descartado por su escasa prevalencia (déficit de alfa-1-antitripsina)(12), no se consideran una forma específica de la EPOC.

\section{Fenotipo no agudizador con enfisema o bronquitis crónica}

Este tipo de paciente se caracteriza por presentar un máximo de un episodio de agudización al año. Es el de menor riesgo de deterioro de su calidad de vida, pérdida de función pulmonar o mortalidad, en comparación con el resto de fenotipos. 


\section{Fenotipo agudizador}

Se define como fenotipo agudizador a todo paciente con EPOC que presente dos o más agudizaciones moderadas o graves al año(13). Estas exacerbaciones deben estar separadas al menos 4 semanas desde la finalización del tratamiento de la agudización previa o 6 semanas desde el inicio de la misma en los casos que no hayan recibido tratamiento, para diferenciar el nuevo evento de un fracaso terapéutico previo. La identificación del fenotipo agudizador se basa en la historia clínica y se ha demostrado que el diagnóstico basado en la declaración del paciente sobre su historial de agudizaciones es fiable(14). Existiendo varios tipos de agudizaciones, relacionadas con su etiología (bacteriana, viral o eosinofílica) que suelen mantenerse constante en episodios sucesivos(15). Este fenotipo no quita que las agudizaciones puedan estar presentes en los tres fenotipos restantes.

En el fenotipo agudizador resulta de gran relevancia preguntar por la historia de exacerbaciones en la entrevista clínica.

En este grupo de pacientes la Tomografía Axial Computerizada (TAC) de tórax es muy útil para el diagnóstico, ya que mediante la imagen obtenida se puede visualizar la presencia de bronquioectasias, así como su gravedad y extensión, permitiendo el tratamiento eficaz para bronquiectasias por infección(9).

Por tanto las exacerbaciones frecuentes pueden presentarse en cualquier de los tres fenotipos restantes $(15,16)$.

\section{Fenotipo mixto EPOC-asma}

Se define como una obstrucción crónica al flujo aéreo donde existen individuos asmáticos fumadores que desarrollan una obstrucción no completa pero reversible y fumadores sin antecedentes asmáticos cuyo patrón inflamatorio bronquial tiene un predominio de eosinófilos y se manifiesta por la reversibilidad al flujo aéreo aumentada con respecto a otros fenotipos(17¹9). Este grupo se desarrolló ya que los jóvenes asmáticos que desarrollan EPOC tenían características diferentes de las que presentaban los pacientes con EPOC con antecedentes asmáticos. Ya que presentan rinitis alérgica, hiperactividad bronquial inespecífica y la presencia de sibilantes, así como mayores concentraciones de Inmunoglogulina E (Ig E)(19), lo que es indicativo del fenotipo mixto (20). La principal causa de este fenotipo es el consumo de tabaco en pacientes asmáticos (21).

Existen investigaciones que afirman que los pacientes con este fenotipo presentan mayor riesgo de exacerbaciones(16). La prevalencia de este fenotipo es desconocida(20), hay estudios que han estimado la misma en un $23 \%$ de los pacientes EPOC entre 50 y 59 años, cifra que aumenta con la edad has el $52 \%$ de los casos con EPOC entre los 70 y 79 años.

En este tipo de pacientes la prueba espirométrica post broncodilatación es característica por la gran reversibilidad de la obstrucción tras la inhalación de los fármacos broncodilatadores (22). 


\section{Fenotipo bronquitis}

Según la Organización Mundial de la Salud (OMS) y la American Thoracic Society (ATS) este fenotipo se define como: pacientes que presentan tos productiva o expectoración durante más de 3 meses al año y durante 2 años consecutivos(23). La bronquitis crónica es el síndrome predominante, ya que presentan una inflamación en la vía aérea y en consecuencia una mayor hipersecreción bronquial así como un mayor riesgo de infecciones respiratorias (24). Un significativo grupo de pacientes con bronquitis crónica y agudizaciones repetidas suelen manifestar bronquiectasias tras una Tomografía Axial Computerizada de tórax de Alta Resolución (TACAR) $(9,11)$.

\section{Fenotipo enfisema}

Se define como una afección de los pulmones caracterizada por un aumento de tamaño de los espacios aéreos situados más allá del bronquiolo terminal y que se acompaña de cambios destructivos en sus paredes. Dado que el concepto de enfisema es anatómico, el diagnóstico es clínico y funcional, a partir de signos como la disnea, intolerancia al ejercicio físico, índice de masa corporal (IMC) reducido, datos de funcionalismo pulmonar de hiperinsuflación y evidencias radiológicas de afección pulmonar. El diagnóstico diferencial entre el enfisema y la EPOC enfisematosa es el número de agudizaciones. En este grupo de pacientes la presencia de agudizaciones está relacionada con un mal pronóstico al ser predictor de un descenso del Volumen Espiratorio Forzado al primer segundo $\mathrm{FEV}_{1}(25)$.

\subsection{Epidemiología}

La epidemiología y la distribución de la EPOC en la población general es todavía una asignatura pendiente, comparada con las enfermedades oncológicas o cardiovasculares. Como consecuencia del desconocimiento de la sociedad y el bajo impacto en la opinión pública (26). Se ha visto reducida la percepción de necesidad y urgencia para paliar el problema en la asignación de recursos.

Aspecto que se ha visto alimentado por las diferentes definiciones que se han usado para su diagnóstico, a lo largo de la historia hasta la publicación de las pautas de la Global Initiative for Chronic Obstructive Lung Disease (GOLD), donde se aceptó el requisito de la espirometría posbroncodilatadora para establecer el diagnóstico de la EPOC.

La prevalencia, la OMS estima que hay 210 millones de personas en el mundo que presentan EPOC, en edades comprendidas entre los 40 y los 70 años, en España los datos estimados de prevalencia oscilan en el 8 y $9,1 \%$ de la población y el $20 \%$ en Latinoamerica (5). Siendo la tercera causa de muerte en España y en el mundo. Se prevé que las cifras de prevalencia de la 
EPOC aumenten en el siglo XXI, ya que hoy hay más fumadores que en cualquier otro momento de la historia de la humanidad, acrecentado por cambios sociodemográficos, asociados al aumento en el envejecimiento de la población.

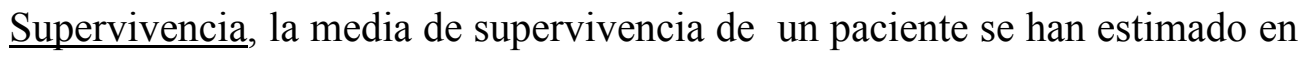
5,7 años, siendo la propia EPOC y en muchas ocasiones dichos datos se ven mermados por la aparición del cáncer de pulmón adelantando la muerte y disminuyendo la supervivencia (27).

Mortalidad, según la OMS, todos los años provoca la muerte de al menos 2,9 millones de personas en el mundo. Siendo la tercera causa de muerte en España, ya que ocasiona 15.994 muertes, $77,43 \%$ en hombres y $22,57 \%$ en mujeres. Siendo la EPOC la enfermedad respiratoria que más muertes produce, a excepción de los tumores 33,79\%. Se estima que en España mueren 18.000 personas por la EPOC. Estos datos comparados con los países de la Unión Europea (UE), España se sitúa en un rango intermedio, lista encabezada por países de Europa del Este y anglosajones, destacando las bajas tasas de EPOC en la población femenina en España con respecto a los países de la UE. La mortalidad por exacerbación de la EPOC que requiere ingresos hospitalarios se encuentra en torno a un 14\% llegando hasta un $30 \%$ si se precisa ventilación mecánica, además el propio ingreso por exacerbación condiciona una mortalidad del 40\% al año del ingreso (28). En 1990 era la quinta causa de muerte en el mundo, en 2000 paso a ser la cuarta causa de muerte y en 2020 se espera que pase a ser la tercera. Así como las estimaciones de la (OMS) prevén que la EPOC seguirá siendo la causa de 7,8\% de todas las muertes y representará el $27 \%$ de las muertes relacionadas con el tabaco, sólo superadas por el cáncer, con el 33\%, y por las enfermedades cardiovasculares, con el 29\% (29).

Coste sanitario, dadas las características de enfermedad crónica y progresiva la EPOC supone un elevado coste sanitario, tanto en el consumo de recursos sanitarios, así como la pérdida de calidad de vida relacionada con la salud (CVRS) de los pacientes.

Según los datos de morbilidad hospitalaria del Instituto Nacional de Estadística (INE) para el año 2013, la EPOC causó 784.348 estancias hospitalarias, siendo el $68 \%$ causadas en hombres y el $32 \%$ restante causadas en mujeres, con una estancia media de 6,29 días (30). Si observamos los datos según Comunidades Autónomas, las comunidades con mayor número de ingresos hospitalarios fueron Cataluña (151.224), seguidas de la comunidad de Madrid (123.542) y Andalucía (77.197). Ocupando el quinto lugar con mayor número de estancias la Comunidad Valenciana, donde tuvieron lugar en ese mismo año 61.861 estancias. Con 26.292 ingresos en la provincia de Valencia, seguido por 61.861 en la provincia de Alicante y 10.912 en la provincia de Castellón. 
Siendo la estimación de costes del Sistema Nacional de Salud (SNS) según la Estrategia de la EPOC de 750-1.000 millones de euros/año, incluyendo los costes directos, indirectos e intangibles (31). Estimando que el coste medio por paciente con EPOC en 1.712 - 3.238 euros/año. Estos costes directos se distribuyen en gastos hospitalarios (40-45\%), farmacológicos (35-40\%) y visitas y pruebas diagnósticas (15-25\%)(32). Siendo el mayor coste sanitario dentro de los gastos de la EPOC los ingresos hospitalarios (45\%), gasto que a medida que aumenta la gravedad de la enfermedad se van incrementando (28).

\subsection{Historia de la EPOC}

Si la EPOC es una enfermedad muy frecuente sus aspectos históricos son poco conocidos en nuestro medio. Aunque los datos históricos están documentados desde el siglo XVI. Muchos médicos como Hipócrates, no utilizaban este término para referirse a pacientes que presentaban tos, expectoración, disnea y sibilancias, si no el término de "asma" para todas las alteraciones que estaban relacionadas con la falta de aire. $\mathrm{Y}$ otros términos como enfisema, que designaba a aquellas patologías que presentaban una falta de aire en sus tejidos.

No fue hasta el siglo XVII, basándose en el estudio de las autopsias, donde se utilizó el término EPOC, tal como lo conocemos actualmente. Existiendo gran confusión con el termino bronquitis crónica, EPOC y enfisema. Dudas que poco a poco fueron disipándose con el descubrimiento del estetoscopio y el diagnóstico de la obstrucción bronquial, que permitió diferenciar el enfisema de la bronquitis.

Sin embargo, no es hasta el 1.958 cuando un grupo de expertos, realizó el primer intento por elaborar una definición a los términos de bronquitis crónica, enfisema y EPOC, dando lugar a las definiciones que actualmente conocemos. El momento de mayor avance en el conocimiento de la enfermedad, es la última década del siglo $\mathrm{XX}$, destacada por varios acontecimientos como, la creación de las sociedades científicas en los países desarrollados, que han permitido elaborar normas de prevención, tratamiento y diagnóstico de la EPOC, al unificar y mejorar conductas en la atención a estos pacientes, así como la trascendencia de los efectos nocivos del tabaco en las personas y otros factores de riesgo como la quema de combustibles y la exposición a determinados gases. Igualmente las investigaciones en costes, han puesto en valor la importancia de la EPOC por los elevados costes sociales y económicos que supone el tratamiento de la misma (33). 


\subsection{Diagnóstico}

El proceso diagnóstico de la EPOC se estructura en tres fases:

- Diagnóstico de la EPOC

Sospecha clínica, toda persona mayor de 40 años(4), con una exposición al tabaco o a agentes tóxicos inhalados en el hogar o en el lugar de trabajo $(4,34)$.

Con presencia de tos crónica, con o sin producción de esputo o disnea. Ya que las manifestaciones clínicas en etapas tempranas de la EPOC, son inespecíficas, así como la intensidad y la progresión de las mismas, es variante en cada individuo, incluso pudiendo estar asintomáticos en estadios muy avanzados de la enfermedad. La presencia de tos crónica y expectoración suele preceder a años de obstrucción de la vía aérea. La sospecha clínica debe de confirmarse por medio de una espirometría forzada con prueba broncodilatadora realizada en la fase estable de la enfermedad.

\section{Pruebas diagnósticas:}

Espirometría, prueba no invasiva, sencilla, barata, estandarizada, reproducible y objetiva, que mide la limitación del flujo aéreo, permitiendo el diagnóstico de la EPOC. Siendo necesario que el personal este formado para la realización de la misma $(35,36)$.

Esta prueba nos permite el diagnóstico de la EPOC, donde se hace uso de la disminución de la $\mathrm{FEV}_{1}$ y su coeficiente con la capacidad vital forzada $(\mathrm{CVF}),\left(\mathrm{FEV}_{1} / \mathrm{CVF}\right)$. Realizándose dos mediciones, una previa a la broncodilatación y otra posterior a la broncodilatación, permitiendo observar la capacidad de reversibilidad de la obstrucción. Si el resultado entre ambas dos mediciones es inferior a 0,7 se confirmara el diagnóstico de EPOC. De esta manera la EPOC leve se define como un cociente $\mathrm{FEV}_{1} / \mathrm{CVF}$ postbroncodilatador $<70 \%$ y un $\mathrm{FEV}_{1}<80 \%$. La EPOC moderada, grave y muy grave corresponde a valores de la $\mathrm{FEV}_{1}$ del 50-80\%, el $30-50 \%$ y menos del $30 \%$ respectivamente (29). Ver tabla 1. 
Tabla 1. Escala de clasificación GOLD de la EPOC

$\begin{array}{lll}\text { Estadío } & \mathrm{FEV}_{1} / \mathrm{FVC}^{*} & \mathrm{FEV}_{1} \\ \text { I. Leve } & <0,70 & \geq 80 \% \\ \text { II. Moderado } & <0,70 & 50 \% \leq \mathrm{FEV}_{1}<80 \% \\ \text { III. Grave } & <0,70 & 30 \% \leq \mathrm{FEV}_{1}<50 \% \\ \text { IV. Muy grave } & <0,70 & \mathrm{FEV}_{1}<30 \% \mathrm{FEV} \mathrm{FV}_{1}<50 \% \text { Insf. } \\ & & \text { Resp.Crónica }\end{array}$

*Todos los valores posbroncodilatación; $\mathrm{FEV}_{1}$ : Volumen espiratorio al primer segundo; FVC: Capacidad Vital Forzada; Insf. Resp: Insuficiencia Respiratoria. Fuente: Pulmonar, Grupo de trabajo de la Guía de Práctica Clínica para el Tratamiento de Pacientes con EPOC (22)

Aunque la utilización del coeficiente FEV1/FVC postbroncodilatación como criterios diagnóstico de la EPOC tiene ventajas por su sencillez y no precisa tablas de referencia para su interpretación (29), su aplicación también comporta riesgo de infradiagnóstico en personas jóvenes o a la inversa de sobrediagnóstico en edades avanzadas (mayores de 70 años) sin exposición importante al tabaco, escasos síntomas respiratorios o con una $\mathrm{FEV}_{1}$ normal.

Cabe destacar que, la prueba broncodilatadora es muy variable en la EPOC y con frecuencia se observan cambios a lo largo del tiempo, con lo cual la existencia de una prueba broncodilatadora significativa (aumento de la $\mathrm{FEV}_{1}$ superior a $200 \mathrm{ml}$ y al $12 \%$ del valor prebroncodilatación), no excluye el diagnóstico de la EPOC ni confirma el diagnóstico del asma. Un estudio llevado a cabo en Noruega, observó que un 35\% de los individuos sanos, no fumadores y mayores de 70 años presentaban un coeficiente inferior al $70 \%$ de su $\mathrm{FEV}_{1} / \mathrm{CVF}$ (37). Esto indica que a partir de los 70 años, los puntos de corte utilizados para diagnosticar la EPOC deberían corregirse por la edad, para evitar sobrediagnósticos.

\section{Pruebas complementarias al diagnóstico:}

Radiografía simple de tórax, La radiografía de tórax puede ser normal en la mayoría de los casos o mostrar signos de hiperinsuflación pulmonar, atenuación vascular y radiotransparencia, que indican la presencia de enfisema (38). También pueden detectarse bullas, zonas radiolucentes o signos de hipertensión arterial pulmonar.

La sensibilidad de la prueba es baja para detectar la EPOC (detecta al 50\% en los pacientes moderados-graves) pero una lectura sistemática de la radiografía de tórax es muy útil para la detección de enfisema. El 
reconocimiento se basa en pruebas que reflejen la estructura pulmonar en lugar de la función (39).

La radiografía de tórax se debe solicitar para la valoración inicial del paciente y para descartar posibles complicaciones: disnea inexplicada de origen brusco (neumotórax), cambio en el patrón de la tos, esputo hemoptoico (neoplasia), o sospecha de neumonía (40).

Tomografía axial computarizada (TAC), permite evaluar los cambios patológicos asociados a la EPOC y separar en diferentes fenotipos. Es una técnica poco utilizada por su elevado coste y por aportar información similar a la radiografía en el fenotipo enfisematoso(39).

Pletismografía corporal, prueba cuyo objetivo es medir el volumen pulmonar, en una cabina herméticamente cerrada. Mide la cantidad de aire que se queda en el pulmón tras una espiración forzada, midiendo el aire atrapado en el pulmón. Permitiendo conocer el valor de la capacidad pulmonar total, no siendo muy utilizada (40).

Oximetría, mide la saturación de oxígeno en la sangre, mediante el pulsioxímetro, colocándose tanto en el dedo como en el lóbulo de la oreja, midiendo la saturación de oxígeno en los glóbulos rojos mediante rayos de luz.

Análisis de sangre, el hemograma no suele afectarse, a menos que se presenten complicaciones. La leucocitosis con neutrofilia puede aparecer en las exacerbaciones de causa infecciosa. Una leucocitosis leve puede ser debida al tabaquismo activo o al tratamiento con corticoides. La eosinofilia puede hacer pensar en la posibilidad de un fenotipo mixto EPOC-asma, al igual que una concentración elevada de Inmunoglobulona E (IgE). La poliglobulia es proporcional a la gravedad y a la antigüedad de la insuficiencia respiratoria. Aproximadamente, un 12,6\% de los hombres y un $18,5 \%$ de las mujeres con EPOC pueden presentar anemia, de predominio normocítico-normocrómico. Esta anemia se ha relacionado con la presencia de inflamación sistémica y comporta un peor pronóstico.

Gasometría arterial, obtención del nivel de oxígeno y dióxido de carbono en sangre arterial, obteniéndose mediante punción arterial en la muñeca, en la femoral o en la brazo.

Prueba de marcha de 6 minutos, consiste en que el paciente recorra la mayor distancia posible en 6 minutos, en terreno llano y siguiendo un protocolo estandarizado y en compañía del responsable del examen, quien previamente le ha informado de las características de la prueba. Es una prueba de referencia de la capacidad de tolerancia a esfuerzos máximos y ha 
demostrado ser un buen predictor de supervivencia y de la tasa de reingresos hospitalarios por exacerbación (40). Además, es un componente del índice de Body Mass Index, Airflow Obstruction, Dysnea and Excercise capacity index (BODE).

Tabla 2. Índice de BODE

$\begin{array}{llcccc}\text { B } & \text { IMC } & \mathbf{0} & \mathbf{1} & \mathbf{2} & \mathbf{3} \\ \mathbf{O} & \text { FEV }_{\mathbf{1}}(\boldsymbol{\%}) & >21 & \leq 21 & & \\ \mathbf{D} & \text { Disnea (MRC) } & \geq 65 & 50-64 & 36-49 & \leq 35 \\ \mathbf{E} & \mathbf{6 M M}(\mathbf{m}) & 0-1 & 2 & 3 & 4 \\ & & \geq 350 & 250-349 & 150-249 & \leq 149\end{array}$

6MM: distancia recorrida en la prueba de los 6 minutos de marcha; IMC: Índice de Masa Corporal; $\mathrm{FEV}_{1}$ : Volumen Espiratorio en el primer segundo; MRC: Medical Resoult Council. Fuente: Soler-Cataluña et al (41)

Muestra de esputo y cultivo de secreciones, prueba que consiste en recoger mucosidad del paciente, previo al tratamiento para analizar su contenido microbiológico. Utilizado principalmente para el tratamiento antibiótico en episodios de exacerbación por infección.

Estudio del sueño mediante polisomnografía, técnica que se utiliza cuando se sospecha apnea del sueño. El paciente es monitorizado mientras duerme mediante electrodos colocados por su cuerpo que permiten observar su frecuencia cardíaca y respiratoria. Midiendo el número de veces que deja de respirar.

\subsection{Historia natural de la EPOC}

En el curso clínico de la EPOC, se ve reflejada en una disminución progresiva de la función pulmonar. Según el British Medical Research Council (BMRC) (42), hay diferencias en la evolución, en relación al hábito tabáquico y la susceptibilidad al mismo. En la misma línea se encuentra el estudio Framingham (43) que sugiere que la progresión de la enfermedad en diferentes personas no es uniforme, pero en todos resulta beneficioso el hecho de dejar de fumar. La evolución de la enfermedad, es distinta, según sexos respecto a la perdida de la función pulmonar y coincide en ambos sexos con el beneficio del abandono del hábito tabáquico, si se realiza de forma precoz y antes de los 40 años (43). 


\subsubsection{Exacerbaciones}

En el trascurso de la enfermedad existen periodos de inestabilidad clínica, conocidos como exacerbaciones o agudizaciones que se caracterizan por un empeoramiento mantenido de los síntomas que va más allá de sus variaciones diarias. Los principales síntomas referidos son empeoramiento de la disnea, tos, incremento del volumen y/o cambios en el color del esputo.

Existen investigaciones que han utilizado diarios de signos y síntomas para la obtención de datos, reportando que más de la mitad de las agudizaciones no se notifican al médico(44-46)

Los pacientes que padecen EPOC experimentan un promedio de 1 - 4 exacerbaciones anuales. Resulta complicado distinguir entre una nueva exacerbación o una resolución incompleta de la anterior. Por tanto según la guía GesEPOC (44), se definen tres situaciones relacionadas:

- Fracaso terapéutico: se define como un empeoramiento de los síntomas dentro de la misma agudización, que requiere un tratamiento adicional. La recuperación de las agudizaciones va entorno a los 2 semanas y en algunos de los casos hasta las 6 semanas.

- Recaída: Se considera como un nuevo empeoramiento de los síntomas tras finalizar el tratamiento de la agudización y las 4 semanas posteriores.

- Recurrencia: Aparición de los síntomas de una agudización en un plazo inferior a un año, después de un periodo relativamente bueno, tras haber dejado al menos 4 semanas el tratamiento de la agudización o bien 6 semanas desde el inicio de los síntomas.

Se ha observado que las exacerbaciones son las principales causantes de deterioro en la calidad de vida, ingresos hospitalarios, utilización de los servicios de salud e ingreso en unidades de cuidados intensivos en estos pacientes. La reiteración de las mismas es sinónimo de progreso de la enfermedad y aumento de riesgo de muerte. La progresión está asociada con una considerable morbilidad y mortalidad, tanto inmediatos como a largo plazo. Estos episodios tienen un impacto negativo en el paciente y la enfermedad incluyendo la sobrecarga económica, aumento de la mortalidad, empeoramiento del estado de salud, limitación de la actividad, y agravamiento de las comorbilidades, incluyendo, la osteoporosis y las complicaciones neuropsiquiátricas y cardiovasculares. Así mismo se produce un aumento progresivo del deterioro de la función pulmonar, que conduce a un peor pronóstico. Su impacto es tan elevado que, actualmente se incluye la evaluación del riesgo de exacerbaciones como un componente importante de la evaluación inicial de un paciente con EPOC, junto con el parámetro de función pulmonar utilizado tradicionalmente, el volumen espiratorio forzado en un segundo $\left(\mathrm{FEV}_{1}\right)$ (47). 
De hecho desde un punto de vista estratégico y según las recomendaciones de la Estrategia Nacional del Paciente con EPOC (31), es necesario reducir la frecuencia de las agudizaciones y su prevención es un objetivo terapéutico importante en la gestión de la EPOC (47).

\subsubsection{Gravedad de las exacerbaciones}

Una vez establecido el diagnóstico de exacerbación es importante describir la gravedad del episodio. En los últimos años la gravedad de las exacerbaciones se ha venido clasificando en el consumo de fármacos y la utilización de recursos (catalogándose una exacerbación grave a todos los pacientes que requerían hospitalización y la exacerbación moderada a los pacientes que recibían tratamiento con corticoides orales o antibióticos). Sin embargo esta clasificación puede tener sesgos, puesto que puede estar influenciada por criterios socioeconómicos o de accesibilidad al sistema. En la actual guía GesEPOC (48) se plantea una nueva clasificación. Esta clasificación se divide en cuatro grupos:

- Exacerbación muy grave, relacionada con la aparición de algunos de los siguientes acontecimientos de riesgo de muerte como: una parada cardiorespiratoria, disminución del nivel de consciencia, inestabilidad hemodinámica o acidosis metabólica.

- Exacerbación grave, MRC de 3-4, cianosis de nueva aparición, uso de la musculatura accesoria para la respiración, edemas periféricos nuevos, complicación de alguna de sus comorbilidades, acidosis respiratoria e hipercapnia o saturación del $90 \%$ de oxígeno $\left(\mathrm{O}_{2}\right)$.

- Exacerbación moderada, clasificada con una $\mathrm{FEV}_{1}<50 \%$, historia de dos o más agudizaciones en el último año, presencia de alguna comorbilidad cardiaca no grave.

- Exacerbación leve, clasificada cuando no han acontecido ningún criterio de los anteriormente citados. 
También cabe destacar que en España la población se inicia al hábito tabáquico cada vez más precozmente (16 años). Siendo el 40,4 \% de la población entre 15 y 34 años fumadora habitual, cifra que ha ido descendiendo a lo largo de los años.

\section{- Tabaquismo pasivo}

El tabaquismo pasivo, también llamado humo ambiental de tabaco, es la inhalación involuntaria del humo de otra persona que fuma tabaco. Los riesgos de salud son menores a los del tabaquismo activo, sin embargo a diferencia de los fumadores activos, esta exposición es involuntaria. Una proporción de casos de EPOC ocurre en personas que no han fumado nunca. Entre personas no fumadoras (54) el tabaquismo pasivo es un factor de riesgo para el desarrollo de la EPOC (55-58). Un estudio elaborado en niños de entre 6 y 18 años gallegos, donde el $56 \%$ de ellos estaban expuestos al humo del tabaco de alguno de sus progenitores, mostro un $75 \%$ tenían reducida la capacidad espiratoria forzada (FEF), con el efecto obstructivo en la vía distal, tal y como ocurre en los pacientes fumadores activos (59).

\section{- Quema de combustible biomasa}

En diversas revisiones sistemáticas han identificado la biomasa y otros combustibles para la calefacción o la cocina en áreas rurales como factores de riesgo de padecer EPOC (54,60-63). Un ensayo clínico llevado a cabo en España, en 120 mujeres, que utilizaban el horno o la calefacción a base de leña, con una exposición media de 16 años, mostro que la exposición al humo de leña o carbón está fuertemente asociada a la EPOC.

No estando relacionado el hecho de trabajar de cocinero o tener una cocina en el interior (64). Existen otros autores que afirman que la exposición al humo de leña podría igualar hasta 20 paquetes al año de exposición activa al humo del cigarro (65). La exposición al humo de leña también se ha asociado a la aparición de carcinomas de pulmón escamoso de células pequeñas (66). Otras investigaciones han relacionado la presencia de EPOC con vivir cerca o trabajar en fábricas que realizaban quemas de combustibles fósiles como la madera (67). Así como, los estudios experimentales han determinado que el contenido dañino en la quema de leña, se encuentra en los elementos volátiles que se liberan durante la combustión de la misma.

\section{- Contaminación atmosférica}

La atmósfera está llena de una mezcla de sustancias tóxicas, tanto naturales como artificiales cuya inhalación produce alteraciones en el sistema pulmonar. Existen investigaciones que afirman que la exposición al polvo ambiental y humos en países en vías de desarrollo o desarrollados (54-56,58-64,68), como el ozono, las partículas en suspensión, el monóxido de carbono ( $\mathrm{CO})$, el dióxido de sulfuro $\left(\mathrm{SO}_{2}\right)$, el dióxido de nitrógeno $\left(\mathrm{NO}_{2}\right)$, otros gases (54), materiales industriales, partículas procedentes de la minería y la combustión, productos 
químicos agrícolas, el humo de los cigarros presentes en la contaminación atmosférica, asociados al tráfico rodado, es un factor de predisposición a las exacerbaciones (69). Sin embargo existe controversia en cuanto a su relación como factor de causa directa de la enfermedad (54).

\section{- Exposición ocupacional}

Diversos polvos, gases y humos tóxicos relacionados con el empleo habitual se asocian a un mayor riesgo de EPOC $(54,70)$. Uno de los productos cuya relación se ha asociado a un aumento del riesgo de EPOC es el amianto. Trabajadores expuestos a esta sustancia experimentan una reducción a largo plazo del flujo aéreo, observándose además que no solo es un factor ocupacional sino que la población que vive a dos horas caminando de las fábricas que trabajan con estas sustancias también experimentan un aumento significativo de padecer EPOC. El amianto no solo relacionada con la EPOC si no con el cáncer de pulmón (71).

Respecto al uso de pesticidas, como es el caso de gremios como la agricultura, presente en gran medida en nuestro país, experimentan un aumento significativo de padecer EPOC respecto a otras profesiones (72). Si además el cultivo es de café y trabajan en la molición del mismo, el riesgo de padecer EPOC se dispara, como ocurre en las plantaciones de café en países Latino Americanos (73).

En menor medida se ha observado también un aumento del número de pacientes EPOC entre los trabajadores de la minería, en especial minas de carbón y sílice $(74,75)$, donde han podido inhalar gases o partículas de polvo en suspensión, como trabajadores en fábricas de cemento, arcillas o en canteras (76-78).

\section{- Tuberculosis pulmonar(TBC)}

La TBC, parece ser un factor de riesgo para padecer EPOC, de acuerdo a dos estudios desarrollados en China y Latinoamerica.

El estudio de China en personas mayores de 50 años, mostro que personas con evidencias radiológicas de haber presentado una tuberculosis, presentaban un incremento de la reducción del flujo aéreo, independientemente de que fueran fumadores, o estuvieran expuestos a otros agentes etiológicos de la reducción del flujo aéreo (79). Así como el estudio Platino, llevado a cabo en Latino América sobre la EPOC, evidencio que la infección por tuberculosis incrementa entre 2 y 4 veces más el riesgo de padecer una reducción del flujo aéreo (80).

\section{- Factores genéticos}

Los factores genéticos, presentes en prácticamente la totalidad de enfermedades conocidas, en la EPOC se atribuyen a la deficiencia del alfa-1-antitripsina (DAAT) que está relacionado con el enfisema hereditario.

Se trata de la enfermedad congénita, potencialmente mortal más frecuente en la edad adulta. La alfa-1-antitripsina (AAT) es una glucoproteína, encargado de la inhibición de las proteasas, así como inhibir o enlentecer la replicación e infección de los virus del sida y la de otros virus y bacterias. En conjunto la AAT es una molécula antiinflamatoria natural de amplio espectro, cuya función 
sería modular las reacciones inflamatorias que se producen continuamente en el organismo humano.

Es la proteína más abundante en el suero humano, donde circula en concentraciones $120-220 \mathrm{mg} / \mathrm{dl}$, la presencia en el suero es solo del $40 \%$ del total de la proteína y el $60 \%$ restante se encuentra en el espacio extracelular impregnando los tejidos corporales (12).

El gen de la AAT se transmite por herencia mendeliana simple, de manera autosómica codominante mediante 2 alelos, uno de cada progenitor, que se expresan independientemente en los hijos al 50\%. Este gen presenta un gran polimorfismo, identificándose hasta 70 variantes que siguen aumentando con al avance de las técnicas de identificación. Su déficit supone la presencia de una enfermedad autosómica recesiva que causa EPOC y diversos tipos de hepatopatías (incluidas colestasis neonatal, hepatitis juvenil, cirrosis hepática en niños y adultos y hepatocarcinoma) por lo que se trata de una enfermedad sistémica. También se ha sugerido que el DAAT puede estar asociado al riesgo incrementado de desarrollo y progresión de cánceres, incluidos los de vejiga, vesícula biliar, pulmón y linfomas (12).

El déficit congénito del alfa-1-antitripsina predispone a una disminución acelerada de la función pulmonar (12,81). Se estima que es responsable del 1\% de los casos de EPOC. Pudiendo ser prevenible mediante el diagnóstico precoz y la posterior administración intravenosa de alfa-1-antitripsina de otros donantes. Por tanto todo paciente con EPOC debe de tener una determinación de esta proteína (82).

En España, el número de casos diagnosticados de déficit grave de AAT es de aproximadamente 500 individuos, lo que representa menos del $10 \%$ de los 12.000 casos que se calculan que debe de haber en España. Estos mismos porcentajes se han diagnosticado en Estados Unidos o en el Reino Unido, y únicamente en Dinamarca se han diagnosticado el $28 \%$ de los casos esperados.

Existe una importante variabilidad en la edad de inicio de los síntomas respiratorios, que raramente aparecen antes de los 25 años de edad. Esta variabilidad se asocia al consumo de tabaco, la hiperreactividad bronquial e infecciones respiratorias de repetición. En sujetos fumadores con déficit grave de AAT los síntomas aparecen a los 35-40 años de edad, mientras que en los no fumadores lo hacen una década más tarde (83).

La enfermedad tiene un debut similar a los síntomas habituales de la EPOC; disnea en el $80-90 \%$ de los casos; el 65-75\% refiere sibilancias, ya sea de forma habitual o en relación con infecciones respiratorias y hasta un $40 \%$ presenta tos productiva o no, en relación a la existencia de bronquioectasias, así como expectoración y agudizaciones frecuentes. En el estudio del Registro del National Heart, Lung, and Blood Institute (NHLBI), el 35\% de los individuos refería una historia de asma y más del 50\% mostraba una prueba broncodilatadora positiva (84). Otra medida también utilizada para conocer el pronóstico de la enfermedad, es la densidad pulmonar mediante tomografía 
computerizada (TAC) y el índice de masa corporal (IMC) inferior a 20, factores relacionados con el incremento de la mortalidad a los 5 años (85).

El principal factor pronóstico de supervivencia en estos pacientes es el $\mathrm{FEV}_{1}$, la supervivencia a los 2 años es prácticamente del 100\% hasta que el $\mathrm{FEV}_{1}$ alcanza el $33 \%$ y a partir de ese momento, desciende de forma exponencial y supone el $50 \%$ cuando el $\mathrm{FEV}_{1}$ es del 15\% del teórico (86). Los pacientes que dejan de fumar consiguen reducir la caída del $\mathrm{FEV}_{1}$.

El principal condicionante es el tabaco, así pues, los individuos no fumadores tienen una esperanza de vida similar a la población general, mientras que los fumadores tienen una caída de la función pulmonar más acelerada que el resto de afectados por la EPOC (87). Ya que el $60 \%$ de los individuos puede desarrollar obstrucción crónica al flujo aéreo (88) y el factor de riesgo más importante será el grado de tabaquismo, lo que indica que el DAAT, por sí solo, no suele ser suficiente para desarrollar enfermedad y deben existir otros factores genéticos y ambientales favorecedores (89).

La importancia del diagnóstico precoz de esta alteración genética se basa en hacer un esfuerzo especial en la deshabituación tabáquica, que es determinante en el pronóstico de la enfermedad, tratar los síntomas del enfisema y las agudizaciones, realizar estudios familiares para diagnosticar otros casos de forma precoz y dar consejo genético. También se puede iniciar un tratamiento sustitutivo en los casos en que esté indicado (90) ya que esta sustancia infundida a estos pacientes, se ha demostrado que mantiene su actividad enzimática en plasma y en lavado bronco alveolar; además su actividad pulmonar se correlaciona de forma directa con su concentración plasmática, lo que permite monitorizar el tratamiento a través de la determinación de las concentraciones plasmáticas mínimas (91).

Como prevención se han obtenido resultados positivos en la protección frente a infecciones bronquiales, aspecto de gran relevancia por el elevado número de bronquioectasias en esta población, reduciendo el número de agudizaciones tras la administración del tratamiento sustitutivo, donde el $85 \%$ de los pacientes no presenta ningún efecto adverso y en los pacientes que presentan efectos adversos son: cefaleas (47\%), vértigo (17\%), náuseas $(9 \%)$ y disnea $(9 \%)(92)$. 


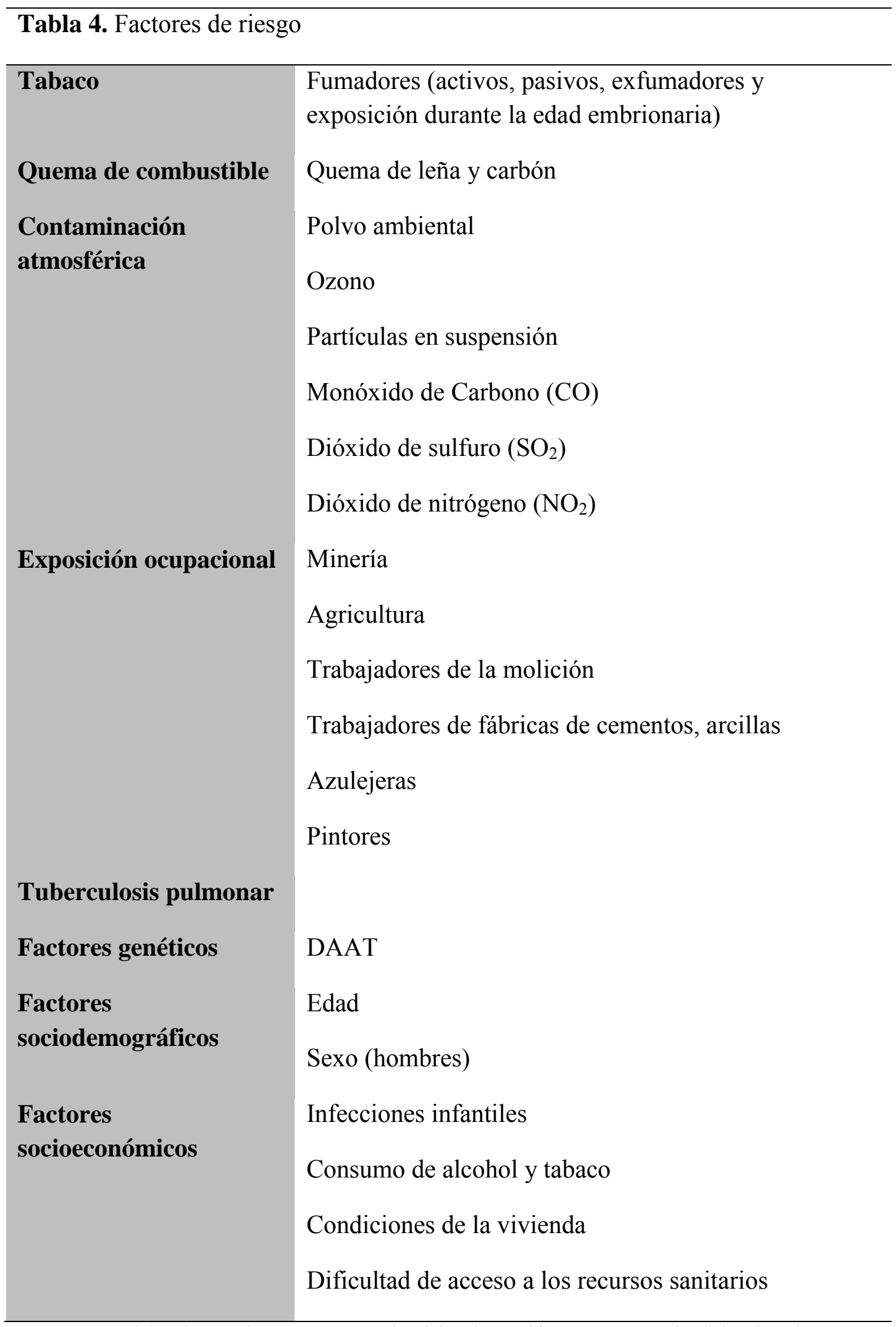

CO: Monóxido de Carbono; $\mathrm{SO}_{2}$ : Dióxido de Sulfuro; $\mathrm{NO}_{2}$ : Dióxido de nitrógeno; DAAT; Deficiencia del Alfa-1-antitripsina. Fuente: Elaboración Propia 


\subsection{Comorbilidades asociadas a la EPOC}

Recientes investigaciones han indicado que el 68,4\% de los pacientes EPOC sufre al menos una comorbilidad crónica y alrededor del $16 \%$ de los pacientes EPOC tiene dos o más comorbilidades (93). Con frecuencia presentan una inflamación sistémica, pérdida no intencionada de peso, miopatías, aumento de enfermedades crónicas asociadas. Las más frecuentes son: las enfermedades cardiovasculares (cardiopatía isquémica, insuficiencia cardíaca o ictus), hipertensión, diabetes mellitus, insuficiencia renal, osteoporosis, enfermedades psiquiátricas (ansiedad y depresión), deterioro cognitivo, anemia, neoplasia de pulmón (94). Dichas comorbilidades empeoran el pronóstico de la EPOC y constituyen una causa frecuente de mortalidad (95).

Muchas de las comorbilidades de los pacientes con EPOC están presentes en el momento del diagnóstico, pero su gravedad y evolución empeoraran a medida que también lo hace la EPOC (96).

- Enfermedades cardiovasculares, la probabilidad de tener alguna alteración cardiovascular se multiplica entre 2 y 4 veces en los pacientes con EPOC (97). De hecho la probabilidad de sufrir un infarto de miocardio es 10 veces superior en pacientes con EPOC entre 35 y 44 años (98). Las semanas posteriores a una exacerbación aumenta le incidencia de padecer algunas de estas enfermedades (99-101).

Así pues, existen investigaciones que afirman que la EPOC puede contribuir al desarrollo de enfermedades cardiovasculares, como consecuencia de la hipoxia, la inflamación sistémica y el estrés oxidativo (102). Otra de las enfermedades cardíacas prevalentes es la insuficiencia cardíaca, que en la mayoría de situaciones se ve enmascarada por la EPOC, lo que dificulta su diagnóstico y empeora el pronóstico

- Cáncer de pulmón, la probabilidad de padecer cáncer y en especial el de pulmón se incrementa entre 2 y 6 veces más en una persona con EPOC, con independencia de su historia tabáquica. La prevalencia de tener un diagnóstico de EPOC varía entre el $40 \%$ y el $70 \%$ de los pacientes con cáncer de pulmón(103). Parece que existe un factor de riesgo genético común que hace más susceptible al humo del tabaco, a determinadas personas(104).

Actualmente no existe ninguna recomendación específica para detectar el cáncer de pulmón en los pacientes EPOC, pero sí que existe una investigación reciente, que muestra una reducción del $20 \%$ de la mortalidad por cáncer de pulmón en un grupo de cribado mediante tomografía axial computarizada (TAC) en comparación con el grupo de cribado mediante radiografía de tórax, entre los fumadores o ex fumadores de edades comprendidas entre los 55 años y los 74 años con una historia de tabaquismo de más de 30 paquetes al año (105).

- $\quad$ Ansiedad y depresión, el 40\% de los pacientes con EPOC presentan niveles altos de ansiedad y depresión, con respecto a pacientes sin EPOC. La fisiopatología 
de esta comorbilidad es compleja y posiblemente se explica por factores de riesgo como: la sintomatología o las alteraciones bioquímicas asociadas. Además la presencia de ansiedad y depresión en estos pacientes se asocia a un aumento de la mortalidad, mayores tasas de exacerbación, mayor duración de las estancias hospitalarias, disminución de la calidad de vida, mayor deterioro de la función respiratoria, mayor mortalidad con pacientes de la misma franja de edad y sin evidencias de EPOC. No existe un consenso para la detección de la ansiedad y depresión en este tipo de pacientes, ni el tratamiento más óptimo. Opciones de tratamiento que se están llevando a cabo son entre otras: el tratamiento psicológico, farmacológico, la rehabilitación pulmonar y recientemente programas educativos de mejora de la gestión de las enfermedades crónicas, no existiendo todavía suficientes evidencias relacionadas con el efecto positivo de estos tratamientos (106).

- Osteoporosis, en los pacientes con EPOC existe un riesgo aumentado de padecer osteoporosis, como consecuencia del tabaquismo, inflamación sistémica, deficiencia de vitamina $\mathrm{D}$, los tratamientos con corticoides durante periodos muy prolongados y en altas dosis, en las exacerbaciones, además del hipogonadismo. Tienen vital importancia, porque las principales facturas que se producen se dan en la columna vertebral, las costillas, la cadera y la muñeca, ya que muchos de estos huesos facilitar el proceso de inspiración y expiración. Por ejemplo, las costillas, tienen una prevalencia del $41 \%$ de las fracturas en pacientes con EPOC, produciendo en consecuencia un declive de la función pulmonar (94).

- Desnutrición, en el paciente EPOC existen tres perfiles: pacientes con bajo peso y con bajo IMC, pacientes con bajo peso pero con un IMC normal y pacientes con peso corporal normal y estable (107). Este aspecto es de gran interés ya que la ingesta inadecuada de nutrientes puede causar disnea, tanto por una ingesta abusiva como por una carencia (108). Existen diferencias en la desnutrición según sexos, siendo las mujeres las que presentan mayor desnutrición y siendo perjudicial para el paciente EPOC (109).

- $\quad$ Obesidad, Existen pocas investigaciones que relacionen EPOC con obesidad, unas muestran la misma como factor protector y otras como factor que dificulta una mayor expansión del tórax en caso de dificultad respiratoria(110-112). Siendo la obesidad perjudicial para la evolución de la enfermedad.

- Diabetes, la prevalencia de diabetes en los pacientes con EPOC varía según estudios entre el 10,3\% (113) y el 18,7\% (114). Así los estudios de cohortes han demostrado que los pacientes con EPOC moderada a grave tienen un incremento del riesgo de diabetes. En las mismas líneas otro estudio ha afirmado que la presencia de enfermedades inflamatorias respiratorias como el asma y la EPOC están relacionadas con la aparición de la diabetes tipo 2 en ocasiones, asociada al tratamiento (115). 
- Trastornos del sueño, el deterioro del sueño es común en estos pacientes ya que según un estudio llevado a cabo por Cormick (116), el 36\% se quejaba de problemas para dormirse, el $42 \%$ de sueño no reparador y el $76 \%$ de más de dos episodios recientes de vigilia por la noche, mientras que el $28 \%$ utilizaba hipnóticos.

- $\quad$ Anemia, se trata de una complicación que afecta al $12,3 \%$ de los pacientes con EPOC, que también está relacionada con la insuficiencia cardíaca, como consecuencia de la inflamación sistémica. No existe suficiente evidencia que permita afirmar una relación entre ambas o que esté relacionada con otras comorbilidades $(117,118)$.

Tabla 5. Comorbilidades asociadas a la EPOC

Cardiopatía isquémica

Insuficiencias cardíacas

Arritmias

Hipertensión pulmonar

Cáncer de pulmón

Osteoporosis

Miopatía

Caquexía

Glaucoma/Cataratas

Trastorno psicológicos (ansiedad y depresión)

Deterioro cognitivo

Hipertensión arterial

Diabetes Mellitus

Síndrome Metabólico

Anemia

Síndrome de apnea del sueño

Enfermedad tromboembólica

Fuente: Barnes et al(119) y Soriano et al(120) 


\section{10 Prevención de la EPOC}

Como ya se ha comentado el factor más relacionado con la aparición de la EPOC es el tabaquismo, y en consecuencia, las medidas preventivas parece que, deben encaminarse a la deshabituación tabáquica y a la prevención del tabaquismo.

El tabaquismo es una enfermedad adictiva crónica y recidivante, que está catalogada con el código F-17 en la Clasificación Internacional de Enfermedades (CIE) y es la primera causa evitable de muerte prematura en el mundo. Por tanto es una responsabilidad de todos los profesionales sanitarios diagnosticar y tratar correctamente el tabaquismo y los distintos abordajes del abandono del hábito tabáquico (44).

La eliminación del hábito tabáquico es la medida más eficaz en la prevención de la EPOC y tiene un impacto determinante en la reducción de la mortalidad por la misma, siendo la medida más coste efectiva en el tratamiento de la EPOC (121). La eliminación del tabaco, retrasa la pérdida de función pulmonar y mejora la supervivencia incluso en la EPOC grave(122). El principal problema del paciente fumador es el elevado porcentaje de recaída del hábito tabáquico que oscila entre el $70-80 \%$ durante el primer año del abandono. En el grupo de pacientes fumadores con EPOC estas cifras se ven incrementadas, lo que dificulta las tasas de éxito de los programas de abandono del tabaco. Son pocos los fumadores que consiguen dejar de fumar de forma permanente en el primer intento.

Según el estudio IBERPOC (123), los pacientes con EPOC presentan una media de 7 puntos en el Test de Fargerström que mide la dependencia al tabaco, así como presencia de comorbiliadades psiquiátricas y falta de motivación (40).

El tratamiento del tabaquismo es diferente para cada fumador y depende fundamentalmente de la motivación que estos tengan para abandonar definitivamente el consumo del tabaco. Aquellos fumadores que estén dispuestos a realizar un serio intento para dejar de fumar deben recibir dos tipos de intervención: una conductual, encaminada a combatir la dependencia psíquica que pudieran padecer y otra, farmacológica, para aliviar la dependencia física por la nicotina (124).

Tratamiento de deshabituación tabáquica

- Consejo profesional, incluyen una intervención breve que puede ser tanto individual como grupal que, consiste en aplicar programas educativos o informativos adaptados a las características de los pacientes. Que incluyan estrategias que suelen ser beneficiosas como la creación de una lista de beneficios y prejudicios, ya que durante el proceso de abandono de hábito tabáquico, son muchos los síntomas que acontecen en el proceso de abstinencia como ansiedad, inquietud, tensión, frustración, impaciencia, dificultad de concentración, dolor de cabeza, aumento del apetito, irritabilidad o depresión.

En muchos casos resulta de gran ayuda la elaboración de un diario de los momentos que el paciente tiene más ganas de fumar. Los pacientes refieren la adicción mientras toman el café, después de cada comida o cuando ingieren 
bebidas alcohólicas. Puede ser recomendable la sustitución de estas bebidas por otras como por ejemplo el café por el té.

Igualmente se aconseja deshacerse de utensilios relacionados con el tabaco, como ceniceros, encendedores, cachimbas o lugares que relacione con el tabaco(125).

- Tratamiento farmacológico, El tratamiento farmacológico del tabaquismo se ha desarrollado ampliamente en los últimos años y han aparecido fármacos relacionados (124):

Tratamiento Sustitutivo con nicotina (TSN), se define como la administración de nicotina por una vía diferente a la del consumo del cigarrillo, y en una cantidad suficiente para disminuir los síntomas del síndrome de abstinencia, ya que si fuera insuficiente se crearía dependencia. La administración se hace por vía oral, en forma de chicles de nicotina, inhalador bucal, caramelos de nicotina, tabletas sublinguales; por vía transdérmica si se utilizan los parches de nicotina, y por vía nasal si se utiliza el spray nasal. Este tratamiento ha sido utilizado por unos 30 millones de fumadores durante varios años y parece demostrada su eficacia y seguridad. En cualquiera de las formas, la concentración plasmática de nicotina nunca alcanza a los niveles que se obtienen cuando se fuma un cigarrillo. Las diferentes formas que se comercializan para la administración del TSN:

- El chicle de nicotina, es una pieza de goma de mascar que contiene 2 o $4 \mathrm{mg}$ de nicotina. Mediante la masticación, la nicotina es liberada al interior de la cavidad bucal donde se absorbe a través de la mucosa para alcanzar la sangre, y desde allí estimular los receptores nicotínicos de las neuronas. Es muy importante que el chicle de nicotina se utilice correctamente por el fumador, ya que se relacionan fallos en el tratamiento con la utilización del chicle. La pieza se debe masticar lentamente, y cuando el fumador sienta un sabor fuerte dejará de masticar y guardará el chicle entre la mejilla y la encía hasta que se vaya dicho sabor; cuando la masticación se hace sin control de una manera continuada, la nicotina que se libera no se absorbe en la mucosa de la boca y por la tanto se deglute, ocasionando epigastralgias, y además al ser metabolizada en el hígado, disminuyen sus propiedades terapéuticas. Es importante que el fumador se entrene y se familiarice con los chicles antes de dejar de fumar. Así como la utilización de bebidas ácidas (soda, café, cerveza, etc.) pueden disminuir la absorción bucal de nicotina; por ello, su uso debe ser evitado durante el proceso de masticación y al menos 15 minutos después de finalizar el masticado.

- Comprimido para chupar, contiene 1 o $2 \mathrm{mg}$ de nicotina. Su mecanismo de absorción así como su farmacocinética es relativamente similar a los 
chicles de 2 o de $4 \mathrm{mg}$, respectivamente. Es una forma de tratamiento recomendada para los fumadores menos dependientes. La dosis es de 1 a 2 comprimidos cada hora mientras que el sujeto esté despierto, durante 6 a 8 semanas, para reducir progresivamente su consumo hasta cumplir 12 semanas de tratamiento. La principal ventaja de esta forma de TSN es su fácil utilización y la escasez de efectos adversos.

- Los parches, hay dos tipos dependiendo de la duración de la liberación de nicotina: unos que liberan nicotina durante 24 horas y que deben ser utilizados durante todo el día y otros que la liberan durante 16 horas y que deben ser utilizados mientras el sujeto está despierto. Siendo igual de eficaces ambos dos. Existen tres tipos de parches de nicotina; unos y otros se diferencian por las distintas concentraciones de nicotina que tienen y liberan, por su diferente tiempo de liberación y porque consiguen distintos niveles de nicotina en sangre. Es muy importante explicar el uso correcto y la aplicación del parche. El parche debe ser adherido a una zona limpia de la piel, sin vello, en las extremidades superiores o en el tronco. El parche será colocado todos los días en el momento de levantarse y se retirará ese mismo día al acostarse, si es de 16 horas, se quitaría al día siguiente, cuando se levante, si fuera de 24 horas de liberación. Es recomendable cambiar todos los días el sitio de colocación del parche para evitar la aparición de efectos adversos locales.

El parche de nicotina presenta una forma de administración de nicotina lenta y progresiva, es de fácil utilización, no se necesita una participación muy activa del fumador, y además los efectos adversos que produce son escasos. Para su correcta utilización conviene seguir las siguientes recomendaciones:

Los parches de nicotina deben ser utilizados en fumadores con levemoderada dependencia física por la nicotina. En fumadores con dependencia severa ( 7 o más puntos en el test de Fagerström), conviene utilizarlos a dosis altas y en combinación con los chicles de nicotina. Los parches de nicotina deben ser utilizados durante un periodo no inferior a 6-8 semanas y no superior a 12 semanas. La suspensión precoz del parche de nicotina, antes de la 6-8 semanas, facilita la recaída. La prolongación de un tratamiento con parches de nicotina más allá de 12 semanas no incrementa las posibilidades de éxito.

Los parches deben ser utilizados a dosis altas durante las primeras 4-6 semanas. En el caso de parches de 16 horas, la dosis alta recomendada es de $25 \mathrm{mg} /$ día; esta dosis se consigue con la utilización conjunta de un parche de $15 \mathrm{mg}$ más otro de $10 \mathrm{mg}$. Para el parche de nicotina de 24 horas la dosis alta es de $21 \mathrm{mg} /$ día. 
Bupropión, se comercializa en forma de comprimidos de liberación sostenida que contienen $150 \mathrm{mg}$ de sustancia activa. Este fármaco está indicado para cualquier fumador que haya hecho un intento serio de dejar de fumar, consumiera más de 10 cigarrillos al día y que no tenga contraindicaciones. Una de sus principales contraindicaciones están en que cuando se consume alcohol y otras sustancias, el umbral de tolerancia al mismo se ve disminuido, así como hay otros fármacos que también se deben evitar, como la cafeína ya que podría actuar como desencadenante para fumar (124).

Vareniclina, es un nuevo fármaco de reciente introducción en España con respecto al resto de tratamientos farmacológicos, que ha sido aprobado por la Agencia Europea del Medicamento y Productos Sanitarios como tratamiento específico para dejar de fumar. Es un fármaco que como el bupropion, requiere prescripción médica (124).

De acuerdo a estas consideraciones, se entiende que el tratamiento idóneo del tabaquismo debe incluir una combinación de tratamiento farmacológico, para aliviar la dependencia del fumador por la nicotina y apoyo psicológico, para combatir la adicción que tiene por el consumo inhalado de tabaco. Es importante que este tipo de tratamiento sea suministrado a todo fumador que esté realizando un serio intento de abandono de consumo de tabaco, a no ser que existan contraindicaciones para ello. De esta forma se incrementarán sensiblemente sus posibilidades de éxito en el intento (124).

Tabla 6. Tratamientos para la deshabituación tabáquica

\section{Tratamiento médico/psicológico}

Tratamiento farmacológico:

- Tratamiento Sustitutivo con Nicotina

- Chicles

- Comprimidos para chupar

- Parches

- Bupropion

- Vareniclina

Fuente: elaboración propia 


\subsection{Tratamiento del paciente EPOC}

Las principales estrategias terapéuticas para el paciente EPOC se engloban en la cirugía, intervenciones farmacológicas y no farmacológicas:

\subsubsection{Cirugía}

La cirugía es una opción de tratamiento en el paciente EPOC, pero nunca es la primera opción de hecho pocos son los pacientes que son sometidos a una intervención quirúrgica. Las opciones existentes son bullitectomía, reducción del volumen pulmonar o el trasplante de pulmón (2).

- Bullitectomía: es la indicación más común para el tratamiento de la disnea por una bulla gigante o neumotórax espontáneo secundario, considerándose una bulla gigante a una bulla que ocupe el $30 \%$ del hemitórax.

- Reducción del volumen pulmonar: técnicas endoscópicas o bien de resección directa, que solo han demostrado un beneficio terapéutico en situaciones de enfisemas muy graves. Las técnicas endoscópicas que se están llevando a cabo son:

- Válvulas unidireccionales: válvulas que permiten la salida del aire pero no la entrada, intentando colapsar las zonas hiperinsufladas.

- Reducción biológica, consiste en administrar sustancias no dañinas para nuestro cuerpo que colapsan las zonas enfisematosas.

- Bypass aéreo: creación de un stent entre el parénquima hiperinsuflado y el árbol bronquial.

En caso de la resección quirúrgica directa, consiste en una eliminación de las zonas pulmonares enfisematosas que no contribuyen al intercambio gaseoso para permitir una mejor mecánica ventilatoria del resto de parénquima pulmonar (126).

- Trasplante pulmonar: la EPOC es la indicación más frecuente de trasplante de pulmón, existiendo controversia en cuanto al aumento de la supervivencia del paciente trasplantado. Según la International Society for Heart and Lung Transplantation Registry (ISHLT), la mejor supervivencia de estos pacientes se obtiene en receptores menores de 50 años a los que se les realiza un trasplante bilateral, frente a los que se les realiza un trasplante a mayores de 50 años unilateral (127). Se considera el trasplante en pacientes con EPOC muy grave, según la actual normativa SEPAR. El trasplante se debe de considerar en los siguientes casos: pacientes con un BODE $>5$ o un BODE entre 7-10 pero con hipercapnia documentada, cor pulmonare, FEV $1<20 \%$ y la Capacidad de difusión del monóxido de carbono (DLCO) $<20 \%$ o enfisema homogéneo difuso (128). Existe evidencia que afirman que en los pacientes trasplantados existe una mejoría en su función pulmonar, mejorando en el intercambio de gases, la tolerancia al ejercicio y la calidad de vida (127). 


\subsubsection{Tratamiento farmacológico:}

En las principales guías de consenso dividen el tratamiento farmacológico de la EPOC en fase estable y en fase agudizada (22).

- Fase estable: existen diversas opciones para los pacientes en esta fase:

- Broncodilatadores de corta duración, como el bromuro de ipatropio y $\beta 2$ agonistas de acción corta, son fármacos eficaces para el control rápido de los síntomas. Así como en pacientes con síntomas ocasionales reducen los síntomas y mejoran la tolerancia al esfuerzo. Siendo fármacos de elección cuando se requieren dosis adicionales en momento puntuales, sea cual sea la gravedad de la enfermedad.

- Broncodilatadores de larga duración, son más utilizados en pacientes que requieren largos periodos de tratamientos de broncodilatación, ya que resultan más efectivos que los de corta duración. Suelen ser bien tolerados por los pacientes pero presentan diversos efectos adversos como:

- Beta adrenérgicos de larga duración (LABA): temblor en extremidades, calambres musculares, taquicardia, hipertensión, vaso dilatación periférica, cefalea, hiperglucemia, hipopotasemia, tos, broncoespasmo, irritación orofaríngea y dispepsia.

- Anticolinergicos de larga duración (LAMA), sequedad de boca, retención urinaria, aumento de la presión ocular e irritación faríngea.

- Corticoides inhalados, este tratamiento se administra en pacientes con EPOC grave o muy grave, asociada a bronquitis crónica en pacientes adultos con un historial de exacerbaciones frecuentes, no como tratamiento único, sino empleado como tratamiento adicional al uso de broncodilatadores. Así como medicación de rescate para aliviar el broncoespasmo agudo. No empleado en otros pacientes con EPOC, ni pacientes asmático o EPOC con déficit de alfa-1 antitripsina.

- Broncodilatadores de larga duración + corticoides inhalados, esta resulta la opción más utilizada cuando la monoterapia con broncodilatadores es insuficiente para controlar la enfermedad.

- Mucolíticos, utilizados por la característica de hipersecreción mucosa excesiva o espesa. Estos fármacos reducen la viscosidad del esputo, facilitando su expulsión con la expectoración. Siendo 
muy beneficiosos en las fases estables de los pacientes. En países como Reino Unido no son muy utilizados ya que consideran que son poco efectivos.

- Vacunación de la gripe, la vacunación anual de la gripe es un tratamiento opcional, que se debe de recomendar a los pacientes con diagnóstico de EPOC, como consecuencia de efectos más lesivos y más duraderos de la gripe, en este grupo de pacientes con respecto a la población sana o con otras patología.

- Vacunación del neumococo, al igual que en el caso de la vacunación de la gripe, la vacunación del neumococo es un tratamiento opcional administrado a partir de los 65 años cada 5 años, para la prevención de las neumonías.

- Fase de agudización, también conocida como fase de exacerbación, normalmente suelen tener lugar en invierno en los climas más templados, tienen como opciones farmacológicas, las siguientes $(4,22,40,44,48)$ :

- Corticoides sistémicos, se administran comúnmente en episodios de exacerbación, como la prednisona, administrada, por vía parenteral o bien por vía oral. Mejora la disnea, la función pulmonar, así como reducen las estancias hospitalarias. Teniendo como efectos secundarios la descalcificación ósea y el efecto rebote si la retirada del fármaco no es progresiva.

- Antibióticos, existe gran controversia en el uso de los mismos, con investigaciones que afirman que en España se utilizan en el 90\% de los casos, aunque solamente se realizan estudios microbiológicos en una cuarta parte de los mismos. No siempre las infecciones del tracto respiratorio son por virus y bacterias. Se recomienda la administración de antibióticos en pacientes con aumento de la disnea habitual, fiebre, aumento del volumen y la purulencia del esputo, así como reagudizaciones que cursan con insuficiencia respiratoria aguda o crónica (129).

En España se han detectado cepas resistentes (40\% Haemophilus influenzae, $90 \%$ Micrococo Catarralis, 30\% neumococos) a las penicilinas, macrolidos y betalactámicos. Por tanto hacen aconsejable la utilización de amoxicilina clavulánico o cefalosporinas (130). 
Tabla 7. Agentes infecciosos causantes en mayor medida de las exacerbaciones

\begin{tabular}{|c|c|}
\hline \multirow[t]{6}{*}{ Virus } & Rinovirus (resfriado común) \\
\hline & Influenza \\
\hline & Parainfluenza \\
\hline & Coronavirus \\
\hline & Adenovirus \\
\hline & Virus respiratorio sincitial \\
\hline \multirow[t]{4}{*}{ Bacterias } & Haemophilus influenzae \\
\hline & Stretococcus pneumoniae \\
\hline & Moraxella catarrhalis \\
\hline & Pseudomonas aeruginosa \\
\hline \multirow[t]{2}{*}{ Organismos atípicos } & Chlamydophila pneumoniae \\
\hline & Mycoplasma pneumoniae \\
\hline \multirow[t]{4}{*}{ Contaminación ambiental } & Ozono \\
\hline & Partículas $\leq 10 \propto \mathrm{cm}$ de diámetro \\
\hline & Dióxido de Sulfuro \\
\hline & Dióxido de nitrógeno \\
\hline
\end{tabular}

Fuente: Grupo GesEPOC, 2012 (48)

Para tratar las comorbilidades y su prevención se utilizan las heparinas para la prevención del tromboembolismo, los diuréticos en caso de insuficiencias cardíacas y el soporte nutricional unido al control del balance hidroelectrolítico para controlar la malnutrición.

- Oxigenoterapia, se trata de un tratamiento, cuyo objetivo es administrar oxígeno mientras el resto de tratamientos controlan los síntomas. Suele ser administrado a pacientes EPOC que se encuentran en insuficiencia respiratoria (IR), que precisa oxígeno suplementario para, mejora algunos síntomas causados por la falta de oxígeno como una mejor tolerancia al ejercicio, sueño más reparador y mejora de la capacidad cognitiva. Para obtener un beneficio terapéutico, se recomienda un uso 16 horas diarias, pudiéndolo utilizar más horas siempre que sea necesario, por ejemplo cuando se realicen tareas que requieran más esfuerzo físico o situaciones 
de mayor ahogo. El oxígeno se puede administrar mediante diversos dispositivitos dependiendo de las necesidades del paciente, como:

- Bombas de oxígeno

- Concentradores

- Oxígeno líquido.

Los dispositivos como las bombas de oxígeno y las mochilas de oxígeno líquido el gas que liberan se trata de oxígeno en estado puro y en el caso de los concentradores de oxígeno, se trata de dispositivos que obtienen aire ambientan y concentran unas cantidades mayores de oxígeno, que las que puede obtener un paciente al hacer una respiración normal de aire ambiental.

En el caso de la oxigenoterapia, el volumen de oxigeno administrado al pacientes se basa en su estado funcional y en consecuencia debe estar ajustado a las necesidades individuales de cada paciente. Ver anexo I.

\subsubsection{Tratamiento no farmacológico.}

Se han mencionado anteriormente estrategias no farmacológicas que han obtenido buenos resultado en su implementación con pacientes EPOC, como la deshabituación tabáquica, existiendo muchas otras como la rehabilitación pulmonar, la mejora de los conocimientos de la EPOC, instrucción en el uso de los inhaladores así como programas de autogestión de la EPOC en caso de exacerbaciones. Dichas intervenciones se basan en recomendaciones de la guía GesEPOC (48) que indican entre otras cuestiones que, los pacientes deberían participar en programas de educación encaminados a enseñar las habilidades necesarias en el tratamiento de la enfermedad. Comprenden actividades orientadas al mantenimiento y mejora del estado de salud y bienestar, constituir una estrategia importante para la protección de la salud y la prevención de la enfermedad.

\section{$\underline{\text { Rehabilitación pulmonar }}$}

La rehabilitación respiratoria tiene como objetivo mejorar la capacidad de ejercicio, funcionamiento pulmonar y la calidad de vida del paciente ya que mejora la tolerancia al esfuerzo y los síntomas de disnea y fatiga. Obteniendo buenos resultados incluso después de un solo programa de rehabilitación respiratoria.

Normalmente la rehabilitación pulmonar se compone de un entrenamiento con ejercicios físicos y entrenamiento para eliminar secreciones bronquiales, con una duración mínima para que sea efectivo de 6 semanas. Se obtienen mejores resultados, cuando se prolonga más de 6 semanas. El principal problema reside en que los beneficios suelen desaparecer tras concluir el programa, pero se pueden mantener si se realiza un entrenamiento físico en el domicilio (131). 
Autogestión y tratamiento en la exacerbación

Otros programas educativos están orientados hacia la autogestión y el autotratamiento. Están dirigidos a permitir el reconocimiento precoz de las exacerbaciones, así como los brotes de enfermedades concomitantes, para intentar reducir la gravedad de la enfermedad y/o agravamiento de otras comorbilidades (132). La autogestión de las exacerbaciones con planes de acción reduce la duración de las exacerbaciones, hospitalizaciones y costes de atención de la salud $(133,134)$.

Sin embrago los planes de acción no siempre son adecuados ya que tienen un potencial que no es seguro para pacientes con múltiples comorbilidades, porque los síntomas de alguna de las comorbilidades puede manifestarse y puede ser de sintomatología similar a la exacerbación de la EPOC (135). Además también existe literatura que indica que los beneficios son limitados si no se aplican medidas específicas e individualizadas (136).

Como consecuencia de los elevados costes que supone el tratamiento de los pacientes con EPOC (el 70\% de los costes totales de la enfermedad), y en algunos casos, la escasez de camas hospitalarias en unidades especializadas, sobretodo en invierno, muchos pacientes son tratados en unidades de hospitalización alternativas, con la participación de equipos multidisciplinarios, donde adquiere una mayor importancia la autogestión en el tratamiento de la exacerbación (137). Existen algunas investigaciones que afirman, que estos programas son seguros, ya que no existen diferencias significativas en las tasas de reingresos a los 2 meses del alta relacionadas con el modelo de hospitalización. Obtenido buenos resultados en la reducción del tiempo de ingreso, el número de vistas de urgencia y una mejor calidad de vida frente a los pacientes ingresados (138). En cualquier caso, el alta hospitalaria, parece el momento idóneo para iniciar programas de educación terapéutica (139).

\subsection{Educación terapéutica}

La educación representa hoy una práctica indisociable en la terapéutica farmacológica de este tipo de pacientes, como queda reflejado en la Estrategia Nacional del Paciente con EPOC (140), donde se plantea la educación terapéutica como un método para la reducción de la frecuencia de las agudizaciones y la mejora de la calidad de vida relacionada con la salud (CVRS).

Para la OMS la educación terapéutica es un proceso continuo, integrado en los cuidados y centrado sobre el paciente. Comprende actividades organizadas de sensibilización, información, aprendizaje y acompañamiento psicosocial relacionado con la enfermedad y el tratamiento prescrito. Contempla ayudar al paciente y a sus educadores, vivir lo más sanamente posible y mantener o mejorar la calidad de vida y así poder gestionar óptimamente su vida con la enfermedad (141). 
Dos de las últimas revisiones Cochrane $(139,142)$ publicadas, ponen de manifiesto la mayor capacidad de los pacientes con EPOC en reconocer y reaccionar de manera adecuada ante una exacerbación después de haber recibido contenidos de educación terapéutica.

\subsubsection{Contenido de los programas de educación terapéutica en pacientes EPOC}

Muchos de los estudios consultados, afirman que la educación terapéutica (ET) mejora a los pacientes con EPOC, pero no existe un programa establecido con los contenidos que, se deben abordar en el mismo, ni la duración, número de sesiones o si son mejores las sesiones individuales o grupales.

Aunque han adquirido interés en los últimos 5 años, los ensayos clínicos que evalúan la aplicación de un programa de educación terapéutica, no se han podido extraer grandes evidencias por la diversidad de variables estudiadas y las diversas escalas de valoración que se han aplicado en cada una de ellas.

La EPOC es una enfermedad prevenible y tratable, aunque no tiene tratamiento que implique el alta definitiva, sin embargo, los síntomas se pueden controlar para mejorar la calidad de vida. Un gran número de programas de intervención han utilizado sesiones grupales, con uso de folletos de información para reforzar los conocimientos, seguimiento telefónico o utilización de diarios de síntomas(143-146). Los programas de educación abordan temas como la anatomía y la físiología, descripción de la enfermedad, signos y síntomas de una exacerbación, servicios hospitalarios de los que puede hacer uso en caso de exacerbación (79,147-149). El tratamiento farmacológico, con instrucción en la técnica de inhalación, medicación en las exacerbaciones, oxigenoterapia y vacunación (150-156).

\subsubsection{Recomendaciones generales de los programas de educación terapéutica}

En la literatura revisada, aparecen las recomendaciones que deben incluirse en los programas de educación terapéutica, con objeto de que se pueda evaluar con garantías la efectividad de los programas. Información explicada más ampliamente en anexo I.

\section{Se describen brevemente en los apartados siguientes}

Motivar al paciente a que realice actividades, normalmente los ejercicios que se recomiendan no requerirían un gran esfuerzo físico, como por ejemplo caminar de 20 a 30 minutos diarios, practicar natación, salir en bicicleta, hacer ejercicio en un bicicleta estática, baile, subir las escaleras diariamente o hacer pesas han demostrado ser efectivas en el tratamiento de la EPOC $(157,158)$. No solo puede ser beneficioso a 
nivel respiratorio, si no que la práctica de ejercicio mejoraría el estado cardiorespiratorio.

La rehabilitación pulmonar, mediante la educación terapéutica, se debe instruir en ejercicios fáciles para poder mejorar o seguir mejorando el funcionalismo pulmonar del paciente con EPOC $(159,160)$. Ejercicios como, la técnica de inspiración por la nariz y expulsión del aire con los labios fruncidos, otras técnicas como la respiración abdominal y diafragmática y la limpieza de las secreciones bronquiales. Ejercicios para tonificar la musculatura coordinados con la respiración, como la flexión de brazos, abducción de brazos y la movilización caja torácica:

La nutrición, mantener una dieta equilibrada, con control del peso y reducir el consumo de alcohol $(108,111)$.

El sueño, las recomendaciones para poder tener un sueño más reparador (116) se basan en:

- Incorporarse en el borde de la cama intentando controlar la respiración, en caso de ahogo.

- Dormir con la cama un poco incorporada, haciendo uso de almohadones o camas articuladas.

- Colocarse un ventilador cerca de la mesita de noche.

- Dejarse la medicación de rescate en la mesita donde tenga fácil acceso.

Ansiedad y depresión Aprender a relajarse conociendo algunas técnicas de relajación. $(106,161,162)$.

El sexo y las relaciones,

- Tenga la medicación de rescate cerca por si la necesita, pudiéndola utilizar antes y después y si tiene oxígeno puede utilizarlo durante el mismo sin mayor inconveniente.

- Intente adoptar posturas que no dificulten la respiración.

Ocio y viajes, informar al médico de que va a viajar, ajustar las dosis de medicación. Evitar viajar a lugares con climas extremos en las épocas de más calor o frio. O lugares por encima de los 1.500 metros de altitud. Si el desplazamiento es en automóvil, autobús o tren y es portador de oxígeno debe dejar el equipo de oxígeno en posición vertical. Si viaja en avión debe informar con suficiente antelación a la compañía aérea para que si lo necesita le proporcione oxígeno durante el vuelo. También sería recomendable la medicación la guardara en los equipajes de mano por si se producen extravíos o si los necesita durante el viaje.

Aseo personal, se recomienda que para vestirse utilice la ropa adecuada a la estación del año, holgada y fácil de poner y quitar, evitar el uso de cinturones y fajas, que oprimen dificultando la respiración. Así como para el baño usar un taburete en la bañera y uso de toallas pequeñas. 
Mejora del entorno, evitara ambientes contaminados y procurar tener temperaturas constantes.

Signos y síntomas de las agudizaciones, (163) se recomienda, intentar relajarse para mejorar su disnea, aumentar la ingesta de líquidos, tomarse la temperatura, observarse las piernas por la posibilidad de edemas.

Técnicas que mejoran la efectividad del tratamiento farmacológico, los pacientes con EPOC, suelen tener pautados varios fármacos en forma de spray, pastillas y en algunos casos oxigenoterapia. La correcta administración es necesaria para asegurar su eficacia, siendo necesaria la inclusión de instrucciones de técnicas de administración de esta medicación en cualquier programa de educación terapéutica.

En el tratamiento de la oxigenoterapia, se recomienda hacer incidencia en que el oxígeno no tiene beneficio terapéutico si no se lleva más de 16 horas. No pudiendo modificar el volumen de litros de oxígeno ya que está basado en los datos gasométricos del paciente.

Atención a los cuidadores, el cuidador es uno de los pilares básicos en el paciente con EPOC, por tanto si el cuidador lo desea puede acudir a sesiones de educación terapéutica para pacientes con EPOC. Ya que su asistencia reforzaría en un mayor cumplimiento de las indicaciones terapéuticas. Así como se le debe indicar que el paciente con EPOC no es inválido y que debe de hacer todas las actividades, y ayudar en aquellas que sabemos que no puede realizar, escuchando las necesidades que puede tener para poder dar soluciones satisfactorias. 


\subsection{Justificación}

Desde la perspectiva enfermera de cuidar y desde un punto de vista estratégico que se recoge en las recomendaciones de la Estrategia Nacional del Paciente con EPOC (4), es importante tratar de reducir la frecuencia de las agudizaciones, a través de diferentes abordajes. Uno de ellos es la educación terapéutica. Como se ha evidenciado en algunos estudios con patologías respiratorias como el asma, han mostrado mejorías en la Calidad de vida relacionada con la salud (CVRS) y la función pulmonar en aquellos pacientes que han recibido un programa educativo de su patología (164). Exiendo investigaciones en pacientes con EPOC que indican una reducción del número de hospitalizaciones, días de estancia hospitalaria, mejora de la calidad de vida y del cumplimiento terapéutico después de ser incluidos en un programa estructurado de educación terapéutica (ET) acompañado de soporte telefónico e intervención temprana (147). Igualmente, la normativa internacional de rehabilitación respiratoria publicada conjuntamente por la European Respiratory Society y la American Thoraric Society (ATS) (165) plantea una nueva definición de rehabilitación que incluye además del ejercicio, la educación terapéutica, los cambios de actitud del paciente que le ayuden a convivir mejor con la enfermedad y tener una actitud proactiva desde el inicio de la enfermedad. Por tanto, parece pertinente seguir las recomendaciones de la literatura y profundiza en el estudio de la efectividad de los programas educativos y preventivos de la

EPOC. 


\subsection{Hipótesis}

Un programa estructurado de educación terapéutica en pacientes con Enfermedad Pulmonar Obstructiva Crónica (EPOC) es efectivo para la disminución de la utilización de recursos y mejorar: la calidad de vida, los conocimientos sobre la enfermedad, su tratamiento y la adherencia al tratamiento.

\subsection{Objetivos}

\subsubsection{Objetivos principales}

1. Identificar los estudios que evalúen intervenciones educativas en pacientes con EPOC para conocer las características sociodemográficas, las variables resultado, sus instrumentos de valoración y los componentes de las intervenciones de educación terapéutica estudiadas. A través de una Revisión Integradora.

2. Conocer las características de población con diagnóstico de Exacerbación de la EPOC catalogado con el GRD088 y que ingresan en el Hospital Universitario General de Castellón desde 2008 hasta 2013.

- Determinar las características sociodemográficas

- Determinar las características clínicas del ingreso

3. Determinar y evaluar la efectividad de un programa estructurado de educación terapéutica (ET), durante el ingreso, en comparación con la atención tradicional, en relación a la utilización de recursos ( ingresos hospitalarios, visitas a urgencias y a consultas externas, por causa respiratoria o no respiratoria), calidad de vida, conocimientos sobre la enfermedad, su tratamiento y adherencia al tratamiento.

- Evaluar la efectividad del tipo de atención en el grupo de pacientes asignados al grupo intervención en base a la utilización de recursos la calidad de vida, los conocimientos sobre la enfermedad, su tratamiento y la adherencia al tratamiento.

- Evaluar la efectividad del tipo de atención en el grupo de pacientes asignados al grupo control en base a la utilización de recursos la calidad de vida, los conocimientos sobre la enfermedad, su tratamiento y la adherencia al tratamiento. 
METODOLOGÍA 


\section{METODOLOGÍA}

El diseño empleado para esta tesis doctoral consiste en 3 fases de estudio, acordes a los objetivos planteados .

- Identificar los estudios que evalúen intervenciones educativas en pacientes con EPOC para conocer las características sociodemográficas, las variables resultado y sus instrumentos de valoración y los componentes de las intervenciones de educación terapéutica estudiadas. A través de una Revisión integradora.

- Conocer las características de población con diagnóstico de Exacerbación de la EPOC catalogado con el GRD088 y que ingresan en el Hospital Universitario General de Castellón desde 2008 hasta 2013.

- Determinar y evaluar la efectividad de un programa estructurado de educación terapéutica (ET).

\section{1 Metodología Revisión Integradora}

\subsubsection{Diseño}

Revisión integradora de la literatura científica sobre estudios de intervención basados en programas de educación terapéutica en pacientes con EPOC, en la base de datos internacional de Medline (Pubmed) y búsqueda en todas las referencias de los artículos incluidos.

\subsubsection{Criterios de selección}

$\underline{\text { Tipos de estudios }}$

Ensayos clínicos controlados, cuasiexperimentales, que evaluaban la implantación de un programa de educación terapéutica en pacientes con diagnóstico clínico de EPOC. Criterios de exclusión, estudios con una puntuación entre 0 y 2 puntos en la escala Jadad (166).

\section{Tipos de participantes}

Pacientes con EPOC, diagnosticados por un profesional de la salud, mediante criterios espirométricos $\left(\mathrm{FEV}_{1}<80 \%\right.$ del valor teórico y un $\mathrm{FEV}_{1} / \mathrm{CVF}<70 \%$ del valor teórico). Se excluyeron los estudios de participantes con diagnóstico primario de asma.

\section{$\underline{\text { Tipo de intervención }}$}

La definición de programa de educación sobre EPOC utilizada fue: "trasferencia de información sobre la EPOC y su tratamiento en cualquiera de las siguientes formas: escrita, verbal, visual o auditiva. La educación mínima incluyó la provisión de material escrito o una breve interacción verbal estructurada entre un profesional de asistencia sanitaria y un paciente". Sin embargo, tenían que enmarcarse en un programa formal. El programa educativo podía dirigirse al 
abandono del hábito tabáquico, instrucción en la técnica de inhalación, mejora de sus hábitos de vida, autocuidado durante las exacerbaciones, capacidad para realizar las actividades de la vida diarias o una combinación de las anteriores.

$\underline{\text { Tipo de medidas de resultado }}$

Los resultados primarios seleccionados fueron:

- Calidad de vida

- Variables ventilatorias (FEV1, Saturación de oxígeno, gasometría arterial, disnea (MRC), walking Test)

- Utilización de recursos sanitarios (ingresos hospitalarios y visitas a urgencias)

Los resultados secundarios:

- Comorbilidades

- Signos y síntomas

- Adherencia terapéutica

- Consumo de tabaco

- Medicación (Medicamentos utilizados en el momento de la evaluación )

- Vacunación en el último año

- Conocimiento de la EPOC

- Índice de masa corporal (IMC)

- Ansiedad y depresión

- Satisfacción personal

\subsubsection{Identificación de los estudios}

Para la búsqueda en la base de datos Medline Pubmed, se utilizaron los descriptores, del Medical Subject Headings (MeSH), "COPD " y "education" con el operador booleano "and" entre ambos. También se realizó una búsqueda de todas las referencias bibliográficas de los artículos incluidos. No hubo restricciones con respecto al lugar de la investigación, idioma o fechas de publicación, es decir, desde el comienzo de indexación de cada base, hasta marzo de 2014.

\subsubsection{Valoración de la calidad metodológica}

La evaluación de la calidad metodológica, fue realizada por pares mediante la utilización de la escala Jadad, que evalúa la calidad de los estudios incluidos, utilizando un sistema de calificación en base a las respuestas de las 7 preguntas que plantea el cuestionario. Cada pregunta afirmativa se suma 1 punto y cada pregunta negativa 0 puntos, restando las dos preguntas finales si sus respuestas son afirmativas -1 y en el caso de negación se sumaría 0 puntos. Considerándose estudios de baja calidad entre 0 a 2 puntos y de buena calidad entre 3 y 5 puntos. Los ítems evaluados son la asignación al azar, el cegamiento, la descripción de las 
perdidas y motivos de abandono. Seleccionando a todos los estudios que tenían una valoración de la calidad metodológica entre 3 y 5 puntos, siendo excluidos los artículos con una puntuación entre 0 y 2 puntos en la escala Jadad. No siendo penalizado el ítem que evalúa el cegamiento de los participantes por la naturaleza de la intervención de los ensayos clínicos.

\subsubsection{Análisis de los datos}

Se realizó una síntesis narrativa de los datos obtenidos. De los datos obtenidos se ha realizado un análisis exhaustivo del diseño del estudio, edad media, sexo predominante, tipo de centro de realización del estudio (universidad, hospitalario, atención primaria), número de participantes, número de pacientes asignados al grupo control, número de pacientes asignados al grupo intervención, programa de intervención realizado en cada estudio, variables medidas, periodo de seguimiento, evaluación y resultados obtenidos. Así como se ha realizado una análisis descriptivo de las variables, categorizándolas como efecto favorable, igual o desfavorable. 
3.2 Metodología del análisis de las características de la población con diagnóstico de Exacerbación de la EPOC catalogado con el GRD088 y que ingresan en el Hospital Universitario General de Castellón desde 2008 hasta 2013.

\subsubsection{Diseño}

Estudio observacional, trasversal, retrospectivo con revisión de historias clínicas, con limitación en el tiempo desde el 22 de diciembre de 2008 al 28 de diciembre de 2013.

\subsubsection{Población y muestra}

Pacientes que ingresaron en el periodo estudiado en el Hospital Universitario General de Castellón con el diagnóstico de (GRD088) identificado este como exacerbación de la EPOC.

Criterios de inclusión: Paciente con diagnóstico de exacerbación de EPOC con GRD 088 (491.1; 491.9; 492.0; 493.2; 494; 496; 518.81 + (491.2, 492.8, 493.2, $494,496) ; 137.0+518.81 ; 416.8 ; 416.9 ; 500 ; 502 ; 503 ; 504 ; 505 ; 519.8$; $518.83 ; 714.0 ; 517.8$ ICD9-CM).

Criterios de exclusión: pacientes EPOC que ingresen por otro motivo diferente a la exacerbación o pacientes EPOC que ingresan en una unidad hospitalaria que no registrara sus datos.

\subsubsection{Variables estudiadas}

Variables sociodemográficas:

- $\quad$ Edad (años); Sexo (hombre/ mujer)

\section{$\underline{\text { Variables clínicas }}$}

- Número de ingresos hospitalarios total y por unidad de hospitalización (neumología, corta estancia, medicina interna, hospitalización domiciliaria, cardiología, cirugía general y hematología)

- Número de reingresos total

- Defunciones (si/no)

- Número de ingresos por mes y año (enero, febrero, marzo, abril, mayo, junio, julio, agosto, septiembre, octubre, noviembre y diciembre) (2008, 2009, 2010, 2011, 2012, 2013) 


\section{Variables de control:}

- Número de comorbilidades clasificadas en:

Cardíacas (insuficiencia cardiaca, infartos, enfermedad arterial periférica, aneurismas abdominales, hipertensión arterial, hipercolesterolemia, obesidad)

Endocrinas y renales (diabetes, insuficiencia renal)

Tumores (próstata, tracto urinario, vejiga, colon y recto, pulmón, tiroides, cavidad oral y faringe, mama, hepáticos, óseos y cerebrales).

Hepáticas y digestivas (cirrosis alcohólica, ulceras gástricas, gastritis, esofagitis, varices esofágicas, angioplastias de estómago y esófago de Barret)

Neurológicas (demencia senil y Alzheimer)

Infecciosas (tuberculosis, hepatitis B y C, VIH)

- Hábitos tóxicos, clasificados en: consumo de alcohol (si/no), consumo de cannabis (si/no)

- Procedimientos más utilizados: gasometría arterial (si/no), electrocardiogramas (si/no), espirometrias (si/no), TAC (si/no), broncoscopias (si/no) y biopsias (si/no).

- Tratamientos más utilizados: nebulizadores (si/no), oxigenoterapia (si/no), esteroides (si/no), antibióticos (si/no), ventilación mecánica no invasiva (si/no), diálisis (si/no).

\subsubsection{Procedimiento de recogida de datos}

Se realizó un estudio descriptivo de las variables categóricas (con frecuencias absolutas y relativas) y continuas ( media, desviación típica, máximo y mínimo. Haciendo uso del programa estadístico SPSS versión 23.

\subsubsection{Consideraciones éticas}

El protocolo del estudio fue aprobado por el comité de bioética e investigación del Hospital Universitario General de Castellón. El estudio se llevará a cabo siguiendo las normas especificadas en la Declaración de Helsinki, los principios éticos de la investigación biomédica. El tratamiento de los datos de carácter personal de los sujetos se ajustó a lo establecido en la Ley orgánica de Protección de Datos de Carácter Personal, 15/1999 de 13 de Diciembre y la Ley 41/2002 de 14 de Noviembre Básica reguladora de la autonomía del paciente y de derechos y obligaciones en materia de información y documentación clínica. Se garantizó el 
anonimato de los participantes y confidencialidad de los datos. Los datos no estuvieron accesibles a personas ajenas al estudio. 


\subsection{Metodología para determinar y evaluar la efectividad de un programa estructurado de educación terapéutica (ET)}

\subsubsection{Diseño}

Estudio experimental, controlado, simple ciego con utilización de la técnica de enmascaramiento en la asignación y el análisis de datos. Con el objetivo de comparar la aplicación de un programa estructurado de educación terapéutica (grupo intervención), con la atención tradicional (grupo control), de acuerdo con las variables objeto de estudio, en pacientes con diagnóstico clínico de EPOC, con un seguimiento de 3 meses post-alta hospitalaria debido a una exacerbación de su patología respiratoria.

\subsection{2 Ámbito}

\subsubsection{Hospital Universitario General de Castellón}

Hospital perteneciente a la red de hospitales de la Agencia Valenciana de Salud, encargado de atender a la población del Departamento de Salud número 2 de la Comunidad Valenciana, con un volumen de población entorno a las 300.000 personas, dando servicio a 39 municipios. Siendo el centro de referencia en la provincia de Castellón.

Cuenta con 580 camas, (468 son de adulto y 112 de pediatría) 24 puestos de cirugía sin ingreso, 16 quirófanos y 50 puestos de urgencias. Cubierto por 12 servicios médicos divididos en 8 plantas.

Las plantas que albergaron a pacientes con EPOC fueron:

- Neumología dividida en dos unidades de hospitalización (621- 635),(540-554)

- Medicina Interna también dividida en dos unidades de hospitalización (321335),(555-569)

- Unidad de Corta Estancia (UCE) (155-169)

- Unidad de Hospitalización Domiciliaria (UHD).

Imagen 1. Hospital Universitario General de Castellón

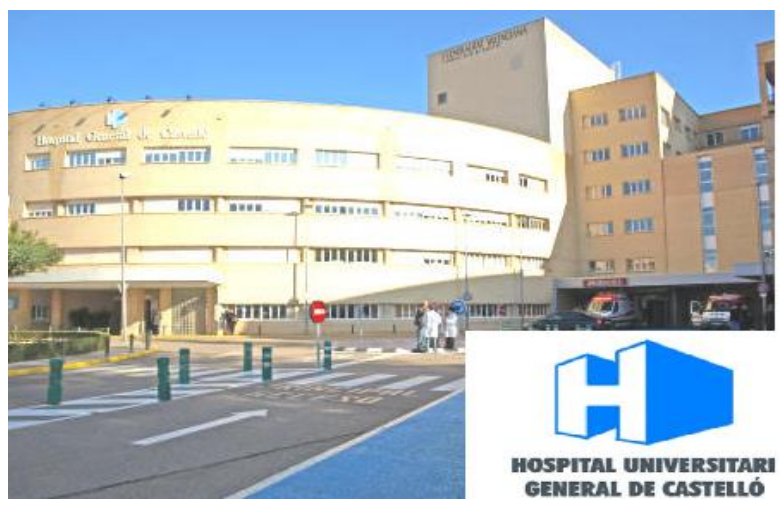




\subsubsection{Procedimiento de captación según unidad hospitalaria}

Las diversas estrategias de captación de Medicina Interna, Hospitalización Domiciliaria, Unidad de corta estancia y otras unidades hospitalarias, fueron creadas por la escasa captación que habíamos obtenido tras un año de implantación del estudio. Siendo la estrategia inicial la captación a través del servicio médico de neumología. Para la captación de todos los pacientes ingresados en el Hospital Universitario General de Castellón, que cumplían con el diagnóstico de ingreso por exacerbación de la EPOC, las estrategias fueron las siguientes:

- Servicio médico de Neumología: todos los pacientes EPOC que fueron atendidos por el servicio médico de Neumología de dicho hospital, fueron valorados a través de la hoja de caracterización, ver imagen 2, que resumía los criterios de inclusión y exclusión. Una vez cumplan con los criterios de selección se informaba al paciente y se pedía la firma del consentimiento informado. Seguidamente la supervisora de la unidad de neumología cogía uno de los sobres cerrados y opacos que estaban depositados en una caja en el despacho de la misma. Sobres que estaban ordenados por el orden de generación de los número aleatorios del programa informático Epidat 3.1.Seguidamente las enfermeras de la unidad cumplimentaban los tres tipos de cuestionarios y le daban la información en caso de pertenecer al grupo intervención del horario y las citas de las sesiones de educación, y en el caso de pertenecer al grupo control de la cita para la evaluación a los 3 meses. Las sesiones de educación y la evaluación a los 3 meses post alta hospitalaria fueron realizadas por la autora de la presente tesis.

- Medicina Interna: el jefe de servicio de forma semanal enviaba un correo a la autora de la presente tesis de los pacientes ingresados, así como sus habitaciones, que cumplían con la hoja de caracterización, esta enfermera se desplazaba al hospital informaba al paciente y cumplimentaba los tres cuestionarios. Cogía uno de los sobres donde estaba la asignación al azar, si el paciente pertenecía al grupo intervención, esta misma enfermera se ponían en contacto telefónico con el paciente para facilitarle los días y los horario de las sesiones de educación. Y a los pacientes del grupo control les llamaba por teléfono para informarles del día que debían de acudir a los 3 meses para la evaluación.

- Hospitalización Domiciliaria, la gestora de casos del hospital junto con el equipo de UHD, de forma semanal se revisaban los ingresos que cumplían con la hoja de caracterización, la enfermera de la presente tesis informaba al paciente y este daba un consentimiento verbal de ser incluido en el estudio. Seguidamente esta persona realizaba las encuestas de forma telefónica, e informaba al paciente del grupo al que había sido asignado, abriendo uno de los sobres al finalizar la encuesta. Del mismo modo los pacientes del grupo control se les informaba del día que debían acudir para la evaluación a los 3 meses post alta hospitalaria. 
- Unidad de corta estancia y otras Unidades Hospitalarias: la gestora de casos del hospital mediante la herramienta informática denominada "Integración" se elaboró una búsqueda prediseñada de todos los pacientes ingresados en el hospital cuyo motivo de ingreso fuera exacerbación de la EPOC con el código , Código Internacional de Enfermedades (CIE) 491.21. Estas búsquedas se realizaron de forma semanal, donde los resultados obtenidos indicaban el número de habitación, teléfono, número de comorbilidades, índice de Chalson, número de SIP, teléfono de contacto, nombre completo, edad, sexo, número de ingresos en los últimos 12 meses y visitas a urgencias en los últimos 12 meses. Una enfermera se desplazaba a la habitación informaba al paciente, este firmaba el consentimiento y cumplimentaba los cuestionarios. Cogía uno de los sobres donde estaba la asignación al azar, si el paciente pertenecía al grupo intervención, esta misma enfermera se ponían en contacto telefónico con el paciente para facilitarle los días y los horario de las sesiones de educación. Y a los pacientes del grupo control les llamaba por teléfono para informarles del día que debían de acudir a los 3 meses para la evaluación.

\subsection{Población y muestra}

Durante el periodo de reclutamiento se incluyeron a todos los pacientes que ingresaban en el Hospital Universitario General de Castellón cuyo motivo de ingreso era exacerbación de la EPOC, CIE 491.21. Para conocer los conceptos de las definiciones susceptibles de controversia en el proceso de captación ver anexo II.

\subsubsection{Criterios de inclusión:}

a) Paciente con diagnóstico de exacerbación de EPOC con grupos relacionados con el diagnóstico (GRD) 088 (491.1; 491.9; 492.0; 493.2; 494; 496; 518.81) $(491.2,492.8,493.2,494,496) ; 137.0+518.81 ; 416.8 ; 416.9 ; 500 ; 502 ; 503$; 504; 505; 519.8; 518.83; 714.0; 517.8 ICD9-CM) Que ingresa en cualquier unidad del Hospital Universitario General de Castellón.

b) Vivir en el área de influencia del hospital.

c) Comprender el catalán o castellano.

d) Aceptar entrar en la investigación, conociendo y comprendiendo todos los aspectos del mismo y firmando el consentimiento informado.

\subsubsection{Criterios de exclusión:}

b) Pacientes EPOC que ingresen por otro motivo diferente a la exacerbación.

d) Pacientes con incapacidad para comunicarse. 
e) Pacientes en estado terminal de una patología con esperanza de vida $<6$ meses de vida, bajo criterio médico.

Todas los criterios de inclusión se resumen la siguiente hoja de caracterización elaborada para la captación de pacientes ver imagen 2 .

Imagen 2. Hoja de caracterización

\begin{tabular}{|c|c|c|}
\hline Enfermedad Pulmonar Obstructiva Crónica. & $\begin{array}{l}\mathrm{Si} \\
\mathrm{No}\end{array}$ & No continuar \\
\hline Ingreso por exacerbación grave de la EPOC. & $\begin{array}{l}\mathrm{Si} \\
\mathrm{NO}\end{array}$ & No continuar \\
\hline Teléfono. & $\begin{array}{l}\mathrm{Si} \\
\mathrm{No}\end{array}$ & No continuar \\
\hline Existe barrera idiomática. & $\begin{array}{l}\mathrm{Si} \\
\mathrm{No}\end{array}$ & No continuar \\
\hline $\begin{array}{l}\text { El paciente tiene una esperanza de vida }<6 \\
\text { meses. }\end{array}$ & $\begin{array}{l}\mathrm{Si} \\
\mathrm{No}\end{array}$ & No continuar \\
\hline Incapacidad para seguir un programa educativo. & $\begin{array}{l}\mathrm{Si} \\
\mathrm{No}\end{array}$ & No continuar \\
\hline Puede acudir a las sesiones formativas. & Si & No continuar \\
\hline $\begin{array}{l}\text { Solo en Hospital General de Castellón: } \\
\text { Seguimiento por el servicio de Neumología. }\end{array}$ & Si & No continuar \\
\hline Aceptación y firma del consentimiento informado. & $\begin{array}{l}\mathrm{Si} \\
\mathrm{No}\end{array}$ & No continuar \\
\hline Ha sido anteriormente incluido en este estudio. & $\begin{array}{l}\mathrm{Si} \\
\mathrm{No}\end{array}$ & No continuar \\
\hline ¿Se incluye? & & \begin{tabular}{|l} 
Si (inicio del proceso) \\
No (no continuar)
\end{tabular} \\
\hline \multicolumn{3}{|c|}{$\begin{array}{l}\text { Codificación para diagnóstico de EPOC. } \\
\text { CIE 10: J41.1; J42; J43.9; J44.9; J96; J96.9; J43.9; J44.9; B9.9; J96; J96.9; I27.2; } \\
\text { I27.89; I27.81; I27.9; J6; J62.8; J63; J63.1; J63.2; J63.3; J63.4; J63.5; J63.6; J64; } \\
\text { J98.8; J96.1; M6.9; J99. } \\
\text { ICD9-CM: 491.1;491.9;492.0;493.2;494;496;518.81;491.2;492.8;493.2;494; } \\
\text { 496; 137.0; 518.81;416.8;416.9;500;502;503;504;505;519.8;519.83;714.0; } \\
\text { 517.8 } \\
\text { Se considerará que el paciente tiene incapacidad para seguir un programa educativo si } \\
\text { tiene como diagnóstico F00-F27, F30-F97, F99 con CIE } 10 \text { o CIE 9: } 220-319 .\end{array}$} \\
\hline
\end{tabular}

\subsubsection{Duración}

El periodo de reclutamiento de pacientes fue de 1 año y 6 meses. Iniciándose en el 3 de febrero de 2014 y finalizándose el 31 de julio de 2015, ambos inclusive.

\subsubsection{Variables:}

3.3.5.1 Variables sociodemográficas: edad (años), sexo (hombre, mujer), nivel de estudios (sin estudios, estudios básicos, estudios de secundaria o formación profesional y estudios universitarios) residencia habitual (su casa, en una residencia o en un centro sociosanitario), convivencia (marido/esposa, hijos, otros familiares, solo, varios miembros de la familia), apoyo social percibido a los 3 meses (No necesita ningún apoyo, tiene apoyo por parte de los vecinos, tiene apoyo social formal suficiente (centro de día, trabajadora social, institución), tiene soporte social pero no es suficiente, no tiene ningún soporte social y no lo necesita, no tiene apoyo y lo necesita).

3.3.5.2 Variable Explicativa: (Grupo Intervención) Programa de educación terapéutica (basado en la guía española (GesEPOC)(48) y la actual normativa Internacional de 
Rehabilitación Respiratoria), constituido por cuatro sesiones educativas y seguimiento telefónico; (Grupo control): tratamiento convencional

- Programa de educación terapéutica estructurado: La duración estimada de cada una de las sesiones fue de 40 minutos. Las sesiones fueron grupales de entre $5 \mathrm{y}$ 6 personas, pudiéndose realizar las sesiones educativas de forma telefónica. Y con posible asistencia de algún familiar si así lo desean. Todas las sesiones fueron realizadas en el edificio anexo al hospital, ubicado en frente del mismo, donde alberga a la unidad de docencia del Hospital Universitario General de Castellón, disponen de aulas con proyecto, pizarra y de fácil acceso para personas con discapacidad. Ver anexo I.

La primera sesión denominada como conocimiento de la EPOC consta de los siguientes ítems:

- Cómo funcionan los pulmones. Diagnóstico. Que quiere decir EPOC y factores de riesgo.

- Signos y síntomas de la EPOC.

- Detección precoz de la exacerbación y medidas a tomar.

- Como afecta la EPOC a las actividades de la vida diaria.

La segunda sesión denominada tratamiento farmacológico abordando los siguientes ítems:

- Terapia inhalada. Como, cuando, por qué y para qué sirven cada una de ellas. Control de la técnica según normativa SEPAR.

- Pastillas/inyecciones. Para que sirven, como tomarlas.

La tercera sesión denominada tratamiento no farmacológico aborda los siguientes ítems:

- Deshabituación tabáquica, práctica regular de ejercicio, nutrición, aspectos psicológicos, calidad del sueño.

- Recomendaciones nutricionales, durante las exacerbaciones y los periodos sin exacerbación.

- Condiciones del hogar, recomendaciones.

- Vacunación ¿Cuándo? ¿Dónde? ¿Efectos adversos?

- Drenaje de secreciones. Ejercicios de mantenimiento de la función pulmonar.

La cuarta sesión denominada oxigenoterapia aborda los siguientes ítems:

- Oxigenoterapia, ventilación. Como, cuando, por qué y para qué sirven cada una de ellas. 
En el estudio se consideraron que todos los sujetos habían completado el programa de ET si su asistencia había sido igual o superior al $75 \%$ de las sesiones de educación. Si no acudían al 75\% fueron considerados como perdidas en el grupo intervención.

\section{$\underline{\text { Formación de los instructores en las sesiones de educación }}$}

Para aumentar conocimiento en los pacientes con EPOC, una investigadora realizó una estancia en el Hospital Clinic de Barcelona, referente en educación sanitaria para pacientes con EPOC. Durante la estancia se elaboraron las sesiones de educación y se implementaron las mismas con un grupo experimental de pacientes.

Todas las sesiones de educación estaban desarrolladas con la aplicación informática de Microsoft Power Point, donde en la parte inferior contenida la información que se debía decir en cada una de las diapositivas. Los dibujos de las diapositivas y el contenido de las mismas estuvo basado en el libro "Controlando la Epoc" de la Sociedad Científica de Enfermedades respiratorias (SEPAR). Además para que resultara más ameno se utilizaron material audiovisual de Forum Clinic, disponible en el siguiente enlace: http://www.forumclinic.org/es/enfermedad-pulmonar-obstructiva-cr\%C3\%B3nica

Para asegurar la correcta implementación y recogida de datos de forma homogénea a todos los profesionales implicados en el estudio, se les instruyo durante las dos primeras semanas en la recogida de las variables así como se les dio una copia del proyecto y del libro blanco del mismo donde están recogidas las recomendaciones para implementar los cuestionarios. Además de una dirección y un teléfono de contacto.

Durante el desarrollo del mismo, se realizaron las siguientes reuniones, para garantizar la correcta implementación de los cuestionarios e intentar solucionar las pérdidas de muestra y mejorar la captación.

Tabla 8. Cronograma de reuniones

\begin{tabular}{ll}
\hline & Fechas \\
\hline Presentación del proyecto & 7 de Enero de 2014 \\
Presentación de la intervención del proyecto & 22 de Enero de 2014 \\
Presentación de los instrumentos a utilizar & 31 de Enero de 2014 \\
Inicio del proyecto & 3 de Febrero de 2014 \\
Seguimiento a las 2 semanas & 17 de Febrero de 2014 \\
Seguimiento al mes & 3 de Marzo de 2014 \\
Seguimiento a los 3 meses & 2 de Junio de 2014 \\
Seguimiento a los 6 meses & 15 de Septiembre de 2014 \\
Seguimiento al año. & 2 de Febrero de 2015 \\
\hline
\end{tabular}

Fuente: elaboración propia

- Atención tradicional/convencional: estos pacientes no recibieron ninguna sesión de educación, ni seguimiento telefónico. Siendo solo instruidos con el uso de inhaladores por el personal de enfermería durante el ingreso. 
3.3.5.3 Variables de resultado principal: utilización de recursos, calidad de vida, conocimiento de la enfermedad y cumplimiento terapéutico.

3.3.5.3.1 Variables de utilización de recursos: número de visitas a urgencias en los últimos 12 meses, número de visitas a una Unidad de Cuidados Intensivos (UCI) en los últimos 12 meses, atención sociosanitaria recibida en los últimos 12 meses. A los 3 meses post alta hospitalaria, número de ingresos hospitalarios en esos 3 meses, número de visitas a urgencias en esos 3 meses.

3.3.5.3.2 Variables de calidad de vida: la calidad de vida fue evaluada mediante dos escalas la COPD Assesment Test (CAT) y el cuestionario St. George.

COPD Assesment Test (CAT)(167): cuestionario de autocumplimentación que evalúa el estado respiratorio, mide el bienestar y la calidad de vida del paciente con EPOC, constituido por 8 preguntas todas ellas con 5 opciones de respuesta, valoradas de 0 al 5 , donde los valores más próximos al 0 hacen referencia a estados de salud mejores y valores más próximos al 5 hacen referencia a estados más avanzados o con más signos y síntomas de la enfermedad pulmonar, en cada pregunta solo se puede cumplimentar con una única respuesta. Para la interpretación de la escala es necesaria la suma de los valores indicados por el paciente en las 8 preguntas establecidas, con la interpretación mediante la siguiente escala. Expuesto en la tabla 9.

Tabla 9. Puntuaciones escala calidad de vida CAT

\begin{tabular}{cl}
\hline Puntuación & \multicolumn{1}{c}{ Impacto total } \\
$0-10$ & Bajo impacto \\
$11-20$ & Impacto medio \\
$21-30$ & Impacto alto \\
$31-40$ & Impacto muy alto \\
\hline
\end{tabular}

Fuente: Jones et al(167)

St.George Cuestionnaire(168): cuestionario de autocumplimentación, diseñado para cuantificar el impacto de una enfermedad de las vías aéreas respiratorias en el estado de salud, el bienestar percibido por los pacientes respiratorios y al mismo tiempo, ser suficientemente sensible para reflejar los cambios en la actividad de la enfermedad. Permite además la comparación entre poblaciones de pacientes y cuantificar cambios en el estado de salud después de un tratamiento. El cuestionario consta de 50 ítems, dependiendo de la pregunta el paciente tiene que responder a preguntas con diferentes respuestas o bien a preguntas con una única opción sí o no. La cuantificación de los ítems se hizo mediante la página web: http://www.fundacionneumologica.org/asma/asma/sangeorge2.htm para posteriormente aplicar la escala para mayores de 60 años del cuestionario St. George. En la tabla 10 se describen la interpretación de las puntuaciones obtenidas. 
Tabla 10. Puntuación escala calidad de vida St. George

\begin{tabular}{llccl}
\hline & & Bajo & Normal & Alto \\
& Síntomas & $<16.1$ & $(16.1-32.9)$ & $32.9<$ \\
Hombres & Actividad & $<16.3$ & $16.3-36.7)$ & $36.7<$ \\
& Impacto & $<8.1$ & $(8.1-12.3)$ & $12.3<$ \\
& Global & $<12.2$ & $(12.2-27,1)$ & $27.1<$ \\
\hline \multirow{4}{*}{ Mujeres } & Síntomas & $<9.2$ & $(9.2 \pm 12.6)$ & $12.6<$ \\
& Actividad & $<19.4$ & $(19.4 \pm 42.0)$ & $42.0<$ \\
& Impacto & $<6.4$ & $(6.4 \pm 19.7)$ & $19.7<$ \\
& Global & $<11.1$ & $(11.1 \pm 26.0)$ & $26.0<$ \\
\hline
\end{tabular}

Fuente: Mon et al (168)

3.3.5.3.3 Variables de conocimiento de la enfermedad, fueron evaluadas a través de los siguientes ítems:

Conocimiento de la enfermedad (sabe cómo se llama la enfermedad que padece), conocimiento de los signos y síntomas de alarma de la exacerbación (conoce cuales son los síntomas de alarma de su enfermedad), autoeficacia en el abordaje de problemas (sabe que medicación tiene que tomar cuando se encuentra mal). Estas tres preguntas el entrevistador apunto la respuesta dada por el paciente y enjuicio si había sido correcta su respuesta o incorrecta.

Evaluación de la técnica inhalatoria, la evaluación de la técnica inhalatoria se realizó mediante la evaluación del entrevistador del cumplimiento de todos los pasos que según la normativa SEPAR se debe de seguir para la correcta realización de los 6 dispositivos existentes en el mercado (cartucho presurizado, cámara, turbuhaler, accuhaler, inhaletas y nebulizador) así como también se anotó el tipo de fármaco sin marcas comerciales ( $\beta 2$ adrenérgico de corta duración, $\beta 2$ adrenérgico de larga duración, anticolinérgico, corticoide inhalado, $\beta 2$ adrenergico más corticoide inhalado, antibiótico inhalado).

\subsection{Adherencia farmacológica}

La adherencia farmacológica fue evaluada a través del cuestionario Morinski-Green Questionnaire(169), que consta de 4 preguntas que se deben de realizar de forma no directa mediante una conversación, para considerar que una persona tiene un buen cumplimiento terapéutico debe de seguir el patrón de respuesta $(\mathrm{No} / \mathrm{Si} / \mathrm{No} / \mathrm{No})$, si alguna de las preguntas no responde a ese patrón establecido se considera que el paciente no es cumplidor. Evaluando aspectos como, se olvida de toda las pastillas a las horas establecidas, cuando se encuentra mal deja de toma la medicación o cuando se encuentra bien deja de tomar la medicación indicada. 


\section{$\underline{\text { 3.3.5.4 Variables de control }}$}

Las variables de control evaluaron aspectos como los hábitos de vida, función pulmonar, seguimiento médico, estado psicológico y dependencia para la realización de las actividades diarias.

Variables de hábitos de vida

- Tabaco la historia de tabaquismo, se valoró si era el paciente fumador (no, si, exfumador) y la dosis de tabaco acumulada (años de fumador y media de cigarrillos fumados al día, mediante la fórmula (cigarrillos al día $x$ años de fumador) 120). Teniendo en cuenta si el paciente era fumador de pipa, cada pipa fumada equivalía a 3 cigarros, al igual que los puros pequeños cada puro pequeño fumado equivalía también a 3 cigarros y en el caso de los puros grandes equivalían a 5 cigarros.

- $\quad$ Alcohol, el alcohol se preguntó si consumía alcohol y se cuantifico el número de vasos o copas que bebía al día. En caso de no consumir se indicó un 0 y en caso de consumir se cuantificaron los valores en número de vasos o botellines.

- Estado nutricional: se valoro si el paciente seguía alguna dieta (si/no), si consumía alcohol (si/no) el índice de masa corporal (IMC)(170) mediante la fórmula peso $(\mathrm{Kg}) / \mathrm{Altura}^{2}(\mathrm{~m})$, con la obtención de los resultados ver tabla 11. También se cuantificó la cantidad de agua, preguntando el número de vasos ingeridos de agua al día, multiplicando dicha cantidad de vasos por $0,25 \mathrm{cc}$ obteniendo el número litros de agua ingeridos al día.

\begin{tabular}{ll}
\hline Tabla 11. Puntuación IMC & \\
\hline IMC & Situación \\
$<18,5$ & Bajo peso \\
$18,5-24,9$ & Normopeso \\
$25-29,9$ & Sobrepeso \\
$30->50$ & Obesidad \\
\hline IMC:Índice de masa corporal; Fuente: OMS, (170)
\end{tabular}

- $\quad$ Sedentarismo, para la valoración del sedentarismo se realizaron dos preguntas con respuestas dicotómicas (si/no), la primera hace referencia a si camina más de 30 minutos al día, fuera de casa, siendo una de las recomendaciones de la actual normativa para el paciente EPOC. La siguiente pregunta sobre sedentarismo hacía referencia a si pasa la mayor parte del tiempo en el sofá, siendo las respuestas sí o no a las afirmaciones anteriores.

- Vacunación, en esta variable se contabilizó si el paciente estaba vacunado el año anterior de la gripe con las respuestas sí, no o no lo sabe, siendo esta última cuantificada en los resultados como no. Y también se contabilizó si estaba vacunado del pneumococo cuya vacunación es cada 5 años con las mismas opciones de respuesta que la anterior pregunta. 
Variables de función pulmonar

- Variables espirométricas, estas variables se utilizan para medir la severidad de la obstrucción de la EPOC, mediante la escala Global Iniciative of Chronic Obstructive Lung Disease (GOLD)(171), que tiene como objetivo valorar la capacidad pronostica, el riesgo de futuras exacerbaciones y las comorbilidades del paciente, mediante la valoración de la espirometría y el nivel de síntomas de la EPOC. Dependiendo de la espirometría y de la clínica el paciente se clasifica en 5 grandes grupos que van de menor a mayor gravedad de la enfermedad. Denominados estadío o también gold 1, 2, 3 o 4,vease tabla 12.

\begin{tabular}{|c|c|c|}
\hline Estadios & Espirometria & Clínica \\
\hline Estadio 0 (En riesgo) & Normal & Tos, flemas \\
\hline Estadio I (Leve) & $\begin{array}{l}\mathrm{FEV}_{1} / \mathrm{FVC}<0,7 ; \mathrm{FEV}_{1} \\
>80 \%\end{array}$ & Con o sin síntomas (tos, flemas) \\
\hline $\begin{array}{l}\text { Estadio II } \\
\text { (Moderada) }\end{array}$ & $\begin{array}{l}\mathrm{FEV}_{1} / \mathrm{FVC}<0,7 ; \mathrm{FEV}_{1} \\
50-80 \%\end{array}$ & $\begin{array}{l}\text { Con o sin síntomas (tos, flemas, } \\
\text { disnea) }\end{array}$ \\
\hline Estadio III (Grave) & $\begin{array}{l}\mathrm{FEV}_{1} / \mathrm{FVC}<0,7 ; \mathrm{FEV}_{1} \\
30-50 \%\end{array}$ & $\begin{array}{l}\text { Con o sin síntomas (tos, flemas, } \\
\text { disnea) }\end{array}$ \\
\hline $\begin{array}{l}\text { Estadio IV (Muy } \\
\text { grave) }\end{array}$ & $\begin{array}{l}\mathrm{FEV}_{1} / \mathrm{FVC}<0,7 \\
\mathrm{FEV}_{1}<30 \%\end{array}$ & $\begin{array}{l}\mathrm{FEV}_{1}<50 \% \text { con insuficiencia } \\
\text { respiratoria o signos clínicos de } \\
\text { insuficiencia cardiaca }\end{array}$ \\
\hline
\end{tabular}

FEV1: Flujo espiratorio en el primer segundo; FVC: Capacidad vital forzada; Fuente: Pauwels et al (171)

- Gasometría arterial, en la gasometría arterial se valoraron en base a los datos expuestos en la tabla 13:

\begin{tabular}{lc}
\hline \multicolumn{3}{l}{ Tabla 13 Valores normales de la gasometría arterial } \\
\hline Gasometría arterial & Parámetros normales \\
$\mathrm{Ph}$ sanguíneo & $(7,350-7,450)$ \\
$\mathrm{PO}_{2}(\mathrm{mmHg})$ & $(69-115)$ \\
$\mathrm{PCO}_{2}(\mathrm{mmHg})$ & $(35-45)$ \\
\hline $\mathrm{PO} 2$ presión de oxígeno; PCO2.Presión de Dióxido de carbono; mmHg: milígramos de \\
mercurio Fuente: datos obtenidos con los niveles medios que figuran en la analítica del \\
paciente.
\end{tabular}

- $\underline{\text { Signos y síntomas, }}$ se valoraron la presencia de disnea, la tos, la expectoración, sibilancias, somnolencia diurna, precisa dormir sentado, edemas y fiebre, clasificados según los valores si/no. Y se cuantifico la disnea media el cuestionario del Medical Research Council (MRC)(172), con 5 opciones de clasificación según el grado de disnea, ver tabla 14.

En el caso de la presencia de expectoración se valoró el color del esputo, en blanco, marrón, verde y amarillo. Siendo importante su valoración pronostica de la exacerbación. En el caso del dolor, fue evaluado a través de la escala EVA, 
que puntúa del 0 al 10 el dolor de un paciente, donde 0 es el valor referido a la ausencia del dolor y el 10 el máximo dolor que puede soportar una persona.

Tabla 14. Grado de disnea MRC

\begin{tabular}{cl}
\hline GRADO & $\begin{array}{l}\text { Interpretación } \\
0\end{array}$ \\
1 & $\begin{array}{l}\text { Ausencia de disnea, excepto al realizar ejercicio intenso } \\
\text { pronunciada }\end{array}$ \\
2 & $\begin{array}{l}\text { Incapacidad de mantener el paso de otras personas de la misma edad } \\
\text { debido a una dificultad respiratoria o a la necesidad de pararse a } \\
\text { descansar al andar en plano siguiendo el propio paso. }\end{array}$ \\
& $\begin{array}{l}\text { Necesidad de pararse a descansar al caminar unos } 100 \text { metros o a } \\
\text { pocos minutos de caminar en plano }\end{array}$ \\
& $\begin{array}{l}\text { La disnea impide al paciente salir de casa o aparece en actividades } \\
\text { como vestirse y desvestirse }\end{array}$
\end{tabular}

MRC: Medical Resoult Council; Fuente: J. Ccmig et al (172)

- Las comorbilidades, se cuantificaron con el número de comorbilidades y el índice de Chalson modificado por edad(173), es la escala de cálculo de comorbilidades y esperanza de vida más utilizada, puede utilizarse de forma individual o en combinación con otros aspectos para calcular el riesgo de mortalidad a los 10 años. Estructurado en 19 condiciones clínicas, catalogadas en cuatro grupos de acuerdo con el peso asignado a cada enfermedad. La obtención de estas enfermedades se realiza mediante revisión de historia clínica. Donde el resultado de su puntuación total es la suma de todas las patologías presentadas por el paciente obteniendo un riesgo relativo de mortalidad y modificado por edad ya que a partir de los 40 años se suma 1 punto adicional por cada decena superior a 40 años. Ver tabla 15.

Tabla 15. Puntuación índice de Chalson

\begin{tabular}{ll}
\hline Índice de Chalson & Situación \\
$\mathbf{0 - 1}$ & Ausencia de comorbilidad \\
$\mathbf{2}$ & Baja comorbilidad \\
$>3$ & Alta comorbilidad \\
\hline
\end{tabular}

Fuente: Wang et al (173) 


\section{Variables de seguimiento médico}

- Número de pastillas, inyecciones e inhalaciones al día, para la cuantificación de esta pregunta se indicó el número de pastillas, inyecciones e inhaladores de forma cuantitativa, no existiendo ni mínimo ni máximo.

- Dispositivos según fármaco, en esta variable se valoró el dispositivo y la función del principio activo del inhalador cartucho presurizado, cámara, turbuhaler, accuhaler, inhaletas y nebulizado, siendo las opciones de respuesta (broncodilatador de corta duración, broncodilatador de larga duración, corticoide inhalado y broncodilatador más corticoide inhalado.

- Lugar donde se visita normalmente, siendo las opciones de respuesta (Atención Primaria, hospital, ninguno, no lo sé).

- Periodo de seguimiento médico: siendo las opciones de respuesta (una vez cada 3 a 6 meses, una vez al año, no me acuerdo, no tengo seguimiento).

- Donde acude cuando se encuentra mal, siendo las opciones de respuesta (Atención Primaria, hospital, urgencias y nadie)

- Ha recibido educación sanitaria anteriormente, siendo la respuesta dicotómica, en el caso de ser afirmativa se preguntó si la educación que recibió era de su problema respiratorio o de otras patologías, así como si recibió material adicional en esas sesiones.

- Complicación del tratamiento, en esta pregunta se valoró si el paciente era portador de oxígeno domiciliario, CPAP o ventilación mecánica en su domicilio. Así como se valoró si era cumplidor de las 16 horas en caso del oxígeno y en el caso de la CPAP y la ventilación mecánica si lo llevaba como mínimo las 8 horas para obtener un beneficio terapéutico.

\section{Variables psicológicas}

Ansiedad y depresión, fue valorada mediante la escala Hospital Anxiety and Depression Scale (HAD)(174) mediante la respuesta a 14 preguntas, 7 valoran aspectos de la ansiedad y 7 aspectos de la depresión. Cada pregunta tiene 4 posibles respuesta, con los valores de 0 a 3, los valores más altos hacen referencia a una mayor afectación de la ansiedad o la depresión, donde finalmente la suma de las preguntas de la ansiedad y por separado las preguntas de la depresión podemos obtener un resultado que se traducirá en los valores de la tabla 16.

Tabla 16. Puntuación HAD

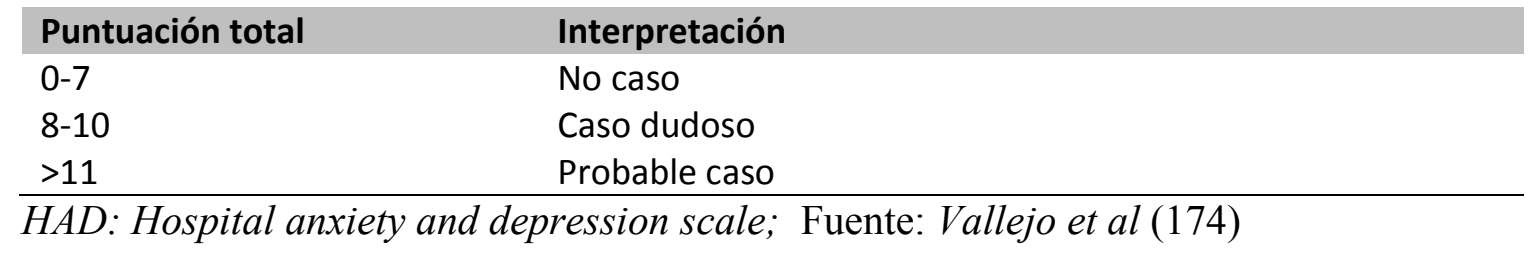


Variables de dependencia física en la realización de las actividades diarias

Dependencia, valorada mediante el índice de Barthel(175), se trata de un cuestionario heteroadministrado con 10 ítems tipo likert. El rango de posibles valores del Índice de Barthel está entre 0 y 100, con intervalos de 5 puntos. A menor puntuación, más dependencia; y a mayor puntuación, más independencia. Los puntos de corte sugeridos por algunos autores para facilitar la interpretación, ver tabla 17.

\begin{tabular}{ll}
\hline Tabla 17. Puntuación Barthel & \\
\hline Índice de Barthel & Situación \\
$0-20$ & Dependencia total \\
$21-60$ & Dependencia severa \\
$61-90$ & Dependencia moderada \\
$91-99$ & Dependencia escasa \\
100 & Dependencia completa \\
\hline
\end{tabular}

Fuente: Cid-Cruzada et al (175)

\subsubsection{Recogida de datos}

En el proceso de captación y recogida de los datos, se utilizó el diagrama de flujo para ensayos clínicos establecido en la guía CONSORT como se puede ver en el Diagrama 1.

Instrumentos de recogida de datos para la consecución de esta tesis doctoral, se pueden ver en los anexos III y IV.

- Cuestionario de recogida de datos al ingreso hospitalario.

- Cuestionario a los 3 meses post alta.

Diagrama 1. Diagrama de flujo

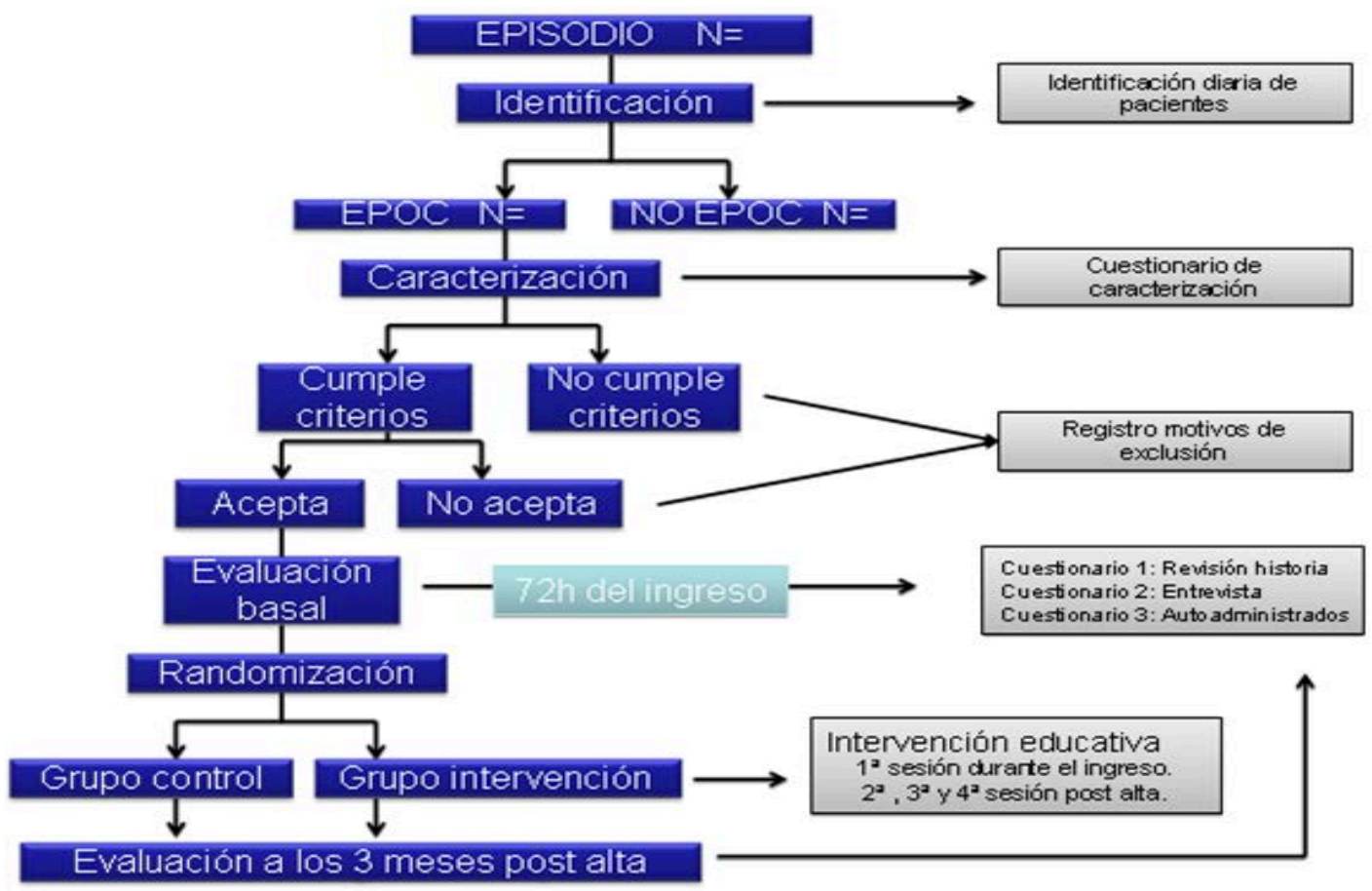




\subsubsection{Programas informáticos utilizados para la obtención de datos}

Todos los programas informáticos utilizados, se han hecho uso para la obtención de las variables de historia clínica del paciente:

- Integración, es una herramienta informática elaborada con el fin de unificar la información de las unidades de atención primaria con la información de la unidades de atención especializada, para completar la historia clínica del paciente, siendo accesible desde cualquier punto corporativo de la Agencia Valenciana de Salud(176).

- Abucasis, herramienta informática, utilizada por los profesionales sanitarios para mejorar la atención sanitaria del paciente, ya que permite la gestión de la agenda profesional del personal sanitario, prescripción farmacológica $y$ recomendaciones, amplia la información del paciente en su historia clínica ya que quedan registradas las pruebas médicas del mismo.

- Orion, es una herramienta informática aplicado en la Comunidad Valenciana y elaborada para mejorar los cuidados al paciente ingresado en una unidad hospitalaria.

En el caso de las espirómetrias no estaban introducidas dentro de la historia clínica electrónica y fueron facilitadas por el personal de funcionalismo pulmonar del Hospital Universitario General de Castellón.

\subsubsection{Análisis estadístico}

Una vez recogida toda la información y finalizado el periodo de estudio, se realizó un control de calidad de la cumplimentación de todos los cuestionario. Para posteriormente introducirlos en la aplicación informática SPSS versión 23 para Windows, para realizar el análisis estadístico. La base de datos solo fue accesible para la autora y directoras de esta tesis.

\subsubsection{Estadística descriptiva general}

Se realizará una descripción estadística de las variables categóricas y continuas de este estudio: distribución de frecuencias y proporciones para las variables categóricas, y la media, mediana, desviación típica, máximo y mínimo, para las variables cuantitativas.

\subsubsection{Estadística homogeneidad de muestras al ingreso}

Para la comparación de variables categóricas se utilizó la prueba de ji cuadrado $\left(\mathrm{X}^{2}\right)$ mediante tablas de contingencia y para comparar variables cuantitativas se utilizó la prueba T Student para la comparación de muestras independientes. Asumiendo un nivel de significación bilateral de $\mathrm{p}<0.05$. 


\subsubsection{Estadística bivariante de contraste de hipótesis}

Para la comparación de los resultados a los 3 meses se utilizó para las variables cuantitativas la comparación de medias para muestras independientes mediante la prueba de T-Student y para variables cualitativas la prueba de ji cuadrado $\left(\mathrm{X}^{2}\right)$, y en caso de muestras pequeñas se utilizó el Test de Fisher, todas las variables cualitativas a través de tablas de contingencia. Asumiendo un nivel de significación bilateral de $\mathrm{p}<0.05$.

Para la comparación del antes y después según grupo de asignación se utilizó para las variables cuantitativas la prueba T-Student para muestras relacionadas y para las variables cualitativas la prueba del ji cuadrado $\left(\mathrm{X}^{2}\right)$.

\subsubsection{Tamaño muestral:}

Para la estimación del tamaño muestral se solicitó a la unidad de Documentación Científica del Hospital Universitario General de Castellón, los ingresos por exacerbación en los últimos 5 años.

Por tanto se estimó un tamaño muestral mínimo de 150 pacientes en base al análisis del número de ingresos por exacerbación de la EPOC, aceptando un riesgo alfa de 0.05 y un riesgo beta de 0.2 en un contraste bilateral. Estimándose una tasa de pérdidas de seguimiento del $22 \%$, dato obtenido de la revisión integradora elaborada para la consecución de esta tesis.

\subsubsection{Aleatorización}

\subsubsection{Generación de la secuencia}

El proceso de aleatorización se realizó en una proporción de 1:1, haciendo uso del programa informático Epidat 3.1, para garantizar el anonimato en el muestreo y la asignación aleatoria de los sujetos a cada uno de los grupos. Este programa informático generó tantos documentos como pacientes fueron necesarios en nuestro estudio. Una vez generada la lista de aleatorización, se crearon sobres opacos y cerrados que contenían el grupo al que el paciente había sido asignado. Por tanto la asignación solo era conocida cuando el paciente había sido incluido en el estudio y elaborados los cuestionarios. Limitando así los posibles sesgos que pudieran generar el conocimiento de la asignación.

\subsubsection{Mecanismo de ocultación de la asignación}

Para la ocultación de la asignación se utilizó la técnica de enmascaramiento para el análisis de datos, como consecuencia de la naturaleza de la intervención los participantes clínicos y los pacientes no estarán cegados en su asignación a los grupos de estudio. 


\subsubsection{Consideraciones éticas}

El protocolo de investigación de este estudio fue aprobado el comité de bioética e investigación del Hospital Universitario General de Castellón y por el Comité Deontológico de la Universidad Jaume I. El estudio se llevó a cabo siguiendo las normas especificadas en la Declaración de Helsinki, los principios éticos de la investigación biomédica. El tratamiento de los datos de los sujetos que participan en el estudio se ajustó a lo establecido en la Ley orgánica de Protección de Datos de Carácter Personal, 15/1999 de 13 de Diciembre y la Ley 41/2002 de 14 de Noviembre Básica reguladora de la autonomía del paciente y de derechos y obligaciones en materia de información y documentación clínica.

Se garantizó el anonimato de los participantes y confidencialidad de los datos. Los datos no estuvieron accesibles a personas ajenas al estudio. Todos los pacientes participantes en el estudio firmaron el consentimiento informado. Dicho consentimiento informado constó de: invitación a participar en el estudio, propósito del mismo, motivo por el que ha sido seleccionado, descripción de los procedimientos de recogida de datos, molestias y beneficios, la garantía del anonimato, la confidencialidad, las personas de referencia para responder a dudas, el consentimiento voluntario, la opción de abandonar el estudio y el consentimiento de una revelación incompleta relacionada con la pertenencia al grupo control o experimental, disponible en el Anexo VI. 


\section{RESULTADOS}




\section{RESULTADOS}

La exposición de los resultados de esta tesis doctoral se exponen acorde a las 3 fases expuestas según los objetivos de la investigación y la metodología de trabajo.

- Identificar los estudios que evalúen intervenciones educativas en pacientes con EPOC para conocer las características sociodemográficas, las variables resultado y sus instrumentos de valoración y los componentes de las intervenciones de educación terapéutica estudiadas. A través de una Revisión Integradora.

- Conocer las características de población con diagnóstico de Exacerbación de la EPOC catalogado con el GRD088 y que ingresaron en el Hospital Universitario General de Castellón desde 2008 hasta 2013.

- Determinar y evaluar la efectividad de un programa estructurado de educación terapéutica (ET)

\subsection{Resultados Revisión Integradora}

Se identificaron 321 artículos, véase diagrama 2, con la estrategia antes citada. Tras la lectura del título y resumen se seleccionaron 58 artículos que podían cumplir con los criterios de inclusión. A continuación se realizó una lectura completa del artículo para verificar los criterios de selección, quedando un total de 28 artículos. Los motivos de exclusión de los 30 estudios fueron: protocolos de investigación sin resultados(177-183), incluían a pacientes con EPOC y pacientes sanos (184-186), los sujetos asignados al grupo control no tenían una atención convencional (187-193) estudio repetido (194-198) la intervención era un programa de canto (199), no tenía una intervención educativa $(200,201)$ se centraba principalmente en un programa de rehabilitación pulmonar basado en ejercicios físicos (202-204), se basaba en un abstract de un congreso (205) u otros cuyo objetivo era validar un cuestionario para la tos (206). Se realizó una búsqueda manual de las referencias de los 28 artículos que cumplían los criterios de selección $(79,143-$ 155,164,207-219) con la inclusión de 4 artículos más (156,220-222). Los 32 artículos fueron valorados por su calidad metodológica, excluyendo $(164,209,211,213-216,218,220)$ de ellos por puntuaciones en la escala de Jadad entre 0 y 2 puntos. Finalmente 22 (143151,153-156,207,208,210,219,221,222) artículos fueron incluidos y clasificados según: diseño, país, tipo de centro, participantes totales, participantes asignados al grupo control (GC), participantes asignados al grupo intervención (GI), intervención educativa, variables cuantificadas, periodo de seguimiento y resultados obtenidos. 
Diagrama 2. Diagrama de flujo Revisión Integradora

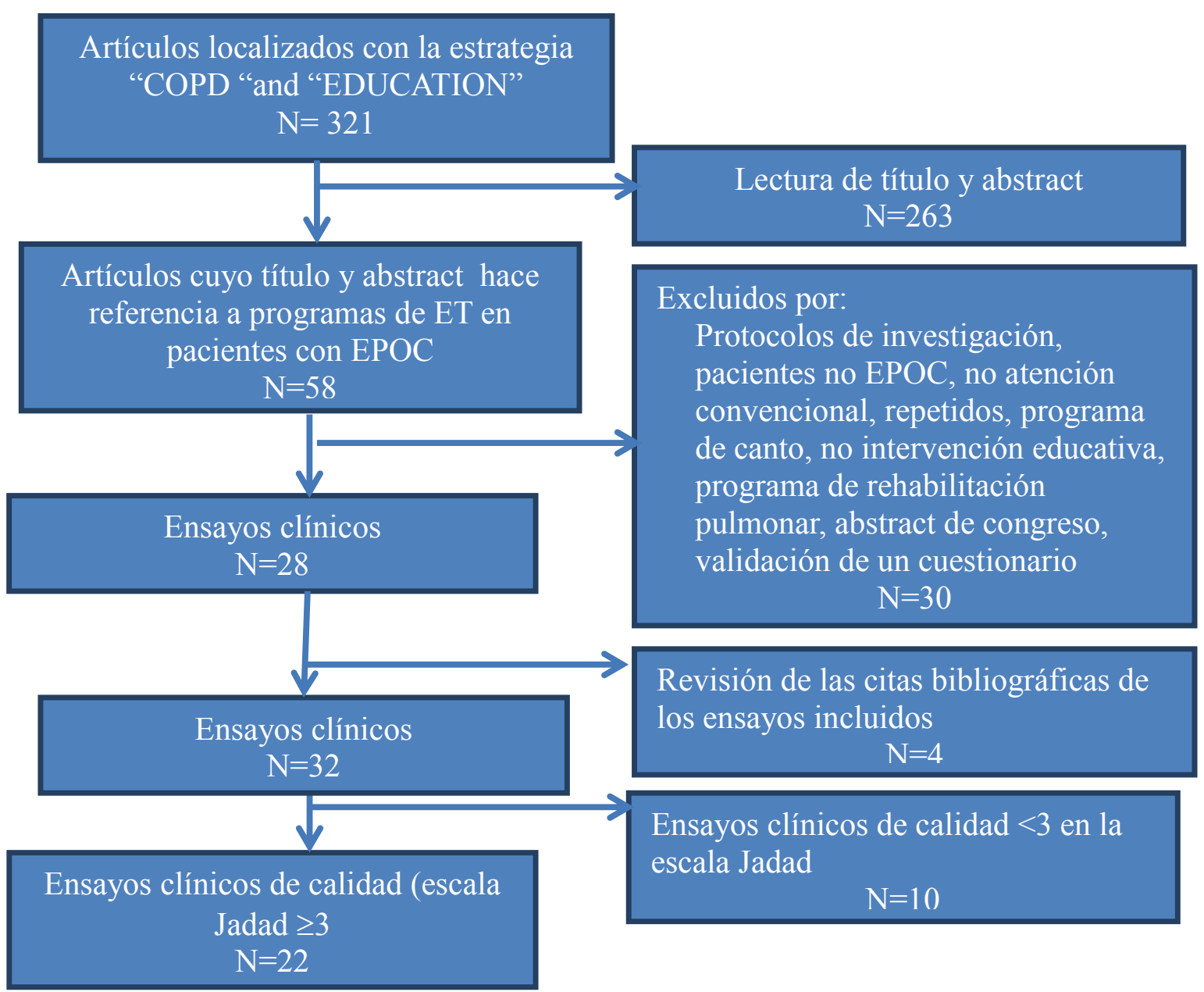

\subsubsection{Participantes/ reclutamiento}

En el total de artículos encontrados se asignaron al azar un total de 8369 pacientes; 7211 $(76,2 \%)$ pacientes completaron estos estudios. Las tasas de abandono oscilaron entre el $0 \%$ y $66,3 \%$, con un porcentaje medio de $20,84 \%$ en número medio de abandonos. De los 22 estudios, $12(54,6 \%)$ estudios reclutaron a sus pacientes en hospitales, $8(36,4 \%)$ estudios en centros de atención primaria, $1(4,55 \%)$ en un centro universitario y en otro estudio incluido no indicaba el tipo de centro(210).

En el 45,5\% (n=10) de los estudios fueron más frecuentes los hombres, frente a un 40,9\% $(n=9)$ donde la mayor prevalencia eran mujeres y en un $13,6 \%(n=3)$ fue equitativo el reparto entre sexos, todos los estudios llevados a cabo en España muestra unas diferencias muy significativas de la prevalencia de la EPOC en el sexo masculino. La media de edad de todos los estudios es de 66,4 años, siendo la comorbilidad más frecuente las enfermedades coronarias, de los estudios que así lo analizaron ( $\mathrm{n}=5)$ $(144,150,152,156,217)$. 
En uno de los estudios que así lo recogen afirman que el $90 \%$ de los pacientes se vacunó contra la gripe el año anterior, no teniendo los resultados de incidencia de la vacunación tras la implementación del programa de educación terapéutica (208).

La mitad de los estudios desarrolló su investigación con un periodo de seguimiento de un año de duración $(\mathrm{n}=10)$, siguiéndole los estudios que han tenido menos de un año de duración ( $\mathrm{n}=9$ ), los que han tenido una duración de dos años $(\mathrm{n}=2)$ así como un estudio no reveló la duración del mismo(221). Se observó una gran heterogeneidad en los periodos de evaluación durante el trascurso de las mismas, realizándose con mayor prevalencia de dos evaluaciones, estudios de antes y después.

\subsubsection{Intervenciones}

Los 22 estudios describieron la educación en autocuidados en la EPOC comparada con la atención convencional. En todos los estudios, salvo uno (155), el modo de educación fue grupal, en algunos de los casos además se realizó de un plan individual (143$146,150,152,155,156,221)$, uso de folletos informativos para reforzar la educación $(143,144,146,149,152,207,210,217)$ seguimiento telefónico $(143,144,147)$ o utilización de un diario $(143,148,210)$. El contenido de las sesiones educativas fue: en 18 estudios $(81,8 \%)$ en sus sesiones educativas hablaron sobre el conocimientos sobre la EPOC, con los siguientes componentes: anatomía y fisiología $(148,149,154)$, descripción de la enfermedad (144,145,147,150-152,155,207,208,217) signos y síntomas de la EPOC $(79,149,221)$ signos y síntomas de las exacerbaciones (79,145,147$149,152,154,155,217,221)$ diagnóstico de la EPOC $(79,152,154)$ desencadenantes de una exacerbación $(147,148,152,154,155,217)$ y servicios hospitalarios de los cuales puede hacer uso $(208,217,221)$.

Otro de los apartados fue el tratamiento no farmacológico abordado en 19 estudios $(86,4 \%)$, con los siguientes componentes: deshabituación tabáquica $(79,143-$ $146,149,150,152-156,207,210,217)$ práctica regular de ejercicio físico $(143,145,146,149$ $152,154,207)$ hábitos nutricionales $(143,145,146,150-153,207,208,210)$ control de las emociones $(143,145,151)$ gestión de la disnea $(143,145,151)$ técnicas de respiración $(143-$ $145,147,154,208)$ sueño y descanso $(145,151,207,210)$ limpieza de secreciones $(210)$, sexualidad (145), higiene de manos(154), pérdida de peso(146) y actividades de ocio y viajes (145).

En relación al tratamiento farmacológico era abortado en el 86,4\% $(n=19)$ de los estudios, específicamente en la instrucción en la técnica de inhalación (145-149,152,154$156,207,217,222)$ medicación en las exacerbaciones $(143,145,147,152,154,155,207)$ oxigenoterapia $(145,155,208)$ y vacunación $(146,155,156)$. Haciendo uso del material educativo del Living well with COPD (223) en 3 estudios $(147,149,212)$ 


\subsubsection{Medidas de resultado}

Los estudios consultados informaron de las siguientes medidas de resultado:

Variables sociodemográficas (sexo y edad) (143-151,153-156,207,208,210,219,221,222) CVRS (79,143-145,148,150-154,156,207,208,210,212,217,221) variables ventilatorias: $\mathrm{FEV}_{1} \quad(79,143-145,147,149,152,153,155,156,207,210,212,217,221,222)$ walking Test $(145,147,153,156,222)$ FEV1/FVC $(143,145,147,149,152,155,207,210,217)$ gasometría arterial $(207,222)$, disnea (MRC), FVC $(145,147,149,152,153,207,217,222)$, tabaquismo $(144,149-154,217,222)$ índice de masa corporal (IMC) $(144,150,152,153,207)$ comorbilidades $(144,150,152,153,207)$, medicación $(144,145,152,210,217)$ número de ingresos hospitalarios (79,144-146,148,150-154,207,208,210,212,217,222), ansiedad y depresión (151,222), signos y síntomas (207,208,210), satisfacción (154,210,222), vacunación (208), adherencia terapéutica (144) evaluación de la técnica inhalatoria $(155,207,212,217)$ y el conocimiento de la EPOC $(143,144,146,149,152,154,155,210)$.

\subsubsection{Resultados de los programas educativos}

La intervención educativa disminuye los ingresos hospitalarios y las visitas a urgencias en el $(\mathrm{n}=10) 58,8 \%$ de los estudios, favorece o no modifica la deshabituación tabáquica en el $(n=7) 77,8 \%$, mejora los conocimientos de la EPOC en el $(n=5) 62,5 \%$ y el conocimiento para realizar la técnica de inhalación de forma correcta en el 100\% todos los estudios que así lo han analizado. Así como mejora la satisfacción en el (n=3) 66,6 \%.

El $(n=7) 50 \%$ de los estudios que han evaluado la calidad de vida afirman que no se experimenta un cambio en la misma después de la intervención educativa frente al $43 \%$ que afirma que si se experimenta una mejora y un único estudio (153) que afirma que perjudica a la intervención educativa. Del mismo modo ocurre en aquellos estudios que evalúan las variables ventilatorias donde el $(n=8) \quad 66,7 \%$ observa que la intervención educativa ni perjudica a la misma ni afecta negativamente, siendo un $(n=3) 25 \%$ de los estudios que sus resultados muestran que puede beneficiar a los parámetros respiratorios, como se observa en la tabla 18.

Otros parámetros como los signos y los síntomas, en dos $(207,210)$ de los tres estudios que lo analizaron no se vieron afectados ni de forma negativa ni positiva tras la intervención y el restante estudio mostro que era negativo (208). La adherencia farmacológica solo un estudio la han analizado no mejorando, ni disminuyendo la misma tras la intervención educativa (144). Otro de los parámetros estudiados por los investigadores de los distintos ensayos fue el IMC, en uno de ellos solo valorado al inicio de la investigación (150) y aquellos estudios que lo han valorado al inicio $y$ al final han obtenido que mayoritariamente la intervención educativa no mejora este parámetro, pero tampoco lo empeora $(144,152,153)$ y solo en uno de ellos ha mejorado tras la intervención educativa (207). 
Tabla 18. Efecto de los programas educativos en las principales variables de resultado

\begin{tabular}{|c|c|c|c|c|c|c|c|c|}
\hline & Edad & Sexo & $\begin{array}{l}\text { Seguimiento } \\
\text { (años) }\end{array}$ & CVRS & V. ventilatorias & $\begin{array}{l}\text { Ingresos, } \\
\text { Visitas } \\
\text { hospital }\end{array}$ & Tabaco & $\begin{array}{l}\text { Conocimiento } \\
\text { EPOC }\end{array}$ \\
\hline Khdour et al. 2011 & 66,45 & $\mathrm{M}$ & 1 & + & $=$ & - & - & $=$ \\
\hline $\begin{array}{l}\text { Hoogendoorn et al. } \\
2010\end{array}$ & 66,5 & $\mathrm{H}$ & 2 & + & & + & + & \\
\hline Koff et al. 2009 & 65,8 & $=$ & 0 & + & & - & & \\
\hline Siddique et al. 2012 & 70,0 & $\mathrm{H}$ & 1 & & & $=$ & & $=$ \\
\hline Taylor et al. 2012 & 69,75 & $\mathrm{M}$ & 0 & $=$ & & - & + & \\
\hline Bucknall et al. 2012 & 69,1 & $\mathrm{M}$ & 1 & + & & - & & \\
\hline Soler et al. 2006 & 73,0 & $\mathrm{H}$ & 1 & + & - & - & & \\
\hline Watson et al. 1997 & 67,5 & $\mathrm{H}$ & 0 & $=$ & $=$ & - & & + \\
\hline Hill et al. 2010 & 64,5 & $\mathrm{M}$ & 0 & & $=$ & & $=$ & + \\
\hline Bourbeau et al. 2006 & 69,5 & $\mathrm{M}$ & 1 & + & $=$ & - & & \\
\hline Coultas et al. 2005 & 69,0 & $\mathrm{M}$ & 0 & $=$ & & $=$ & & \\
\hline Kiser et al. 2012 & 63,0 & $\mathrm{M}$ & 0 & $\begin{array}{l}\text { Al } \\
\text { inicio }\end{array}$ & & + & & \\
\hline $\begin{array}{l}\text { Wakabayashi et al. } \\
2011\end{array}$ & 71,7 & $\mathrm{H}$ & 1 & $=$ & $=$ & $=$ & - & + \\
\hline Theander et al. 2009 & 65,0 & $=$ & 0 & - & $=$ & & $=$ & \\
\hline $\begin{array}{l}\text { Efraimsson et al. } \\
2008\end{array}$ & 67,0 & $=$ & 0 & + & + & & - & + \\
\hline $\begin{array}{l}\text { Rootmensen et al. } \\
2008\end{array}$ & 60,5 & $\mathrm{H}$ & 0 & & & + & & + \\
\hline Hesselink et al. 2004 & 47,3 & $\mathrm{M}$ & 2 & $=$ & $=$ & & $=$ & \\
\hline Rea et al. 2004 & 68,0 & $\mathrm{M}$ & 1 & $=$ & + & - & & \\
\hline Cockcroft et al. 1987 & 69,85 & $\mathrm{H}$ & & $=$ & $=$ & - & - & \\
\hline Littlejohns et al. 1991 & 62,7 & $\mathrm{H}$ & 1 & & + & & & \\
\hline Seden et al. 2009 & 69,25 & $\mathrm{H}$ & 1 & & & - & & \\
\hline Fan et al. 2012 & 66,0 & $\mathrm{H}$ & 1 & $=$ & & + & & $=$ \\
\hline \multicolumn{9}{|c|}{$\begin{array}{l}\text { * En la variable sexo, se ha medido el sexo más predominante en la investigación el valor } \mathrm{H} \text { hace referencia a los hombres y el valor } \mathrm{M} \text { h hace referencia a las mujeres. } \\
\text { Los valores + de las variables hacen referencia a mejores resultados del grupo intervención frente al grupo control o con respecto a la evaluación basal } \\
\text { Los valores - de las variables hacen referencia a peores resultados del grupo intervención frente al grupo control o con respecto a la evaluación basal } \\
\text { Los valores = de las variables hacen referencia a resultados similares entre los dos grupos control e intervención o con respecto a la evaluación basal }\end{array}$} \\
\hline
\end{tabular}

\subsubsection{Calidad metodológica}

En cuanto a la evaluación de la calidad metodológica a través de la escala Jadad, la media total de todos los estudios fue de 3,9. De los 22 estudios incluidos $n=5$ de ellos han obtenido la máxima puntuación metodológica, $n=9$ han obtenido 4 puntos y $n=8$ han obtenido 3 puntos. Siendo el ítem menos valorado el enmascaramiento.

Pendiente de publicación y presentado en formato poster el congreso de la SEPAR 2015 en el área de EPOC. 


\subsection{Resultados del análisis de las características de la población con diagnóstico de Exacerbación de la EPOC catalogado con GRD088 y que ingresan en el Hospital Universitario General de Castellón desde 2008 hasta 2013}

Los resultados se basan en los dos objetivos de este apartado.

- Determinar las características sociodemográficas

- Determinar las características clínicas del ingreso

\section{$\underline{4.2 .1 \text { Variables sociodemográficas }}$}

Un total de 1145 personas ingresaron en dicho centro, por el motivo principal de ingreso de exacerbación de la EPOC, catalogado con el GRD 088.

El 74,1\% ( $\mathrm{n}=849)$ fueron hombres, frente al 25,9\% $(\mathrm{n}=296)$ que fueron mujeres, existiendo un rango de edades comprendidas desde los 3 años, hasta los 96 años, con una

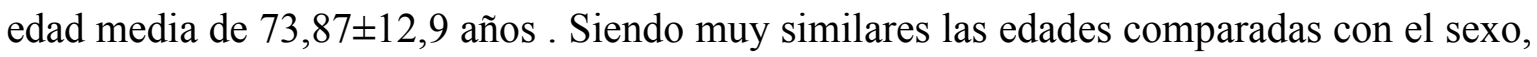
valores que sitúan a los hombres en una media de 72 años y a las mujeres en 73 años.

\subsubsection{Variables clínicas}

\subsubsection{Ingresos hospitalarios}

De los 1145 pacientes, los servicios que más pacientes recibieron con diagnóstico de exacerbación de la EPOC fueron neumología 55\% ( $\mathrm{n}=630)$, unidad de corta estancia $20,7 \%(n=237)$ y el servicio de medicina interna 16,9\% ( $n=1964)$. Siendo los servicios con menor número de ingresos cirugía general y el servicio de Unidad de cuidados intensivos (UCI) pediátricos. En la tabla 19 se presenta a modo de resumen, la frecuencia de hospitalizaciones.

Tabla 19. Frecuencia de hospitalizaciones por unidad hospitalaria

\begin{tabular}{lcc}
\hline Servicio & $\mathbf{n}$ & $\mathbf{( \% )}$ \\
Neumología & 630 & 55 \\
Unidad de corta estancia & 237 & 20,7 \\
Medicina Interna & 194 & 16,9 \\
Cardiología & 42 & 3,7 \\
UCI & 13 & 1,1 \\
Nefrología & 10 & 0,9 \\
Medicina digestiva & 6 & 0,5 \\
Hematología & 3 & 0,3 \\
Unidad de enfermedades infecciosas & 3 & 0,3 \\
Pediatría & 3 & 0,3 \\
Neurología & 2 & 0,2 \\
Cirugía General & 1 & 0,1 \\
UCI Pediátrica & 1 & 0,1 \\
Total & $\mathbf{1 1 4 5}$ & $\mathbf{1 0 0}$ \\
\hline
\end{tabular}

UCI: Unidad de Cuidados intensivos 
La duración media de los ingresos fue de $7 \pm 5,5$ días con unas tasas se reingreso del $22 \%$ y una mortalidad del $1,9 \%(n=22)$.

\subsubsection{Número de ingresos por año}

Según los últimos cinco años, desde el 2009 hasta el 2013, el año con mayor número de ingresos hospitalarios por exacerbación de la EPOC fue; 2012 con el 24,1\% $(\mathrm{n}=276)$ y el año con menor número de ingresos por exacerbación fue 2013 con el $17,3 \%$ ( $n=198)$. Siendo el número medio de ingresos anual de $229 \pm 1,4$. Ver tabla 20.

Tabla 20. Frecuencia de ingresos por año

\begin{tabular}{lcc}
\hline Año & n & \% \\
2008 & 7 & 0,6 \\
2009 & 253 & 22,1 \\
2010 & 225 & 19,7 \\
2011 & 198 & 17,3 \\
2012 & 277 & 24,2 \\
2013 & 198 & 17,3 \\
Total & $\mathbf{1 1 4 5}$ & $\mathbf{1 0 0}$ \\
\hline
\end{tabular}

\subsubsection{Número de ingresos por mes}

Los meses con mayor número de ingresos por exacerbación fueron los meses de enero $15,1 \%(n=173)$, febrero $12,8 \%(n=146)$ y marzo $11,5 \%(n=132)$ y los meses con menor número de ingresos fueron los meses más calurosos como agosto 5,9\% $(n=68)$, junio 5,6\% $(n=64)$ y septiembre 5,2\% $(n=60)$. Ver gráfico 1.

Grafico 1. Frecuencia de exacerbaciones por año y mes

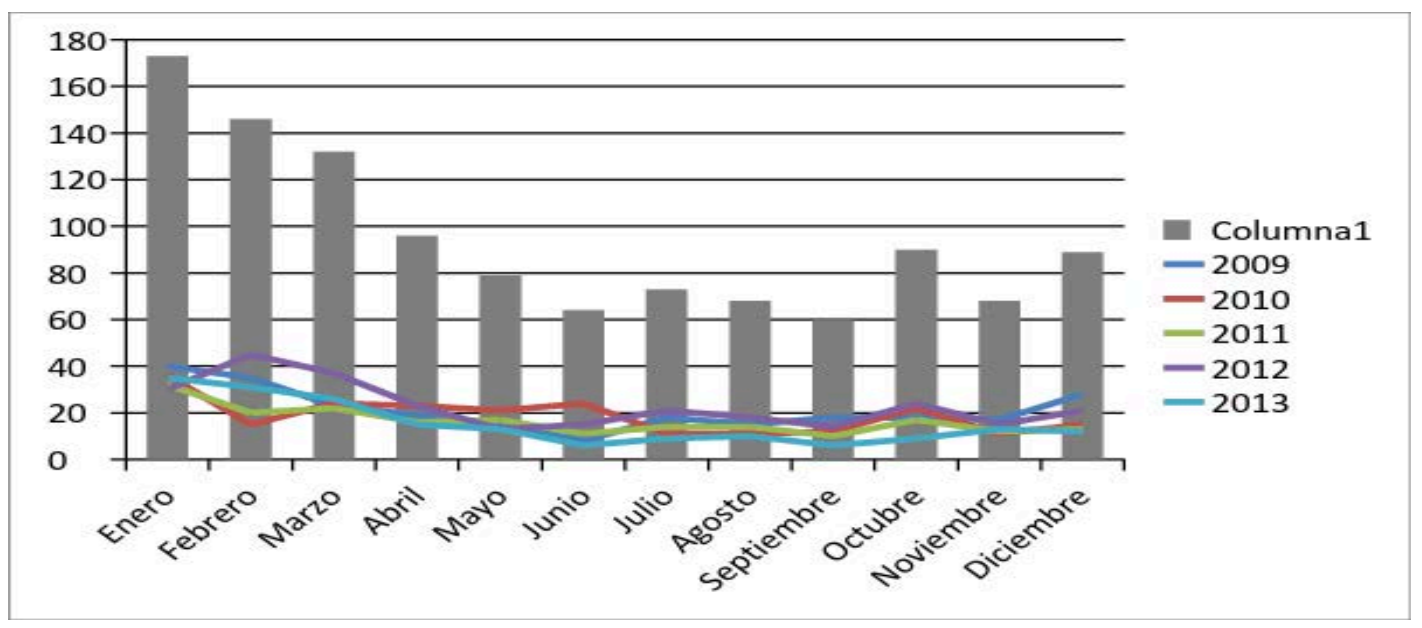




\section{$\underline{4.2 .3 \text { Variables de control }}$}

\section{$\underline{\text { 4.2.3.1 Comorbilidades }}$}

Los pacientes estudiados presentan un número elevado de comorbilidades, según la

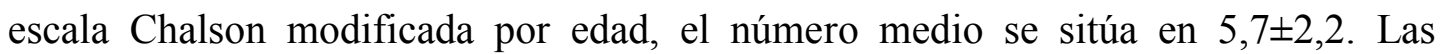
comorbilidades más frecuentes son las cardíacas $64,3 \%(n=1483)$, seguidas de las endocrino-renales $20,4 \% \quad(n=471) \quad y$ neurológicas $5,2 \%(n=120)$. Siendo menos frecuentes las comorbilidades hepáticas y digestivas $2,1 \%(n=49)$.

Si analizamos las comorbilidades cardíacas más frecuentes son insuficiencia cardiaca $(n=380)$, infartos $(n=101)$, enfermedad arterial periférica $(n=173)$ donde se incluyeron también los aneurismas abdominales $(\mathrm{n}=19)$. Siendo destacable el número de pacientes que presentaron problemas de hipertensión arterial $(n=481)$, hipercolesterolemia $(n=249)$ y obesidad $(n=80)$ elevando su riesgo cardiovascular.

En el caso de las comorbilidades endocrino-renales, destaca la presencia de diabetes $(n=350)$ e insuficiencia renal $(n=121)$ donde se incluyeron a todos los pacientes en situación de diálisis renal.

Siendo también analizados los tumores presentes en un 5,1\% de los casos. Ordenados de mayor presencia a menor, el de próstata $31,6 \%$, tracto urinario $17,1 \%$ y pulmón $15,4 \%$. Y los menos frecuentes son los hepáticos $(n=1)$, óseos $(n=1)$ y cerebrales $(\mathrm{n}=1)$. Ver gráfico 2 y tabla 21.

Grafico 2. Frecuencia de los tumores

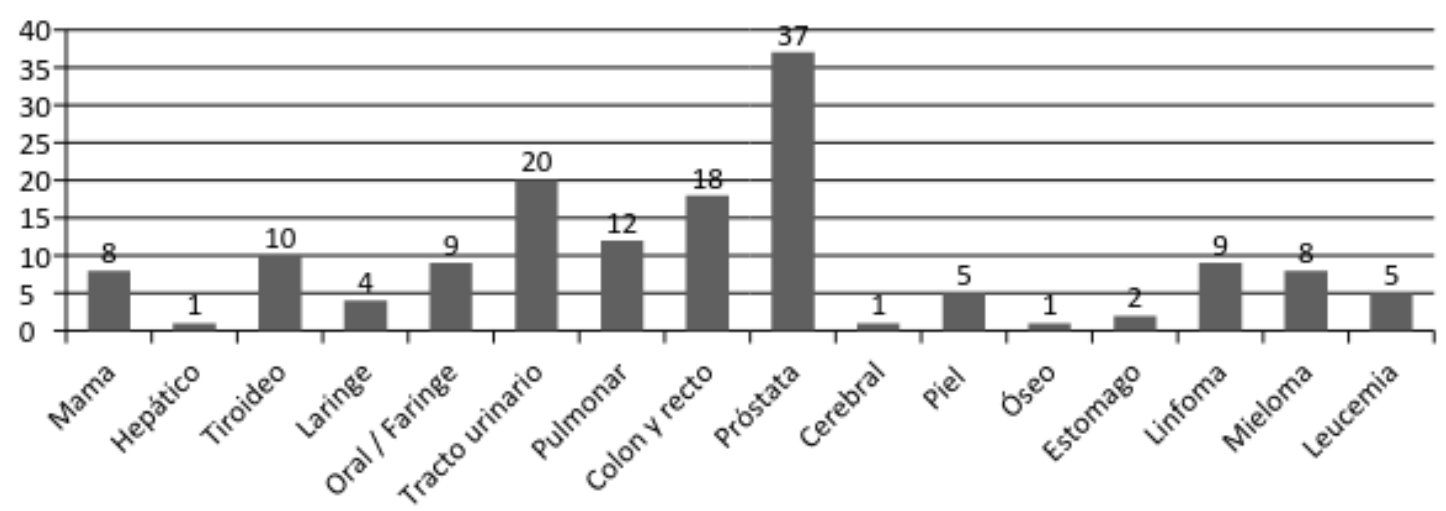

$\mathrm{Si}$ atendemos a las alteraciones hepáticas y digestivas $2,1 \%$ dentro de las cuales las más frecuentes fueron la cirrosis alcohólica $42,9 \%$, seguida de las varices esofágicas $20,4 \%$, la ulcera gástrica $10,2 \%$ y la gastritis $14,3 \%$. Dentro de las alteraciones neurológicas 5,2\%, son frecuentes los Accidentes Cerebro Vasculares (ACV) con una proporción del 45,8\% y las demencias 54,1\%. Cabe destacar la presencia de enfermedades infecciosas como la tuberculosis, Virus de la Inmunodeficiencia Humana (VIH) y la Hepatitis B y C, datos disponibles en la tabla 21. 


\begin{tabular}{|c|c|c|}
\hline & $\mathbf{n}$ & $\%$ \\
\hline Cardíacas & 1483 & 64,3 \\
\hline Insuficiencia cardiaca & 380 & 25,6 \\
\hline Infarto & 101 & 6,8 \\
\hline Enf. Art. Periférica & 173 & 11,7 \\
\hline Aneurisma abdominal & 19 & 1,3 \\
\hline Hipercolesterolemia & 481 & 32,4 \\
\hline Hipertensión & 249 & 16,8 \\
\hline Obesidad & 80 & 5,4 \\
\hline Endocrinas y renales & 471 & 20,4 \\
\hline Diabetes & 350 & 74,3 \\
\hline Insuficiencia renal & 121 & 25,7 \\
\hline Tumores & 117 & 5,1 \\
\hline Próstata & 37 & 31,6 \\
\hline Tracto urinario & 20 & 17,1 \\
\hline Colon y recto & 18 & 15,4 \\
\hline Pulmón & 12 & 10,3 \\
\hline Tiroides & 10 & 8,5 \\
\hline Cavidad oral y faringe & 9 & 7,7 \\
\hline Mama & 8 & 6,8 \\
\hline Hepáticos, óseos y cerebrales & 3 & 2,6 \\
\hline Hepáticas y digestivas & 49 & 2,1 \\
\hline Cirrosis alcohólica & 21 & 42,9 \\
\hline Ulceras gástricas & 5 & 10,2 \\
\hline Gastritis & 7 & 14,3 \\
\hline Esofagitis & 3 & 6,1 \\
\hline Várices Esofágicas & 10 & 20,4 \\
\hline Angioplastias de estomago & 2 & 4,1 \\
\hline Esófago de Barret & 1 & 2,0 \\
\hline Neurológicas & 120 & 5,2 \\
\hline $\mathrm{ACV}$ & 55 & 45,8 \\
\hline Demencia Senil y Alzheimer & 65 & 54,1 \\
\hline Infecciosas & 65 & 2,8 \\
\hline Tuberculosis & 34 & 52,3 \\
\hline Hepatitis B y C & 27 & 41,5 \\
\hline VIH & 4 & 6,2 \\
\hline Total & 2305 & 100 \\
\hline
\end{tabular}

Enf.Art: Enfermedad Arterial; ACV: Accidente Cerebro Vascular; VIH:

Virus de la Inmunodeficiencia humana 


\subsubsection{Hábitos tóxicos}

Respecto a los hábitos tóxicos un total de $(\mathrm{n}=103)$ pacientes el $9 \%$ de la muestra estudiada presentó un registro de consumo de alcohol y un $(n=195) 17 \%$ de consumo de cannabis de los que tal solo 2 estuvieron registrados en programas de desintoxicación .

\subsubsection{Procedimientos diagnósticos utilizados}

Los procedimientos diagnósticos más utilizados fueron la medición de gases en sangre arterial 79,4\%, electrocardiograma 48,5\%, determinación de la capacidad vital pulmonar $11,7 \%$ y el TAC de tórax $8 \%$ también siendo frecuentes los TACs de cabeza $1,9 \%$ y abdomen en un $1,2 \%$.

Otras técnicas diagnósticas y de tratamiento también utilizadas en pacientes con EPOC son la broncoscopia $0,6 \%$ con realización de biopsia bronquial en $82,4 \%$. La frecuencia de procedimientos se presenta en la tabla 22 .

Tabla 22. Procedimientos diagnósticos más utilizados

\begin{tabular}{lcc}
\hline Procedimientos diagnósticos & n & $\mathbf{\%}$ \\
Medición de gases en la sangre arterial sistémica & 909 & 79,4 \\
Electrocardiograma & 555 & 48,5 \\
Determinación de capacidad vital & 134 & 11,7 \\
TAC de tórax & 92 & 8,0 \\
Ultrasonidos diagnóstico de corazón & 78 & 6,8 \\
Ultrasonidos de abdomen y retroperitoneal & 35 & 3,1 \\
Medición de gases mixtos en la sangre venosa & 25 & 2,2 \\
TAC de cabeza & 22 & 1,9 \\
TAC abdomen & 14 & 1,2 \\
Otros TACs & 9 & 0,8 \\
Biopsia cerrada bronquial endoscópica & 7 & 0,6 \\
Biopsia cerrada de masa intraabdominal & 7 & 0,6 \\
Arteriografía de arterias pulmonares & 6 & 0,5 \\
Otra entrevista y evaluación psiquiátricas & 9 & 0,8 \\
Polisomnograma & 4 & 0,4 \\
Total & $\mathbf{1 9 0 6}$ & $\mathbf{1 0 0}$ \\
\hline
\end{tabular}

TAC: Tomografía Axial Computerizada 


\subsubsection{Tratamientos terapéuticos utilizados}

En cuanto a los procedimientos terapéuticos más utilizados destacan la administración de medicación mediante nebulizador, como uno de los tratamientos más utilizados $39,3 \%$, seguido de las administración de oxígeno $37,7 \%$, inyección de esteroides $22,4 \%$ y antibióticos $9,5 \%$. Siendo otros tratamientos menos utilizados la ventilación mecánica no invasiva 3,3\% y las trasfusiones $1,2 \%$ entre otros, como se observa en la tabla 23.

Tabla 23. Procedimientos terapéuticos utilizados

\begin{tabular}{lcc}
\hline Procedimientos terapéuticos & $\mathbf{n}$ & $\mathbf{\%}$ \\
Medicación administrada con nebulizador & 450 & 39,3 \\
Oxigeno & 432 & 37,7 \\
Inyección de esteroide & 256 & 22,4 \\
Inyección de antibiótico & 109 & 9,5 \\
Ventilación mecánica no invasiva & 38 & 3,3 \\
Transfusión de concentrado de hematíes & 14 & 1,2 \\
Hemodiálisis & 11 & 1,0 \\
Inserción de catéter urinario permanente & 6 & 0,5 \\
Inyección de insulina & 4 & 0,4 \\
Total & $\mathbf{1 3 2 0}$ & $\mathbf{1 0 0}$ \\
\hline
\end{tabular}




\subsection{Resultados de la efectividad de un programa estructurado de educación terapéutica (ET), durante el ingreso, en comparación con la atención tradicional}

\subsubsection{Participantes del estudio}

El número total de ingresos durante el periodo del estudio, en el Hospital Universitario General de Castellón fue de 27675, de los cuales el 1,4\% fueron pacientes con diagnóstico de EPOC y un total de 131 pacientes cumplieron los criterios de selección.

Los criterios de exclusión presentes fueron: el 29,4\% por presentar deterioro cognitivo, ocasionado por comorbilidades asociadas a demencias seniles, diagnóstico de Alzheimer o alteraciones neurológicas; un $25,5 \%$ presentaron incapacidad de seguir un programa educativo, por problemas de sordera, no disponer de teléfono o tener un teléfono erróneo, muchas de ellas valoradas durante el trascurso de la entrevista; el 2,4\% fueron excluidos por existir una barrera idiomática; en el $14,7 \%$ de los casos estaban repetidos y ya habían sido previamente incluidos en el mismo y como último criterio de exclusión fue la consideración de ser un paciente paliativo, cuyo porcentaje fue del $36,4 \%$ y cuya definición fue tener una esperanza de vida inferior a 6 meses a criterio médico.

De los 131 pacientes que cumplían los criterios 54 no aceptaron entrar en el estudio. Se aleatorizaron por tanto un total de 77 pacientes, 32 en el grupo control y 45 en el experimental. El total de pérdidas fue de 17 donde $(n=4)$ por fallecimiento, $(n=8)$ no asistencia a un mínimo del $75 \%$ de las sesiones educativas, $(n=5)$ del grupo control no asistieron a la evaluación a los 3 meses. Por tanto la muestra total fue de un total de 60 sujetos. Ver diagrama 3 de flujo. 
Diagrama 3. Diagrama de flujo de los participantes del estudio

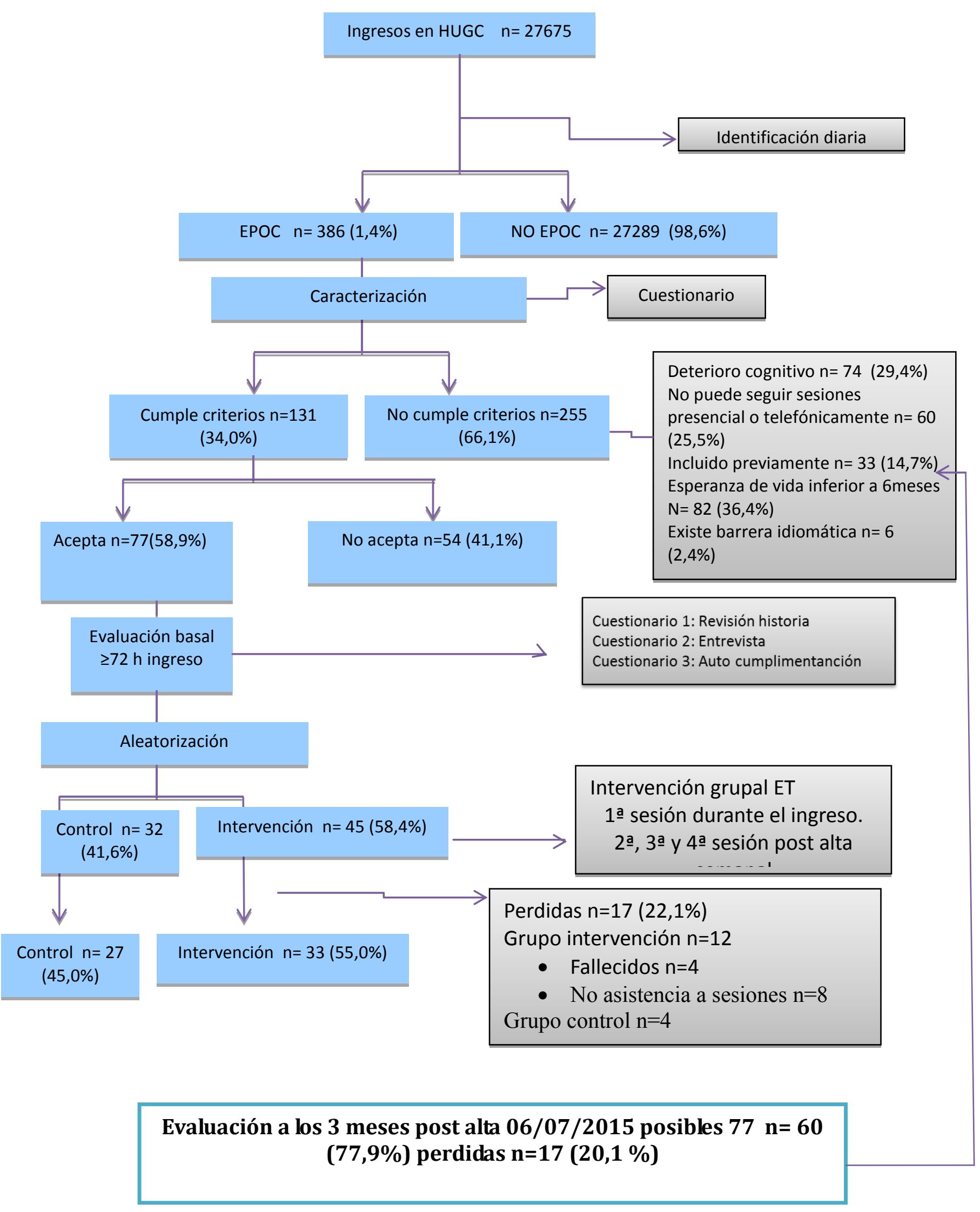




\subsubsection{Descriptivo general}

\subsubsection{Variables sociodemográficas}

\subsection{Sexo y edad}

El 81,6\% de los participantes fueron hombres, con una media de edad de 73,5 años. Siendo en la muestra total la media de 73,2 años (tabla 24).

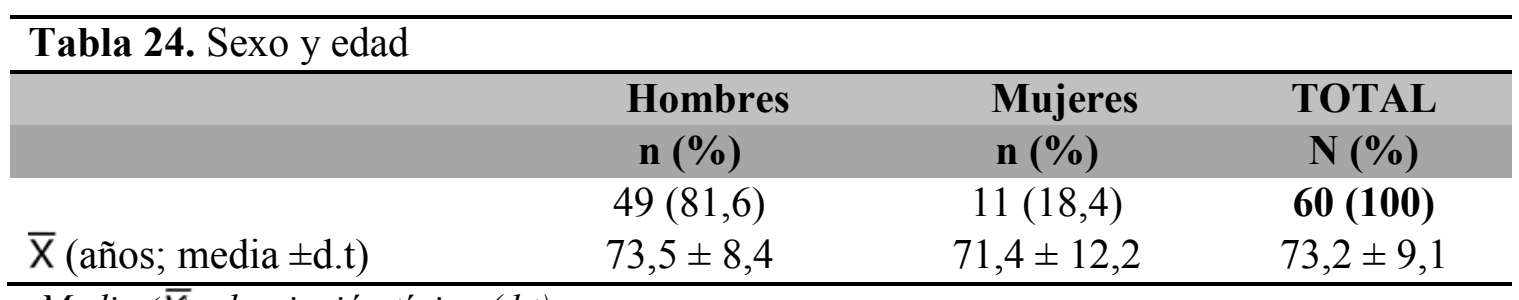

Media $(\bar{X})$, desviación típica (d.t)

\subsection{Nivel de estudios}

El 43,3\% (n=26) tenían estudios básicos, seguidos de los que tenían estudios de secundaria o formación profesional $30 \%(\mathrm{n}=18)$, sin estudios el $18,3 \%(\mathrm{n}=11)$ y el $8,3 \%(\mathrm{n}=5)$ tenían estudios universitarios. En el gráfico 4 se puede observar la distribución del nivel de estudios de la muestra.

Gráfico 3. Nivel de estudios

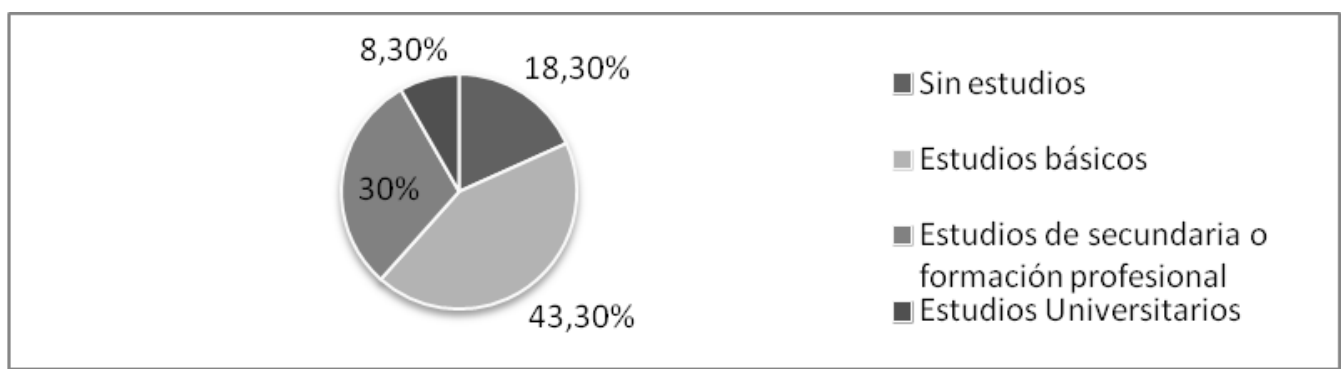

\subsection{Residencia habitual y convivencia}

Respecto al lugar de residencia en el momento del ingreso, todos los pacientes vivían en sus domicilios durante el año previo al ingreso.

Los datos generales con respecto a la convivencia muestran que durante el año anterior a la fecha de ingreso, el 48,3\% de la población vivió con su pareja, seguido del 18,3\% que vivió con sus hijos y en igual proporción, el 13,3\%, convivieron con varios miembros de la familia o solos (tabla 25). 


\begin{tabular}{lcc}
\hline Tabla 25. Convivencia & & \\
\hline & $\mathbf{n}$ & \% \\
Marido/Esposa & 29 & 48,3 \\
Hijos & 11 & 18,3 \\
Solo & 8 & 13,3 \\
Varios miembros de la familia & 8 & 13,3 \\
Otros Familiares & 4 & 6,7 \\
\hline TOTAL & 60 & 100 \\
\hline
\end{tabular}

\subsection{Apoyo social percibido}

El apoyo social percibido solo fue evaluado a los 3 meses posteriores al alta, donde el 35\% afirmo no necesitar ningún apoyo y el $25 \%$ tuvo apoyo social formal pero no era suficiente. Siendo destacable que el $6,6 \%$ de la población estudiada no tenía ningún apoyo y lo necesitaba (tabla 26).

Tabla 26. Apoyo social percibido

\begin{tabular}{lcc}
\hline No necesita ningún apoyo & $\mathbf{n}$ & $\mathbf{\%}$ \\
Tiene soporte social pero no es suficiente & 21 & 35,0 \\
No tiene ningún soporte social y no lo necesita & 15 & 25,0 \\
Tiene apoyo social formal suficiente (centro de día, trabajadora social, & 12 & 20,0 \\
institución) & 5 & 8,3 \\
No tiene apoyo y lo necesita & 4 & 6,6 \\
Tiene apoyo por parte de los vecinos & 3 & 5,0 \\
\hline TOTAL & 60 & 100 \\
\hline
\end{tabular}




\subsubsection{Resultados principales}

Las variables de resultado principal están compuestas por el gasto sanitario, la calidad de vida, conocimiento de la enfermedad y el cumplimiento terapéutico.

- $\quad$ Variables de uso de servicios hospitalarios

El 60,6\% de los sujetos tuvo un ingreso hospitalario en los últimos 12 meses por causa respiratoria, así como un 75,4\% visito urgencias en ese mismo periodo.

Como se puede apreciar en la tabla 27, uno de los servicios que más demanda tuvo fue la asistencia al servicio de urgencias con una media de 1,9 $\pm 2,0$ visitas en los últimos 12 meses, por causa respiratoria, con un máximo 9 de visitas. Siendo menos frecuentes las visitas a urgencias por causa no respiratoria con una media de $0,3 \pm 0,8$.

El segundo recurso más utilizado fueron las hospitalizaciones, con una media de hospitalizaciones anuales por causa respiratoria de $1 \pm 1,2$ y las hospitalizaciones por cusas no respiratorias de $0,1 \pm 0,3$. Así pues la media de ingreso durante el último año en la UCI fue de $0,1 \pm 0,2$ por causas respiratorias, siendo mínimos los ingresos en UCI por causa distinta a la respiratoria. 
Tabla 27. Uso de servicios hospitalarios

\begin{tabular}{llccc} 
& & $\bar{X} \pm$ d.t & Mínimo & Máximo \\
\hline Ingresos hospitalarios & Causa respiratoria & $1,0 \pm 1,2$ & 0 & 4 \\
& $\begin{array}{l}\text { Causa no } \\
\text { respiratoria }\end{array}$ & $0,1 \pm 0,3$ & 0 & 1
\end{tabular}

Ingresos UCI

$\begin{array}{llll}\text { Causa respiratoria } & 0,1 \pm 0,2 & 0 & 1 \\ \begin{array}{l}\text { Causa no } \\ \text { respiratoria }\end{array} & 0,0 \pm 0,1 & 0 & 1\end{array}$

Visitas Urgencias

$\begin{array}{llll}\text { Causa respiratoria } & 1,9 \pm 2,0 & 0 & 9 \\ \begin{array}{l}\text { Causa no } \\ \text { respiratoria }\end{array} & 0,3 \pm 0,8 & 0 & 4\end{array}$

Visitas Consultas

$0,6 \pm 1,6 \quad 0 \quad 10$

\begin{tabular}{|c|c|c|c|c|c|c|c|}
\hline & & & i & & & & $\mathbf{A L}$ \\
\hline & & $\mathbf{n}$ & $\%$ & $\mathbf{n}$ & $\%$ & $\mathbf{N}$ & $\%$ \\
\hline Ingresos hospitala1 & & & & & & & \\
\hline & Causa respiratoria & 34 & 60,6 & 23 & 40,4 & 57 & 100 \\
\hline & $\begin{array}{l}\text { Causa no } \\
\text { respiratoria }\end{array}$ & 3 & 5,3 & 54 & 94,7 & 57 & 100 \\
\hline Ingresos UCI & & & & & & & \\
\hline & Causa respiratoria & 4 & 7,0 & 53 & 93,0 & 57 & 100 \\
\hline & $\begin{array}{l}\text { Causa no } \\
\text { respiratoria }\end{array}$ & 1 & 1,8 & 56 & 98,2 & 57 & 100 \\
\hline Visitas Urgencias & & & & & & & \\
\hline & Causa respiratoria & 43 & 75,4 & 14 & 24,6 & 57 & 100 \\
\hline & $\begin{array}{l}\text { Causa no } \\
\text { respiratoria }\end{array}$ & 9 & 15,8 & 48 & 84,2 & 57 & 100 \\
\hline Visitas Consultas & & & & & & & \\
\hline & & 12 & 21,1 & 45 & 75,0 & 57 & 100 \\
\hline
\end{tabular}

$\overline{M e d i a}(\overline{\mathrm{X}})$, desviación típica (d.t) 
- $\quad$ Variables de calidad de vida

\section{Calidad de vida CAT}

El bienestar y la calidad de vida medida a través del CAT muestra que el 44,6\% $(n=25)$ de los pacientes presentan un impacto alto en su calidad de vida, seguido de los que presentan un impacto medio con una proporción del 35,7\% $(n=20)$. Siendo el valor menos frecuente los que presentaron un impacto bajo con una proporción del 5,4\% $(\mathrm{n}=3)$. Gráfico 5.

Gráfico 4. Calidad de vida CAT valores totales

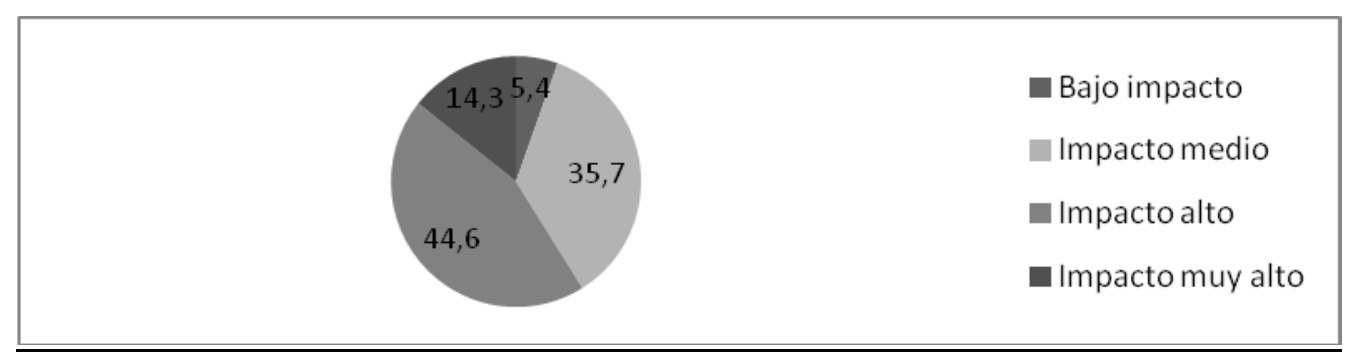

En cuanto a las puntuaciones medias obtenidas en cada uno de los ítems (véase tabla 28), los valores que mayores puntuaciones tuvieron fueron, subir escaleras/pendientes y limitaciones en la realización de actividades domésticas con una media de $3,8 \pm 1,1$ y $3,4 \pm 1,3$ respectivamente.

\begin{tabular}{lcccc}
\hline Tabla 28. Calidad de vida CAT & & & & \\
\hline & $\overline{\mathbf{X}} \pm \mathbf{d . t}$ & Md & Mínimo & Máximo \\
Tos & $2,7 \pm 1,6$ & 3 & 0 & 5 \\
Flemas & $2,8 \pm 1,5$ & 3 & 0 & 5 \\
Opresión en el pecho & $2,1 \pm 1,6$ & 2 & 0 & 5 \\
Subir escaleras/pendiente & $3,8 \pm 1,1$ & 4 & 1 & 5 \\
Limitación realización act. domésticas & $3,4 \pm 1,3$ & 4 & 0 & 5 \\
Seguridad cuando sale de casa & $2,7 \pm 1,5$ & 3 & 0 & 5 \\
Dormir & $2,2 \pm 1,7$ & 2 & 0 & 5 \\
Energía & $3,2 \pm 1,4$ & 3 & 0 & 5 \\
\hline
\end{tabular}

CAT: COPD Assessment Test $\bar{X} ; \pm$ d.t media \pm desviación típica; $M d$ : mediana

\section{Calidad de vida St. George}

\section{$\underline{\text { Signos y síntomas }}$}

Cuando tenía infección, sólo presentaban tos $(38,6 \%)$, esputo $(40,4 \%)$, falta de respiración $(52,6 \%)$ y pitos $(29,8 \%)$. Siendo las opción menos indicada no presentar ningún signo ni síntoma nunca. (tabla 29). 


\begin{tabular}{|c|c|c|c|c|c|c|c|c|}
\hline \multicolumn{9}{|c|}{ Tabla 29. Calidad de vida St. George síntomas } \\
\hline & $\mathbf{n}$ & $\%$ & $\mathbf{n}$ & $\%$ & $\mathbf{n}$ & $\%$ & $\mathbf{n}$ & $\%$ \\
\hline Casi todos los días de la semana & 10 & 17,5 & 1 & 21,1 & 3 & 5,3 & 3 & 5,3 \\
\hline Varios días a la semana & 15 & 26,3 & 1 & 26,3 & 8 & 14,0 & 7 & 12,3 \\
\hline Unos pocos días al mes & 7 & 12,3 & 5 & 8,8 & 14 & 24,6 & 8 & 14,0 \\
\hline Sólo cuando tuve infección & 22 & 38,6 & 2 & 40,4 & 30 & 52,6 & 1 & 29,8 \\
\hline Nada en absoluto & 3 & 5,3 & 2 & 3,5 & 2 & 3,5 & 2 & 38,6 \\
\hline
\end{tabular}

\section{$\underline{\text { Exacerbaciones }}$}

En la tabla 30 se detallan todos los datos referidos a la descripción de las exacerbaciones.

El 40\% de la población indicó que había tenido una exacerbación en el año anterior seguido de los que había tenido entre 3 y 2 ataques de agudizaciones, con una proporción $23,3 \%$ en ambos.

Los valores más frecuentes se sitúan en la duración de las exacerbaciones de 3 a 6 días $(38,3 \%)$, seguido de los que indicaron que sus exacerbaciones tenían una duración superior a una semana o más $(36,7 \%)$.

En cuanto a los resultados de cuantos días buenos pasan a la semana los pacientes, indicaron que casi cada día tenían días buenos $(29,8 \%)$, seguido los que solo tenían uno o dos días buenos (24,8\%). Siendo la frecuencia menos indicada la correspondiente a los pacientes que tenían cada día malo (10,5\%). El 71,9\% de la muestra indico que la EPOC era el problema más importante. Por el contrario ningún sujeto informó que la EPOC no le causaba ningún problema.

El $49,1 \%$ de los pacientes identificaron que sus problemas respiratorios no les dificultaban a la hora de desempeñar su trabajo, así como tampoco tuvieron que cambiar de trabajo por la enfermedad pulmonar que padecen $(29,8 \%)$. 


\begin{tabular}{lcc}
\hline Tabla 30. Exacerbaciones & & \\
\hline Exacerbaciones anuales & $\mathbf{n}$ & $\%$ \\
& 8 & 13,3 \\
$>3$ ataques & 14 & 23,3 \\
3 ataques & 14 & 23,3 \\
2 ataques & 24 & 40,0 \\
1 ataque & & \\
Duración de las exacerbaciones & 8 & 13,3 \\
$>3$ ataques & 14 & 23,3 \\
3 ataques & 14 & 23,3 \\
2 ataques & 24 & 40,0 \\
1 ataque & \multicolumn{3}{c}{} \\
Días buenos a la semana & 8 & 14,0 \\
Ninguno & 14 & 24,6 \\
Uno o dos días & 12 & 21,1 \\
Tres o cuatro días & 17 & 29,8 \\
Casi cada día & 6 & 10,5 \\
Cada día & & \\
Valoración subjetiva & 41 & 71,9 \\
Es el problema más importante & 11 & 19,3 \\
Me causa bastantes problemas & 5 & 8,8 \\
Me causa algún problema & & \\
Afectación en el trabajo & 17 & 29,8 \\
Mis problemas respiratorios me obligaron a dejar de trabajar & 12 & 21,1 \\
Mis problemas respiratorios me dificultan mi trabajo & 28 & 49,1 \\
Mis problemas respiratorios no me afectan & \multicolumn{2}{l}{} \\
\hline
\end{tabular}

$\underline{\text { Limitación en las actividades de la vida diarias }}$

Los pacientes se sienten limitados en la realización de actividades como lavarse $(52,6 \%)$, caminar fuera de casa $(59,7 \%)$ y actividades como subir escaleras o subir una cuesta son las que en mayor dificultad presentan todos los pacientes con porcentajes entorno al $89 \%$.

Así pues otros de los aspectos que más molestan a los pacientes con EPOC, son asustarse cuando no pueden respirar (93\%), sentir que no pueden controlar su problema respiratorio, cuando se agudizan $(75,4 \%)$ y otros aspectos como molestias a la hora de dormir, están presentes en el 70,2\% de la muestra. Sin embargo aspectos como la falta de respiración al hablar, dolor o vergüenza al toser eran poco frecuentes en nuestra población.

Los pacientes considera que la medicación no le produce efectos desagradables, ni le da vergüenza tomarla en público, con valores que ronda el $96,5 \%$ y el $93 \%$ respectivamente.

Las actividades básicas que más les limitaron fueron aquellas que estaban relacionadas con la realización de actividad física, donde el $86 \%$ de la población afirmo que sus problemas respiratorios le obligan a ir más despacio que una persona de su edad o subir escaleras con un porcentaje del $80,7 \%$. Por el contrario 
un $71,9 \%$ indico que podían salir a hacer deporte, el $80,7 \%$ podían salir a distraerse y el $66,7 \%$ que la enfermedad no le impedía hacer trabajos. Tabla 31.

\begin{tabular}{|c|c|c|c|c|}
\hline \multirow[t]{2}{*}{ Limitaciones en las actividades de la vida diaria } & \multicolumn{2}{|c|}{$\mathbf{S i}$} & \multicolumn{2}{|c|}{ No } \\
\hline & $\mathbf{n}$ & $\%$ & $\mathbf{n}$ & $\%$ \\
\hline Falta de respiración estando sentado & 13 & 22,8 & 44 & 77,2 \\
\hline Falta de respiración cuando se lava & 30 & 52,6 & 27 & 47,4 \\
\hline Falta de respiración cuando camina por casa & 26 & 45,6 & 31 & 54,4 \\
\hline Falta de respiración cuando camina fuera de casa & 34 & 59,7 & 23 & 40,4 \\
\hline Falta de respiración cuando sube escaleras & 51 & 89,5 & 6 & 10,5 \\
\hline Falta de respiración cuando sube una cuesta & 51 & 89,5 & 6 & 10,5 \\
\hline Falta de respiración al hacer deporte & 42 & 73,7 & 15 & 26,3 \\
\hline \multirow{2}{*}{ Molestias con la enfermedad } & \multicolumn{2}{|c|}{$\mathbf{S i}$} & \multicolumn{2}{|c|}{ No } \\
\hline & $\mathbf{n}$ & $\%$ & $\mathbf{n}$ & $\%$ \\
\hline Dolor al toser & 14 & 24,6 & 43 & 75,4 \\
\hline Cansancio al toser & 31 & 54,4 & 26 & 45,6 \\
\hline Falta de respiración al hablar & 13 & 22,8 & 44 & 77,2 \\
\hline Falta de respiración al agacharse & 29 & 50,9 & 28 & 49,1 \\
\hline Molestias al dormir & 40 & 70,2 & 17 & 29,8 \\
\hline Agotamiento enseguida & 35 & 61,4 & 22 & 38,6 \\
\hline Vergüenza al toser & 5 & 8,8 & 52 & 91,2 \\
\hline Molestias a la familia & 16 & 28,1 & 41 & 71,9 \\
\hline Asustarse cuando no puede respirar & 53 & 93,0 & 4 & 7,0 \\
\hline No poder controlar su problema respiratorio & 43 & 75,4 & 14 & 24,6 \\
\hline Creer que su problema respiratorio no va a mejorar & 34 & 59,7 & 23 & 40,4 \\
\hline Su problema respiratorio le ha convertido en débil & 19 & 33,3 & 38 & 66,7 \\
\hline Creer que hacer ejercicio es peligroso & 19 & 33,3 & 38 & 66,7 \\
\hline Cualquier cosa es un esfuerzo excesivo & 23 & 40,4 & 34 & 59,7 \\
\hline \multirow[t]{2}{*}{ Molestias con la medicación } & \multicolumn{2}{|c|}{$\mathbf{S i}$} & \multicolumn{2}{|c|}{ No } \\
\hline & $\mathbf{n}$ & $\%$ & $\mathbf{n}$ & $\%$ \\
\hline La medicación no me sirve & 9 & 15,8 & 48 & 84,2 \\
\hline La medicación me da vergüenza & 4 & 7,0 & 53 & 93,0 \\
\hline La medicación me produce efectos desagradables & 2 & 3,5 & 55 & 96,5 \\
\hline La medicación me altera mucho la vida & 9 & 15,8 & 48 & 84,2 \\
\hline \multirow[t]{2}{*}{ Limitación en las actividades básicas de la vida diaria } & \multicolumn{2}{|c|}{$\mathbf{S i}$} & \multicolumn{2}{|c|}{ No } \\
\hline & $\mathbf{n}$ & $\%$ & $\mathbf{n}$ & $\%$ \\
\hline Tardo en lavarme y vestirme & 19 & 33,3 & 38 & 66,7 \\
\hline Tardo en ducharme o me es imposible & 23 & 40,4 & 34 & 59,6 \\
\hline Camino más despacio que los demás & 37 & 64,9 & 20 & 35,1 \\
\hline Tardó mucho en hacer tareas domesticas & 26 & 45,6 & 31 & 54,4 \\
\hline Tardó mucho en subir escaleras & 46 & 80,7 & 11 & 19,3 \\
\hline Tengo que ir despacio para caminar o correr & 49 & 86,0 & 8 & 14,0 \\
\hline Mis problemas respiratorios me dificultan muchas cosas & 45 & 79,0 & 12 & 21,1 \\
\hline Me impide hacer deportes y jugar & 16 & 28,1 & 41 & 71,9 \\
\hline Puedo salir de casa a distraerme & 46 & 80,7 & 11 & 19,3 \\
\hline Puedo salir de casa para comprar & 44 & 77,2 & 13 & 22,8 \\
\hline Puedo hacer trabajo & 38 & 66,7 & 19 & 33,3 \\
\hline Puedo alejarme mucho de la cama o de una silla & 46 & 80,7 & 11 & 19,3 \\
\hline
\end{tabular}




\section{$\underline{\text { Valores totales del cuestionario St. George }}$}

El $89,5 \%$ de los pacientes, durante el ingreso, manifestaron tener un nivel alto de síntomas, así como una gran afectación en la realización de actividades $(82,5 \%)$ y un $91,2 \%$ presentó un gran impacto de la enfermedad en su vida diaria. Resultados que se resumen en el apartado que evalúa dichos ámbitos, obteniendo que el 84,2\% de la población estudiada presento una escasa calidad de vida durante su periodo de exacerbación (tabla 32).

\begin{tabular}{lcccccccc}
\hline \multicolumn{1}{l}{ Tabla 32. Calidad de vida St. George: total } \\
\hline \multicolumn{2}{c}{ Síntomas } & \multicolumn{2}{c}{ Actividad } & \multicolumn{2}{c}{ Impacto } & \multicolumn{2}{c}{ Calidad Global } \\
\hline & $\mathbf{n}$ & $\mathbf{\%}$ & $\mathbf{n}$ & $\mathbf{\%}$ & $\mathbf{n}$ & $\%$ & $\mathbf{n}$ & $\boldsymbol{\%}$ \\
Bajo & 0 & 0,0 & 0 & 0,0 & 0 & 0,0 & 0 & 0,0 \\
Normal & 6 & 10,5 & 10 & 17,5 & 5 & 8,8 & 9 & 15,8 \\
Alto & 51 & 89,5 & 47 & 82,5 & 52 & 91,2 & 48 & 84,2 \\
\hline TOTAL & 57 & 100 & 57 & 100 & 57 & 100 & 57 & 100 \\
\hline
\end{tabular}

- Conocimiento de la enfermedad y el tratamiento

- Conocimiento de los aspectos de la enfermedad

A la respuesta a la pregunta si conocía el nombre de su enfermedad, con una proporción del 55\%, respondieron de forma correcta, si conocían los signos y síntomas de inicio de la exacerbación de la EPOC, respondiendo con un $75 \%$ de forma correcta a la misma. De distintos modo ocurrió con el conocimiento de la medicación de rescate donde, el $60 \%$ respondió de forma incorrecta. El resto de respuestas están recogidas en la tabla 33.

Tabla 33.Conocimiento de la enfermedad

\begin{tabular}{lccccccc} 
& \multicolumn{2}{c}{ Nombre } & Signos & \multicolumn{3}{c}{ Medicación } \\
& $\mathbf{n}$ & $\mathbf{\%}$ & $\mathbf{n}$ & $\mathbf{\%}$ & $\mathbf{n}$ & $\boldsymbol{\%}$ \\
Respuesta correcta & 33 & 55,0 & 45 & 75,0 & 24 & 40,0 \\
Respuesta incorrecta & 27 & 45,0 & 15 & 25,0 & 36 & 60,0 \\
\hline TOTAL & 60 & 100 & 60 & 100 & 60 & 100 \\
\hline
\end{tabular}


- Evaluación del uso de los dispositivos de inhalación

El dispositivo de inhalación más utilizado durante el ingreso fue el cartucho presurizado con un 46,7\% seguido de otros dispositivos como el accuhaler o las inhaletas con un uso del $40 \%$. Si atendemos a su correcto uso, el dispositivo que mejor uso tuvo fueron las inhaletas en un $83,3 \%$, sin tener ningún fallo en ninguno de los pasos. Y el dispositivo que más errores presentó fue el nebulizador con un $88,2 \%$, siendo el punto que mayores fallos albergó la limpieza de manos antes de colocar la medicación en la cazoleta. Datos disponibles en la tabla 34 .

\begin{tabular}{lcccccc}
\hline \multicolumn{3}{c}{ Tabla 34. Uso de los dispositivos de inhalación } & \multicolumn{3}{c}{ Mal uso } \\
\hline & Uso del dispositivo & \multicolumn{2}{c}{ Correcto } & n & \% \\
\hline & $\mathbf{n}$ & $\mathbf{\%}$ & $\mathbf{n}$ & $\mathbf{\%}$ & 21 & 75,0 \\
Cartucho & 28 & 46,7 & 7 & 25,0 & 83 & 66,7 \\
Cámara & 12 & 20,0 & 4 & 33,3 & 7 & 70,0 \\
Turbuhaler & 10 & 16,7 & 3 & 30,0 & 18 & 75,0 \\
Accuhaler & 24 & 40,0 & 6 & 25,0 & 4 & 16,7 \\
Inhaletas & 24 & 40,0 & 20 & 83,3 & 15 & 88,2 \\
Nebulizador & 17 & 28,3 & 2 & 11,8 & 73 & 63,5 \\
\hline TOTAL & 115 & & 42 & 36,5 & 73 &
\end{tabular}

- Adherencia al tratamiento

Los resultados obtenidos en la escala de evaluación de la adherencia terapéutica muestran que el $47 \%(n=28)$ de la población estudiada es cumplidora con su tratamiento y el $53 \%$ $(n=32)$ de la población no es cumplidora con su tratamiento. Ver gráfico 5 de adherencia terapéutica según periodo de evaluación.

Gráfico 5. Adherencia terapéutica

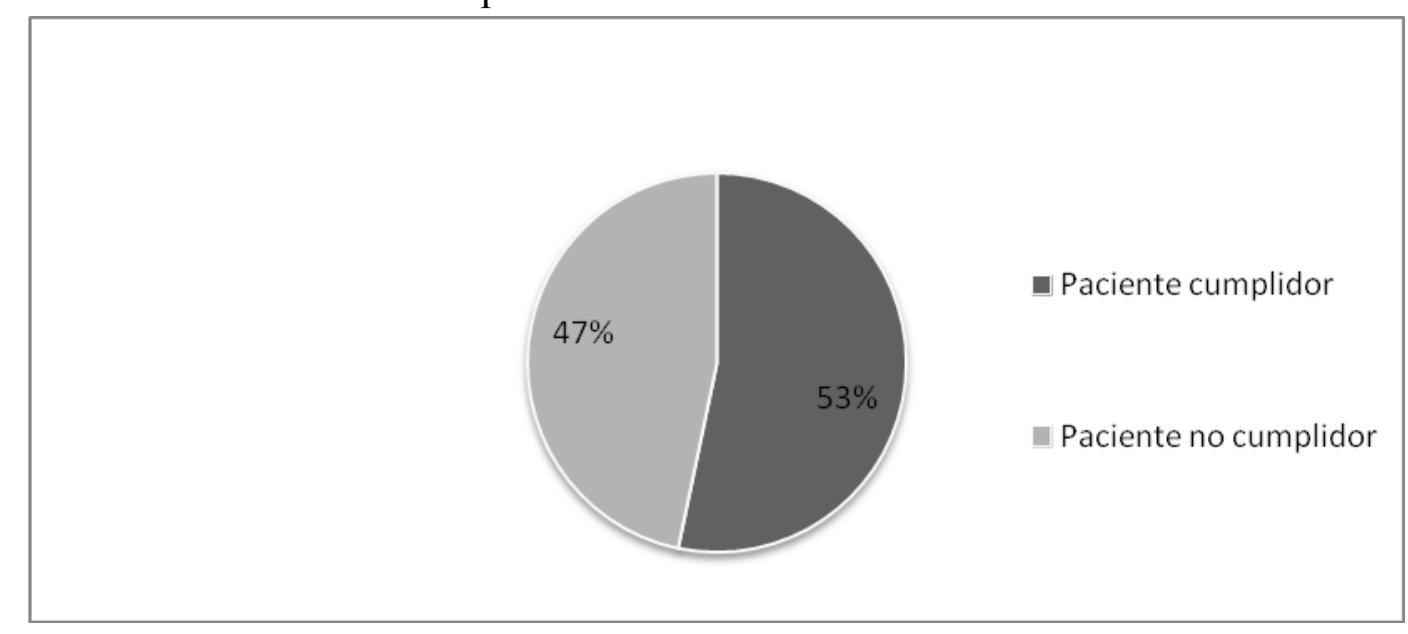




\subsubsection{Resultado de las variables de control}

Las variables de control se engloban en 4 grandes grupos:

- Variables de hábitos de vida

- Variables de función pulmonar

- Variables de seguimiento médico

- Variables psicológicas

- Variables de dependencia física

\section{Variables de control hábitos de vida}

El 65\% eran exfumadores y el 13,3\% de los pacientes nunca habían fumado.

La media de años de fumador se sitúo en torno a los 41,6 \pm 15 años con un mínimo de 9 y un máximo de 70 años. Si atendemos al número de cigarrillos al día la media es de $25,3 \pm 17$ cigarros, equivalente a más de un paquete de tabaco, con un mínimo de cigarrillos de 2 y un máximo de 80 cigarrillos equivalente a 4 paquetes al día. Por tanto la dosis de tabaco acumulada de los pacientes de la muestra, es de una media de 55,1 $\pm 43,7$ con un máximo de 180 paquetes/año.

El consumo de alcohol se sitúa en una media de 1,9 vasos de alguna bebida alcohólica al día, siendo el mínimo de 1 y el máximo consumo de 4 vasos. Ver tabla 35 de hábitos tóxicos.

\begin{tabular}{|c|c|c|c|c|}
\hline \multicolumn{5}{|c|}{ Tabla 35. Hábitos de vida } \\
\hline & n & \multicolumn{3}{|c|}{$\%$} \\
\hline No fumador & 8 & \multicolumn{3}{|c|}{13,3} \\
\hline Fumador & 13 & \multicolumn{3}{|c|}{21,7} \\
\hline Ex-fumador & 39 & \multicolumn{3}{|c|}{65,0} \\
\hline TOTAL & 60 & \multicolumn{3}{|c|}{100} \\
\hline \multicolumn{5}{|l|}{ Tabaco } \\
\hline & $\bar{X} \pm$ d.t & mínimo & & máximo \\
\hline Años de fumador & $41,6 \pm 15$ & 9 & & 70 \\
\hline Cigarrillos día & $25,3 \pm 17$ & 2 & & 80 \\
\hline Dosis acumulada & $55,1 \pm 43,7$ & 2,5 & & 180 \\
\hline \multicolumn{5}{|l|}{ Alcohol } \\
\hline Consumo diario (litros) & $1,9 \pm 1,1$ & 1 & & 4 \\
\hline
\end{tabular}

Media $(\bar{X})$, desviación típica (d.t)

- Estado nutricional

La media de peso fue de $76,8 \pm 18,7 \mathrm{Kg}$ y la de media de altura de $1,7 \pm 0,1 \mathrm{~m}$. Si valoramos el índice de masa corporal podemos observar que el $40 \%$ son pacientes obesos, seguidos de los que tienen sobrepeso con un porcentaje del $30 \%$, siendo los menos frecuentes los pacientes con un IMC bajo, significando el 6,7\% de la población estudiada. 
$\mathrm{Si}$ atendemos al número de vasos de líquidos que ingieren al día los pacientes de la muestra podemos observar que la media es de 1,31 $\pm 0,6$ litros al día, son un mínimo de 0,25 litros y un máximo de 2,5 litros.

El $63,3 \%$ de los pacientes afirmo que no seguía ninguna dieta, frente al 36,7\% que sí que indico que seguía alguna dieta por sus problemas de salud. Ver tabla 36.

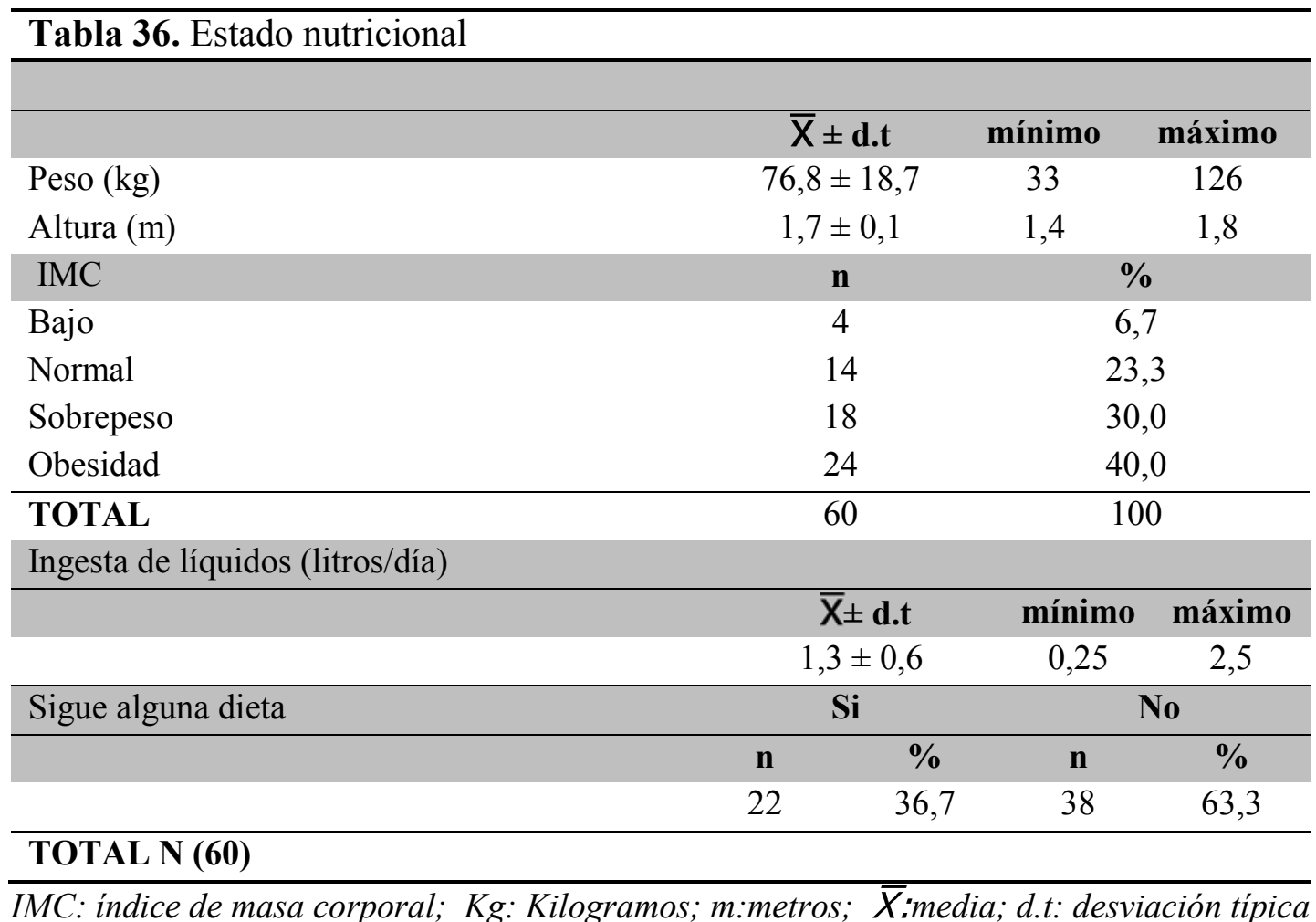

- Sedentarismo

El 50\% de la población estudiada afirmo que caminaba 30 minutos al día fuera de casa, del mismo modo el $50 \%$ de la población también afirmo que pasaba la mayor parte del tiempo tumbado en el sofá (tabla 37).

- Vacunación

La vacuna de la gripe es la más utilizada ya que el $70 \%$ de ellos afirmo habérsela puesto el año anterior. Sin embargo, en cuanto a la vacunación del neumococo $80 \%$ de la muestra desconoce de su existencia. (Tabla 37).

\begin{tabular}{lccccc|cc}
\hline Tabla 37. Sedentarismo y vacunación & \multicolumn{1}{c}{ SI } & \multicolumn{2}{c|}{ NO } & \multicolumn{2}{c}{ TOTAL } \\
\hline Sedentarismo & n & \% & n & $\%$ & N & $\%$ \\
& 30 & 50,0 & 30 & 50,0 & 60 & 100 \\
Camina 30 minutos al día fuera de casa & 30 & 50,0 & 30 & 50,0 & 60 & 100 \\
Pasa la mayor parte del tiempo en el sofá & & & & & & \\
Vacunación & 42 & 70,0 & 18 & 30,0 & 60 & 100 \\
Gripe & 12 & 20,0 & 48 & 80,0 & 60 & 100 \\
Neumococo & & & & &
\end{tabular}




\section{Variables de control de función pulmonar}

La descripción de los datos referidos al control de la función pulmonar se exponen en la tabla 38 .

Los pacientes evaluados presentan una espirometría con una grado de obstrucción en estadio III.

La media del Ph sanguíneo se sitúa en los parámetros de normalidad. Si atendemos a los valores sanguíneos del oxígeno podemos observar que también está en la normalidad, sin embargo los valores de la presencia de carbónico en sangre no se encuentran en los límites de la normalidad.

El $45 \%$ de la muestra presentó durante el ingreso una disnea de grado III y el segundo nivel más frecuente con un porcentaje del $23,3 \%$ una disnea de grado IV. Siendo el grado de disnea menos indicado el grado 0 , con un $5 \%$ de la población.

Los síntomas más frecuentes fueron, la expectoración (63,3\%), siendo el color de secreción más frecuente el blanco $(34,3 \%)$, la necesidad de dormir sentado $(58,3 \%)$ y la tos $(50 \%)$, siendo la presencia de edemas $(31,7 \%)$ el signo menos presentado.

Así como el dolor tuvo una media general de 4,1, con un valor máximo indicado por un paciente de 6 en la escala de valoración analógica.

La media de comorbilidades se situó en 2,6 con un máximo de 7 comorbilidades y un mínimo de 0 . Si estos datos los observamos a través del índice de Chalson modificado por edad, podemos observar que el $91,5 \%$ de la población estudiada presenta una alta comorbilidad. 


\begin{tabular}{|c|c|c|c|c|}
\hline \multicolumn{5}{|l|}{ Espirometría } \\
\hline & \multicolumn{2}{|c|}{$\bar{X} \pm$ d.t } & mínimo & máximo \\
\hline $\mathrm{FEV}_{1}(\%)$ & \multicolumn{2}{|c|}{$44,6 \pm 22,0$} & 10 & 112 \\
\hline FVC (\%) & \multicolumn{2}{|c|}{$58,7 \pm 17,9$} & 28 & 107 \\
\hline $\mathrm{FEV}_{1} / \mathrm{FCV}(\%)$ & \multicolumn{2}{|c|}{$69,7 \pm 24,6$} & 39 & 122 \\
\hline \multicolumn{5}{|l|}{ Gasometría } \\
\hline & \multicolumn{2}{|c|}{$\bar{X} \pm$ d.t } & mínimo & máximo \\
\hline $\mathrm{Ph}$ & \multicolumn{2}{|c|}{$7,4 \pm 0,1$} & 7,3 & 7,6 \\
\hline $\mathrm{O}_{2(\mathrm{mmHg})}$ & \multicolumn{2}{|c|}{$70,0 \pm 23,7$} & 48 & 162 \\
\hline $\mathrm{CO}_{2(\mathrm{mmHg})}$ & \multicolumn{2}{|c|}{$45,8 \pm 11,2$} & 28 & 79 \\
\hline \multicolumn{5}{|l|}{ MRC } \\
\hline & \multicolumn{2}{|c|}{$\mathbf{n}$} & \multicolumn{2}{|c|}{$\%$} \\
\hline 0 & \multicolumn{2}{|c|}{3} & \multicolumn{2}{|c|}{5,5} \\
\hline I & \multicolumn{2}{|c|}{4} & \multicolumn{2}{|c|}{7,3} \\
\hline II & \multicolumn{2}{|c|}{7} & \multicolumn{2}{|c|}{12,7} \\
\hline III & \multicolumn{2}{|c|}{27} & \multicolumn{2}{|c|}{49,1} \\
\hline IV & \multicolumn{2}{|c|}{14} & \multicolumn{2}{|c|}{25,5} \\
\hline TOTAL & \multicolumn{2}{|c|}{55} & \multicolumn{2}{|c|}{100} \\
\hline \multicolumn{5}{|l|}{ Signos y síntomas } \\
\hline & \multicolumn{2}{|c|}{ SI } & \multicolumn{2}{|c|}{ NO } \\
\hline & $\mathbf{n}$ & $\%$ & $\mathbf{n}$ & $\%$ \\
\hline Tos & 30 & 50,0 & 30 & 50,0 \\
\hline Expectoración & 38 & 63,3 & 22 & 35,6 \\
\hline Sibilancias & 26 & 43,3 & 34 & 56,7 \\
\hline Somnolencia diurna & 20 & 33,3 & 40 & 66,7 \\
\hline Dormir sentado & 35 & 58,3 & 25 & 41,7 \\
\hline Edemas & 19 & 31,7 & 41 & 68,3 \\
\hline Fiebre & 2 & 3,3 & 58 & 96,7 \\
\hline
\end{tabular}

\begin{tabular}{|c|c|c|}
\hline Dolor & & \\
\hline & $\bar{X} \pm$ d.t & mínimo máximo \\
\hline EVA & $4,1 \pm 1,7$ & 6 \\
\hline Comorbilidades & & \\
\hline & $\bar{X} \pm$ d.t & mínimo máximo \\
\hline $\mathrm{N}^{\mathrm{o}}$ Comorbilidades & $2,6 \pm 1,9$ & 0 \\
\hline Chalson & & \\
\hline & $\mathrm{n}$ & $\%$ \\
\hline Ausencia de comorbilidad & 3 & 5,1 \\
\hline Baja comorbilidad & 2 & 3,4 \\
\hline Alta comorbilidad & 54 & 91,5 \\
\hline TOTAL & 59 & 100 \\
\hline
\end{tabular}

EVA: escala de valoración analógica; $\bar{X}$ : media; d.t: desviación típica FEV1:Flujo espiratorio en el primer segundo; FVC: Capacidad vital forzada; $\mathrm{O}_{2}$ oxígeno; $\mathrm{CO}_{2}$. Dióxido de carbono ;mmHg: milígramos de mercurio; MRC: Medical Resoult Council $\bar{X}$ : media; d.t: desviación típica 


\section{$\underline{\text { Variables de seguimiento médico }}$}

El número medio de pastillas que toman los pacientes de la muestra se sitúa en 5,6 pastillas diarias, con un máximo de consumo de 15 pastillas. Si atendemos al uso de los inyectables, su media de uso de 0,5 inyectables al día y el uso más frecuente de 3 inyectables atribuibles al uso de insulina. Si atendemos a otro de los dispositivos utilizados por los pacientes con EPOC para administrarse la medicación pulmonar, son los inhaladores con una media de consumo de 3,7 inhaladores al día, cabe desatacar que todos los pacientes hacen uso de algún dispositivo de inhalación siendo el mínimo uso de una inhalación y el máximo uso de 8 inhalaciones al día.

Si observamos en la tabla 39, podemos apreciar los dispositivos y los fármacos más utilizados con los diferentes dispositivos de inhalación existentes en el mercado. Siendo el cartucho presurizado, el accuhaler y las inhálelas los dispositivos con más uso por los pacientes, es destacable que el cartucho su fármaco más utilizado en un $96,6 \%$ sea el broncodilatador de corta duración, en el caso del accuhaler el broncodilatador de larga duración con una proporción del 70,8\% y en el caso de las inhaletas con una proporción del 69,6\% la combinación de broncodilatador de larga duración junto con el corticoide inhalado.

Otros dispositivos de inhalación como la cámara también utilizan en mayor proporción los broncodilatadores de corta duración como los fármacos más frecuentes en una proporción del 92,9\%.

La mayor parte de los pacientes afirmo recibir un seguimiento médico, el $50 \%$ de ellos recibió este seguimiento desde su centro de atención primaria, frente al 33,3\% que afirmo recibir el seguimiento desde el hospital. Existiendo un volumen del 13,3\% de los pacientes que afirmo no saber dónde le realizaban el seguimiento. Los periodos de seguimiento más frecuentes fueron en el 56,9\% entre los 3 y los 6 meses al año o el 15,5\% que afirmo tener seguimiento médico una vez al año por su problemas respiratorio.

Normalmente los pacientes cuando se encuentran mal suelen acudir preferentemente a su centro de Atención Primaria en un 50\%, seguido de los que acuden primero a urgencias tanto hospitalarias como de atención primaria en un $35 \%$.

A la pregunta si alguna vez había acudido a sesiones de educación terapéutica el 10\% de la población afirmó que sí que había acudido, pero en ninguno de los casos fueron sesiones de educación por su problema respiratorio si no por otras patología como la diabetes, así como no recibieron material adicional en las mismas como folletos informativos $\mathrm{u}$ otros. Por tanto ninguno de los pacientes de la muestra recibió educación terapéutica anterior sobre la EPOC.

Durante el ingreso el $46,7 \%$ de los pacientes era portadores de oxígeno durante el mismo, siendo solo portadores de CAP y ventilación mecánica no invasiva el 1,7\% respetivamente de cada dispositivo. 


\begin{tabular}{|c|c|c|}
\hline \multicolumn{3}{|l|}{ № de patillas/día } \\
\hline & $\bar{X} \pm$ d.t & mínimo máximo \\
\hline & $5,6 \pm 3,5$ & 15 \\
\hline \multicolumn{3}{|l|}{ № de inyecciones/día } \\
\hline & $\bar{X} \pm$ d.t & mínimo máximo \\
\hline & $0,5 \pm 0$ & 3 \\
\hline \multicolumn{3}{|l|}{ № de inhalaciones/día } \\
\hline & $\bar{X} \pm$ d.t & mínimo máximo \\
\hline & $3,7 \pm 1,6$ & 8 \\
\hline \multicolumn{3}{|l|}{ Dispositivos según fármaco } \\
\hline \multicolumn{3}{|l|}{ Cartucho presurizado } \\
\hline & $\mathbf{n}$ & $\%$ \\
\hline Broncodilatador de corta duración & 28 & 96,6 \\
\hline Broncodilatador de larga duración & 1 & 3,4 \\
\hline Corticoide inhalado & 0 & 0,0 \\
\hline Broncodilatador + corticoide & 0 & 0,0 \\
\hline TOTAL & 30 & 100 \\
\hline \multicolumn{3}{|l|}{ Cámara } \\
\hline Broncodilatador de corta duración & 13 & 92,9 \\
\hline Broncodilatador de larga duración & 1 & 7,1 \\
\hline Corticoide inhalado & 0 & 0,0 \\
\hline Broncodilatador + corticoide & 0 & 0,0 \\
\hline TOTAL & 14 & 100 \\
\hline \multicolumn{3}{|l|}{ Turbuhaler } \\
\hline Broncodilatador de corta duración & 0 & 0,0 \\
\hline Broncodilatador de larga duración & 2 & 22,2 \\
\hline Corticoide inhalado & 2 & 22,2 \\
\hline Broncodilatador + corticoide & 5 & 55,6 \\
\hline TOTAL & 9 & 100 \\
\hline \multicolumn{3}{|l|}{ Accuhaler } \\
\hline Broncodilatador de corta duración & 1 & 4,2 \\
\hline Broncodilatador de larga duración & 17 & 70,8 \\
\hline Corticoide inhalado & 4 & 16,7 \\
\hline Broncodilatador + corticoide & 2 & 8,3 \\
\hline TOTAL & 24 & 100 \\
\hline Inhaletas & & \\
\hline Broncodilatador de corta duración & 0 & 0,0 \\
\hline Broncodilatador de larga duración & 7 & 30,4 \\
\hline Corticoide inhalado & 0 & 0,0 \\
\hline Broncodilatador + corticoide & 16 & 69,6 \\
\hline TOTAL & 23 & 100 \\
\hline
\end{tabular}




\begin{tabular}{|c|c|c|}
\hline \multicolumn{3}{|l|}{ Nebulizador } \\
\hline Broncodilatador de corta duración & 0 & 0,0 \\
\hline Broncodilatador de larga duración & 4 & 23,5 \\
\hline Corticoide inhalado & 6 & 35,3 \\
\hline Broncodilatador + corticoide & 7 & 41,2 \\
\hline TOTAL & 17 & 100 \\
\hline \multicolumn{3}{|l|}{ Lugar donde se visita normalmente } \\
\hline Atención Primaria & 30 & 50,0 \\
\hline Hospital & 20 & 33,3 \\
\hline Ninguno & 2 & 3,3 \\
\hline No lo se & 8 & 13,3 \\
\hline TOTAL & 60 & 100 \\
\hline \multicolumn{3}{|l|}{ Periodo de seguimiento médico } \\
\hline Una vez cada 3-6 meses & 33 & 56,9 \\
\hline Una vez al año & 9 & 15,5 \\
\hline No me acuerdo & 6 & 10,3 \\
\hline No tengo seguimiento & 10 & 17,2 \\
\hline TOTAL & 58 & 100 \\
\hline \multicolumn{3}{|c|}{ Donde acude cuando se encuentra mal } \\
\hline Atención Primaria & 30 & 50,0 \\
\hline Hospital & 9 & 15,0 \\
\hline Urgencias & 21 & 35,0 \\
\hline A nadie & 0 & 0,0 \\
\hline TOTAL & 60 & 100 \\
\hline \multicolumn{3}{|l|}{ Educación anterior } \\
\hline $\mathrm{Si}$ & 6 & 10,0 \\
\hline No & 54 & 90,0 \\
\hline TOTAL & 60 & 100 \\
\hline \multicolumn{3}{|l|}{ Complicación del tratamiento } \\
\hline Oxígeno & 28 & 46,7 \\
\hline CPAP & 1 & 1,7 \\
\hline Ventilación Mecánica no invasiva & 1 & 1,7 \\
\hline
\end{tabular}

CPAP: Los datos indican número de casos (n), porcentaje (\%), media $(\bar{X})$, desviación típica (d.t) 


\section{Variables psicológicas (ansiedad y depresión)}

Si atendemos a las variables psicológicas podemos observar en la tabla 40 que los pacientes presentan mayor ansiedad que depresión. Siendo en iguales proporciones el $23,3 \%$ el número de pacientes que presenta un caso dudoso de ansiedad y depresión.

\begin{tabular}{lcc}
\hline Tabla 40. Estado psicológico & & \\
\hline Ansiedad & n & \% \\
& 31 & 51,7 \\
No caso & 14 & 23,3 \\
Caso dudoso & 13 & 21,7 \\
Probable caso & 58 & 100 \\
\hline TOTAL & & \\
\hline Depresión & 37 & 63,8 \\
No caso & 14 & 24,1 \\
Caso dudoso & 7 & 12,1 \\
Probable caso & 58 & 100 \\
\hline TOTAL & & \\
\hline
\end{tabular}

Variables de dependencia (Barthel)

La mayor parte de la población presentó en un 31,7\% un grado de independencia en la realización de las actividades diarias, seguido del 36,7\% que presento una dependencia moderada, siendo el valor menos indicado los que presentaron una dependencia completa $(1,7 \%)$. Ver datos tabla 41.

\begin{tabular}{lcc}
\hline \multicolumn{2}{l}{ Tabla 41. Dependencia en las actividades de la vida diaria } \\
\hline & $\mathbf{n}$ & $\mathbf{\%}$ \\
Independencia & 19 & 31,7 \\
Escasa & 5 & 8,3 \\
Moderada & 22 & 36,7 \\
Severa & 13 & 21,7 \\
Completa & 1 & 1,7 \\
\hline TOTAL & 60 & 100 \\
\hline
\end{tabular}




\subsubsection{Resultados homogeneidad entre grupos}

\subsubsection{Variables sociodemográficas}

Como se puede apreciar en la tabla 42, no existieron diferencias significativas según asignación grupal en las variables sociodemográficas. La comparabilidad de los grupos de estudio queda descrita en la tabla 42.

\begin{tabular}{|c|c|c|c|c|c|}
\hline \multicolumn{6}{|l|}{ Sexo } \\
\hline & \multicolumn{2}{|c|}{ Intervención } & \multicolumn{2}{|c|}{ Control } & \multirow[b]{2}{*}{ p-value } \\
\hline & n & $\%$ & $\mathbf{n}$ & $\%$ & \\
\hline Hombres & 28 & 87,5 & 21 & 75,0 & \multirow{2}{*}{0,481} \\
\hline Mujeres & 5 & 15,6 & 6 & 21,4 & \\
\hline TOTAL & 33 & 100 & 27 & 100 & \\
\hline \multicolumn{6}{|l|}{ Edad } \\
\hline & \multicolumn{2}{|c|}{$\begin{array}{c}\text { Intervención } \\
\bar{X} \pm \text { d.t }\end{array}$} & \multicolumn{2}{|c|}{$\begin{array}{l}\text { Control } \\
\bar{X} \pm \text { d.t }\end{array}$} & P-value \\
\hline & \multicolumn{2}{|c|}{$71,9 \pm 9,7$} & \multicolumn{2}{|c|}{$74,4 \pm 8,4$} & 0,290 \\
\hline \multirow{3}{*}{ Nivel de estudios } & \multirow{2}{*}{\multicolumn{2}{|c|}{ Intervención }} & \multirow{2}{*}{\multicolumn{2}{|c|}{ Control }} & \multirow{6}{*}{0,518} \\
\hline & & & & & \\
\hline & $\mathbf{n}$ & $\%$ & $\mathbf{n}$ & $\%$ & \\
\hline Sin estudios & 8 & 25,0 & 3 & 10,7 & \\
\hline Estudios básicos + estudios de secundaria & 22 & 66,7 & 22 & 81,5 & \\
\hline Estudios Universitarios & 3 & 9,4 & 2 & 7,1 & \\
\hline TOTAL & 33 & 100 & 27 & 100 & \\
\hline \multicolumn{6}{|l|}{ Convivencia } \\
\hline Marido/Esposa & 16 & 50,0 & 13 & 46,4 & \multirow{4}{*}{0,831} \\
\hline Hijos + Otros familiares & 8 & 24,2 & 7 & 25,9 & \\
\hline Solo & 5 & 15,6 & 3 & 10,7 & \\
\hline Varios miembros de la familia & 4 & 12,5 & 4 & 14,3 & \\
\hline TOTAL & 33 & 100 & 27 & 100 & \\
\hline \multicolumn{6}{|l|}{ Apoyo social percibido } \\
\hline No necesita ningún apoyo & 19 & 57,6 & 14 & 51,9 & \multirow{5}{*}{0,357} \\
\hline Tiene apoyo por parte de vecinos & 3 & 9,1 & 0 & 0,0 & \\
\hline Tiene apoyo social formal suficiente & 4 & 12,1 & 1 & 3,7 & \\
\hline Tiene apoyo social formal pero no es suficiente & 6 & 18,2 & 9 & 33,3 & \\
\hline No tiene apoyo y lo necesita & 1 & 3,0 & 3 & 11,1 & \\
\hline TOTAL & 33 & 100 & 27 & 100 & \\
\hline
\end{tabular}




\subsubsection{Variables principales}

En cuanto a la comparabilidad de los grupos en las variables principales no se observaron diferencias estadísticamente significativas entre los grupos de estudio, a continuación se detallan los resultados del uso de servicios hospitalarios, calidad de vida, conocimiento y adherencia al tratamiento.

\subsection{Uso de servicios hospitalarios homogeneidad al ingreso}

Como se puede apreciar en la tabla 43, los pacientes del grupo control ingresaron por problemas respiratorios el 69,2\% en el último año y en el grupo intervención el 65,5\%. Valor que también es apreciable con una media de ingresos en el grupo control $(1,1 \pm 1,1)$, frente a la media anual del grupo intervención $(0,9 \pm 1,3)$.

Así como las visitas a urgencias del grupo control tuvieron una frecuencia del (84,6\%) con respecto a los del grupo intervención que solo acudió el 38,3\% de ellos. Sin embargo la proporción de pacientes que acudió a urgencias del grupo intervención fue de $(1,6 \pm 2,0)$ comparada con el grupo control $(2,2 \pm 1,9)$.

Las visitas al servicio de urgencias, es el grupo control el que ha tenido un seguimiento en consultas externas del (26,9\%) y el grupo intervención el que presenta una media de visitas anuales del $(0,7 \pm 1,9)$. Datos apreciables en la tabla 43.

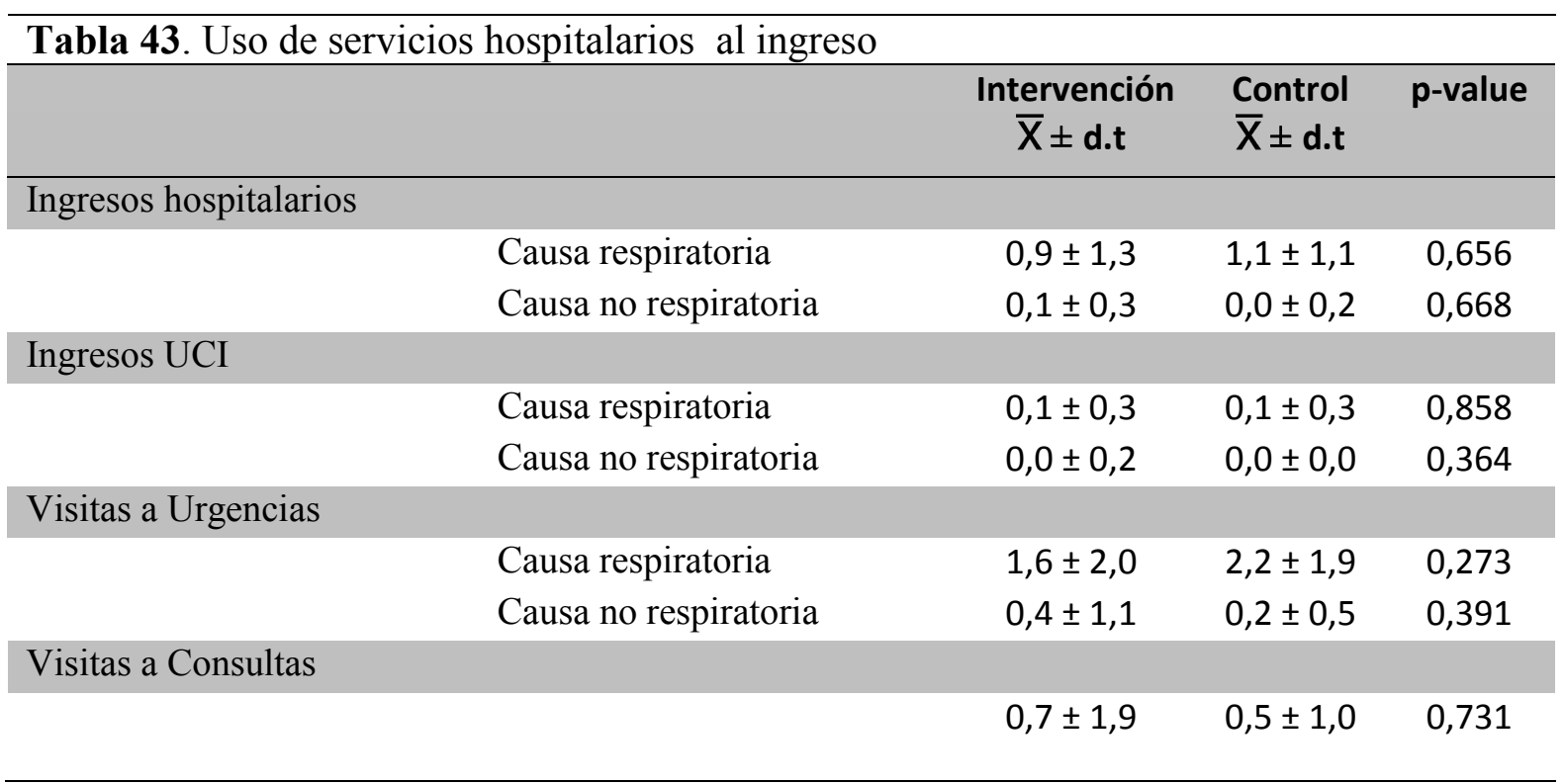


Tabla 43. Uso de servicios hospitalarios ingreso (continuación)

\begin{tabular}{llcc|ccc}
\hline & & Intervención & \multicolumn{2}{c}{ Control } & p-value \\
& & $\mathbf{n}$ & $\mathbf{\%}$ & $\mathbf{n}$ & $\mathbf{\%}$ & \\
\hline Ingresos hospitalarios & Causa respiratoria & 20 & 65,5 & 18 & 69,2 & 0,216 \\
& Causa no respiratoria & 2 & 6,5 & 1 & 3,8 & 1,000 \\
\hline TOTAL & & & & & \\
Ingresos UCI & Causa respiratoria & 2 & 6,5 & 2 & 7,7 & 1,000 \\
& Causa no respiratoria & 1 & 3,2 & 0 & 0,0 & 1,000 \\
\hline TOTAL & & 0 & 0 & & & \\
\hline Visitas Urgencias & & & & & & \\
& & 21 & 38,3 & 22 & 84,6 & 0,188 \\
& Causa respiratoria & 4 & 12,9 & 4 & 15,4 & 0,550 \\
\hline TOTAL & Causa no respiratoria & & & & & \\
\hline Visitas Consultas & & 5 & 16,1 & 7 & 26,9 & 0,161 \\
\hline
\end{tabular}

Los datos indican media $(\bar{X})$, desviación típica (d.t); UCI: Unidad de Cuidados Intensivos

\section{$\underline{4.3 .3 .2 .2 ~ C a l i d a d ~ d e ~ v i d a ~}$}

\subsection{Calidad de vida CAT homogeneidad al ingreso}

Como se puede apreciar en la tabla 44, no existieron diferencias significativas en la calidad de vida según la asignación grupal. Sí que podemos observar que los pacientes asignados al grupo intervención presentaron una calidad de vida en su evaluación inicial con una media de $21,7 \pm 8,3$ con respecto al grupo control con una media de $24,6 \pm 7,4$. Siendo para ambos grupos los valores más frecuentes presentar un impacto alto y medio en la realización de actividades de la vida diaria.

\begin{tabular}{|c|c|c|c|c|c|}
\hline & \multicolumn{2}{|c|}{$\begin{array}{l}\text { Intervención } \\
\bar{X} \pm \text { d.t }\end{array}$} & \multicolumn{2}{|c|}{$\begin{array}{l}\text { Control } \\
\bar{X} \pm \text { d.t }\end{array}$} & p-value \\
\hline & \multicolumn{2}{|c|}{$21,7 \pm 8,3$} & \multicolumn{2}{|c|}{$24,6 \pm 7,4$} & 0,173 \\
\hline & \multicolumn{2}{|c|}{ Intervención } & \multicolumn{2}{|c|}{ Control } & \\
\hline & n & $\%$ & n & $\%$ & p-value \\
\hline Bajo impacto & 2 & 6,5 & 1 & 4,0 & \multirow{4}{*}{0,713} \\
\hline Impacto medio & 12 & 38,7 & 8 & 32,0 & \\
\hline Impacto alto & 14 & 45,2 & 11 & 44,0 & \\
\hline Impacto muy alto & 3 & 9,7 & 5 & 20,0 & \\
\hline TOTAL & 31 & 100 & 25 & 100 & \\
\hline
\end{tabular}

Los datos indican media $(\bar{X})$, desviación típica (d.t) 


\subsection{Calidad de vida St. George homogeneidad al ingreso}

El grupo intervención presento una afectación en los síntomas con un 90,6\% frente al grupo control con un $88 \%$. El resto de aspectos es el grupo control el que tiene unos niveles del $88 \%$ en la actividad y un $92 \%$ en el impacto en la realización de sus actividades diarias. Obteniendo en el cómputo global de todos los aspectos de la escala una afectación el grupo intervención del 84,4\% frente al grupo control del 84,0\%. Ver tabla 45.

\begin{tabular}{llcc|ccr}
\hline Tabla 45. Calidad de vida St. George al ingreso & \multicolumn{2}{c}{ Intervención } & \multicolumn{2}{c}{ Control } & p-value \\
& & $\mathbf{n}$ & $\mathbf{\%}$ & $\mathbf{n}$ & $\mathbf{\%}$ & \\
\hline Síntomas & Bajo & 0 & 0,0 & 0 & 0,0 & \\
& Normal & 3 & 9,4 & 3 & 12,0 & 0,539 \\
& Alto & 29 & 90,6 & 22 & 88,0 & \\
Actividad & Bajo & 0 & 0,0 & 0 & 0,0 & \\
& Normal & 7 & 21,9 & 3 & 12,0 & 0,270 \\
& Alto & 25 & 78,1 & 22 & 88,0 & \\
Impacto & Bajo & 0 & 0,0 & 0 & 0,0 & \\
& Normal & 3 & 9,4 & 2 & 8,0 & 0,618 \\
Alto & 29 & 90,6 & 23 & 92,0 & \\
Calidad global & Bajo & 0 & 0,0 & 0 & 0,0 & \\
& Normal & 5 & 15,6 & 4 & 16,0 & 0,624 \\
& Alto & 27 & 84,4 & 21 & 84,0 & \\
\hline TOTAL & & 32 & 100 & 25 & 100 & \\
\hline
\end{tabular}

\subsection{Conocimiento de la enfermedad}

\subsection{Conocimiento de la enfermedad homogeneidad al ingreso}

Si atendemos a las preguntas sobre conocimiento de la enfermedad, existió homogeneidad en las respuestas, dado que tanto los pacientes del grupo intervención como control respondieron mayoritariamente de forma correcta al conocimiento del nombre de la enfermedad y de los signos y síntomas de alarma y de forma contraria respondieron en ambos grupos de forma incorrecta al conocimiento de la medicación de rescate en caso de necesidad. Por tanto no existieron diferencias significativas entre ambos grupos. Datos apreciables en tabla 46. 


\begin{tabular}{|c|c|c|c|c|c|c|}
\hline & & \multicolumn{2}{|c|}{ Intervención } & \multicolumn{2}{|c|}{ Control } & \multirow{2}{*}{ p-value } \\
\hline & & $\mathbf{n}$ & $\%$ & $\mathbf{n}$ & $\%$ & \\
\hline \multicolumn{7}{|c|}{ Nombre de la enfermedad } \\
\hline & Respuesta correcta & 19 & 57,6 & 14 & 51,9 & 0,795 \\
\hline & Respuesta incorrecta & 14 & 42,4 & 13 & 48,1 & \\
\hline \multicolumn{7}{|c|}{ Síntomas de alarma } \\
\hline & Respuesta correcta & 24 & 72,7 & 21 & 77,8 & 0,768 \\
\hline & Respuesta incorrecta & 9 & 27,3 & 6 & 22,2 & \\
\hline \multicolumn{7}{|c|}{ Medicación de rescate } \\
\hline & Respuesta correcta & 14 & 42,4 & 10 & 37,0 & 0,793 \\
\hline & Respuesta incorrecta & 19 & 57,6 & 17 & 63,0 & \\
\hline TOTAL & & 33 & 100 & 27 & 100 & \\
\hline
\end{tabular}

\subsection{Uso de los dispositivos de inhalación homogeneidad al ingreso}

Todos los pacientes tanto asignados al grupo control como intervención en la evaluación inicial realizan mayoritariamente el inhalador de forma incorrecta, a excepción del dispositivo inhaletas.

Es el grupo intervención el que realiza de forma incorrecta un mayor número de dispositivos, como son la cámara $75 \%$, el sistema turbuhaler $71,4 \%$ y el nebulizador $88,9 \%$. Siendo el grupo control el que realiza peor el dispositivo accuhaler $81,8 \%$.

Pese a realizar más dispositivos de forma incorrecta el grupo intervención frente al grupo control, ambos dos realizan en proporciones similares incorrectamente los inhaladores, no existiendo diferencias significativas entre ambos. Dichos datos son apreciables en la tabla 47. 


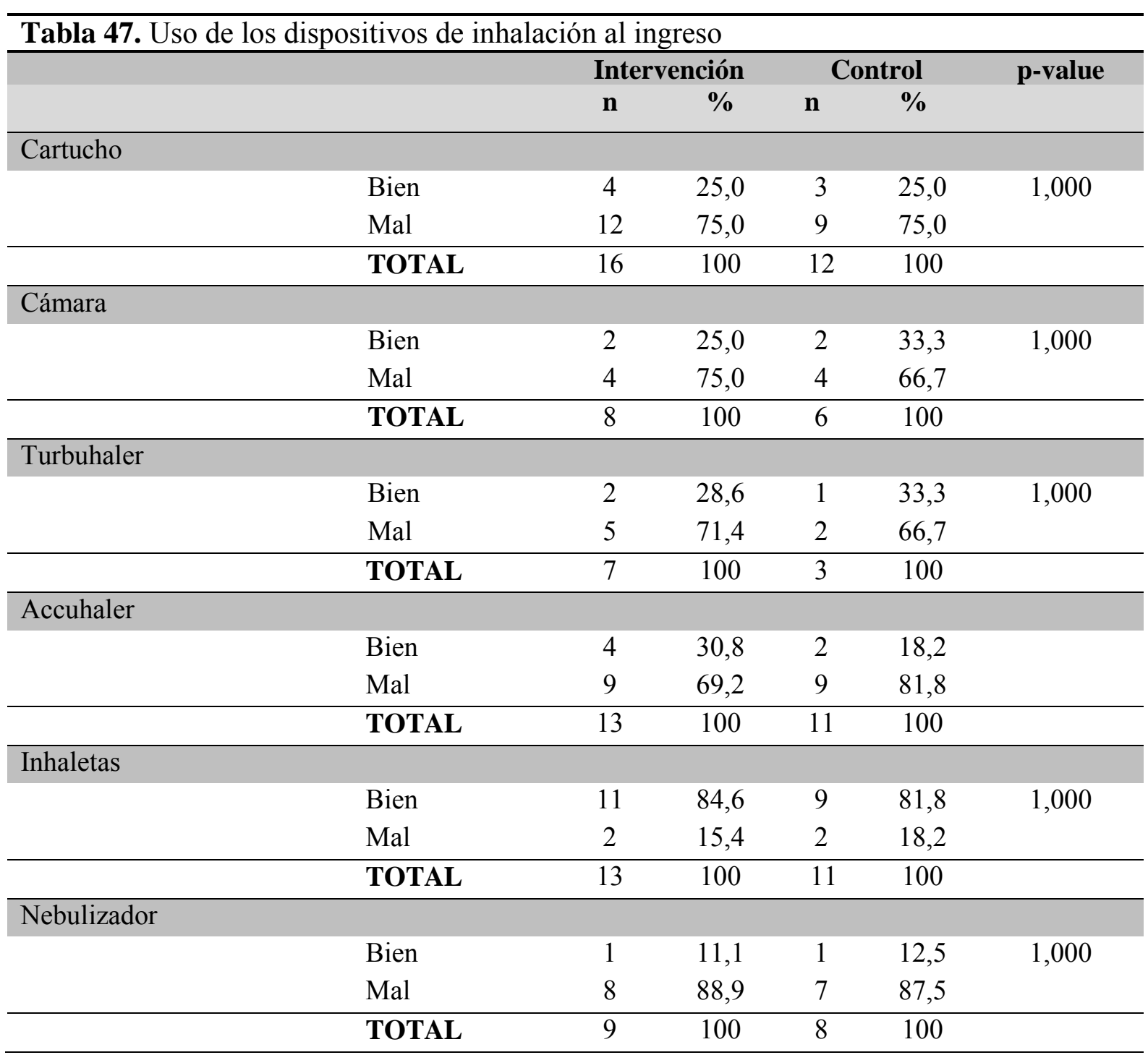

\subsection{Adherencia farmacológica homogeneidad}

Si observamos la tabla 48 sobre la adherencia al tratamiento los pacientes del grupo control fueron más cumplidores con un 59,3\% que los pacientes del grupo intervención con un porcentaje de adherencia del 48,5\%. No siendo significativas las diferencias estadísticas.

Tabla 48. Adherencia al tratamiento al ingreso

\begin{tabular}{cccc|c}
\hline \multirow{3}{*}{ Intervención } & & $\mathbf{n}$ & \% & p-value \\
& $\mathrm{Si}$ & 16 & 48,5 & \\
& $\mathrm{No}$ & 17 & 51,5 & \\
\cline { 2 - 3 } & TOTAL & 33 & 100 & \\
\cline { 2 - 3 } Control & $\mathrm{Si}$ & 16 & 59,3 & \multirow{2}{*}{0,446} \\
& $\mathrm{No}$ & 11 & 40,7 & \\
& TOTAL & 27 & 100 & \\
\cline { 2 - 3 } & & & & \\
\hline
\end{tabular}




\section{$\underline{4.3 .3 .3 ~ V a r i a b l e s ~ d e ~ c o n t r o l ~}$}

En cuanto a la comparabilidad de los grupos en las variables de control no se observaron diferencias estadísticamente significativas entre los grupos de estudio, a continuación se detallan los resultados principales apoyados por las tablas 49, 50 y 51 .

Hábitos de vida

Si observamos la tabla 49, sobre hábitos de vida, es el grupo intervención el que tiene un número de fumadores del $24,2 \%$ de su muestra frente al 18,5\% del grupo control.

$\mathrm{Si}$ atendemos a los años de consumo de tabaco, es el grupo control el que tiene una mayor longevidad de años de consumo, con una media de 39,8 $\pm 19,7$ años frente a los $34,3 \pm 19,2$ años del grupo intervención.

Sin embargo aunque los pacientes del grupo control lleva más años fumando son los pacientes del grupo intervención los que tienen un mayor consumo de cigarrillos diarios, con una media de 22,8 819,4 cigarrillos al día frente a los $21,8 \pm 16,3$. Datos que entre ellos no son muy dispersos, ambos dos grupos tienen un consumo medio de una cajetilla de tabaco diaria.

Otra de las variables estudiadas fue la dosis de tabaco acumulada, donde se observa que el grupo control presenta 46 paquetes/año y el grupo intervención 48,3 paquetes/ año.

\section{Estado nutricional}

Al estudiar el estado nutricional, observamos que los valores más frecuentes fueron presentar obesidad, siendo respectivamente el 33,4\% y 48,1\% en el grupo intervención y en el grupo control.

$\mathrm{Si}$ atendiendo al consumo de líquidos, no excede en ninguno de los casos a los 2 litros diarios, siendo el grupo que mayor ingesta de líquidos tuvo el grupo intervención con una media de consumo de 1,3 litros diarios frente al valor medio del grupo control que fue de 1,2 litros.

Otro de los valores estudiados en cuanto a la valoración del estado nutricional fue, si seguían alguna dieta, donde en ambos grupos los mayores porcentajes que situaron en los pacientes que no seguían ninguna dieta, siendo en el grupo intervención el 63,6\% y en el grupo control el 55,5\%.

\section{$\underline{\text { Sedentarismo }}$}

Las preguntas relacionadas con la actividad física mostraron que el grupo intervención fue más activo que en el grupo control, puesto que en el grupo intervención el 54,4\% caminaba 30 minutos y en el grupo control solo el 44,5\%. Así pues los pacientes del grupo intervención manifestaron en menor medida que pasan todo el día en el sofá $45,5 \%$, frente al grupo control que su respuesta mayoritaria era estar en el sofá $(55,5 \%)$. Ver tabla 49. 


\section{Vacunación}

Los resultados sobre vacunación muestran que los pacientes tanto del grupo control como del grupo intervención presentan valores altos de vacunación, ya en el grupo intervención el año anterior se vacuno de la gripe el $75,9 \%$ y en el grupo control el $63 \%$. No podemos afirmar lo mismo de la vacuna del pneumoco ya que tan solo el $27,3 \%$ del grupo intervención se vacuno de la misma y en el grupo control el 11,1\%. (Tabla 49).

Tabla 49. Hábitos de vida al ingreso

\begin{tabular}{|c|c|c|c|c|c|}
\hline \multicolumn{6}{|l|}{ Tabaco } \\
\hline & \multicolumn{2}{|c|}{ Intervención } & \multicolumn{2}{|c|}{ Control } & \multirow[b]{2}{*}{ p-value } \\
\hline & n & $\%$ & $\mathbf{n}$ & $\%$ & \\
\hline Fumadores & 8 & 24,2 & 5 & 18,5 & \multirow{3}{*}{0,343} \\
\hline Exfumadores & 19 & 57,6 & 20 & 74,0 & \\
\hline No fumadores & 6 & 18,2 & 2 & 7,4 & \\
\hline TOTAL & 33 & 100 & 27 & 100 & \\
\hline \multicolumn{6}{|c|}{ Años de fumador } \\
\hline & \multicolumn{2}{|c|}{$\bar{X} \pm$ d.t } & \multicolumn{2}{|c|}{$\bar{X} \pm$ d.t } & p-value \\
\hline & \multicolumn{2}{|c|}{$34,3 \pm 19,2$} & \multicolumn{2}{|c|}{$39,8 \pm 19,7$} & 0,279 \\
\hline \multicolumn{6}{|c|}{ Cigarrillos al día } \\
\hline & \multicolumn{2}{|c|}{$22,8 \pm 19,4$} & \multicolumn{2}{|c|}{$21,8 \pm 16,3$} & 0,831 \\
\hline \multicolumn{6}{|c|}{ Dosis acumulada } \\
\hline & \multicolumn{2}{|c|}{$46,0 \pm 42,1$} & \multicolumn{2}{|c|}{$48,3 \pm 9,3$} & 0,614 \\
\hline \multicolumn{6}{|l|}{ Alcohol } \\
\hline & \multicolumn{2}{|c|}{$0,6 \pm 1$} & \multicolumn{2}{|c|}{$0,7 \pm 1,2$} & 0,818 \\
\hline \multicolumn{6}{|l|}{ IMC } \\
\hline & $\mathbf{n}$ & $\%$ & $\mathbf{n}$ & $\%$ & p-value \\
\hline Bajo & 3 & 9,1 & 1 & 3,7 & \multirow{4}{*}{0,705} \\
\hline Normal & 10 & 30,3 & 4 & 14,8 & \\
\hline Sobrepeso & 9 & 27,3 & 9 & 33,3 & \\
\hline Obesidad & 11 & 33,4 & 13 & 48,1 & \\
\hline TOTAL & 33 & 100 & 27 & 100 & \\
\hline \multicolumn{6}{|c|}{ Ingesta de líquidos } \\
\hline & \multicolumn{2}{|c|}{$\bar{X} \pm$ d.t } & \multicolumn{2}{|c|}{$\bar{X} \pm$ d.t } & $p$-value \\
\hline & \multicolumn{2}{|c|}{$1,3 \pm 0,6$} & \multicolumn{2}{|c|}{$1,2 \pm 0,6$} & 0,607 \\
\hline \multicolumn{6}{|l|}{ Dieta } \\
\hline & $\mathbf{n}$ & $\%$ & $\mathbf{n}$ & $\%$ & p-value \\
\hline $\mathrm{Si}$ & 12 & 36,4 & 10 & 30,3 & \multirow{2}{*}{0,957} \\
\hline No & 21 & 63,6 & 17 & 51,5 & \\
\hline TOTAL & 33 & 100 & 27 & 100 & \\
\hline \multicolumn{6}{|c|}{ Sedentarismo_caminar 30minutos } \\
\hline $\mathrm{Si}$ & 18 & 54,5 & 12 & 44,5 & 0426 \\
\hline No & 15 & 45,5 & 15 & 55,5 & 0,436 \\
\hline TOTAL & 33 & 100 & 27 & 100 & \\
\hline
\end{tabular}




\begin{tabular}{|c|c|c|c|c|c|}
\hline \multicolumn{6}{|c|}{ Sedentarismo_todo el día en el sofá } \\
\hline $\mathrm{Si}$ & 15 & 45,5 & 15 & 55,5 & \multirow[t]{2}{*}{0,436} \\
\hline No & 18 & 54,5 & 12 & 44,5 & \\
\hline TOTAL & 33 & 100 & 27 & 100 & \\
\hline \multicolumn{6}{|c|}{ Vacunación gripe } \\
\hline $\mathrm{Si}$ & 25 & 75,9 & 17 & 63,0 & \multirow[t]{2}{*}{0,282} \\
\hline No & 8 & 24,2 & 10 & 37,0 & \\
\hline TOTAL & 33 & 100 & 27 & 100 & \\
\hline \multicolumn{6}{|c|}{ Vacunación pneumococo } \\
\hline $\mathrm{Si}$ & 9 & 27,3 & 3 & 11,1 & \multirow{3}{*}{0,132} \\
\hline No & 19 & 57,7 & 15 & 55,5 & \\
\hline No se acuerdan & 5 & 15,0 & 9 & 33,4 & \\
\hline TOTAL & 33 & 100 & 27 & 100 & \\
\hline
\end{tabular}

IMC: índice de masa corporal, media $(\bar{X})$, desviación típica $($ d.t $)$

\section{$\underline{\text { Variables de función pulmonar }}$}

Si atendemos a los valores espirometrico de la muestra podemos observar que es el grupo intervención el que presentar un mayor grado de obstrucción pulmonar.

Los valores gasométricos, sitúan al Ph dentro de la normalidad, en ambos grupos y peores niveles de oxígeno en sangre en el grupo control.

En cuanto a la retención de carbónico en ambos dos grupos superan los niveles normales, siendo en el grupo control el que mayor nivel de carbónico retiene.

Por tanto es el grupo control el que presenta peores valores gasométricos frente al grupo intervención. No siendo significativas las diferencias entre ambos dos grupos.

Atendiendo a las signos y síntomas es destacable un mayor porcentaje de pacientes asignados al grupo intervención $(62,1 \%)$ que presentaron un grado de disnea de III frente al $34,6 \%$ del grupo control. Por el contrario hubo un mayor volumen de pacientes del grupo control que presentaron el máximo nivel de disnea $(34,6 \%)$ frente al 17,2\% del grupo intervención.

La presencia de tos $(54,5 \%)$ y edemas $(33,3 \%)$, fue más frecuente en el grupo intervención frente al grupo control que mostro mayores tasas de sibilancia $(51,9 \%)$, somnolencia diurna $(40,7 \%)$ y necesidad de dormir sentado (63\%).

Otro de los signos y síntomas también valorado fue el grado de dolor, donde se puede apreciar que son los pacientes del grupo control presentan un mayor nivel de dolor con una media del $1,7 \pm 2,2$ frente a los del grupo intervención con $0,8 \pm 1,9$ no existiendo diferencias significativas entre ambos dos grupos.

La media de comorbilidades en el grupo control fue de 2,7 $\pm 1,9$ y para el grupo intervención de 2,5 $\pm 2,0$. Si valoramos el Chalson modificado por edad, se aprecia que es el grupo intervención, el que presentaba un número de $87,9 \%$ de comorbilidades altas, 
frente al grupo control con una población del 92,6\% de comorbilidades altas. No existiendo diferencias significativas entre ambos grupos. Ver tabla 50.

\begin{tabular}{|c|c|c|c|c|c|c|c|c|c|}
\hline \multicolumn{10}{|c|}{\begin{tabular}{l|} 
Tabla 50. Función Pulmonar al ingreso \\
Espirometría
\end{tabular}} \\
\hline & & \multirow{2}{*}{\multicolumn{4}{|c|}{$\begin{array}{c}\text { Intervención } \\
\bar{X} \pm \text { d.t }\end{array}$}} & \multicolumn{3}{|c|}{ Control } & \\
\hline & & & & & & \multicolumn{3}{|c|}{$\bar{X} \pm$ d.t } & p-value \\
\hline FEV1 (\%) & & \multicolumn{4}{|c|}{$40,6 \pm 13,8$} & \multicolumn{3}{|c|}{$49,4 \pm 28,8$} & 0,319 \\
\hline $\operatorname{FVC~}(\%)$ & & \multicolumn{4}{|c|}{$54,4 \pm 14,0$} & \multicolumn{3}{|c|}{$63,6 \pm 21,0$} & 0,191 \\
\hline \multicolumn{2}{|l|}{ FEV1/FVC (\%) } & \multicolumn{4}{|c|}{$68,6 \pm 19,0$} & \multicolumn{3}{|c|}{$71,0 \pm 30,7$} & 0,807 \\
\hline \multicolumn{10}{|l|}{ Gasometría } \\
\hline $\mathrm{Ph}$ & & \multicolumn{4}{|c|}{$7,4 \pm 0,1$} & \multicolumn{3}{|c|}{$7,4 \pm 0,1$} & 0,674 \\
\hline $\mathrm{O}_{2}$ & & \multicolumn{4}{|c|}{$71,1 \pm 23,4$} & \multicolumn{3}{|c|}{$68,9 \pm 24,5$} & 0,765 \\
\hline $\mathrm{CO}_{2}$ & & \multicolumn{4}{|c|}{$45,3 \pm 11,9$} & \multicolumn{3}{|c|}{$46,3 \pm 10,6$} & 0,768 \\
\hline \multicolumn{10}{|l|}{ MRC } \\
\hline & & \multicolumn{3}{|c|}{ Intervención } & & \multicolumn{3}{|c|}{ Control } & \\
\hline & & \multicolumn{3}{|r|}{$\%$} & & \multicolumn{2}{|c|}{ n } & $\%$ & p-value \\
\hline 0 & & \multicolumn{2}{|c|}{0} & \multicolumn{2}{|l|}{0,0} & \multicolumn{2}{|l|}{3} & 11,5 & \\
\hline $\mathrm{I}$ & & 2 & & 6,9 & & 2 & & 7,7 & \\
\hline II & & 4 & & 13,8 & & 3 & & 11,5 & 0,129 \\
\hline III & & 1 & & 62,1 & & 9 & & 34,6 & \\
\hline IV & & 5 & & 17,2 & & 9 & & 34,6 & \\
\hline TOTAL & & 2 & & 100 & & 26 & & 100 & \\
\hline Signos y síntomas & & & & & & & & & \\
\hline & & & erven & & & & ntrol & & \\
\hline & & $\mathbf{S i}$ & & No & & Si & & No & \\
\hline & $\mathbf{n}$ & $\%$ & $\mathbf{n}$ & $\%$ & $\mathbf{n}$ & $\%$ & $\mathbf{n}$ & $\%$ & p-value \\
\hline Tos & 18 & 54,5 & 14 & 42,4 & 11 & 40,7 & 16 & 59,3 & 0,235 \\
\hline Expectoración & 21 & 63,6 & 11 & 12,8 & 17 & 63,0 & 10 & 37,0 & 0,832 \\
\hline Sibilancias & 12 & 36,4 & 21 & 63,6 & 14 & 51,9 & 13 & 48,1 & 0,228 \\
\hline Somnolencia diurna & 9 & 27,3 & 24 & 72,7 & 11 & 40,7 & 16 & 59,3 & 0,271 \\
\hline Dormir sentado & 18 & 54,5 & 15 & 45,5 & 17 & 63,0 & 10 & 37,0 & 0,511 \\
\hline Edemas & 11 & 33,3 & 22 & 66,7 & 8 & 29,6 & 19 & 70,4 & 0,759 \\
\hline Fiebre & 1 & 3,0 & 32 & 97,0 & 1 & 3,7 & 26 & 96,3 & 0,885 \\
\hline Dolor & & & & & & & & & \\
\hline & & & erven & & & & ntrol & & \\
\hline & & & $\bar{X} \pm d$ & & & & \pm d.t & & $p$-value \\
\hline & & & $0,8 \pm 1$ & & & & $\pm 2,2$ & & 0,077 \\
\hline
\end{tabular}




\begin{tabular}{|c|c|c|c|c|c|}
\hline \multicolumn{6}{|l|}{ Comorbilidades } \\
\hline $\mathrm{N}^{\mathrm{o}}$ Comorbilidades & \multicolumn{2}{|c|}{$2,5 \pm 2,0$} & \multicolumn{2}{|c|}{$2,7 \pm 1,9$} & 0,641 \\
\hline \multirow[t]{3}{*}{ Chalson } & \multirow{2}{*}{\multicolumn{2}{|c|}{ Intervención }} & \multirow{2}{*}{\multicolumn{2}{|c|}{ Control }} & \\
\hline & & & & & \\
\hline & $\mathbf{n}$ & $\%$ & $\mathbf{n}$ & $\%$ & p-value \\
\hline $\begin{array}{l}\text { Ausencia de } \\
\text { comorbilidad }\end{array}$ & 2 & 6,3 & 1 & 3,7 & \\
\hline Baja comorbilidad & 1 & 3,1 & 1 & 3,7 & 0,902 \\
\hline Alta comorbilidad & 29 & 90,6 & 25 & 92,6 & \\
\hline TOTAL & 32 & 100 & 27 & 100 & \\
\hline
\end{tabular}

\section{Variables de seguimiento médico}

Como se puede apreciar en la tabla 51, el número de inhalaciones diarias en el grupo

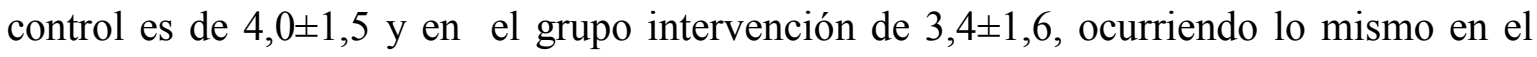
grupo control con el consumo de pastillas diarias. No siendo significativa la diferencia entre ambos.

Si observamos en uso de los dispositivos de inhalación, es muy homogéneo y en ambos grupos siguen la misma disposición, donde el broncodilatador de corta duración, es el fármaco más utilizado en los dispositivos de cartucho presurizado y cámara de inhalación, el broncodilatador de larga duración es el dispositivo más utilizado en el dispositivo accuhaler, la combinación de varios fármacos broncodilatador más corticoide inhalado se utiliza más con el dispositivo inhaleras y turbuhaler.

Solo existiendo una ligera diferencia, aunque no significativa en el uso del nebulizador donde el fármaco más utilizado en el grupo intervención es el corticoide inhalado y en el grupo control el broncodilatador más corticoide. No existiendo diferencias significativas entre ninguno de los grupos, según el uso de los dispositivos y los fármacos.

$\mathrm{Si}$ atendemos al lugar donde les realizan los controles de su enfermedad también sigue una distribución homogénea entre grupos siendo Atención Primaria y hospitalaria las opciones más indicadas por los pacientes. Si atendemos al seguimiento médico el 48,5\% de los pacientes del grupo intervención recibe el seguimiento cada 3-6 meses frente al grupo control con un porcentaje del $70,4 \%$.

Siendo el grupo intervención el que tiene un $18,2 \%$ de su población que no recibe seguimiento médico frente al $14,8 \%$ del grupo control que tampoco recibe seguimiento.

Cuando se encuentran mal son más los pacientes del grupo control los que acuden primero al servicio de urgencias, que los del grupo intervención que afirman acudir primero a su centro de Atención Primaria. 


\begin{tabular}{|c|c|c|c|c|c|}
\hline \multicolumn{6}{|l|}{$\mathrm{N}^{\mathrm{o}}$ de fármacos/día } \\
\hline & \multicolumn{2}{|c|}{ Intervención } & \multicolumn{2}{|c|}{ Control } & \\
\hline & \multicolumn{2}{|c|}{$\bar{X} \pm$ d.t } & \multicolumn{2}{|c|}{$\bar{X} \pm$ d.t } & p-value \\
\hline $\mathrm{N}^{\circ}$ de patillas/día & \multicolumn{2}{|c|}{$5,0 \pm 3,4$} & \multicolumn{2}{|c|}{$6,4 \pm 3,4$} & 0,121 \\
\hline $\mathrm{N}^{0}$ de inyecciones/día & \multicolumn{2}{|c|}{$0,0 \pm 0,2$} & \multicolumn{2}{|c|}{$0,3 \pm 0,8$} & 0,107 \\
\hline $\mathrm{N}^{\mathrm{o}}$ de inhalaciones/día & \multicolumn{2}{|c|}{$3,4 \pm 1,6$} & \multicolumn{2}{|c|}{$4,0 \pm 1,5$} & 0,122 \\
\hline \multicolumn{6}{|l|}{ Cartucho presurizado } \\
\hline & \multicolumn{2}{|c|}{ Intervención } & \multicolumn{2}{|c|}{ Control } & \\
\hline & $\mathbf{n}$ & $\%$ & $\mathbf{n}$ & $\%$ & p-value \\
\hline $\begin{array}{l}\text { Broncodilatador de corta } \\
\text { duración }\end{array}$ & 15 & 93,8 & 13 & 100 & 1 \\
\hline $\begin{array}{l}\text { Broncodilatador de larga } \\
\text { duración }\end{array}$ & 1 & 6,2 & 0 & 0,0 & \\
\hline TOTAL & 16 & 100 & 13 & 100 & \\
\hline \multicolumn{6}{|l|}{ Cámara } \\
\hline $\begin{array}{l}\text { Broncodilatador de corta } \\
\text { duración }\end{array}$ & 7 & 100 & 6 & 85,7 & 1 \\
\hline $\begin{array}{l}\text { Broncodilatador de larga } \\
\text { duración }\end{array}$ & 0 & 0,0 & 1 & 14,3 & \\
\hline TOTAL & 7 & 100 & 7 & 100 & \\
\hline \multicolumn{6}{|l|}{ Turbuhaler } \\
\hline $\begin{array}{l}\text { Broncodilatador de larga } \\
\text { duración }\end{array}$ & 2 & 28,6 & 0 & 0,0 & \\
\hline Corticoide inhalado & 2 & 28,6 & 0 & 0,0 & 0,198 \\
\hline $\begin{array}{l}\text { Broncodilatador }+ \\
\text { corticoide }\end{array}$ & 3 & 42,9 & 2 & 100 & \\
\hline TOTAL & 7 & 100 & 2 & 100 & \\
\hline \multicolumn{6}{|l|}{ Accuhaler } \\
\hline $\begin{array}{l}\text { Broncodilatador de corta } \\
\text { duración }\end{array}$ & 0 & 0,0 & 1 & 9,1 & \multirow{4}{*}{0,425} \\
\hline $\begin{array}{l}\text { Broncodilatador de larga } \\
\text { duración }\end{array}$ & 9 & 69,2 & 8 & 72,7 & \\
\hline Corticoide inhalado & 2 & 15,4 & 2 & 18,2 & \\
\hline $\begin{array}{l}\text { Broncodilatador }+ \\
\text { corticoide }\end{array}$ & 2 & 15,4 & 0 & 0,0 & \\
\hline TOTAL & 13 & 100 & 11 & 100 & \\
\hline \multicolumn{6}{|l|}{ Inhaletas } \\
\hline $\begin{array}{l}\text { Broncodilatador de larga } \\
\text { duración }\end{array}$ & 4 & 33,3 & 3 & 27,3 & \multirow{2}{*}{0,865} \\
\hline $\begin{array}{l}\text { Broncodilatador }+ \\
\text { corticoide }\end{array}$ & 8 & 66,7 & 8 & 72,7 & \\
\hline TOTAL & 12 & 100 & 11 & 100 & \\
\hline \multicolumn{6}{|l|}{ Nebulizador } \\
\hline $\begin{array}{l}\text { Broncodilatador de corta } \\
\text { duración }\end{array}$ & 2 & 22,2 & 1 & 12,5 & \\
\hline $\begin{array}{l}\text { Broncodilatador de larga } \\
\text { duración }\end{array}$ & 1 & 11,1 & 0 & 0,0 & 0,356 \\
\hline
\end{tabular}


Corticoide inhalado

4

44,4

2

25,0

Tabla 51. Seguimiento médico al ingreso (Continuación)

\begin{tabular}{|c|c|c|c|c|c|c|c|c|c|}
\hline \multirow{2}{*}{$\begin{array}{l}\text { Broncodilatador }+ \\
\text { corticoide } \\
\text { TOTAL }\end{array}$} & \multicolumn{2}{|r|}{2} & \multicolumn{2}{|c|}{22,2} & \multicolumn{2}{|l|}{5} & \multicolumn{2}{|c|}{62,5} & \\
\hline & \multicolumn{2}{|c|}{9} & \multicolumn{2}{|c|}{100} & \multicolumn{2}{|l|}{8} & \multicolumn{2}{|c|}{100} & \\
\hline \multicolumn{10}{|c|}{ Lugar donde se visita normalmente } \\
\hline Atención Primaria & \multicolumn{2}{|r|}{18} & \multicolumn{2}{|c|}{54,5} & \multicolumn{2}{|c|}{12} & \multicolumn{2}{|c|}{44,4} & \multirow{4}{*}{0,268} \\
\hline Hospital & \multicolumn{2}{|r|}{8} & \multicolumn{2}{|c|}{24,2} & \multicolumn{2}{|c|}{12} & \multicolumn{2}{|c|}{44,4} & \\
\hline Ninguno & \multicolumn{2}{|r|}{2} & \multicolumn{2}{|c|}{6,1} & \multicolumn{2}{|c|}{0} & \multicolumn{2}{|c|}{0,0} & \\
\hline No lo se & \multicolumn{2}{|r|}{5} & \multicolumn{2}{|c|}{15,2} & \multicolumn{2}{|c|}{3} & \multicolumn{2}{|c|}{11,1} & \\
\hline TOTAL & \multicolumn{2}{|r|}{33} & \multicolumn{2}{|c|}{100} & \multicolumn{2}{|c|}{27} & & & \\
\hline Periodo de seguimiento 1 & édic & & & & & & & & \\
\hline Una vez cada 3-6 meses & & 16 & & & & 9 & & & \\
\hline Una vez al año & & 6 & & & & 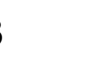 & & & \\
\hline No me acuerdo & & 5 & & & & & & & 0,288 \\
\hline No tengo seguimiento & & 6 & & & & + & & & \\
\hline TOTAL & & 33 & & & & 7 & & & \\
\hline Donde acude cuando se & cue & tra mal & & & & & & & \\
\hline Atención Primaria & & 17 & & & & 3 & & & 0,342 \\
\hline Hospital + Urgencias & & 16 & & & & 4 & & & \\
\hline TOTAL & & 33 & & & & 7 & & & \\
\hline Educación anterior & & & & & & & & & \\
\hline $\mathrm{Si}$ & & 2 & & & & + & & & 0,366 \\
\hline No & & 30 & & & & 3 & & & \\
\hline TOTAL & & 32 & & & & 7 & & & \\
\hline Complicación del tratan & ento & & & & & & & & \\
\hline & & & rvenc & & & & ntro & & \\
\hline & & Si & & $\mathbf{N}$ & & SI & & & \\
\hline & $\mathbf{n}$ & $\%$ & $\mathbf{n}$ & $\%$ & $\mathbf{n}$ & $\%$ & $\mathbf{n}$ & $\%$ & p-value \\
\hline Oxígeno & 14 & 42,4 & 19 & 57,6 & 14 & 51,9 & 13 & 48,1 & 0,320 \\
\hline CPAP & 3 & 9,1 & 30 & 90,9 & 4 & 14,8 & 23 & 85,2 & 0,386 \\
\hline $\begin{array}{l}\text { Ventilación Mecánica no } \\
\text { invasiva }\end{array}$ & 1 & 3,0 & 32 & 97,0 & 0 & 0,0 & 27 & 100 & 0,550 \\
\hline
\end{tabular}




\section{Variables psicológicas}

Las variables psicológicas de ansiedad y depresión en ambos dos grupos el valor con mayor incidencia es no presentar ansiedad y depresión, siendo en el grupo intervención el probable caso de depresión del 25\% frente al grupo control de $19,3 \%$. De distinto modo el probable caso de depresión está presente en el grupo control en el 19,2\% de los casos y en el grupo intervención en el 6,3\%. No siendo significativas las diferencias entre los grupos como se puede apreciar en la tabla 52.

\begin{tabular}{|c|c|c|c|c|c|}
\hline & \multicolumn{2}{|c|}{$\begin{array}{c}\text { Intervención } \\
\bar{X} \pm \text { d.t }\end{array}$} & \multicolumn{2}{|c|}{$\begin{array}{l}\text { Control } \\
\bar{X} \pm \text { d.t }\end{array}$} & p-value \\
\hline Ansiedad & \multicolumn{2}{|c|}{$8 \pm 3,6$} & \multicolumn{2}{|c|}{$7,3 \pm 4,2$} & 0,510 \\
\hline Depresión & \multicolumn{2}{|c|}{$6 \pm 3,1$} & \multicolumn{2}{|c|}{$6,81 \pm 4$} & 0,174 \\
\hline \multicolumn{6}{|l|}{ Ansiedad } \\
\hline & \multicolumn{2}{|c|}{ Intervención } & \multicolumn{2}{|c|}{ Control } & \multirow[b]{2}{*}{ p-value } \\
\hline & n & $\%$ & n & $\%$ & \\
\hline No caso & 16 & 50,0 & 15 & 57,7 & \\
\hline Caso dudoso & 8 & 25,0 & 6 & 23,0 & 0,821 \\
\hline Probable caso & 8 & 25,0 & 5 & 19,3 & \\
\hline TOTAL & 32 & 100 & 26 & 100 & \\
\hline \multicolumn{6}{|l|}{ Depresión } \\
\hline No caso & 21 & 65,6 & 16 & 61,5 & \multirow{3}{*}{0,285} \\
\hline Caso dudoso & 9 & 28,1 & 5 & 19,2 & \\
\hline Probable caso & 2 & 6,3 & 5 & 19,2 & \\
\hline TOTAL & 32 & 100 & 26 & 100 & \\
\hline
\end{tabular}

Los datos indican media $(\bar{X})$, desviación típica (d.t)

Variables de dependencia

Como se puede apreciar en la tabla 53, en el grupo intervención el valor más frecuente fue presentar una dependencia moderada con un $42,4 \%$ de la población, siendo el valor más frecuente en el grupo control ser independiente para la realización de las actividades diarias con el 33,3\% de la población. No siendo las diferencias significativas entre cada uno de los grupos de asignación.

\begin{tabular}{lccccc}
\hline \multicolumn{5}{c}{ Tabla 53. Dependencia en las actividades de la vida diarias al ingreso } \\
\hline \multicolumn{5}{c}{ Intervención } & \multicolumn{3}{c}{ Control } & \\
Independencia & $\mathbf{n}$ & $\mathbf{\%}$ & $\mathbf{n}$ & $\mathbf{\%}$ & p-value \\
Escasa & 10 & 30,3 & 9 & 33,3 & \\
Moderada & 3 & 9,1 & 2 & 7,4 & \\
Severa & 14 & 42,4 & 8 & 29,6 & 0,664 \\
Completa & 6 & 18,2 & 7 & 25,9 & \\
TOTAL & 0 & 0,0 & 1 & 3,7 & \\
\hline
\end{tabular}




\subsubsection{Determinar y evaluar la efectividad de un programa estructurado de educación terapéutica (ET), a los 3 meses, en comparación con la atención tradicional}

En relación a:

- Uso de servicios hospitalarios

- Calidad de vida

- Conocimiento de la enfermedad

- Adherencia al tratamiento

\subsubsection{Uso de servicios hospitalarios}

Si atendemos a la media de veces que acudieron al servicio de urgencias durante el periodo del ingreso a los 3 meses, podemos observar que es el grupo control es el que tuvo una media de ingresos hospitalarios menor, $0,3 \pm 0,7$ frente al grupo intervención con una media de $0,5 \pm 0,8$.

Datos distintos al número de visitas a urgencias donde el grupo control el que tuvo un uso de ellas del 2,2 $\pm 1,9$ frente al grupo intervención de 1,6 $\pm 2,0$, no siendo significativas las diferencias entre ambos dos grupos.

Cabe destacar que fue el grupo intervención el que recibió $0,7 \pm 1,9$ visitas a consultas externas con respecto a las $0,5 \pm 1,0$ del grupo control, siendo significativas la diferencias. Siendo las diferencias próximas a la significación en los aspectos de ingresos y visitas a urgencias por causas no respiratorias.

Si atendemos al uso individual de cada paciente es el grupo intervención el que más ingresos tuvo, siendo el $40 \%$ de la muestra y el que más visitas a urgencias realizó siendo el $36,4 \%$. Sin embargo fue el que menos visitas a consultas externas tuvo. Datos disponibles en la tabla 54 . 
Tabla 54. Uso de los servicios hospitalarios a los 3 meses

\begin{tabular}{|c|c|c|c|c|c|c|}
\hline & & & $\begin{array}{l}\text { rención } \\
\bar{X} \pm \text { d.t }\end{array}$ & & $\begin{array}{l}\text { ntrol } \\
\pm \text { d.t }\end{array}$ & p-value \\
\hline Ingresos hospitalar & & & & & & \\
\hline & Causa respiratoria & & $5 \pm 0,8$ & & $\pm 0,7$ & 0,286 \\
\hline & Causa no respiratoria & & $1 \pm 0,3$ & & $\pm 0,2$ & 0,068 \\
\hline Ingresos UCI & & & & & & \\
\hline & Causa respiratoria & & $1 \pm 0,3$ & & $\pm 0,3$ & - \\
\hline & Causa no respiratoria & & $0 \pm 0,2$ & & $\pm 0,0$ & - \\
\hline Visitas a Urgencias & & & & & & \\
\hline & Causa respiratoria & & $6 \pm 2,0$ & & $\pm 1,9$ & 0,216 \\
\hline & Causa no respiratoria & & $4 \pm 1,1$ & & $\pm 0,5$ & 0,063 \\
\hline Visitas a Consultas & & & & & & \\
\hline & & & $, 7 \pm 1,9$ & & $\pm 1,0$ & 0,023 \\
\hline & & Inte & ención & & trol & p-value \\
\hline & & & $\%$ & & & \\
\hline Ingresos hospitalar & & & & & & \\
\hline & Causa respiratoria & 13 & 40,0 & 4 & 14,8 & 0,061 \\
\hline & Causa no respiratoria & 1 & 3,0 & 0 & 0,0 & 0,655 \\
\hline TOTAL & & & & & & \\
\hline Ingresos UCI & & & & & & \\
\hline & Causa respiratoria & 0 & 0,0 & 0 & 0,0 & \\
\hline & Causa no respiratoria & 0 & 0,0 & 0 & & \\
\hline TOTAL & & & & & & \\
\hline Visitas Urgencias & & & & & & \\
\hline & Causa respiratoria & 12 & 36,4 & 8 & 29,6 & 0,538 \\
\hline & Causa no respiratoria & 1 & 3,0 & 0 & 0,0 & 0,429 \\
\hline TOTAL & & & & & & \\
\hline Visitas Consultas & & & & & & \\
\hline & & 4 & 12,1 & 5 & 18,5 & 0,537 \\
\hline
\end{tabular}

Los datos indican media $(\bar{X})$, desviación típica (d.t): UCI: Unidad de Cuidados Intensivos

\subsubsection{Calidad de vida}

\section{Calidad de vida CAT a los 3 meses}

Si atendemos a la calidad de vida, son los pacientes del grupo control los que presentan un nivel más alto de afectación de la misma, con un p-value próximo a la significación $(0,063)$. Y ubicando a los pacientes del grupo control en niveles de mayor afectación, con un impacto alto del $33,3 \%$ y muy alto del $14,8 \%$. Siendo en el grupo intervención de $21,2 \%$ y $9,1 \%$ respectivamente, ver tabla 55 . 


\begin{tabular}{|c|c|c|c|c|c|}
\hline \multicolumn{6}{|c|}{ Tabla 55. Calidad de vida CAT 3 meses } \\
\hline & \multicolumn{2}{|c|}{$\begin{array}{c}\text { Intervención } \\
\bar{X} \pm \text { d.t }\end{array}$} & \multicolumn{2}{|c|}{$\begin{array}{l}\text { Control } \\
\bar{X} \pm \text { d.t }\end{array}$} & p-value \\
\hline & \multicolumn{2}{|c|}{$16 \pm 9,2$} & \multicolumn{2}{|c|}{$20,6 \pm 9,2$} & 0,063 \\
\hline & \multicolumn{2}{|c|}{ Intervención } & \multicolumn{2}{|c|}{ Control } & \\
\hline & n & $\%$ & $\mathbf{n}$ & $\%$ & p-value \\
\hline Bajo impacto & 11 & 33,3 & 3 & 11,1 & \\
\hline Impacto medio & 12 & 36,4 & 11 & 40,7 & \\
\hline Impacto alto & 7 & 21,2 & 9 & 33,3 & 0,217 \\
\hline Impacto muy alto & 3 & 9,1 & 4 & 14,8 & \\
\hline TOTAL & 33 & 100 & 27 & 100 & \\
\hline
\end{tabular}

Los datos indican media $(\bar{X})$, desviación típica (d.t)

Calidad de vida St. George a los 3 meses

La calidad de vida evaluada con el cuestionario St. George nos indica que en ambos grupos a los 3 meses presentan niveles normales en la afectación de sus síntomas, la actividad y el impacto de la enfermedad en la realización de las actividades diarias. Siendo los pacientes del grupo intervención lo que presentan valores más frecuentes en los grupos más bajos de impacto con respecto al grupo control. Cabe destacar la mejoría significativa $(0,043)$ del grupo intervención en la realización de actividades con respecto al grupo control. Siendo el resultado final una mejoría global de la calidad a los 3 meses, obteniendo una significación estadísticamente significativa del 0,049. Ver tabla 56.

\begin{tabular}{llcc|ccc}
\hline Tabla 56. Calidad de vida St. George 3 meses & & & \\
\hline & & Intervención & \multicolumn{2}{c}{ Control } & p-value \\
& & $\mathbf{n}$ & $\mathbf{\%}$ & $\mathbf{n}$ & $\mathbf{\%}$ & \\
\hline Síntomas & Bajo & 5 & 15,2 & 3 & 11,1 & \\
& Normal & 28 & 84,8 & 24 & 88,9 & 0,719 \\
& Alto & 0 & 0,0 & 0 & 0,0 & \\
Actividad & Bajo & 11 & 33,3 & 3 & 11,1 & \\
& Normal & 22 & 66,7 & 24 & 88,9 & $\mathbf{0 , 0 4 3}$ \\
& Alto & 0 & 0,0 & 0 & 0,0 & \\
Impacto & Bajo & 4 & 12,1 & 1 & 3,7 & \\
& Normal & 29 & 87,9 & 26 & 96,3 & 0,367 \\
Alto & 0 & 0,0 & 0 & 0,0 & \\
Calidad global & Bajo & 10 & 30,3 & 2 & 7,4 & \\
& Normal & 23 & 69,7 & 25 & 92,6 & $\mathbf{0 , 0 4 9}$ \\
\hline TOTAL & Alto & 0 & 0,0 & 0 & 0,0 & \\
\hline
\end{tabular}




\subsubsection{Conocimiento de la enfermedad}

Conocimiento de la enfermedad a los 3 meses

En las tres preguntas evaluadas es el grupo intervención el que presentan mejores resultado en las preguntas correctas. No siendo significativas las respuestas entre ambos dos grupos como se puede apreciar en la tabla 57.

\begin{tabular}{ccccccc}
\hline Tabla 57. Conocimiento de la enfermedad a los 3 meses & & & \\
\hline & Intervención & \multicolumn{2}{c}{ Control } & p-value \\
& $\mathbf{n}$ & $\mathbf{\%}$ & $\mathbf{n}$ & $\mathbf{\%}$ & \\
\hline Nombre de la enfermedad & & & & & \\
$\quad$ Respuesta correcta & 27 & 81,8 & 18 & 66,7 & 0,235 \\
Respuesta incorrecta & 6 & 18,2 & 9 & 33,3 & \\
Síntomas de alarma & & & & & \\
$\quad$ Respuesta correcta & 31 & 93,9 & 25 & 92,6 & 0,614 \\
$\quad$ Respuesta incorrecta & 2 & 6,1 & 2 & 7,4 & \\
Medicación de rescate & & & & & \\
$\quad$ Respuesta correcta & 30 & 90,9 & 20 & 74,1 & 0,097 \\
$\quad$ Respuesta incorrecta & 3 & 9,1 & 7 & 25,9 & \\
\hline TOTAL & 33 & 100 & 27 & 100 & \\
\hline
\end{tabular}

\section{Uso del dispositivo de inhalación a los 3 meses}

Todos los dispositivos de inhalación son mejor utilizados por los pacientes del grupo intervención que del grupo control a excepción del dispositivo de inhaletas. No siendo significativas las diferencias a excepción del uso del cartucho presurizado, siendo destacable esta diferencia. Ver tabla 58. 


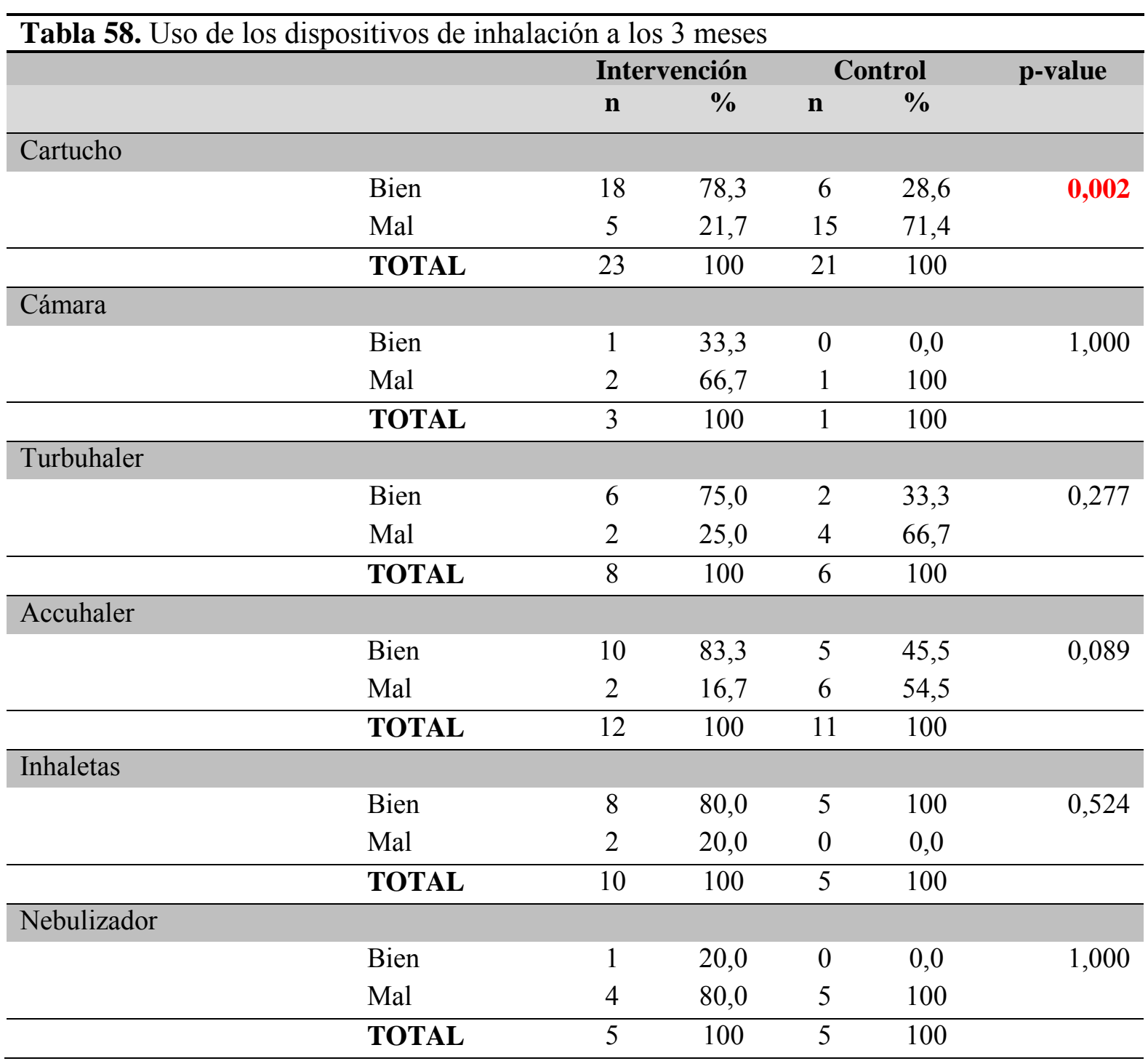

\subsubsection{Adherencia al tratamiento}

Con respecto a la adherencia al tratamiento ambos grupos tuvieron unos valores del $51,5 \%$ en el grupo intervención y en el grupo control del 55,6\%. No existiendo diferencias significativas entre ambos grupos. Ver tabla 59.

Tabla 59. Adherencia al tratamiento a los 3 meses

\begin{tabular}{cccc|c}
\hline \multirow{3}{*}{ Intervención } & & $\mathbf{n}$ & $\boldsymbol{\%}$ & p-value \\
& $\mathrm{Si}$ & 17 & 51,8 & \\
& $\mathrm{No}$ & 16 & 48,5 & \\
\cline { 2 - 3 } & TOTAL & 33 & 100 & \\
\cline { 2 - 3 } Control & $\mathrm{Si}$ & 15 & 55,6 & \multirow{2}{*}{0,799} \\
& $\mathrm{No}$ & 12 & 44,4 & \\
& TOTAL & 27 & 100 & \\
\cline { 2 - 3 } & & & & \\
\hline
\end{tabular}


4.3.5 Resultados evaluación de la efectividad del tipo de atención en el grupo de pacientes asignados al grupo intervención

\subsubsection{Uso de servicios grupo intervención}

Si observamos los datos de la tabla 60 podemos apreciar que el grupo intervención presenta una media superior de ingresos por causa respiratoria, mayor número de ingresos en UCI, más visitas a urgencias y más visitas a consultas externas. Siendo significativa la diferencia entre el número de visitas a consultas externas, 0,002, al inicio del estudio y al finalizar el estudio siendo menos en el final que al inicio. Aunque cabe destacar que dichos datos se deben analizar con cautela puesto que el número de ingresos al inicio del estudio corresponde a los últimos 12 meses previos, frente a la evaluación final que solo se evaluaron los 3 meses posteriores al ingreso índice.

Tabla 60. Uso de servicios hospitalarios grupo intervención

\begin{tabular}{|c|c|c|c|c|c|c|}
\hline & & & $\begin{array}{l}\text { Ingreso } \\
\bar{X} \pm \text { d.t }\end{array}$ & & $\begin{array}{l}\text { nal } \\
=\text { d.t }\end{array}$ & p-value \\
\hline Ingresos hospitalarios & & & & & & \\
\hline & Causa respiratoria & & $, 9 \pm 1,3$ & & $\pm 0,8$ & 0,996 \\
\hline & Causa no respiratoria & & $1 \pm 0,3$ & & $\pm 0,4$ & 0,798 \\
\hline Ingresos UCI & & & & & & \\
\hline & Causa respiratoria & & $, 1 \pm 0,3$ & & $\pm 0,0$ & \\
\hline & Causa no respiratoria & & $0 \pm 0,2$ & & $\pm 0,0$ & \\
\hline Visitas a Urgencias & & & & & & \\
\hline & Causa respiratoria & & $6 \pm 2,0$ & & $\pm 1,0$ & 0,303 \\
\hline & Causa no respiratoria & & $4 \pm 1,1$ & & $\pm 0,2$ & 0,716 \\
\hline Visitas a Consultas & & & & & & \\
\hline & & & $, 7 \pm 1,9$ & & $\pm 0,3$ & 0,002 \\
\hline & & & reso & & & p-value \\
\hline & & & & $\mathbf{n}$ & & \\
\hline Ingresos hospitalarios & & & & & & \\
\hline & Causa respiratoria & 20 & 64,5 & 13 & 40,6 & 1,000 \\
\hline & Causa no respiratoria & 2 & 6,5 & 1 & 3,1 & 1,000 \\
\hline Ingresos UCI & & & & & & \\
\hline & Causa respiratoria & 2 & 6,5 & 1 & 3,0 & - \\
\hline & Causa no respiratoria & 1 & 3,2 & 0 & 0,0 & - \\
\hline Visitas Urgencias & & & & & & \\
\hline & Causa respiratoria & 21 & 67,7 & 12 & 37,5 & 1,000 \\
\hline & Causa no respiratoria & 4 & 12,9 & 1 & 3,1 & 1,000 \\
\hline Visitas Consultas & & & & & & \\
\hline & & 5 & 16,1 & 4 & 12,5 & 1,000 \\
\hline
\end{tabular}

Los datos indican media $(\bar{X})$, desviación típica (d.t): UCI: Unidad de Cuidados Intensivos 


\subsubsection{Calidad de vida grupo intervención}

\section{Calidad de vida CAT grupo intervención}

Si observamos los datos de la calidad de vida, existe un menor volumen de pacientes que presentó un impacto alto de su calidad de vida siendo el $21,2 \%$ a los 3 meses y en el ingreso de $45,2 \%$ de la población.

Siendo destacable también la mejoría, ya que a los 3 meses el 33,3\% de la población tiene un impacto bajo, frente al escaso porcentaje de pacientes que durante el ingreso presentaron un impacto bajo, siendo solo el 6,4\%. Siendo significativa la diferencia de la media en el cómputo global de la escala . Ver tabla 61.

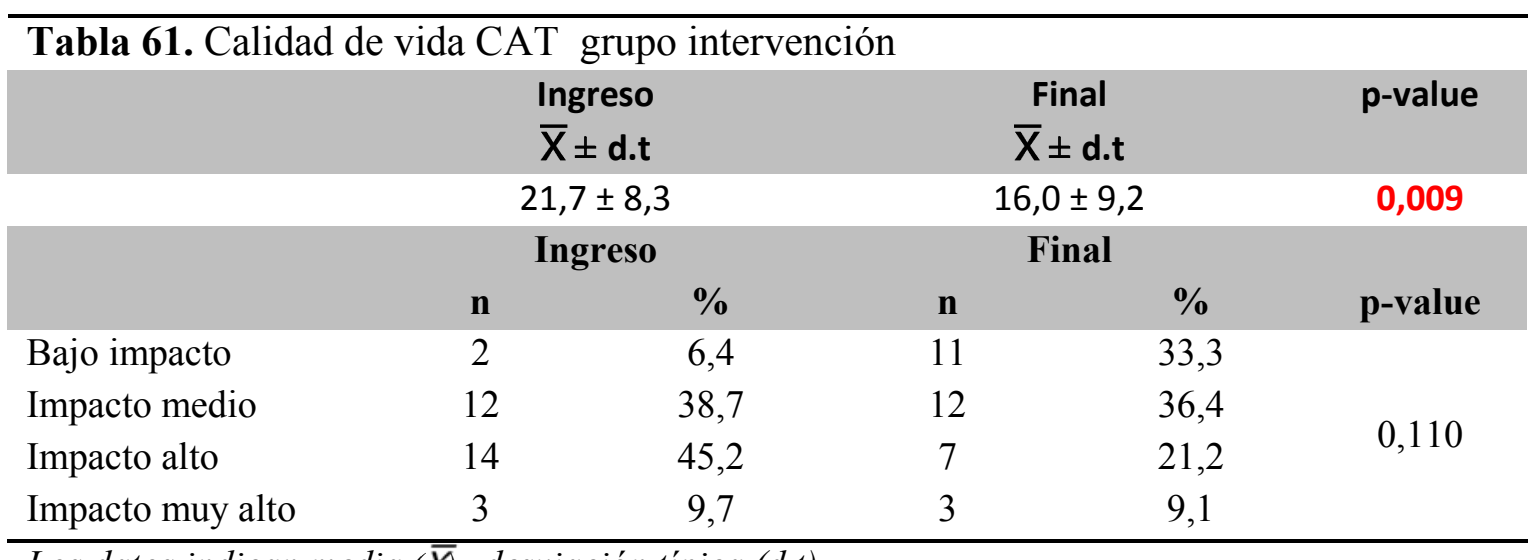

Los datos indican media $(\bar{X})$, desviación típica $(d . t)$

\section{Calidad de vida St. George grupo intervención}

Si observamos la calidad de vida mediante el cuestionario St. George, podemos observar que aspectos como los síntomas y el impacto, presentan mejoría pero no de forma significativa, ya que un mayor volumen de ellos tiene una afectación baja o normal de sus síntomas respiratorios. Si observamos la actividad mejora de forma significativa, dado que al ingreso el 78,8\% de la población tenían un nivel de afectación de su actividad alto, frente al $0,0 \%$ que presentan los pacientes a los 3 meses.

Por tanto la calidad de vida de los pacientes del grupo intervención una vez aplicado y evaluado el programa educativo mejoro de forma considerable en la realización de actividades $(0,003)$ y la calidad de vida global $(0,024)$. Ver tabla 62. 


\begin{tabular}{|c|c|c|c|c|c|c|}
\hline & & \multicolumn{2}{|c|}{ Ingreso } & \multicolumn{2}{|c|}{ Final } & \multirow[t]{2}{*}{$p$-value } \\
\hline & & $\mathbf{n}$ & $\%$ & $\mathbf{n}$ & $\%$ & \\
\hline \multicolumn{7}{|c|}{ Síntomas } \\
\hline & Bajo & 0 & 0,0 & 5 & 15,6 & \\
\hline & Normal & 3 & 9,4 & 28 & 84,4 & 0,410 \\
\hline & Alto & 29 & 90,6 & 0 & 0,0 & \\
\hline \multicolumn{7}{|c|}{ Actividad } \\
\hline & Bajo & 0 & 0,0 & 11 & 33,3 & \\
\hline & Normal & 7 & 21,2 & 22 & 66,7 & 0,003 \\
\hline & Alto & 25 & 78,8 & 0 & 0,0 & \\
\hline \multicolumn{7}{|c|}{ Impacto } \\
\hline & Bajo & 0 & 0,0 & 4 & 12,2 & \\
\hline & Normal & 3 & 9,4 & 29 & 87,9 & 1,000 \\
\hline & Alto & 29 & 90,6 & 0 & 0,0 & \\
\hline \multicolumn{7}{|c|}{ Calidad global } \\
\hline & Bajo & 0 & 0,0 & 10 & 30,3 & \\
\hline & Normal & 5 & 15,6 & 23 & 69,7 & 0,024 \\
\hline & Alto & 27 & 84,4 & 0 & 0,0 & \\
\hline TOTAL & & 32 & & 33 & & \\
\hline
\end{tabular}

\section{$\underline{\text { 4.3.5.3 Conocimiento de la enfermedad grupo intervención }}$}

Conocimiento de la enfermedad grupo intervención

El grupo intervención mejoro sus conocimientos en el nombre de la enfermedad, ya que el $81,8 \%$ de la población identifico de forma correcta su nombre, frente al 57,6\% al inicio. Siendo significativas las diferencias. Así como el conocimiento del nombre del medicamento de rescate donde el $90,9 \%$ al final del estudio conoce su nombre frente a los resultados al inicio donde solo el $42,4 \%$ conocía el nombre de este. Otros resultados también mejoraron pero no de forma significativa como el conocimiento de los signos y síntomas. Ver tabla 57 y 63.

\begin{tabular}{|c|c|c|c|c|c|}
\hline & & & \multicolumn{2}{|c|}{ Final } & \multirow[t]{2}{*}{ p-value } \\
\hline & $\mathbf{n}$ & $\%$ & $\mathbf{n}$ & $\%$ & \\
\hline \multicolumn{6}{|l|}{ Nombre enfermedad } \\
\hline Respuesta correcta & 19 & 57,6 & 27 & 81,8 & 0,062 \\
\hline Respuesta incorrecta & 14 & 42,4 & 6 & 18,2 & \\
\hline \multicolumn{6}{|l|}{ Síntomas de alarma } \\
\hline Respuesta correcta & 24 & 72,7 & 31 & 93,9 & 1,000 \\
\hline Respuesta incorrecta & 9 & 27,3 & 2 & 6,1 & \\
\hline \multicolumn{6}{|l|}{ Medicación de rescate } \\
\hline Respuesta correcta & 14 & 42,4 & 30 & 90,9 & 1,000 \\
\hline Respuesta incorrecta & 19 & 57,6 & 3 & 9,1 & \\
\hline
\end{tabular}


$\underline{\text { Uso de los dispositivos de inhalación grupo intervención }}$

Los dispositivos que mejoraron su práctica después de recibir los pacientes un programa educativo que instruía en una de sus partes en la realización de los dispositivos de inhalación, obtuvimos que el cartucho, el turbuhaler y el accuhaler mejoraron su uso después del programa educativo, pero no de forma significativa.

Sin embargo otros dispositivos como la cámara de inhalación y las inhaleras empeoraron su uso transcurridas las sesiones de educación no siendo significativas estas diferencias. Y otros inhaladores como el nebulizar no mejoro ni empeoro una vez transcurrieron las sesiones. Ver tabla 64.

\begin{tabular}{|c|c|c|c|c|c|c|}
\hline & & \multicolumn{2}{|c|}{ Ingreso } & \multicolumn{2}{|c|}{ Final } & \multirow[t]{2}{*}{ p-value } \\
\hline & & $\mathbf{n}$ & $\%$ & $\mathbf{n}$ & $\%$ & \\
\hline \multicolumn{7}{|l|}{ Cartucho } \\
\hline & Bien & 4 & 25,0 & 18 & 78,3 & 1,000 \\
\hline & Mal & 12 & 75,0 & 5 & 21,7 & \\
\hline TOTAL & & 16 & 100 & 20 & 100 & \\
\hline \multicolumn{7}{|l|}{ Cámara } \\
\hline & Bien & 2 & 33,3 & 1 & 33,3 & - \\
\hline & Mal & 4 & 66,7 & 2 & 66,7 & \\
\hline TOTAL & & 8 & 100 & 3 & 100 & \\
\hline \multicolumn{7}{|c|}{ Turbuhaler } \\
\hline & Bien & 2 & 28,6 & 6 & 75,0 & 1,000 \\
\hline & Mal & 5 & 71,4 & 2 & 25,0 & \\
\hline TOTAL & & 7 & 100 & 8 & 100 & \\
\hline \multicolumn{7}{|c|}{ Accuhaler } \\
\hline & Bien & 4 & 30,8 & 10 & 83,3 & 1,000 \\
\hline & Mal & 9 & 69,2 & 2 & 16,7 & \\
\hline TOTAL & & 13 & 100 & 12 & 100 & \\
\hline \multicolumn{7}{|l|}{ Inhaletas } \\
\hline & Bien & 11 & 84,6 & 8 & 80,0 & - \\
\hline & Mal & 2 & 15,4 & 2 & 20,0 & \\
\hline TOTAL & & 13 & 100 & 10 & 100 & \\
\hline \multicolumn{7}{|c|}{ Nebulizador } \\
\hline & Bien & 1 & 11,1 & 1 & 20,0 & - \\
\hline & Mal & 8 & 88,9 & 4 & 80,0 & \\
\hline TOTAL & & 9 & 100 & 5 & 100 & \\
\hline
\end{tabular}




\subsubsection{Adherencia al tratamiento grupo intervención}

Los resultados con respecto la adherencia al tratamiento muestran ligeras variaciones, puesto que durante el ingreso el número de personas con buena adherencia fue del 48,5\% y trascurrido el programa educativo fue de $51,5 \%$. Por tanto las diferencias no fueron significativas con respecto a la adherencia al tratamiento. Ver tabla 65.

\begin{tabular}{|c|c|c|c|c|}
\hline & & $n$ & $\%$ & p-value \\
\hline \multirow[t]{3}{*}{ Ingreso } & Si & 16 & 48,5 & \multirow{6}{*}{0,303} \\
\hline & No & 17 & 51,5 & \\
\hline & TOTAL & 33 & 100 & \\
\hline \multirow[t]{3}{*}{ Final } & $\mathrm{Si}$ & 17 & 51,5 & \\
\hline & No & 16 & 48,5 & \\
\hline & TOTAL & 33 & 100 & \\
\hline
\end{tabular}


4.3.6 Resultados evaluación de la efectividad del tipo de atención en el grupo de pacientes asignados al grupo control

\subsubsection{Utilización de servicios}

Si observamos los datos de la tabla 66, podemos observar que los pacientes del grupo control disminuyeron sus ingresos hospitalarios $(0,3 \pm 0,7)$, visitas a urgencias $(0,5 \pm 0,9)$ y a consultas externas $(0,3 \pm 0,6)$ con respecto a su ingreso. Siendo significativas dichas diferencias en los ingresos hospitalarios por causa respiratoria y las visitas a urgencias por causa respiratoria, así pues otras medidas como las visitas a urgencias por causa no respiratoria y la visitas a consultas externas obtuvieron niveles próximos a la significación, datos observables en la tabla 66.

Tabla 66. Uso de servicios hospitalarios grupo control

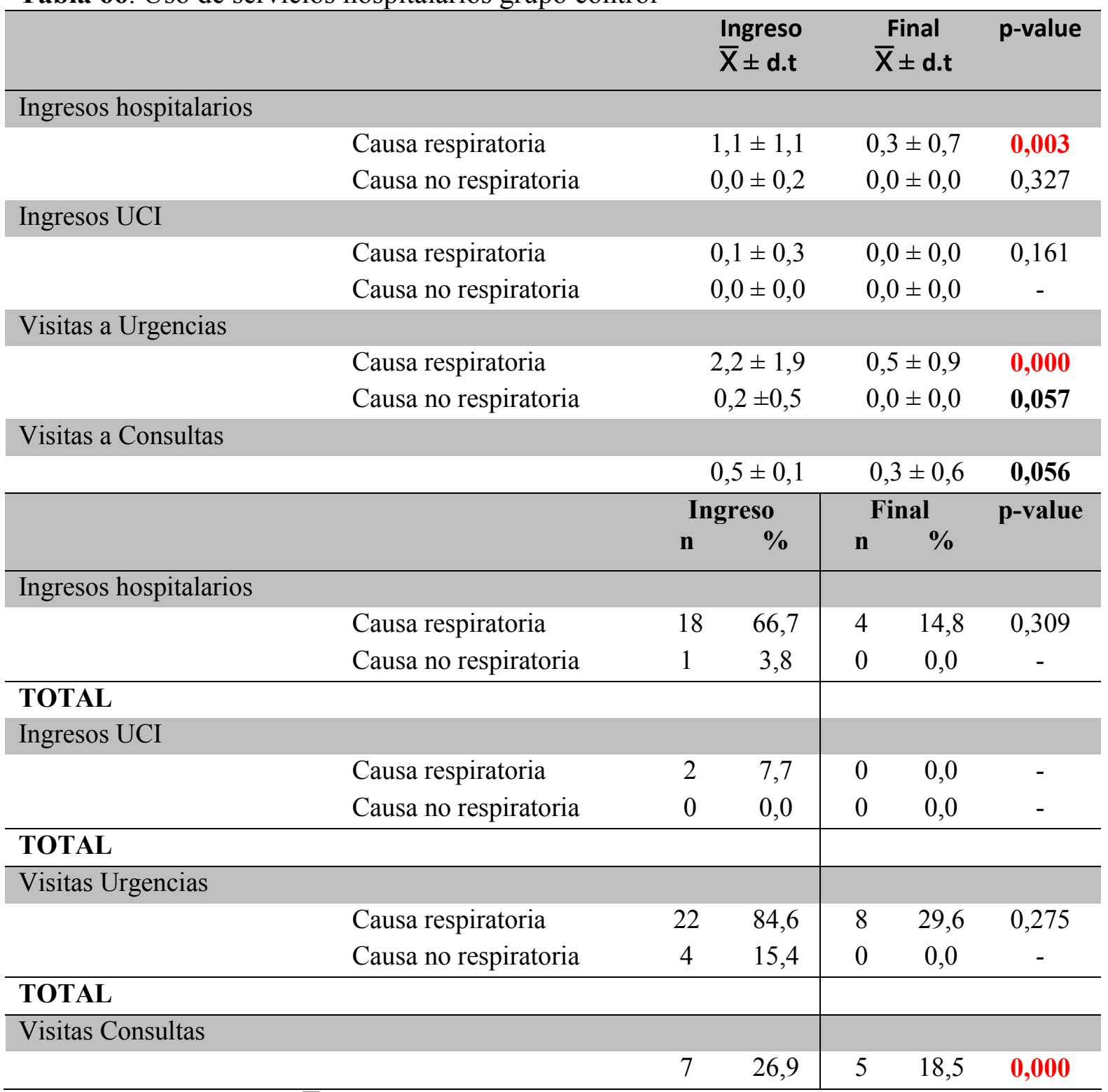

Los datos indican media $(\bar{X})$, desviación típica (d.t) 


\section{$\underline{\text { 4.3.6.2 Calidad de vida }}$}

\section{Calidad de vida CAT grupo control}

La calidad de vida de los pacientes del grupo control también mostró resultados positivos, obteniendo significación estadística dicha mejoría $(0,002)$. Viéndose traducida en un aumento del volumen de pacientes que presentaban un impacto medio $(40,7 \%)$ o bajo $(11,1 \%)$ de su calidad de vida, con respecto a la evaluación inicial. Con porcentajes del $32 \%$ con impacto medio y $4 \%$ con impacto bajo. Ver tabla 67.

\begin{tabular}{|c|c|c|c|c|c|}
\hline \multicolumn{6}{|c|}{ Tabla 67. Calidad de vida CAT grupo control } \\
\hline & \multirow{2}{*}{\multicolumn{2}{|c|}{$\begin{array}{l}\text { Ingreso } \\
\bar{X} \pm \text { d.t }\end{array}$}} & \multirow{2}{*}{\multicolumn{2}{|c|}{$\begin{array}{c}\text { Final } \\
\bar{X} \pm \text { d.t }\end{array}$}} & \multirow[t]{2}{*}{ p-value } \\
\hline & & & & & \\
\hline & \multicolumn{2}{|c|}{$24,6 \pm 7,4$} & \multicolumn{2}{|c|}{$20,3 \pm 9,5$} & 0,002 \\
\hline & \multicolumn{2}{|c|}{ Ingreso } & \multicolumn{2}{|c|}{ Final } & \\
\hline & $\mathbf{n}$ & $\%$ & $\mathbf{n}$ & $\%$ & p-value \\
\hline Bajo impacto & 1 & 4,0 & 3 & 11,1 & \multirow{4}{*}{0,196} \\
\hline Impacto medio & 8 & 32,0 & 11 & 40,7 & \\
\hline Impacto alto & 11 & 44,0 & 9 & 33,3 & \\
\hline Impacto muy alto & 5 & 20,0 & 4 & 14,8 & \\
\hline
\end{tabular}

\section{$\underline{\text { Calidad de vida St. George grupo control }}$}

La calidad de vida valorada por el cuestionario St. George también mostro resultados mejorados en todos sus parámetros, mostrando significación estadística en la reducción de los síntomas y la actividad. Así pues el impacto de la enfermedad también se vio mejorado pero a diferencia del resto de parámetros no mejoro de forma significativa.

Por tanto el parámetro que evaluó la calidad de vida global, mostró una mejoría significativa, como consecuencia de un aumento del número de pacientes que se situaban en los niveles bajos $(7 \%)$ y normales $(92,6 \%)$, con respecto a la evaluación inicial. Ver tabla 68.

\begin{tabular}{llccccc}
\hline Tabla 68. Calidad de vida St. George grupo control & \multicolumn{2}{c}{ Ingreso } & Final & p-value \\
\hline & & n & $\mathbf{\%}$ & $\mathbf{n}$ & $\mathbf{\%}$ & \\
\hline Síntomas & Bajo & 0 & 0,0 & 3 & 11,1 & \\
& Normal & 3 & 12,0 & 24 & 88,9 & $\mathbf{0 , 0 2 9}$ \\
& Alto & 22 & 88,0 & 0 & 0,0 & \\
Actividad & Bajo & 0 & 0,0 & 3 & 11,1 & \\
& Normal & 3 & 12,0 & 24 & 88,9 & $\mathbf{0 , 0 2 9}$ \\
& Alto & 22 & 88,0 & 0 & 0,0 & \\
\hline
\end{tabular}


Tabla 68. Calidad de vida St. George grupo control (continuación)

Impacto

\begin{tabular}{lccccc} 
Bajo & 0 & 0,0 & 1 & 3,7 & \\
Normal & 2 & 8 & 26 & 96,3 & $\mathbf{0 , 0 8 0}$ \\
Alto & 23 & 92 & 0 & 0,0 & \\
& & & & & \\
Bajo & 0 & 0,0 & 2 & 7,0 & \\
Normal & 4 & 16,0 & 25 & 92,6 & $\mathbf{0 , 0 2 0}$ \\
Alto & 21 & 84,0 & 0 & 0,0 & \\
\hline
\end{tabular}

TOTAL

\section{$\underline{4.36 .3 \text { Conocimiento de la enfermedad }}$}

\section{$\underline{\text { Conocimiento de la enfermedad }}$}

En la evaluación a los 3 meses de los conocimiento de su enfermedad se muestra una mejoría significativa, tanto del conocimiento del nombre de su patología como del conocimiento de la medicación de rescate. Observando también una mejoría en el conocimiento de los signos y síntomas de inicio de la exacerbación pero no siendo significativos dichos resultados. Datos apreciables en la tabla 69.

\begin{tabular}{|c|c|c|c|c|c|}
\hline & & & & & p-value \\
\hline & $\mathbf{n}$ & $\%$ & $\mathbf{n}$ & $\%$ & \\
\hline Nombre enfermedad & & & & & \\
\hline Respuesta correcta & 14 & 51,9 & 18 & 66,7 & 0,000 \\
\hline Respuesta incorrecta & 13 & 48,1 & 9 & 33,3 & \\
\hline Síntomas de alarma & & & & & \\
\hline Respuesta correcta & 21 & 77,8 & 25 & 92,6 & 0,402 \\
\hline Respuesta incorrecta & 6 & 22,2 & 2 & 7,4 & \\
\hline Medicación de rescate & & & & & \\
\hline Respuesta correcta & 10 & 37,0 & 20 & 74,1 & 0,026 \\
\hline Respuesta incorrecta & 17 & 63,0 & 7 & 25,9 & \\
\hline
\end{tabular}

\section{$\underline{\text { Uso de los inhaladores }}$}

Si tendemos al uso del inhalador tres dispositivos mejoran su uso, el cartucho presurizado, el dispositivo accuhaler y las inhaletas. Mejorando solo de forma significativa el cartucho.

Siendo estos datos comparables con cautela como consecuencia de la modificación del tratamiento de muchos de los pacientes a los 3 meses, siendo en muchos casos solo comparables con un único sujeto, como es el caso de la cámara. Datos disponibles en la tabla 70 . 


\begin{tabular}{|c|c|c|c|c|c|c|}
\hline & & \multicolumn{2}{|c|}{ Ingreso } & \multicolumn{2}{|c|}{ Final } & \multirow[t]{2}{*}{ p-value } \\
\hline & & $\mathbf{n}$ & $\%$ & $\mathbf{n}$ & $\%$ & \\
\hline \multicolumn{7}{|l|}{ Cartucho } \\
\hline & Bien & 3 & 25,0 & 6 & 28,6 & 0,067 \\
\hline & Mal & 9 & 75,0 & 15 & 71,4 & \\
\hline TOTAL & & 12 & 100 & 21 & 100 & \\
\hline \multicolumn{7}{|l|}{ Cámara } \\
\hline & Bien & 2 & 33,3 & 0 & 0,0 & - \\
\hline & Mal & 4 & 66,7 & 1 & 100 & \\
\hline TOTAL & & 6 & 100 & 1 & & \\
\hline \multicolumn{7}{|c|}{ Turbuhaler } \\
\hline & Bien & 1 & 33,3 & 2 & 33,3 & - \\
\hline & Mal & 2 & 66,7 & 4 & 66,7 & \\
\hline TOTAL & & 3 & 100 & 6 & 100 & \\
\hline \multicolumn{7}{|c|}{ Accuhaler } \\
\hline & Bien & 2 & 12,2 & 5 & 45,5 & - \\
\hline & Mal & 9 & 81,8 & 6 & 54,5 & \\
\hline TOTAL & & 11 & 100 & 11 & 100 & \\
\hline \multicolumn{7}{|l|}{ Inhaletas } \\
\hline & Bien & 9 & 81,8 & 5 & 100 & - \\
\hline & Mal & 2 & 18,2 & 0 & 0,0 & \\
\hline TOTAL & & 11 & 100 & 5 & & \\
\hline \multicolumn{7}{|c|}{ Nebulizador } \\
\hline & Bien & 1 & 12,5 & 0 & 0,0 & - \\
\hline & Mal & 7 & 87,5 & 5 & 100 & \\
\hline TOTAL & & 8 & 100 & 5 & 100 & \\
\hline
\end{tabular}

\subsubsection{Adherencia al tratamiento}

La adherencia al tratamiento trascurridos los 3 meses del ingreso se vio disminuida de forma significativa, disminuyendo desde el ingreso $(59,3 \%)$ el porcentaje de pacientes cumplidores con el tratamiento $(55,6 \%)$. Datos disponibles en la tabla 71 .

Tabla 71. Adherencia al tratamiento grupo control

\begin{tabular}{cccc|c}
\hline \multirow{3}{*}{ Ingreso } & & $\mathbf{n}$ & $\mathbf{\%}$ & p-value \\
& $\mathrm{Si}$ & 16 & 59,3 & \\
& $\mathrm{No}$ & 11 & 40,7 & \\
\cline { 2 - 3 } & TOTAL & 27 & 100 & \\
\cline { 2 - 3 } Final & $\mathrm{Si}$ & 15 & 55,6 & \multirow{2}{*}{0,022} \\
& $\mathrm{No}$ & 12 & 44,4 & \\
& TOTAL & 27 & 100 & \\
\cline { 2 - 3 } & & & & \\
\hline
\end{tabular}




\section{DISCUSIÓN}




\section{Discusión}

La discusión de los resultados se ha realizado de acuerdo a los objetivos, resultados y fases expuestas en la metodología de la investigación.

- Revisión Integradora

- Análisis de las características de la población con diagnóstico de exacerbación de la EPOC catalogado con el GRD088 y que ingresan en el Hospital Universitario General de Castellón desde 2008 hasta 2013.

- Determinación y evaluar la efectividad de un programa estructurado de educación terapéutica, durante el ingreso, en comparación con la atención convencional

\subsection{Discusión Revisión Integradora}

La EPOC es una de las enfermedades más prevalentes en los países desarrollados, donde cada vez existe una mayor preocupación por implantar nuevas soluciones a estos pacientes, viéndose reflejado en un incremento del número de publicaciones en los últimos 5 años, sobre todo de protocolos de estudio sin que posteriormente se hayan hecho las publicaciones de los resultados de los mismos, acontecimiento también puesto de manifiesto por la revisión Cochrane del año 2011(224).

En cuanto al contenido de las sesiones de educación cabe destacar que en esta revisión no se ha hecho una inferencia en los contenidos que pueden afectar positivamente en los mejores resultados de las variables estudiadas, si no que se ha unificado el contenido de los diferentes programas educativos y se ha realizado un análisis descriptivo de los componentes de los mismas.

Se han encontrado pocas revisiones que aborden los componentes de los programas educativos en pacientes con EPOC, de hecho, en una de las revisiones, como consecuencia de la heterogeneidad de las intervenciones no se han podido extraer conclusiones de los programas (224). Sin embargo, revisiones como la de Bourbeau (181) afirman que para obtener beneficios terapéuticos en pacientes con EPOC es necesario elaborar planes individuales, además de dar educación para la salud y un seguimiento telefónico de los pacientes. En esta misma línea también se encuentra la revisión Cochrane (142), donde además pone de manifiesto que los planes de acción deben de ser complementarios con el tratamiento farmacológico por tanto no resulta efectiva la aportación única de folletos informativos como educación única (186).

En los estudios analizados, diversos autores, han estudiado las variables centradas en el ámbito nutricional, existiendo investigaciones que destacan la importancia de la nutrición en el paciente con EPOC por sus complicaciones o bien por exceso de peso o bien por bajo peso (223). La dieta adecuada mejoraría la fuerza de los músculos respiratorios, la actividad física y la calidad de vida (225) mejorando la recuperación de estos pacientes en los periodos de exacerbación. 
Como se observa en la revisión, uno de los componentes que en mayor medida se presenta en los programas educativos en pacientes con EPOC es la deshabituación tabáquica, al ser el tratamiento más eficaz en la mejora de la enfermedad, de acuerdo a la evidencia científica (223). Existen estudios que afirman que la combinación de una intervención psicosocial y un tratamiento farmacológico obtienen mayores tasas de deshabituación, frente a programas educativos específicos para deshabituación tabáquica (226). Otro de los pilares angulares de los pacientes con EPOC son sus problemas en el mal uso de los dispositivos de inhalación (179), siendo necesaria la instrucción de los mismos en los programas educativos, siendo un contenido presente en muchos de los estudios incluidos.

Respecto a las variables resultado recogidas existe un mayor número de estudios que han obtenido una disminución de los ingresos hospitalarios (193) en pacientes con EPOC, como también ha ocurrido en resultados de estudios que han evaluado la atención integrada (227) y la atención domiciliaria (228) frente a la atención convencional en pacientes con EPOC como mejor lugar terapéutico para prevenir exacerbaciones. Igualmente, mayores tasas de deshabituación tabáquica y un aumento de los conocimientos de la EPOC (184), son beneficiosos para la evolución de la enfermedad como queda reflejado en un estudio llevado a cabo en pacientes con asma y EPOC (187) respecto a su evaluación basal o al grupo control.

Si analizamos otros parámetros también han obtenido resultados positivos en aspectos como la calidad de vida $(190,229)$, los parámetros funcionales respiratorios $(185,224)$ y variables que, en nuestro estudio no se han visto afectadas ni de forma positiva ni negativa. En otras dos revisiones llevadas a cabo, una en el año 2005 y otra en el año 2009, se muestra que existe poca evidencia de que los programas educativos en pacientes con EPOC mejoren la calidad de vida, la satisfacción, los reingresos hospitalarios o las visitas a urgencias $(142,230)$. Sin embargo, en contra de esos resultados se presentan programas como la teleasistencia aplicada a pacientes con EPOC que han mostrado niveles significativos de mejoría en las mencionadas variables (231).

Uno de los aspectos de gran relevancia en los pacientes crónicos es la adherencia al tratamiento, sin embargo, la adherencia, ha sido analizada en uno de los estudios que se han encontrado en la revisión, donde se indica que no se mejora tras la aplicación de un programa educativo, sino que es necesario valorar la edad, tratamiento y patología que padecen los pacientes para mejorar la adherencia (232).

Se han encontrado programas que, incluyen ejercicios de rehabilitación pulmonar y educación sanitaria en EPOC que han obtenido resultados positivos en aspectos como la tolerancia al ejercicio, disnea y calidad de vida, siendo más prolongados en el tiempo dicho beneficios comparados con los beneficios de la aplicación de un programa educativo únicamente $(203,204,233)$. Los resultados, no solo aportan beneficios a los pacientes con EPOC, sino también para otras enfermedades crónicas, como pone en evidencia una revisión sistemática del año 2015 que analiza la aplicación de programas de educación terapéutica en paciente con diferentes patologías (234). 
En cuanto a la valoración de la calidad metodológica, cabe destacar que los resultados de la investigación son superiores con los de la revisión elaborada por el equipo de neumología del hospital 12 de Octubre de Madrid (235), donde la calidad de los estudios revisados se sitúa en torno a 2,5 puntos en la escala de Jadad (166). Una revisión elaborada en el año 2012 en Reino Unido (236) coincide con nuestra investigación en que la calidad metodológica de los estudios localizados es cambiante y los mayores sesgos se presentan en la técnica de ocultación. Esta revisión fue aceptada como poster en el último congreso SEPAR y esta enviada para su publicación.

La revisión que se ha realizado para esta investigación aportara evidencias sobre los programas de educación, aportando como innovación los componentes que se explican en cada uno de los programas y sirviendo de base para la implantación de programas de ET en el contexto sanitario. 


\subsection{Discusión del análisis de las características de la población con diagnóstico de exacerbación de la EPOC catalogado con el GRD088 y que ingresaron en el Hospital Universitario General de Castellón desde 2008 hasta 2013.}

En la segunda fase de la investigación y antes de implantar el programa de educación terapéutica, se revisaron las historias clínicas de los últimos 5 años de los pacientes con EPOC hospitalizados en el Hospital Universitario General de Castellón. El perfil identificado responde a un varón con una edad media entorno a los 73,8 años. Resultados similares a los encontrados en estudios epidemiológicos llevados a cabo en España como el estudio IBEREPOC (123), EPI-SCAN (237) o estudios Británicos (238). Otros estudios españoles con menor volumen poblacional han obteniendo medias de edad similares a la de nuestro estudio, como es el caso del estudio llevado a cabo en un hospital español (239) que sitúa su media en 73,4 años o un estudio del hospital de Coruña (240) con una media de 70 años. Este mismo estudio evaluó las dos enfermedades obstructivas más frecuentes, como son el asma y la EPOC, y afirmó que el asma tiene un perfil de paciente opuesto al de la EPOC, ya que en el asma el perfil general es de mujer joven y en la EPOC suele ser un varón de mediana edad o mayor de 65 años (240).

Cabe destacar la existencia de un estudio realizado en el año 1973 en la ciudad de Castellón (241), donde los resultados del mismo no han podido ser obtenidos, ni hubiesen podido ser comparables por los criterios diagnósticos actuales de la EPOC.

Respecto a los datos de reingreso, la media de pacientes que volvieron a ingresar en el hospital de Castellón durante el periodo de los 5 años del estudio fue del 22\% de la muestra. En la misma línea se pueden consultar estudios como el de Sullivan (242) que, analizaron su población con EPOC identificando que el $73 \%$ de la partida presupuestaria destinada a esta enfermedad fue utilizada por una parte de pacientes que no superaba el 10\% de la población total de pacientes con EPOC (243).

Según la estrategia nacional del paciente con EPOC (22), es importante mejorar el estado de estos pacientes por la repercusión en su calidad de vida, por la disminución de gastos que producen las cronicidades en el sistema sanitario, sobre todo por los reingresos, frecuentes en este grupo poblacional.

El consumo de recursos sanitarios en este perfil de pacientes y la concentración temporal es similar en Castellón y en otros estudios (240) donde la distribución de ingresos por agudización suele darse en los meses de diciembre, enero y febrero. El mes con menor número de exacerbaciones en el hospital de estudio, fue junio y en el estudio de Otero (30) fue agosto. Variaciones, atribuibles a la climatología durante los años de análisis, ya que el estudio de Weiss (244) observó que los días con más frío aumentaba el número de pacientes y los días más calurosos disminuían los ingresos. Dichos resultados contrastan en gran medida con estudios epidemiológicos llevados a cabo en otros países donde hay un aumento de las agudizaciones durante los periodos primaverales y otoñales, como ocurre con el asma, como consecuencia de climatologías diversas (245). 
Respecto al número de ingresos, los resultados de nuestro estudio reflejan una media de ingresos anual en torno a 229 ingresos, siendo dichos resultados similares a otros centros como el Hospital de Requena, (Valencia) ubicado en la misma Comunidad Autónoma y con un volumen de cobertura asistencial similar al de nuestro estudio, donde en su caso la media anual se sitúa en torno a los 121 y 263 pacientes al año.

Siendo nuestra media de ingreso de 7 días, estudios españoles han obtenido datos similares en la media de sus ingresos, teniendo una media de 8 días (246) o americanos (247) con una media de 9 días. Sin embargo no todos los datos son superiores a los de nuestro hospital, sin duda estudios como el llevado por Otero (30) en Coruña con un ingreso medio de 4,8 días se aleja mucho de nuestros resultados.

Las estancias hospitalarias y el gasto sanitario no sólo se justifican por el problema respiratorio, si no también hay que considerar el índice de comorbilidades que llevan asociadas los pacientes con EPOC (248), haciendo más dificultoso su tratamiento. Las principales comorbilidades asociadas a la EPOC son la hipertensión arterial, diabetes mellitus, enfermedad arterial coronaria, insuficiencia cardiaca, infecciones respiratorias, cáncer y enfermedad arterial periférica (249), estando presentes todas en nuestros resultados. Es importante destacar que la prevalencia de las mismas varía ampliamente en los distintos estudios que han tratado el tema (250-253). Y donde las comorbilidades se presentan como un factor de empeoramiento de pronóstico de los pacientes en todos los estudios.

La comorbilidad más frecuente es la insuficiencia cardíaca, pudiendo estar justificada por los hallazgos de algunos estudios que afirman que los pacientes con EPOC presentan un riesgo de desarrollar insuficiencia cardiaca de 4,5 superior a una persona sin esta enfermedad (254), dicha situación también puede estar justificada por el uso de inhaladores como los $\beta 2$ Adrenérgicos, asociados efectos secundarios como insuficiencias cardíacas, arritmias, cardiopatías isquémicas y muerte súbita, no existiendo aun suficientes evidencias para contraindicar su uso (255), existiendo también otros fármacos cuyo uso como los corticoides orales han demostrado un riesgo de retención hidrosalína que puede ocasionar insuficiencias cardíacas (256).

Resulta complejo comparar el gasto sanitario medio ocasionado por los pacientes de forma anual, por carecer de información necesaria para su cálculo. Muchos autores han analizado su elevado coste y han instado a la elaboración de estrategias para mejorar la gestión de estos pacientes $(257,258)$. 


\subsection{Discusión de la determinación y evaluación de la efectividad de un programa estructurado de educación terapéutica, durante el ingreso, en comparación con la atención convencional}

La tercera fase de nuestra investigación consistió en la evaluación de un programa de educación terapéutica, para tal fin fueron seleccionadas cuatro variables principales de resultado, el uso de recursos, la calidad de vida, el conocimiento de la patología y los medicamentos, así como la adherencia al tratamiento. Por tanto la discusión de los mismos es secuencial, incorporando al inicio, los aspectos relativos a las características del total de participantes y la homogeneidad de los grupos de estudio.

\subsubsection{Descripción de la población}

Los pacientes captados cumplen el perfil mayoritario del paciente con EPOC, coincidente a los obtenidos en la revisión de historias clínicas y en consecuencia, con estudios de características similares llevados a cabo en la Comunidad Valenciana (207) y a otros lugares de España (259) o países de Latino América (260) que muestran un perfil similar a los resultados del segundo objetivo de esta tesis.

Respecto a las causas de la EPOC, diagnosticadas, es coincidente con la definición que afirma que el tabaco es el causante del 90\% de las EPOCs $(163,261)$. La mayor proporción de población fue de los pacientes exfumadores, siendo la Comunidad Valenciana la autonomía con mayor incidencia de exfumadores de todo el territorio nacional (262). Cabe destacar un $13 \%$ de la población indicó que no había sido fumadora, cifra que incluye pacientes fumadores pasivos, neumonías infantiles recurrentes, alteraciones congénitas y trabajos en empresas con liberación de polvo ambiental contaminante como el sector cerámico de nuestra provincia, (263) puesto de manifiesto en estudios de contaminantes atmosféricos y la guía Gesepoc (7). Otros estudios han probado la mayor prevalencia de EPOC en población femenina frente a la masculina atribuida a una mayor probabilidad de contraer EPOC con una menor dosis de nicotina (261). Esta afirmación no se ha puesto de manifiesto en nuestros estudios por la escasez de muestra de mujeres, siendo homogénea la distribución de estas en ambos dos grupos, es importante destacar la escasez de población femenina con EPOC en el territorio Español con respecto a otros países, por lo tanto nuestra muestra cumpliría con el perfil mayoritario de pacientes EPOC en España.

Si observamos el hábito alcohólico, la dosis de alcohol ingerida por los pacientes se sitúa en una media inferior a un vaso diario. Existen investigaciones que afirman que los pacientes EPOC consumen alcohol de manera poco moderada, produciéndoles un mayor número de exacerbaciones, mayor número de ingresos hospitalarios y visitas a urgencias como consecuencia del efecto inmunosupresor y el riesgo de aspiración (264); otros estudios han identificado que ser varón y consumir alcohol está más relacionado con agudizaciones de la EPOC $(265,266)$. Resultados que, no se ajustan a la población 
objeto de estudio dado que la media de ingresos y visitas a urgencias fue elevada frente a la escasa ingesta de alcohol.

Es destacable el sobrepeso, situando a la mayor parte de la población estudiada con obesidad; datos similares a los obtenidos por otros autores (267), donde se afirma que los estados de aumento de peso van ligados al tiempo de diagnóstico del paciente. Al desconocer en la población del presente estudio, el tiempo de diagnóstico, sí que se puede explicar dichos hallazgos mediante teorías que apuntan, que los estados de bajo peso son atribuibles a estados avanzados de la enfermedad y asociados a peor pronóstico (268), no existiendo evidencias sólidas que nos indiquen las explicaciones de este fenómeno. Algunas tendencias se decantan por un desequilibrio energético, ocasionado por aumento del gasto energético, consecuencia del aumento del trabajo respiratorio, esta teoría está reforzada por el uso de la ventilación mecánica no invasiva que, aumenta el IMC. Esta situación no se da en los pacientes del estudio ya que, fueron excluidos aquellos que tenían una esperanza de vida inferior a 6 meses y con un grado de obstrucción moderado, por tanto es lógico encontrar un perfil de paciente con un IMC indicativo de sobrepeso u obesidad y no bajo peso. Es importante destacar que estadios de obesidad y sobrepeso extremos tampoco son recomendables por el excesivo trabajo respiratorio de la cavidad abdominal.

Otras investigaciones que abordan el IMC en pacientes con EPOC han identificado niveles más altos de $\mathrm{FEV} 1, \mathrm{FEV}_{1} / \mathrm{FVC}$, $\mathrm{Ph}$ y volumen de oxígeno en sangre, en los pacientes con mayor IMC, situación que no se ha observado en la presente investigación de forma directa, pero se puede indicar que los pacientes asignados al grupo control, presentaron porcentajes más elevados en los parámetros de mayor IMC y niveles más altos en sus parámetros espiratorios, indicativos de peor función pulmonar, aunque las diferencias no fueron estadísticamente significativas (110-112).

Es destacable que con elevado IMC, son escasos los pacientes que siguen una dieta o tienen una ingesta hídrica superior a los 2 litros, que favorecería la fluidificación del moco en caso de exacerbación (163). Cabe indicar que la mitad de los pacientes incluidos afirmaron que caminan como mínimo 30 minutos al día y no pasan la mayor parte del tiempo sentados, como perfilan otros estudios (97). Coincidimos con el estudio de Martin Royo (157), llevado a cabo en varios hospitales de la Comunidad Valenciana, donde identifican que la mayor parte de la población EPOC es sedentaria y presenta mayor grado de la disnea, peor calidad de vida y mayor IMC (269), datos reflejados en el grupo control, cuyos niveles de sedentarismo son mayores que en el grupo intervención, presentando mayor disnea, peor calidad y mayor IMC, no siendo las diferencias estadísticamente significativas.

Otro de los aspectos estudiado fue la vacunación tanto de la gripe como del neumococo, obteniendo unos niveles de vacunación más bajos en comparación a otros lugares del territorio español como Galicia (270) con una tasa de vacunación de la gripe y del neumococo del 77\% así como un estudio llevado a cabo en España en centros de atención primaria mostro unas tasas de vacunación del $80 \%$, siendo en nuestro estudio del $60 \%$ en la gripe y tan solo el $20 \%$ del neumococo. Estudios como el de Alfagene 
Michavila, indican que la vacunación de la gripe disminuye el gasto sanitario y disminuye la mortalidad (271), siendo la vacunación del neumococo la que menor indicación tuvo es destacable que su vacunación presenta controversias en cuanto a su efectividad $(272,273)$.

La presencia de ansiedad y depresión no fue muy frecuente en la nuestra del estudio, a diferencia de otras investigaciones que indican que es la comorbilidad psiquiátrica más frecuente en los pacientes con EPOC (274).

\section{3. 2 Homogeneidad de los grupos}

Siendo homogéneos los dos grupos de asignación es destacable que fue el grupo control el que presento una mayor longevidad, mayor número de ingresos y visitas a urgencias, eran más sedentarios, tenían peor función pulmonar, con más comorbilidades, mayor consumo de pastillas, inhaladores e inyectables que el grupo intervención al inicio del estudio, siendo por tanto más notoria su mejoría con respecto al grupo intervención en su evaluación a los 3 meses.

\subsubsection{Recursos sanitarios utilizados}

Los resultados relacionados con el uso de los recursos sanitarios mostraron que los pacientes que habían recibido educación sanitaria disminuyeron sus ingresos hospitalarios con respecto a la evaluación inicial, pero no lo hicieron de forma significativa. Siendo mayor el uso de los recursos del grupo que había recibido la intervención educativa en la comparación a los 3 meses con respecto al grupo control. Por tanto no podemos afirmar que la educación terapéutica disminuye el uso de los recursos asistenciales de los pacientes EPOC como también han obtenido otras investigaciones $(144,145,147,148,156,207,208,221,236,275)$, aunque a diferencia de nuestros resultados existen estudios que han obtenido una disminución de los ingresos hospitalarios de los pacientes sometidos a la ET $(143,150,155,212)$ con respecto a los del grupo control.

Los resultados también mostraron que la mayoría de pacientes acuden por su problema de salud a atención primaria, con una periodicidad de 3 a 6 meses con cita programada y cuando se encontraban mal acuden al hospital, siendo una de las patologías que mayor demanda tiene en los servicios de urgencias hospitalarias (163).

\subsubsection{Calidad de vida}

Los resultados obtenidos relacionados con calidad de vida de los pacientes con EPOC muestran una mejora significativa tras la aplicación del programa de ET, disminuyendo la afectación de todas las áreas que estudia el cuestionario CAT y St. George como los síntomas, el impacto y la actividad, siendo esta última la esfera que mejoro en mayor medida y de forma significativa con respecto a la evaluación inicial. Datos que también se vieron mejorados de forma significativa en el grupo control, por tanto no podemos afirmar que la educación terapéutica mejore la calidad de vida. Como si han obtenido diversos estudios $(144,145,148,150,154,207,208)$, coincidimos con aquellos 
que indican que la calidad de vida no se ve mejorada por el programa educativo si no una vez el paciente se recupera de la exacerbación, $(79,151,152,156,210,217,221)$ y por el contrario no coincidimos con aquellos estudios que indican que los programas educativos empeoran la misma (153).

Otros trabajos han abordado más variables indicando que, la calidad de vida en los pacientes EPOC empeora por sexo, los hombres tienen una peor calidad de vida que las mujeres (276), las visitas a urgencias, disnea (277), edad número de exacerbaciones (278) y una peor adherencia farmacológica (279) ya que son factores predisponentes para el empeoramiento de la calidad de vida en los pacientes con EPOC.

\subsubsection{Conocimientos en la EPOC}

Según los datos obtenidos en nuestra población, existe un gran desconocimiento en la población sobre la EPOC, existiendo un número elevado de pacientes con diagnóstico con EPOC que desconocen el nombre de su enfermedad o el medicamento que deben de tomar en caso de necesidad, representando el $45 \%$ de nuestra población. Resultados coincidentes con los del proyecto CONOCEPOC (262) desarrollado en 17 comunidades autónomas sobre los conocimientos de los españoles de la EPOC, donde el $17 \%$ de la población conoce que es la EPOC, datos que aún son menores cuando hablamos de otras investigación española en el año 2002 donde el $9 \%$ de la población conoce esta enfermedad (26). Sin embargo los términos bronquitis crónica o enfisema tienen niveles de conocimiento de la población entorno al $94 \%$ y al 55,5\% respectivamente (280).

Uno de los objetivos principales de la presente investigación fue determinar si los pacientes del grupo intervención mejoraron sus conocimientos de la enfermedad, de sus signos y síntomas y de la medicación de rescate, puesto que ninguno de ellos había asistido anteriormente a sesiones de educación sobre su enfermedad respiratoria ni tenía material informativo de la misma. Resultados que mejoraron, en la evaluación final por ambos grupos siendo significativas las diferencias en ambos, posiblemente mejoradas por la instrucción de los profesionales de salud durante su ingreso y reforzadas en caso de los pacientes del grupo intervención con las sesiones de educación, obteniendo resultados similares $(149,152,154,155,210)$.

Si atendemos al uso de los inhaladores, la media de uso se sitúa en 3,7 inhalaciones al día, siendo más frecuentes en el grupo control que en el grupo intervención; datos similares a los obtenidos en un estudio de población con EPOC en España (281). Pero si atendemos al correcto uso de los mismos coincidimos con aquellos estudios (282-284) que indican el elevado porcentaje de mala realización de la técnica de inhalación, siendo en nuestro estudio del $65 \%$, siendo muy pocos los pacientes que no cometen ningún error durante la evaluación inicial, datos similares a los obtenidos por Carrión (285) donde solo el 31\% realizaban correctamente el inhalador y el estudio de Benito Ortiz, (286) donde el 21,3\% hacen correctamente la técnica de inhalación en base a su inhalador. 
Con respecto al inhalador empleado, según los resultados de nuestra investigación los inhaladores que más errores presentaron fueron el cartucho presurizado y la cámara de inhalación, resultados similares a una investigación llevada a cabo en diversos centros de salud del territorio de la Comunidad Valenciana (285), donde los dispositivos de polvo seco obtuvieron menor número de errores en la inhalación. Aunque no es posible asegurar que sólo el sistema de inhalación y no otras características de los pacientes, son las responsables de más errores en la técnica, se ha observado que las cámaras de inhalación se utilizan cuando los pacientes tienen problemas de coordinación en la utilización del cartucho, como ha ocurrido en el estudio de Golpe (283). Este resultado es similar al obtenido en nuestra investigación. Así pues, otros inhaladores que también obtuvieron buenos resultados fueron los dispositivos multidosis de polvo seco como Turbuhaler o Accuhaler, explicación dada como consecuencia de que se activan con la inspiración del paciente no siendo necesaria la coordinación.

Algunos estudios han encontrado relaciones que afirman que los pacientes con menor edad tienen mejor cumplimiento de los inhaladores frente a los que son más longevos (287), resultados que en nuestro estudio no se han evidenciado puesto que los pacientes del grupo control eran más longevos y presentaron tasas similares a los del grupo intervención que presentaban una menor edad.

Otros estudios atribuyen dichas deficiencias, a una mala instrucción del inhalador desde el inicio de su administración o una disminución del control de su uso habitual por el personal sanitario $(283,286)$.

Tras la instrucción en el correcto uso de los inhaladores, los pacientes que utilizaron el cartucho presurizado mejoraron la realización de la técnica de forma significativa, siendo significativa esta diferencia en la evaluación a los 3 meses, pero no siendo aplicable únicamente al grupo instruido. Así pues otros dispositivos como la cámara, el turbuhaler, el accuhaler y el nebulizador mejoraron en ambos grupos pero no siendo significativa dichas diferencias.

La instrucción por parte del personal de enfermería en la técnica de inhalación es necesaria, dado que el tratamiento para la EPOC se utiliza fundamentalmente por vía inhalatoria, existiendo investigaciones que afirman que tras la realización de un programa de instrucción en la técnica de inhalación, mejora la correcta realización del inhalador, viéndose reflejado en una mejora de parámetros como la disnea y el BODEX (281), ratificando la importancia de esta correcta instrucción y la mejora de los conocimientos del pacientes con tratamiento inhalados $(155,207,212,217)$.

Los resultados obtenidos sobre el conocimiento de la técnica de inhalación coinciden con la afirmación de Carrión(285), donde expone que en " En la Comunidad Valenciana se encuentra una elevada proporción de pacientes que utilizan mal los inhaladores, especialmente los pacientes que reciben tratamiento con cartucho presurizado". Siendo este tratamiento el que mejor valoración tiene por los pacientes, ya que consideran que al impactar el chorro de gas en la orofaringe les produce una impresión subjetiva de que el medicamento es más eficaz (283). 
Los principales fármacos utilizados con los distintos dispositivos fueron el cartucho presurizado para la administración de broncodilatadores de corta duración, seguido del uso del dispositivo accuhaler para broncodilatadores de larga duración y el dispositivo inhaletas para las terapias combinadas de corticoides con broncodilatadores de larga duración, siendo los tratamientos administrados los recomendados para el paciente agudizado tanto con enfisema como con bronquitis crónica según la guía GESEPOC (163), A los 3 meses de seguimiento, el tratamiento más utilizado fue, los broncodilatadores de larga duración y las asociaciones de broncodilatadores y corticoides inhalados.

\subsubsection{Adherencia al tratamiento}

Estudios que han evaluado la adherencia farmacológica en diferentes pacientes con enfermedades crónicas han afirmado que los pacientes con EPOC tienen una menor adherencia farmacológica que otras patologías como el asma (288). Estos resultados mejoran, tras la aplicación de un programa de educación terapéutica (275), aspecto que no se ha puesto de manifiesto en nuestra investigación ya que los resultados han mostrado una mejoría significativa en el grupo que no recibió formación, no siendo significativa la diferencia en el grupo que recibió la formación. Datos que no se han podido contrastar pero si se han encontrado algún estudio que indica que la educación terapéutica aplicada únicamente no mejora la adherencia al tratamiento (144).

Otros estudios que han conseguido mejorar la adherencia farmacológica tras la instrucción en la técnica de inhalación han afirmado que uno de los aspectos que podría mejorar esta adherencia es la utilización de inhaladores multidosis frente a los inhaladores monodosis, ya que estos tienen menor adherencia farmacológica por sus pacientes (289) aspecto que no se ha puesto en evidencia en nuestros resultados ya que los inhaladores fueron utilizados de forma similar en ambos grupos.

Otro de los estudios que analizan la adherencia farmacológica en los pacientes con EPOC, indica que la adherencia farmacológica de los pacientes con EPOC viene afectada por la el consumo elevado de fármacos, aspecto que no explicaría nuestro resultados dado que es el grupo control el que tiene un mayor número de pastillas, 6,4 pastillas diarias con respecto al grupo intervención de 5 pastillas al día. Las cifras de consumo de fármacos, parecen elevadas, sin embargo son inferiores a la media de otros estudio que, identifican 6,3 medicamentos diarios $(290,291)$.

Igualmente, los continuos cambios en los tratamientos como consecuencia de los frecuentes ingresos hospitalarios y las tasas elevadas de comorbilidades, edad, sexo, el nivel educativo y el nivel socioeconómico, estarían relacionados (290) con la adherencia al tratamiento aspectos no significativos en nuestra población dado que la muestra en ambos grupos es muy homogénea. 
LIMITACIONES 


\section{LIMITACIONES}

Las limitaciones de la investigación se exponen en base a las 3 fases del estudio.

\subsection{Limitaciones en la revisión}

- Fue consultada una base de datos para realizar la revisión Pubmed Medline, siendo esta la base de datos internacional con mayor importancia en el ámbito de Ciencias de la Salud.

6.2 Limitaciones en el análisis de las características de la población con diagnóstico de exacerbación de la EPOC catalogado con el GRD088 y que ingresaron en el Hospital Universitario General de Castellón desde 2008 hasta 2013.

- Existió sesgo en la clasificación de los pacientes con EPOC a la hora de aplicar el GRD088, puesto que existieron gran diversidad de edades, atribuible a que el GRD incluye otras 6 enfermedades respiratorias.

- No catalogación de todas las intervenciones que se les realizaron a los pacientes.

- No se aplicó ningún modelo de cuantificación de gastos, de las intervenciones aplicadas a los pacientes.

6.3 Limitaciones de la determinación y evaluación de la efectividad de un programa estructurado de educación terapéutica, durante el ingreso, en comparación con la atención convencional

- Problemas con la captación de pacientes, durante el primer año de estudio donde se captaron a 22 pacientes, modificándose los criterios aplicados en la metodología, como la captación consecutiva de todos los pacientes que cumplieran con los criterios de inclusión o las personas que realizaban la captación y las entrevistas durante el ingreso.

- Aunque no existieron diferencias significativas entre los grupos de asignación, fue el grupo control el que presentó una mayor longevidad, mayor número de ingresos y visitas a urgencias, eran más sedentarios, tenían peor función pulmonar, con más comorbilidades, mayor consumo de pastillas, inhaladores e inyectables que el grupo intervención al inicio del estudio, siendo por tanto más notoria su mejoría con respecto al grupo intervención.

- Como consecuencia de las elevadas comorbilidades de los pacientes con EPOC, pudieron existir perdidas de pacientes.

- Algunos pacientes no acudieron a la mayoría de las sesiones de educación por imposibilidad de desplazarse, intentando mitigar dichas perdidas citando a los pacientes otros días y realizando seguimiento telefónico y recordatorio de las mismas.

- Limitaciones en la cumplimentación de los cuestionarios autocumplimentados que se realizaron a modo de entrevista, como consecuencia de problemas del paciente con la visión o por imposibilidad de desplazarse varios días de la semana para recoger los cuestionarios.

- El cuestionario St. George durante el ingreso, presento unas pérdidas de 3 pacientes como consecuencia de que el paciente no había podido cumplimentar el cuestionario o bien había sido dado de alta el día que se procedió a su recogida.

- Limitaciones en el tamaño muestral obtenido, donde la estimación del tamaño fue de 150 pacientes y en la presente tesis en el periodo estipulado solo se han podido incluir 60 . 
CONCLUSIONES 


\section{CONCLUSIONES}

Las conclusiones de este estudio están basadas en el análisis de los objetivos planteados y los resultados obtenidos, permitiendo concluir que:

Conclusiones de la revisión integradora

- Según los datos obtenidos desde el año 1987 al año 2013, 22 estudios han analizado la aplicación de la educación terapéutica en pacientes con EPOC, existiendo mayoritariamente más hombres que mujeres, con una media de edad que ronda los 66,3 años. Las variables resultado más estudiadas fueron la calidad de vida relacionada con la salud, los ingresos hospitalarios, variables ventilatorias como el $\mathrm{FEV}_{1}$, la disnea, el consumo de tabaco, la medicación utilizada y los conocimientos sobre la EPOC. En la mayoría de estudios que así lo abordan la educación terapéutica disminuye los ingresos hospitalarios, favorece o no modifica la deshabituación tabáquica, mejora los conocimientos y el manejo de la EPOC, así como la satisfacción con el servicio y los niveles de ansiedad y depresión.

Conclusiones del análisis de las características de la población con diagnóstico de exacerbación de la EPOC catalogado con el GRD088 y que ingresaron en el Hospital Universitario General de Castellón desde 2008 hasta 2013.

Las características de los pacientes estudiados coinciden con la población EPOC general.

Conclusiones de la determinación de efectividad de un programa estructurado de educación terapéutica a los 3 meses, en comparación con la atención tradicional:

- Si atendemos a los ingresos hospitalarios, la media de ingresos anuales se situó en 1 ingreso por causa respiratoria y 2 visitas a urgencias anuales. Siendo el grupo control el que presento una mayor reducción de los mismos, siendo sus diferencias significativa.

- Todos los pacientes mejoran sus conocimientos tanto de sus signos y síntomas de exacerbación como la medicación de rescate en caso de necesidad, siendo esta mejoría más notoria y significativa en el conocimiento del nombre de su patología.

- La Educación terapéutica mejora el uso del cartucho presurizado de forma significativa, pero no lo hace la comprarla entre los grupos al inicio y al final del estudio.

- La adherencia al tratamiento se mantuvo muy homogénea al principio y al final del mismo. 


\section{RECOMENDACIONES}




\section{RECOMENDACIONES}

En base a los resultados de este estudio se recomienda

- Ampliar este estudio con una muestra superior para poder extraer conclusiones que aporten mayor evidencia, así como replicar esta investigación en otros ámbitos, con otros criterios de selección de los pacientes y de forma más longitudinal en el tiempo, para observar su efecto a largo plazo.

- Con respecto a las sesiones de ET, tal y como indican otros estudios que han obtenido resultados más satisfactorios, sería recomendable aplicar planes individuales de educación para cada paciente pudiendo realizar las sesiones educativas de modo individual satisfaciendo las necesidades individuales de los pacientes. Disminuir las sesiones de educación en dos sesiones o una única sesión para favorecer la asistencia a las mismas. Además también sería recomendable aplicar, formación para la autogestión de las exacerbaciones, indicando que signos y síntomas son de alarma y el tratamiento que deben de seguir en esos casos. 
REFERENCIAS 


\section{REFERENCIAS}

1. Solanes Garcia I, Casan Clarà P. [Causes of death and prediction of mortality in COPD]. Arch Bronconeumol [Internet]. Elsevier; 2010 Jul 1 [cited 2015 Apr 15];46(7):343-6. Available from: http://www.archbronconeumol.org/es/causas-muerte-prediccion-mortalidadepoc/articulo/13152478/

2. GESEPOC G de trabajo. Guía de Práctica Clínica para el Diagnóstico y Tratamiento de Pacientes con Enfermedad Pulmonar Obstructiva Crónica (EPOC) - Guía Española de la EPOC (GesEPOC) [Internet]. [cited 2014 Dec 1]. Available from:

http://apps.elsevier.es/watermark/ctl_servlet?_f=10\&pident_articulo=90141716\&pident_usu ario $=0 \&$ pcontactid $=\&$ pident_revista $=6 \&$ ty $=92$ \&accion $=$ L\&origen $=$ bronco\&we $=$ www. arch

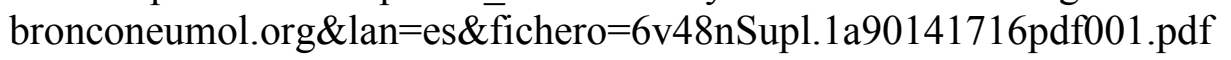

3. Kesten S, Chapman KR. Physician perceptions and management of COPD. Chest [Internet]. 1993 Jul [cited 2014 Dec 5];104(1):254-8. Available from: http://www.ncbi.nlm.nih.gov/pubmed/8325079

4. Germán Peces-Barbaa ; Joan Albert Barberàb ; Àlvar. Guía clínica SEPAR-ALAT de diagnóstico y tratamiento de la EPOC [Internet]. [cited 2014 Dec 1]. Available from: http://apps.elsevier.es/watermark/ctl_servlet?_f=10\&pident_articulo=13119943\&pident_usu ario $=0 \&$ pcontactid $=\&$ pident_revista $=6 \&$ ty $=1 \overline{3} 9 \&$ accion $=$ L $\&$ origen $=$ bronco $\& w e b=$ www .arc 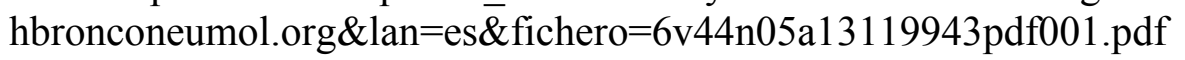

5. María Victorina López Varelaa, , Adriana Muiñoa, Rogelio Pérez Padillab, José Roberto Jardimc, Carlos Tálamod, María Montes de Ocad, Gonzalo Valdiviae, Julio Pertuzée, Ron Halbertf, Ana María Menezesg. Variabilidad en la EPOC. Una visión a través del estudio PLATINO [Internet]. [cited 2014 Dec 9]. Available from:

http://www.archbronconeumol.org/ficheros/eop/S0300-2896(11)00330-9.pdf

6. Han MK, Agusti A, Calverley PM, Celli BR, Criner G, Curtis JL, et al. Chronic obstructive pulmonary disease phenotypes: the future of COPD. Am J Respir Crit Care Med [Internet]. 2010 Sep 1 [cited 2014 Nov 7];182(5):598-604. Available from:

http://www.ncbi.nlm.nih.gov/pubmed/20522794

7. GESEPOC G de trabajo. [Moving towards a new focus on COPD. The Spanish COPD Guidelines (GESEPOC)]. Arch Bronconeumol [Internet]. 2011 Aug [cited 2014 Dec 1];47(8):379-81. Available from: http://www.ncbi.nlm.nih.gov/pubmed/21757283

8. Celli BR, Thomas NE, Anderson JA, Ferguson GT, Jenkins CR, Jones PW, et al. Effect of pharmacotherapy on rate of decline of lung function in chronic obstructive pulmonary disease: results from the TORCH study. Am J Respir Crit Care Med [Internet]. 2008 Aug 15 [cited 2014 Nov 25];178(4):332-8. Available from:

http://www.ncbi.nlm.nih.gov/pubmed/18511702

9. Martínez-García MÁ, Soler-Cataluña JJ, Donat Sanz Y, Catalán Serra P, Agramunt Lerma M, Ballestín Vicente J, et al. Factors associated with bronchiectasis in patients with COPD. Chest [Internet]. 2011 Nov [cited 2014 Dec 1];140(5):1130-7. Available from: http://www.ncbi.nlm.nih.gov/pubmed/21546440 
10. Patel BD, Coxson HO, Pillai SG, Agustí AGN, Calverley PMA, Donner CF, et al. Airway wall thickening and emphysema show independent familial aggregation in chronic obstructive pulmonary disease. Am J Respir Crit Care Med [Internet]. 2008 Sep 1 [cited 2014 Dec 11];178(5):500-5. Available from: http://www.ncbi.nlm.nih.gov/pubmed/18565956

11. Garcia-Aymerich J, Gómez FP, Benet M, Farrero E, Basagaña X, Gayete À, et al. Identification and prospective validation of clinically relevant chronic obstructive pulmonary disease (COPD) subtypes. Thorax [Internet]. 2011 May [cited 2014 Dec 1];66(5):430-7. Available from: http://www.ncbi.nlm.nih.gov/pubmed/21177668

12. Vidal R, Blanco I, Casas F, Jardí R, Miravitlles M. [Guidelines for the diagnosis and management of alpha-1 antitrypsin deficiency]. Arch Bronconeumol [Internet]. 2006 Dec [cited 2014 Dec 1];42(12):645-59. Available from:

http://www.ncbi.nlm.nih.gov/pubmed/17178069

13. Hurst JR, Vestbo J, Anzueto A, Locantore N, Müllerova H, Tal-Singer R, et al. Susceptibility to exacerbation in chronic obstructive pulmonary disease. N Engl J Med [Internet]. 2010 Oct 16 [cited 2014 Oct 31];363(12):1128-38. Available from:

http://www.ncbi.nlm.nih.gov/pubmed/20843247

14. Quint JK, Donaldson GC, Hurst JR, Goldring JJP, Seemungal TR, Wedzicha JA. Predictive accuracy of patient-reported exacerbation frequency in COPD. Eur Respir J [Internet]. 2011 Mar [cited 2014 Dec 1];37(3):501-7. Available from: http://www.ncbi.nlm.nih.gov/pubmed/20650988

15. Bafadhel M, McKenna S, Terry S, Mistry V, Reid C, Haldar P, et al. Acute exacerbations of chronic obstructive pulmonary disease: identification of biologic clusters and their biomarkers. Am J Respir Crit Care Med [Internet]. 2011 Sep 15 [cited 2014 Nov 5];184(6):662-71. Available from: http://www.ncbi.nlm.nih.gov/pubmed/21680942

16. Hardin M, Silverman EK, Barr RG, Hansel NN, Schroeder JD, Make BJ, et al. The clinical features of the overlap between COPD and asthma. Respir Res [Internet]. 2011 Jan [cited 2014 Nov 17];12:127. Available from:

http://www.pubmedcentral.nih.gov/articlerender.fcgi?artid=3204243\&tool=pmcentrez\&rend ertype $=$ abstract

17. Gibson PG, Simpson JL. The overlap syndrome of asthma and COPD: what are its features and how important is it? Thorax [Internet]. 2009 Aug [cited 2014 Nov 10];64(8):728-35. Available from: http://www.ncbi.nlm.nih.gov/pubmed/19638566

18. Boulet L-P, Lemière C, Archambault F, Carrier G, Descary MC, Deschesnes F. Smoking and asthma: clinical and radiologic features, lung function, and airway inflammation. Chest [Internet]. 2006 Mar [cited 2014 Dec 1];129(3):661-8. Available from: http://www.ncbi.nlm.nih.gov/pubmed/16537865

19. De Marco R, Accordini S, Cerveri I, Corsico A, Antó JM, Künzli N, et al. Incidence of chronic obstructive pulmonary disease in a cohort of young adults according to the presence of chronic cough and phlegm. Am J Respir Crit Care Med [Internet]. 2007 Jan 1 [cited 2014 Nov 21];175(1):32-9. Available from: http://www.ncbi.nlm.nih.gov/pubmed/17008642 
20. Miravitlles M. The overlap syndrome between asthma and COPD: implications for management [Internet]. [cited 2014 Dec 1]. Available from: file://C:/Users/Usuario 1/Downloads/The_overlap_syndrome_between_asthma_and_COPD_implications_for_mana gement_635530512560835741.pdf

21. Contoli M, Baraldo S, Marku B, Casolari P, Marwick JA, Turato G, et al. Fixed airflow obstruction due to asthma or chronic obstructive pulmonary disease: 5-year follow-up. J Allergy Clin Immunol [Internet]. 2010 Apr [cited 2014 Dec 1];125(4):830-7. Available from: http://www.ncbi.nlm.nih.gov/pubmed/20227753

22. Pulmonar G de trabajo de la G de PC para el T de P con E, (EPOC). OC. Guía de Práctica Clínica para el Tratamiento de Pacientes con Enfermedad Pulmonar Obstructiva Crónica (EPOC). Plan de Calidad para el Sistema Nacional de Salud del Ministerio de Sanidad; Servicios Sociales e Igualdad. Unidad de Evaluación de Tecnologías S [Internet]. Guías de Práctica Clínica en el SNS: UETS Nº 2011/6. 2012 [cited 2014 Dec 5]. Available from: file:///E:/Doctorado/Antecedentes/Guía de práctica EPO_Ministerio.pdf

23. American Thoracic Society. Chronic bronchitis, asthma, and pulmonary emphysema, a statement by the Committee on Diagnostic Standards for Nontuberculous Respiratory Diseases [Internet]. Am Rev Respir Dis. 1962 [cited 2014 Dec 1]. p. 85:762-8. Available from: http://www.thoracic.org/statements/resources/archive/standards-for-diagnosis-andcare-of-COPD-and-Asthma-patients.pdf

24. Prescott E, Lange P, Vestbo J. Chronic mucus hypersecretion in COPD and death from pulmonary infection. Eur Respir J [Internet]. 1995 Aug [cited 2014 Dec 1];8(8):1333-8. Available from: http://www.ncbi.nlm.nih.gov/pubmed/7489800

25. Nishimura M, Makita H, Nagai K, Konno S, Nasuhara Y, Hasegawa M, et al. Annual change in pulmonary function and clinical phenotype in chronic obstructive pulmonary disease. Am J Respir Crit Care Med [Internet]. 2012 Jan 1 [cited 2014 Dec 1];185(1):44-52. Available from: http://www.ncbi.nlm.nih.gov/pubmed/22016444

26. Miravitlles M, de la Roza C, Morera J, Montemayor T, Gobartt E, Martín A, et al. Chronic respiratory symptoms, spirometry and knowledge of COPD among general population. Respir Med [Internet]. 2006 Nov [cited 2014 Dec 9];100(11):1973-80. Available from: http://www.ncbi.nlm.nih.gov/pubmed/16626950

27. Alvarez F, Bouza E, García-Rodríguez JA, Mensa J, Monsó E, Picazo JJ, et al. [Second consensus report on the use of antimicrobial agents in exacerbations of chronic obstructive pulmonary disease]. Arch Bronconeumol [Internet]. 2003 Jun [cited 2015 Jan 9];39(6):27482. Available from: http://www.ncbi.nlm.nih.gov/pubmed/12797944

28. Masa JF, Sobradillo V, Villasante C, Jiménez-Ruiz CA, Fernández-Fau L, Viejo JL, et al. [Costs of chronic obstructive pulmonary disease in Spain. Estimation from a populationbased study]. Arch Bronconeumol [Internet]. 2004 Feb [cited 2015 Jan 9];40(2):72-9. Available from: http://www.ncbi.nlm.nih.gov/pubmed/14746730

29. Soriano JBM. Datos epidemiológicos de EPOC en España. Arch Bronconeumol [Internet]. Elsevier; 2007 May 20 [cited 2014 Dec 9];43 Suppl 1(Supl.1):2-9. Available from:

http://www.archbronconeumol.org/es/datos-epidemiologicos-epoc-espana/articulo/13100985/ 
30. Ministerio de Sanidad, Servicios Sociales e Igualdad - Portal Estadístico del SNS - Sistema de Información Sanitaria: Portal Estadístico del SNS - Registro de Altas de los Hospitales del Sistema Nacional de Salud. CMBD [Internet]. [cited 2014 Dec 9]. Available from: https://www.msssi.gob.es/estadEstudios/estadisticas/cmbdhome.htm

31. Ancochea J. Estrategia Nacional en Cuidados Paliativos del SNS [Internet]. Ministerio de Sanidad. 2009 [cited 2014 Dec 9]. Available from: http://www.msssi.gob.es/organizacion/sns/planCalidadSNS/docs/EstrategiaEPOCSNS.pdf

32. Miravitlles M, Murio C, Guerrero T, Gisbert R. Costs of chronic bronchitis and COPD: a 1year follow-up study. Chest [Internet]. 2003 Mar [cited 2014 Dec 9];123(3):784-91. Available from: http://www.ncbi.nlm.nih.gov/pubmed/12628879

33. García Guillén M de L. Setenta y un años de historia de la EPOC en el Instituto Nacional de Enfermedades Respiratorias Ismael Cosío Villegas (1935-2006). Rev del Inst Nac Enfermedades Respir [Internet]. Instituto Nacional de Enfermedades Respiratorias; [cited 2014 Dec 31];19(4):316-20. Available from:

http://www.scielo.org.mx/scielo.php?script=sci_arttext\&pid=S018775852006000400016\&lng=es\&nrm=iso\&tlng=es

34. Celli BR, MacNee W. Standards for the diagnosis and treatment of patients with COPD: a summary of the ATS/ERS position paper. Eur Respir J [Internet]. 2004 Jun [cited 2014 Dec 1];23(6):932-46. Available from: http://www.ncbi.nlm.nih.gov/pubmed/15219010

35. Sanchís Aldás J, Casan Clarà P, Castillo Gómez J, Honzález Mangado N P, Ballesteros L RTJ. Normativa para la práctica de la espirometría forzada. Arch Bronconeumol. Arch Bronconeumol. 1989;25:132-42.

36. Monteagudo M, Rodriguez-Blanco T, Parcet J, Peñalver N, Rubio C, Ferrer M, et al. Variability in the performing of spirometry and its consequences in the treatment of COPD in primary care. Arch Bronconeumol [Internet]. Elsevier; 2011 May 1 [cited 2015 Apr 15];47(5):226-33. Available from: http://www.archbronconeumol.org/es/variabilidadrealizacion-espirometria-sus-consecuencias/articulo/90008614/

37. Hardie JA, Buist AS, Vollmer WM, Ellingsen I, Bakke PS, Mørkve O. Risk of overdiagnosis of COPD in asymptomatic elderly never-smokers. Eur Respir J [Internet]. 2002 Nov [cited 2014 Dec 9];20(5):1117-22. Available from: http://www.ncbi.nlm.nih.gov/pubmed/12449163

38. Matthay RA, Niederman MS, Wiedemann HP. Cardiovascular-pulmonary interaction in chronic obstructive pulmonary disease with special reference to the pathogenesis and management of cor pulmonale. Med Clin North Am [Internet]. 1990 May [cited 2014 Dec 10];74(3):571-618. Available from: http://www.ncbi.nlm.nih.gov/pubmed/2186234

39. Miniati M, Monti S, Stolk J, Mirarchi G, Falaschi F, Rabinovich R, et al. Value of chest radiography in phenotyping chronic obstructive pulmonary disease. Eur Respir J [Internet]. 2008 Mar 1 [cited 2014 Dec 10];31(3):509-15. Available from: http://erj.ersjournals.com/content/31/3/509.long

40. GESEPOC G de trabajo. Guía de Práctica Clínica para el Diagnóstico y Tratamiento de Pacientes con Enfermedad Pulmonar Obstructiva Crónica (EPOC) [Internet]. [cited 2014 Jun 12]. Available from: file:///C:/Users/Usuario 1/Desktop/6v48nSupl.1a90141716pdf001.pdf 
41. Soler-Cataluña JJ, Martínez-García MA, Sánchez LS, Tordera MP, Sánchez PR. Severe exacerbations and BODE index: two independent risk factors for death in male COPD patients. Respir Med [Internet]. 2009 May [cited 2016 Jan 15];103(5):692-9. Available from: http://www.sciencedirect.com/science/article/pii/S0954611108004496

42. Fletcher C, Peto R. The natural history of chronic airflow obstruction. Br Med J [Internet]. 1977 Jun 25 [cited 2014 Dec 11];1(6077):1645-8. Available from:

http://www.pubmedcentral.nih.gov/articlerender.fcgi?artid=1607732\&tool=pmcentrez\&rend ertype $=$ abstract

43. Kohansal R, Martinez-Camblor P, Agustí A, Buist AS, Mannino DM, Soriano JB. The natural history of chronic airflow obstruction revisited: an analysis of the Framingham offspring cohort. Am J Respir Crit Care Med [Internet]. 2009 Jul 1 [cited 2014 Nov 23];180(1):3-10. Available from: http://www.ncbi.nlm.nih.gov/pubmed/19342411

44. Marc Miravitlles; Juan José Soler-Cataluña; Myriam. Guía Espanola de la EPOC (GesEPOC). Tratamiento farmacológico de la EPOC estable [Internet]. Arch Bronconeumol. 2012 [cited 2014 Dec 1]. p. 48(7):247-257. Available from:

http://apps.elsevier.es/watermark/ctl_servlet?_f=10\&pident_articulo=90141601\&pident_usu ario $=0 \&$ pcontactid $=\&$ pident_revista $=6 \&$ ty $=148 \&$ accion $=$ L\&origen $=$ bronco\&web $=$ www .arc hbronconeumol.org\&lan $=$ es $\&$ fichero $=6$ v48n07a90141601pdf001.pdf

45. Seemungal TA, Donaldson GC, Paul EA, Bestall JC, Jeffries DJ, Wedzicha JA. Effect of exacerbation on quality of life in patients with chronic obstructive pulmonary disease. Am J Respir Crit Care Med [Internet]. 1998 May [cited 2014 Dec 11];157(5 Pt 1):1418-22. Available from: http://www.ncbi.nlm.nih.gov/pubmed/9603117

46. Langsetmo L, Platt RW, Ernst P, Bourbeau J. Underreporting exacerbation of chronic obstructive pulmonary disease in a longitudinal cohort. Am J Respir Crit Care Med [Internet]. 2008 Feb 15 [cited 2014 Nov 20];177(4):396-401. Available from: http://www.ncbi.nlm.nih.gov/pubmed/18048806

47. Chhabra SK, Dash DJ. Acute exacerbations of chronic obstructive pulmonary disease: causes and impacts. Indian J Chest Dis Allied Sci [Internet]. [cited 2014 Dec 11];56(2):93-104. Available from: http://www.ncbi.nlm.nih.gov/pubmed/25230550

48. GESEPOC G de trabajo. Guía de Práctica Clínica para el Diagnóstico y tratamiento de Pacientes con Enfermedad Pulmonar Obstructiva Crónica (EPOC) - Guía Española de la EPOC (GesEPOC) [Internet]. Guía de Práctica Clínica para el Diagnóstico y tratamiento de Pacientes con Enfermedad Pulmonar Obstructiva Crónica (EPOC) - Guía Española de la EPOC (GesEPOC). 2012 [cited 2014 Dec 1]. p. 48(Supl 1):2-58; Arch Bronconeumol. 2012. Available from:

http://apps.elsevier.es/watermark/ctl_servlet?_f=10\&pident_articulo=90268739\&pident_usu ario $=0 \&$ pcontactid $=\&$ pident_revista $=6 \&$ ty $=62 \&$ accion $=$ L\&origen $=$ bronco\&web $=w w w . a r c h$ bronconeumol.org\&lan $=$ es\&fichero $=6$ v50nSupl.1a90268739pdf001.pdf

49. OSWALD NC, MEDVEI VC. Chronic bronchitis; the effect of cigarette-smoking. Lancet [Internet]. 1955 Oct 22 [cited 2014 Nov 24];269(6895):843-4. Available from: http://www.ncbi.nlm.nih.gov/pubmed/13264626 
50. ANDERSON DO, FERRIS BG. Role of tobacco smoking in the causation of chronic respiratory disease. N Engl J Med [Internet]. 1962 Oct 18 [cited 2014 Nov 12];267:787-94. Available from: http://www.ncbi.nlm.nih.gov/pubmed/14012834

51. Løkke A, Lange P, Scharling H, Fabricius P, Vestbo J. Developing COPD: a 25 year follow up study of the general population. Thorax [Internet]. 2006 Nov [cited 2014 Nov 6];61(11):935-9. Available from:

http://www.pubmedcentral.nih.gov/articlerender.fcgi?artid=2121175\&tool=pmcentrez\&rend ertype $=$ abstract

52. Instituto Nacional de Estadística. (National Statistics Institute) [Internet]. [cited 2014 Dec 1]. Available from:

http://www.ine.es/jaxi/menu.do?type=pcaxis\&path=/t15/a044/a101/\&file=pcaxis

53. Jaén Díaz JI, de Castro Mesa C, Gontán García-Salamanca MJ, López de Castro F.

Prevalencia y factores de riesgo de EPOC en fumadores y ex fumadores. Arch Bronconeumol [Internet]. 2003 Jan [cited 2015 Jul 30];39(12):554-8. Available from:

http://www.sciencedirect.com/science/article/pii/S0300289603754544

54. Salvi SS, Barnes PJ. Chronic obstructive pulmonary disease in non-smokers. Lancet [Internet]. 2009 Aug 29 [cited 2014 Oct 27];374(9691):733-43. Available from: http://www.ncbi.nlm.nih.gov/pubmed/19716966

55. Jaakkola MS, Jaakkola JJK. Effects of environmental tobacco smoke on the respiratory health of adults. Scand J Work Environ Health [Internet]. 2002 Jan [cited 2014 Dec 1];28 Suppl 2:52-70. Available from: http://www.ncbi.nlm.nih.gov/pubmed/12058803

56. Larsson ML, Loit HM, Meren M, Põlluste J, Magnusson A, Larsson K, et al. Passive smoking and respiratory symptoms in the FinEsS Study. Eur Respir J [Internet]. 2003 Apr [cited 2014 Dec 1];21(4):672-6. Available from: http://www.ncbi.nlm.nih.gov/pubmed/12762355

57. Yin P, Jiang CQ, Cheng KK, Lam TH, Lam KH, Miller MR, et al. Passive smoking exposure and risk of COPD among adults in China: the Guangzhou Biobank Cohort Study. Lancet [Internet]. 2007 Sep 1 [cited 2014 Dec 1];370(9589):751-7. Available from: http://www.ncbi.nlm.nih.gov/pubmed/17765524

58. Ho SY, Lam TH, Chung SF, Lam TP. Cross-sectional and prospective associations between passive smoking and respiratory symptoms at the workplace. Ann Epidemiol [Internet]. 2007 Feb [cited 2014 Dec 1];17(2):126-31. Available from: http://www.ncbi.nlm.nih.gov/pubmed/17027296

59. González Barcala FJ, Takkouche B, Valdés L, Temes E, Leis R, Cabanas R, et al. [Parental smoking and lung function in healthy children and adolescents]. Arch Bronconeumol [Internet]. $2007 \mathrm{Feb}$ [cited $2014 \mathrm{Dec} 1$ ];43(2):81-5. Available from: http://www.ncbi.nlm.nih.gov/pubmed/17288896

60. Torres-Duque C, Maldonado D, Pérez-Padilla R, Ezzati M, Viegi G. Biomass fuels and respiratory diseases: a review of the evidence. Proc Am Thorac Soc [Internet]. 2008 Jul 15 [cited 2014 Nov 24];5(5):577-90. Available from: http://www.ncbi.nlm.nih.gov/pubmed/18625750 
61. Hu G, Zhou Y, Tian J, Yao W, Li J, Li B, et al. Risk of COPD from exposure to biomass smoke: a metaanalysis. Chest [Internet]. 2010 Jul [cited 2014 Dec 1];138(1):20-31. Available from: http://www.ncbi.nlm.nih.gov/pubmed/20139228

62. Kurmi OP, Semple S, Simkhada P, Smith WCS, Ayres JG. COPD and chronic bronchitis risk of indoor air pollution from solid fuel: a systematic review and meta-analysis. Thorax [Internet]. 2010 Mar [cited 2014 Nov 20];65(3):221-8. Available from: http://www.ncbi.nlm.nih.gov/pubmed/20335290

63. Po JYT, FitzGerald JM, Carlsten C. Respiratory disease associated with solid biomass fuel exposure in rural women and children: systematic review and meta-analysis. Thorax [Internet]. 2011 Mar [cited 2014 Dec 1];66(3):232-9. Available from: http://www.ncbi.nlm.nih.gov/pubmed/21248322

64. Orozco-Levi M, Garcia-Aymerich J, Villar J, Ramírez-Sarmiento A, Antó JM, Gea J. Wood smoke exposure and risk of chronic obstructive pulmonary disease. Eur Respir J [Internet]. 2006 Mar [cited 2014 Nov 4];27(3):542-6. Available from: http://www.ncbi.nlm.nih.gov/pubmed/16507854

65. Smith KR, Aggarwal AL, Dave RM. Air pollution and rural biomass fuels in developing countries: A pilot village study in India and implications for research and policy. Atmos Environ [Internet]. 1983 Jan [cited 2014 Dec 9];17(11):2343-62. Available from: http://www.sciencedirect.com/science/article/pii/0004698183902342

66. Malats N, Camus-Radon A-M, Nyberg F, Ahrens W, Constantinescu V, Mukeria A, et al. Lung Cancer Risk in Nonsmokers and GSTM1 and GSTT1 Genetic Polymorphism. Cancer Epidemiol Biomarkers Prev [Internet]. 2000 Aug 1 [cited 2014 Dec 9];9(8):827-33. Available from: http://cebp.aacrjournals.org/content/9/8/827.abstract?ijkey=87f94614c4b4a1952e3c2ad944fd e75f008f412e\&keytype $2=\mathrm{tf}$ _ipsecsha

67. Hong Y, Lim MN, Kim WJ, Rhee CK, Yoo KH, Lee J-H, et al. Influence of environmental exposures on patients with chronic obstructive pulmonary disease in Korea. Tuberc Respir Dis (Seoul) [Internet]. 2014 May [cited 2014 Dec 17];76(5):226-32. Available from: http://www.pubmedcentral.nih.gov/articlerender.fcgi? artid=4050070\&tool=pmcentrez\&rend ertype $=$ abstract

68. Eisner MD, Anthonisen N, Coultas D, Kuenzli N, Perez-Padilla R, Postma D, et al. An official American Thoracic Society public policy statement: Novel risk factors and the global burden of chronic obstructive pulmonary disease. Am J Respir Crit Care Med [Internet]. 2010 Sep 1 [cited 2014 Oct 29];182(5):693-718. Available from: http://www.ncbi.nlm.nih.gov/pubmed/20802169

69. Andersen ZJ, Hvidberg M, Jensen SS, Ketzel M, Loft S, Sørensen M, et al. Chronic obstructive pulmonary disease and long-term exposure to traffic-related air pollution: a cohort study. Am J Respir Crit Care Med [Internet]. 2011 Feb 15 [cited 2014 Dec 1];183(4):455-61. Available from: http://www.ncbi.nlm.nih.gov/pubmed/20870755

70. Rushton L. Occupational causes of chronic obstructive pulmonary disease. Rev Environ Health [Internet]. [cited 2014 Dec 1];22(3):195-212. Available from:

http://www.ncbi.nlm.nih.gov/pubmed/18078004 
71. Posgay M, Varró MJ, Szentmihályi R, Lang Z. [Environmental epidemiological study on respiratory diseases in two Hungarian towns]. Orv Hetil [Internet]. 2010 Mar 7 [cited 2014 Dec 17];151(10):378-84. Available from: http://www.ncbi.nlm.nih.gov/pubmed/20178969

72. Barczyk A, Sozańska E, Pierzchała W. [The influence of occupational exposure to pesticides on the frequency of chronic obstructive pulmonary diseases]. Wiad Lek [Internet]. 2006 Jan [cited 2014 Dec 17];59(9-10):596-600. Available from: http://www.ncbi.nlm.nih.gov/pubmed/17338112

73. Sakwari G, Bråtveit M, Mamuya SHD, Moen BE. Dust exposure and chronic respiratory symptoms among coffee curing workers in Kilimanjaro: a cross sectional study. BMC Pulm Med [Internet]. 2011 Jan [cited 2014 Dec 17];11:54. Available from: http://www.pubmedcentral.nih.gov/articlerender.fcgi?artid=3247191\&tool=pmcentrez\&rend ertype $=$ abstract

74. Mamuya SHD, Bråtveit M, Mashalla Y, Moen BE. High prevalence of respiratory symptoms among workers in the development section of a manually operated coal mine in a developing country: a cross sectional study. BMC Public Health [Internet]. 2007 Jan [cited 2014 Dec 17];7:17. Available from:

http://www.pubmedcentral.nih.gov/articlerender.fcgi?artid=1797009\&tool=pmcentrez\&rend ertype $=$ abstract

75. Cohen RAC, Patel A, Green FHY. Lung disease caused by exposure to coal mine and silica dust. Semin Respir Crit Care Med [Internet]. 2008 Dec [cited 2014 Nov 20];29(6):651-61. Available from: http://www.ncbi.nlm.nih.gov/pubmed/19221963

76. Mwaiselage J, Bråtveit M, Moen BE, Mashalla Y. Respiratory symptoms and chronic obstructive pulmonary disease among cement factory workers. Scand J Work Environ Health [Internet]. 2005 Aug [cited 2014 Dec 17];31(4):316-23. Available from: http://www.ncbi.nlm.nih.gov/pubmed/16161715

77. Ahmed HO, Abdullah AA. Dust exposure and respiratory symptoms among cement factory workers in the United Arab Emirates. Ind Health [Internet]. 2012 Jan [cited 2014 Dec 17];50(3):214-22. Available from: http://www.ncbi.nlm.nih.gov/pubmed/22453209

78. Love RG, Waclawski ER, Maclaren WM, Wetherill GZ, Groat SK, Porteous RH, et al. Risks of respiratory disease in the heavy clay industry. Occup Environ Med [Internet]. 1999 Feb [cited 2014 Dec 17];56(2):124-33. Available from:

http://www.pubmedcentral.nih.gov/articlerender.fcgi?artid=1757705\&tool=pmcentrez\&rend ertype $=$ abstract

79. Coultas D, Frederick J, Barnett B, Singh G, Wludyka P. A randomized trial of two types of nurse-assisted home care for patients with COPD. Chest [Internet]. 2005 Oct [cited 2014 Jun 11];128(4):2017-24. Available from: http://www.ncbi.nlm.nih.gov/pubmed/16236850

80. Menezes AMB, Hallal PC, Perez-Padilla R, Jardim JRB, Muiño A, Lopez M V, et al. Tuberculosis and airflow obstruction: evidence from the PLATINO study in Latin America. Eur Respir J [Internet]. 2007 Dec [cited 2014 Dec 1];30(6):1180-5. Available from: http://www.ncbi.nlm.nih.gov/pubmed/17804445 
81. Köhnlein T, Welte T. Alpha-1 antitrypsin deficiency: pathogenesis, clinical presentation, diagnosis, and treatment. Am J Med [Internet]. 2008 Jan [cited 2014 Dec 1];121(1):3-9. Available from: http://www.ncbi.nlm.nih.gov/pubmed/18187064

82. Miravitlles M, Herr C, Ferrarotti I, Jardi R, Rodriguez-Frias F, Luisetti M, et al. Laboratory testing of individuals with severe alpha1-antitrypsin deficiency in three European centres. Eur Respir J [Internet]. 2010 May [cited 2014 Dec 1];35(5):960-8. Available from: http://www.ncbi.nlm.nih.gov/pubmed/20436173

83. Silverman EK, Pierce JA, Province MA, Rao DC, Campbell EJ. Variability of pulmonary function in alpha-1-antitrypsin deficiency: clinical correlates. Ann Intern Med [Internet]. 1989 Dec 15 [cited 2014 Dec 10];111(12):982-91. Available from: http://www.ncbi.nlm.nih.gov/pubmed/2596778

84. McElvaney NG, Stoller JK, Buist AS, Prakash UB, Brantly ML, Schluchter MD, et al. Baseline characteristics of enrollees in the National Heart, Lung and Blood Institute Registry of alpha 1-antitrypsin deficiency. Alpha 1-Antitrypsin Deficiency Registry Study Group. Chest [Internet]. $1997 \mathrm{Feb}$ [cited 2014 Dec 10];111(2):394-403. Available from: http://www.ncbi.nlm.nih.gov/pubmed/9041988

85. Seersholm N. Body mass index and mortality in patients with severe alpha 1-antitrypsin deficiency. Respir Med [Internet]. 1997 Feb [cited 2014 Dec 10];91(2):77-82. Available from: http://www.ncbi.nlm.nih.gov/pubmed/9122515

86. Seersholm N, Dirksen A, Kok-Jensen A. Airways obstruction and two year survival in patients with severe alpha 1-antitrypsin deficiency. Eur Respir J [Internet]. 1994 Nov [cited 2014 Dec 10];7(11):1985-7. Available from: http://www.ncbi.nlm.nih.gov/pubmed/7875269

87. Lara B. [COPD and alpha-1-antitrypsin deficiency]. Arch Bronconeumol [Internet]. Elsevier; 2010 Jan 1 [cited 2014 Dec 10];46 Suppl 4(Supl.4):2-8. Available from:

http://www.archbronconeumol.org/es/epoc-deficit-alfa-1-antitripsina/articulo/13155402/

88. American Thoracic Society/European Respiratory Society statement: standards for the diagnosis and management of individuals with alpha-1 antitrypsin deficiency. Am J Respir Crit Care Med [Internet]. 2003 Oct 1 [cited 2014 Nov 23];168(7):818-900. Available from: http://www.ncbi.nlm.nih.gov/pubmed/14522813

89. DeMeo DL, Silverman EK. Alpha1-antitrypsin deficiency. 2: genetic aspects of alpha(1)antitrypsin deficiency: phenotypes and genetic modifiers of emphysema risk. Thorax [Internet]. 2004 Mar [cited 2014 Dec 10];59(3):259-64. Available from: http://www.pubmedcentral.nih.gov/articlerender.fcgi?artid=1746953\&tool=pmcentrez\&rend ertype $=$ abstract

90. Miravitlles M, Vidal R, Torrella M, Bofill JM, Cotrina M, de Gracia J. [Evaluation of replacement therapy in emphysema caused by alpha 1-antitrypsin deficiency]. Arch Bronconeumol [Internet]. 1994 Dec [cited 2014 Dec 10];30(10):479-84. Available from: http://www.ncbi.nlm.nih.gov/pubmed/7827760

91. Wewers MD, Casolaro MA, Sellers SE, Swayze SC, McPhaul KM, Wittes JT, et al. Replacement therapy for alpha 1-antitrypsin deficiency associated with emphysema. N Engl J Med [Internet]. 1987 Apr 23 [cited 2014 Dec 10];316(17):1055-62. Available from: http://www.ncbi.nlm.nih.gov/pubmed/3494198 
92. Lieberman J. Augmentation therapy reduces frequency of lung infections in antitrypsin deficiency: a new hypothesis with supporting data. Chest [Internet]. 2000 Nov [cited 2014 Dec 10];118(5):1480-5. Available from: http://www.ncbi.nlm.nih.gov/pubmed/11083705

93. Anecchino C, Rossi E, Fanizza C, De Rosa M, Tognoni G, Romero M. Prevalence of chronic obstructive pulmonary disease and pattern of comorbidities in a general population. Int $\mathrm{J}$ Chron Obstruct Pulmon Dis [Internet]. 2007 Jan [cited 2014 Dec 17];2(4):567-74. Available from:

http://www.pubmedcentral.nih.gov/articlerender.fcgi?artid=2699968\&tool=pmcentrez\&rend ertype $=$ abstract

94. Chatila WM, Thomashow BM, Minai OA, Criner GJ, Make BJ. Comorbidities in chronic obstructive pulmonary disease. Proc Am Thorac Soc [Internet]. 2008 May 1 [cited 2014 Nov 23];5(4):549-55. Available from:

http://www.pubmedcentral.nih.gov/articlerender.fcgi?artid=2645334\&tool=pmcentrez\&rend ertype $=$ abstract

95. Calverley PMA, Anderson JA, Celli B, Ferguson GT, Jenkins C, Jones PW, et al. Salmeterol and fluticasone propionate and survival in chronic obstructive pulmonary disease. $\mathrm{N}$ Engl $\mathrm{J}$ Med [Internet]. 2007 Feb 22 [cited 2014 Nov 21];356(8):775-89. Available from: http://www.ncbi.nlm.nih.gov/pubmed/17314337

96. Mannino DM, Thorn D, Swensen A, Holguin F. Prevalence and outcomes of diabetes, hypertension and cardiovascular disease in COPD. Eur Respir J [Internet]. 2008 Oct [cited 2014 Nov 23];32(4):962-9. Available from: http://www.ncbi.nlm.nih.gov/pubmed/18579551

97. Finkelstein J, Cha E, Scharf SM. Chronic obstructive pulmonary disease as an independent risk factor for cardiovascular morbidity. Int J Chron Obstruct Pulmon Dis [Internet]. 2009 Jan [cited 2014 Dec 1];4:337-49. Available from:

http://www.pubmedcentral.nih.gov/articlerender.fcgi? artid=2754086\&tool=pmcentrez\&rend ertype $=$ abstract

98. Feary JR, Rodrigues LC, Smith CJ, Hubbard RB, Gibson JE. Prevalence of major comorbidities in subjects with COPD and incidence of myocardial infarction and stroke: a comprehensive analysis using data from primary care. Thorax [Internet]. $2010 \mathrm{Nov}$ [cited 2014 Nov 11];65(11):956-62. Available from:

http://www.ncbi.nlm.nih.gov/pubmed/20871122

99. Donaldson GC, Hurst JR, Smith CJ, Hubbard RB, Wedzicha JA. Increased risk of myocardial infarction and stroke following exacerbation of COPD. Chest [Internet]. 2010 May [cited 2014 Dec 1];137(5):1091-7. Available from:

http://www.ncbi.nlm.nih.gov/pubmed/20022970

100. Vaidyula VR, Criner GJ, Grabianowski C, Rao AK. Circulating tissue factor procoagulant activity is elevated in stable moderate to severe chronic obstructive pulmonary disease. Thromb Res [Internet]. 2009 Jul [cited 2014 Dec 17];124(3):259-61. Available from: http://www.pubmedcentral.nih.gov/articlerender.fcgi?artid=2877030\&tool=pmcentrez\&rend ertype $=$ abstract

101. Weitzenblum E, Sautegeau A, Ehrhart M, Mammosser M, Pelletier A. Long-term oxygen therapy can reverse the progression of pulmonary hypertension in patients with chronic 
obstructive pulmonary disease. Am Rev Respir Dis [Internet]. 1985 Apr [cited 2014 Dec 17];131(4):493-8. Available from: http://www.ncbi.nlm.nih.gov/pubmed/3922267

102. Eickhoff P, Valipour A, Kiss D, Schreder M, Cekici L, Geyer K, et al. Determinants of systemic vascular function in patients with stable chronic obstructive pulmonary disease. Am J Respir Crit Care Med [Internet]. 2008 Dec 15 [cited 2014 Dec 17];178(12):1211-8. Available from: http://www.ncbi.nlm.nih.gov/pubmed/18836149

103. Loganathan R, Stover D, ... WS. La prevalencia de la EPOC en mujeres que en hombres en todo el momento del diagnóstico de cáncer primario de pulmón. PECHO . [Internet]. 2006 [cited 2014 Dec 17]; Available from:

http://journal.publications.chestnet.org/article.aspx?articleid=1084449

104. Cohen BH, Diamond EL, Graves CG, Kreiss P, Levy DA, Menkes HA, et al. A common familial component in lung cancer and chronic obstructive pulmonary disease. Lancet [Internet]. 1977 Sep 10 [cited 2014 Dec 17];2(8037):523-6. Available from: http://www.ncbi.nlm.nih.gov/pubmed/95731

105. Aberle DR, Adams AM, Berg CD, Black WC, Clapp JD, Fagerstrom RM, et al. Reduced lung-cancer mortality with low-dose computed tomographic screening. N Engl J Med [Internet]. 2011 Aug 4 [cited 2014 Oct 8];365(5):395-409. Available from: http://www.ncbi.nlm.nih.gov/pubmed/21714641

106. Pumar MI, Gray CR, Walsh JR, Yang IA, Rolls TA, Ward DL. Anxiety and depressionImportant psychological comorbidities of COPD. J Thorac Dis [Internet]. 2014 Nov [cited 2014 Dec 10];6(11):1615-31. Available from:

http://www.pubmedcentral.nih.gov/articlerender.fcgi?artid=4255157\&tool=pmcentrez\&rend ertype $=$ abstract

107. Schols AM, Soeters PB, Dingemans AM, Mostert R, Frantzen PJ, Wouters EF. Prevalence and characteristics of nutritional depletion in patients with stable COPD eligible for pulmonary rehabilitation. Am Rev Respir Dis [Internet]. 1993 May [cited 2014 Dec 17];147(5):1151-6. Available from: http://www.ncbi.nlm.nih.gov/pubmed/8484624

108. Ferreira IM, Brooks D, Lacasse Y, Goldstein RS. Nutritional support for individuals with COPD: a meta-analysis. Chest [Internet]. 2000 Mar [cited 2014 Dec 17];117(3):672-8. Available from: http://www.ncbi.nlm.nih.gov/pubmed/10712990

109. Cavaillès A, Brinchault-Rabin G, Dixmier A, Goupil F, Gut-Gobert C, Marchand-Adam S, et al. Comorbidities of COPD. Eur Respir Rev [Internet]. 2013 Dec [cited 2014 Dec 17];22(130):454-75. Available from: http://www.ncbi.nlm.nih.gov/pubmed/24293462

110. Vestbo J, Prescott E, Almdal T, Dahl M, Nordestgaard BG, Andersen T, et al. Body mass, fat-free body mass, and prognosis in patients with chronic obstructive pulmonary disease from a random population sample: findings from the Copenhagen City Heart Study. Am J Respir Crit Care Med [Internet]. 2006 Jan 1 [cited 2014 Dec 17];173(1):79-83. Available from: http://www.ncbi.nlm.nih.gov/pubmed/16368793

111. Ora J, Laveneziana P, Ofir D, Deesomchok A, Webb KA, O'Donnell DE. Combined effects of obesity and chronic obstructive pulmonary disease on dyspnea and exercise tolerance. Am J Respir Crit Care Med [Internet]. 2009 Nov 15 [cited 2014 Dec 17];180(10):964-71. Available from: http://www.ncbi.nlm.nih.gov/pubmed/19897773 
112. Jee SH, Sull JW, Park J, Lee S-Y, Ohrr H, Guallar E, et al. Body-mass index and mortality in Korean men and women. N Engl J Med [Internet]. 2006 Aug 24 [cited 2014 Dec 17];355(8):779-87. Available from: http://www.ncbi.nlm.nih.gov/pubmed/16926276

113. Crisafulli E, Costi S, Luppi F, Cirelli G, Cilione C, Coletti O, et al. Role of comorbidities in a cohort of patients with COPD undergoing pulmonary rehabilitation. Thorax [Internet]. 2008 Jun 1 [cited 2014 Dec 17];63(6):487-92. Available from: http://thorax.bmj.com/content/63/6/487.abstract?ijkey=b5c0371496b47f1663997109a75049e f3d8acb35\&keytype2=tf_ipsecsha

114. Cazzola M, Bettoncelli G, Sessa E, Cricelli C, Biscione G. Prevalence of comorbidities in patients with chronic obstructive pulmonary disease. Respiration [Internet]. 2010 Jan [cited 2014 Dec 12];80(2):112-9. Available from: http://www.ncbi.nlm.nih.gov/pubmed/20134148

115. Ehrlich SF, Quesenberry CP, Van Den Eeden SK, Shan J, Ferrara A. Patients diagnosed with diabetes are at increased risk for asthma, chronic obstructive pulmonary disease, pulmonary fibrosis, and pneumonia but not lung cancer. Diabetes Care [Internet]. 2010 Jan 1 [cited 2014 Dec 17];33(1):55-60. Available from:

http://care.diabetesjournals.org/content/33/1/55.abstract?ijkey=236a4898d55027e8d3133eb2 $727 \mathrm{c} 4170835 \mathrm{f} 8 \mathrm{c} 67 \&$ keytype2=tf_ipsecsha

116. Cormick W, Olson LG, Hensley MJ, Saunders NA. Nocturnal hypoxaemia and quality of sleep in patients with chronic obstructive lung disease. Thorax [Internet]. 1986 Nov 1 [cited 2014 Dec 17];41(11):846-54. Available from:

http://thorax.bmj.com/content/41/11/846.abstract?ijkey=fb468cda8d8e11065e3db141080e0e 81049fa3d0\&keytype2=tf_ipsecsha

117. Markoulaki D, Kostikas K, Papatheodorou G, Koutsokera A, Alchanatis M, Bakakos P, et al. Hemoglobin, erythropoietin and systemic inflammation in exacerbations of chronic obstructive pulmonary disease. Eur J Intern Med [Internet]. 2011 Feb [cited 2014 Dec 17];22(1):103-7. Available from: http://www.ncbi.nlm.nih.gov/pubmed/21238904

118. Okonko DO, Anker SD. Anemia in chronic heart failure: pathogenetic mechanisms. J Card Fail [Internet]. 2004 Feb [cited 2014 Dec 17];10(1 Suppl):S5-9. Available from: http://www.ncbi.nlm.nih.gov/pubmed/15007793

119. Barnes P CB. Systemic manifestations and comorbidities in COPD. Eur Respir J. 2009;33:1165-85.

120. Soriano JB SJC 12. How the COPD patient should be assessed for co-morbidities. En Rennard I, al, eds Clin Manag chronic Obstr lung Dis 2nd ed Bost Inf Healthc. 2007;

121. Anthonisen NR, Skeans MA, Wise RA, Manfreda J, Kanner RE, Connett JE. The effects of a smoking cessation intervention on 14.5-year mortality: a randomized clinical trial. Ann Intern Med [Internet]. 2005 Feb 15 [cited 2015 Jan 11];142(4):233-9. Available from: http://www.ncbi.nlm.nih.gov/pubmed/15710956

122. Godtfredsen NS, Lam TH, Hansel TT, Leon ME, Gray N, Dresler C, et al. COPD-related morbidity and mortality after smoking cessation: status of the evidence. Eur Respir J [Internet]. 2008 Oct [cited 2015 Jan 6];32(4):844-53. Available from: http://www.ncbi.nlm.nih.gov/pubmed/18827152 
123. Soriano JB, Miravitlles M. Datos epidemiológicos de EPOC en España. Archivos de Bronconeumología. 2007. p. 2-9.

124. Díaz-Maroto Muñoz; Jose Luis; Jiménez-Ruiz Carlos. Tratamiento farmacológico del tabaquismo [Internet]. Sistema Nacional de Salud. Volumen 32. 2008 [cited 2015 Jan 12]. p. $\mathrm{n}^{\mathrm{o}} 3$. Available from:

https://www.msssi.gob.es/biblioPublic/publicaciones/docs/vol32_3ManejoTabaquismo.pdf

125. Han M, Zhou Y, Li S, Pan L, Yang X, Li H, et al. [Dominance analysis on the association between reasons for smoking and results related to successful smoking cessation]. Zhonghua Liu Xing Bing Xue Za Zhi [Internet]. 2014 Oct [cited 2015 Jan 12];35(10):1083-6. Available from: http://www.ncbi.nlm.nih.gov/pubmed/25567008

126. Berger RL, Decamp MM, Criner GJ, Celli BR. Lung volume reduction therapies for advanced emphysema: an update. Chest [Internet]. 2010 Aug [cited 2015 Jan 11];138(2):407-17. Available from: http://www.ncbi.nlm.nih.gov/pubmed/20682529

127. Lahzami S, Aubert J-D. Lung transplantation for COPD - evidence-based? Swiss Med Wkly [Internet]. 2009 Jan 10 [cited 2015 Jan 11];139(1-2):4-8. Available from:

http://www.ncbi.nlm.nih.gov/pubmed/19142750

128. Antonio Román, Pietat Ussetti, Amparo Solé, Felipe Zurbano, José M. Borro, José M. Vaquero, Alicia de Pablo, Pilar Morales, Marina Blanco, Carlos Bravo, José Cifrian, Mercedes de la Torre, Pablo Gámez, Rosalía Laporta, Víctor Monforte, Roberto Mons, Ánge AV. Normativa para la selección de pacientes candidatos a trasplante pulmonar [Internet]. Arch Bronconeumol. 2011 [cited 2015 Jan 11]. p. 47(6):303-309; Available from: http://apps.elsevier.es/watermark/ctl_servlet?_f=10\&pident_articulo=90020857\&pident_usu ario $=0 \&$ pcontactid $=\&$ pident revista $=6 \&$ ty $=1 \overline{3} 0 \&$ accion $=$ L $\&$ origen $=$ bronco $\& w e b=w w w$.arc 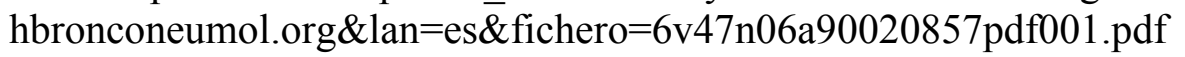

129. Carrera M, Sala E, Cosío BG, Agustí AGN. [Hospital treatment of chronic obstructive pulmonary disease exacerbations: an evidence-based review]. Arch Bronconeumol [Internet]. 2005 Apr [cited 2015 Jan 9];41(4):220-9. Available from: http://www.ncbi.nlm.nih.gov/pubmed/15826532

130. Barberà JA, Peces-Barba G, Agustí AG, Izquierdo JL, Monsó E, Montemayor T, et al. [Clinical guidelines for the diagnosis and treatment of chronic obstructive pulmonary disease]. Arch Bronconeumol [Internet]. 2001 Jun [cited 2015 Jan 9];37(6):297-316. Available from: http://www.ncbi.nlm.nih.gov/pubmed/11412529

131. Global iniciative for Chronic Disease. Guia de bolsillo para el diagnóstico, manejo y prevención de la EPOC [Internet]. Pocket_EPOC. 2014 [cited 2015 Jan 14]. p. 13/7/14 7:35. Available from: http://www.goldcopd.org/uploads/users/files/GOLD_Pocket_Spanish.pdf

132. Lenferink A, Frith P, van der Valk P, Buckman J, Sladek R, Cafarella P, et al. A selfmanagement approach using self-initiated action plans for symptoms with ongoing nurse support in patients with Chronic Obstructive Pulmonary Disease (COPD) and comorbidities: the COPE-III study protocol. Contemp Clin Trials [Internet]. $2013 \mathrm{Sep}$ [cited 2014 Dec 17];36(1):81-9. Available from: http://www.ncbi.nlm.nih.gov/pubmed/23770110

133. Effing T, Zielhuis G, Kerstjens H, van der Valk P, van der Palen J. Community based physiotherapeutic exercise in COPD self-management: a randomised controlled trial. Respir 
Med [Internet]. 2011 Mar [cited 2014 Dec 17];105(3):418-26. Available from:

http://www.scopus.com/inward/record.url?eid=2-s2.0-79151479966\&partnerID=tZOtx3y1

134. Effing T, Kerstjens H, van der Valk P, Zielhuis G, van der Palen J. (Cost)-effectiveness of self-treatment of exacerbations on the severity of exacerbations in patients with COPD: the COPE II study. Thorax [Internet]. 2009 Nov [cited 2014 Dec 17];64(11):956-62. Available from: http://www.scopus.com/inward/record.url?eid=2-s2.072549086564\&partnerID=tZOtx3y1

135. Morgan MDL. Action plans for COPD self-management. Integrated care is more than the sum of its parts. Thorax [Internet]. 2011 Nov [cited 2014 Dec 17];66(11):935-6. Available from: http://www.scopus.com/inward/record.url?eid=2-s2.080054116604\&partnerID=tZOtx3y1

136. Bourbeau J. The role of collaborative self-management in pulmonary rehabilitation. [Internet]. Seminars in respiratory and critical care medicine. 2009. p. 700-7. Available from: http://www.scopus.com/inward/record.url?eid=2-s2.077949317632\&partnerID=tZOtx3y1

137. Instituto Nacional para la Salud y la Excelencia Clínica. Chronic obstructive pulmonary disease | Guidance and guidelines | NICE. Directrices NICE [Internet]. NICE; 2014 [cited 2015 Jan 9]; Available from: https://www.nice.org.uk/guidance/cg101

138. Jeppesen E, Brurberg KG, Vist GE, Wedzicha JA, Wright JJ, Greenstone M, et al. Hospital at home for acute exacerbations of chronic obstructive pulmonary disease. Cochrane database Syst Rev [Internet]. 2012 Jan [cited 2015 Jan 11];5:CD003573. Available from: http://www.ncbi.nlm.nih.gov/pubmed/22592692

139. Zwerink $M$ et al. Self management for patients with chronic obstructive pulmonary disease (Review) [Internet]. Self management for patients with chronic obstructive pulmonary disease (Review). 2014 [cited 2014 Jun 12]. p. Issue 3; The Cochrane Collaboration and published. Available from: http://www.updatesoftware.com//BCP/WileyPDF/EN/CD002990.pdf

140. Anzueto, Antonio; Sethi, Sanjay; Martinez FJ. Exacerbations of chronic obstructive pulmonary disease. Proc Am Thorac Soc [Internet]. 2007 Oct 1 [cited 2014 Jun 8];4(7):55464. Available from: http://www.ncbi.nlm.nih.gov/pubmed/17878469

141. Román JM. Interés de la Educación Terapéutica en el manejo del asma. Monografía Asma y Educación. Arch Bronconeumol [Internet]. 2010;46:600-6 V:65-73. Available from: http://mail.respirar.org/pdf/gae/curso2006.pdf\#page $=65$

142. Walters JA, Turnock AC, Walters EH, Wood-Baker R. Action plans with limited patient education only for exacerbations of chronic obstructive pulmonary disease. Cochrane database Syst Rev [Internet]. 2010 Jan [cited 2014 Aug 10];(5):CD005074. Available from: http://www.ncbi.nlm.nih.gov/pubmed/20464737

143. Fan VS, Gaziano JM, Lew R, Bourbeau J, Adams SG, Leatherman S, et al. A comprehensive care management program to prevent chronic obstructive pulmonary disease hospitalizations: a randomized, controlled trial. Ann Intern Med [Internet]. 2012 May 15 [cited 2014 May 23];156(10):673-83. Available from: http://www.ncbi.nlm.nih.gov/pubmed/22586006 
144. Khdour MR, Agus AM, Kidney JC, Smyth BM, McElnay JC, Elnay JC, et al. Cost-utility analysis of a pharmacy-led self-management programme for patients with COPD. Int J Clin Pharm [Internet]. 2011 Aug [cited 2014 Jun 11];33(4):665-73. Available from: http://www.ncbi.nlm.nih.gov/pubmed/21643784

145. Bourbeau J, Collet J-P, Schwartzman K, Ducruet T, Nault D, Bradley C. Economic benefits of self-management education in COPD. Chest [Internet]. 2006 Dec [cited 2014 Jun 11];130(6):1704-11. Available from: http://www.ncbi.nlm.nih.gov/pubmed/17166985

146. Siddique HH, Olson RH, Parenti CM, Rector TS, Caldwell M, Dewan NA, et al. Randomized trial of pragmatic education for low-risk COPD patients: impact on hospitalizations and emergency department visits. Int J Chron Obstruct Pulmon Dis [Internet]. 2012 Jan [cited 2014 Jun 11];7:719-28. Available from: http://www.pubmedcentral.nih.gov/articlerender.fcgi?artid=3484530\&tool=pmcentrez\&rend ertype $=$ abstract

147. Sedeno MF, Nault D, Hamd DH, Bourbeau J. A self-management education program including an action plan for acute COPD exacerbations. COPD [Internet]. 2009 Oct [cited 2014 Jun 10];6(5):352-8. Available from: http://www.ncbi.nlm.nih.gov/pubmed/19863364

148. Bucknall CE, Miller G, Lloyd SM, Cleland J, McCluskey S, Cotton M, et al. Glasgow supported self-management trial (GSuST) for patients with moderate to severe COPD: randomised controlled trial. BMJ [Internet]. 2012 Jan [cited 2014 Jun 11];344:e1060. Available from:

http://www.pubmedcentral.nih.gov/articlerender.fcgi?artid=3295724\&tool=pmcentrez\&rend ertype $=$ abstract

149. Hill K, Mangovski-Alzamora S, Blouin M, Guyatt G, Heels-Ansdell D, Bragaglia P, et al. Disease-specific education in the primary care setting increases the knowledge of people with chronic obstructive pulmonary disease: a randomized controlled trial. Patient Educ Couns [Internet]. 2010 Oct [cited 2014 Jun 11];81(1):14-8. Available from: http://www.ncbi.nlm.nih.gov/pubmed/19853399

150. Hoogendoorn M, van Wetering CR, Schols AM, Rutten-van Mölken MPMH. Is INTERdisciplinary COMmunity-based COPD management (INTERCOM) cost-effective? Eur Respir J [Internet]. 2010 Jan [cited 2014 Jun 11];35(1):79-87. Available from: http://www.ncbi.nlm.nih.gov/pubmed/19574331

151. Taylor SJC, Sohanpal R, Bremner SA, Devine A, McDaid D, Fernández J-L, et al. Selfmanagement support for moderate-to-severe chronic obstructive pulmonary disease: a pilot randomised controlled trial. Br J Gen Pract [Internet]. 2012 Oct [cited 2014 Jun 11];62(603):e687-95. Available from: http://www.pubmedcentral.nih.gov/articlerender.fcgi?artid=3459776\&tool=pmcentrez\&rend ertype $=$ abstract

152. Wakabayashi R, Motegi T, Yamada K, Ishii T, Jones RC, Hyland ME, et al. Efficient integrated education for older patients with chronic obstructive pulmonary disease using the Lung Information Needs Questionnaire. Geriatr Gerontol Int [Internet]. 2011 Oct [cited 2014 Jun 11];11(4):422-30. Available from: http://www.ncbi.nlm.nih.gov/pubmed/21447136

153. Theander K, Jakobsson P, Jörgensen N, Unosson M. Effects of pulmonary rehabilitation on fatigue, functional status and health perceptions in patients with chronic obstructive 
pulmonary disease: a randomized controlled trial. Clin Rehabil [Internet]. 2009 Feb [cited 2014 Jun 11];23(2):125-36. Available from: http://www.ncbi.nlm.nih.gov/pubmed/19164400

154. Efraimsson EO, Hillervik C, Ehrenberg A. Effects of COPD self-care management education at a nurse-led primary health care clinic. Scand J Caring Sci [Internet]. 2008 Jun [cited 2014 Jun 11];22(2):178-85. Available from: http://www.ncbi.nlm.nih.gov/pubmed/18489687

155. Rootmensen GN, van Keimpema ARJ, Looysen EE, van der Schaaf L, de Haan RJ, Jansen HM. The effects of additional care by a pulmonary nurse for asthma and COPD patients at a respiratory outpatient clinic: results from a double blind, randomized clinical trial. Patient Educ Couns [Internet]. 2008 Feb [cited 2014 Jun 11];70(2):179-86. Available from: http://www.ncbi.nlm.nih.gov/pubmed/18031971

156. Rea H, McAuley S, Stewart A, Lamont C, Roseman P, Didsbury P. A chronic disease management programme can reduce days in hospital for patients with chronic obstructive pulmonary disease. Intern Med J [Internet]. 2004 Nov [cited 2014 Jun 11];34(11):608-14. Available from: http://www.ncbi.nlm.nih.gov/pubmed/15546454

157. Marín Royo M, Pellicer Císcar C, González Villaescusa C, Bueso Fabra MJ, Aguar Benito C, Andreu Rodríguez AL, et al. [Physical activity and its relationship with the state of health of stable COPD patients]. Arch Bronconeumol [Internet]. 2011 Jul [cited $2015 \mathrm{Jul}$ 24];47(7):335-42. Available from: http://www.sciencedirect.com/science/article/pii/S0300289611000895

158. Celli BR, Cote CG, Marin JM, Casanova C, Montes de Oca M, Mendez RA, et al. The bodymass index, airflow obstruction, dyspnea, and exercise capacity index in chronic obstructive pulmonary disease. N Engl J Med [Internet]. 2004 Mar 4 [cited 2015 Apr 16];350(10):100512. Available from: http://www.ncbi.nlm.nih.gov/pubmed/14999112

159. J. Giner, R. Cabarcos, F. Burgos, M. Calpena, F. Morante V. Macián, I. Andres, I. Martínez, M. Benito, G. Peces Barba, Hernández C. ISSUU - Controlando la EPOC. Enfermedad Pulmonar Obstructiva Crónica de SEPAR [Internet]. Editorial Fundación Española del pulmón. ÁREA DE ENFERMERÍA Y FISIOTERAPIA Con la colaboración ÁREA IRTS (SEPAR). 2001 [cited 2015 Jan 22]. Available from:

http://issuu.com/separ/docs/controlando_la_epoc.?e=3049452/2566273

160. Rehabilitación pulmonar para la enfermedad pulmonar obstructiva crónica [Internet]. [cited 2015 Jan 2]. Available from:

http://www.bibliotecacochrane.com/BCPGetDocument.asp?SessionID= 9301462\&DocumentID $=$ CD003793

161. Yohannes AM, Willgoss TG, Baldwin RC, Connolly MJ. Depression and anxiety in chronic heart failure and chronic obstructive pulmonary disease: prevalence, relevance, clinical implications and management principles. Int J Geriatr Psychiatry [Internet]. 2010 Dec [cited 2014 Dec 1];25(12):1209-21. Available from: http://www.ncbi.nlm.nih.gov/pubmed/20033905

162. Ng T-P, Niti M, Tan W-C, Cao Z, Ong K-C, Eng P. Depressive symptoms and chronic obstructive pulmonary disease: effect on mortality, hospital readmission, symptom burden, functional status, and quality of life. Arch Intern Med [Internet]. 2007 Jan 8 [cited 2014 Nov 9];167(1):60-7. Available from: http://www.ncbi.nlm.nih.gov/pubmed/17210879 
163. Miravitlles M, Soler-Cataluña JJ, Calle M, Molina J, Almagro P, Quintano JA, et al. [Spanish COPD Guidelines (GesEPOC): Pharmacological treatment of stable COPD]. Aten Primaria [Internet]. 2012 Jul [cited 2014 Jun 12];44(7):425-37. Available from: http://www.sciencedirect.com/science/article/pii/S0212656712001850

164. Gallefoss F, Bakke PS. Patient satisfaction with healthcare in asthmatics and patients with COPD before and after patient education. Respir Med [Internet]. 2000 Nov [cited 2014 Jun 3];94(11):1057-64. Available from: http://www.ncbi.nlm.nih.gov/pubmed/11127492

165. Spruit MA, Singh SJ, Garvey C, ZuWallack R, Nici L, Rochester C, et al. An official American Thoracic Society/European Respiratory Society statement: key concepts and advances in pulmonary rehabilitation. Am J Respir Crit Care Med [Internet]. 2013 Oct 15 [cited 2014 May 26];188(8):e13-64. Available from: http://www.ncbi.nlm.nih.gov/pubmed/24127811

166. Jadad AR, Moore RA, Carroll D, Jenkinson C, Reynolds DJ, Gavaghan DJ, et al. Assessing the quality of reports of randomized clinical trials: is blinding necessary? Control Clin Trials [Internet]. 1996 Mar [cited 2014 May 30];17(1):1-12. Available from: http://www.ncbi.nlm.nih.gov/pubmed/8721797

167. Jones PW, Harding G, Berry P, Wiklund I, Chen W-H, Kline Leidy N. Development and first validation of the COPD Assessment Test. Eur Respir J [Internet]. 2009 Sep 1 [cited 2015 Apr 3];34(3):648-54. Available from: http://erj.ersjournals.com/content/34/3/648

168. Mon FM. AJ. PL. PV. ST GeorgeValidity and reliability of the Spanish version of the St. George's Respiratory Questionnaire [Internet]. [cited 2015 Jul 6]. Available from: http://www.neumologica.org/asma/sangeorge.htm

169. Morisky DE, Green LW, Levine DM. Concurrent and predictive validity of a self-reported measure of medication adherence. Med Care [Internet]. 1986 Jan [cited 2014 Dec 11];24(1):67-74. Available from: http://www.ncbi.nlm.nih.gov/pubmed/3945130

170. OMS. Base de datos mundial en el Índice de Masa Corporal [Internet]. [cited 2015 Jul 6]. Available from: http://apps.who.int/bmi/index.jsp?introPage=intro_3.html

171. Pauwels RA, Buist AS, Calverley PM, Jenkins CR, Hurd SS. Global strategy for the diagnosis, management, and prevention of chronic obstructive pulmonary disease. NHLBI/WHO Global Initiative for Chronic Obstructive Lung Disease (GOLD) Workshop summary. Am J Respir Crit Care Med [Internet]. 2001 Apr [cited 2014 Dec 11];163(5):1256-76. Available from: http://www.ncbi.nlm.nih.gov/pubmed/11316667

172. J. CCMIG-TM y. La disnea en la EPOC [Internet]. [cited 2015 Jul 6]. Available from: $\mathrm{http} / / /$ apps.elsevier.es/watermark/ctl_servlet?_f=10\&pident_articulo=13084296\&pident_usu ario $=0 \&$ pcontactid $=\&$ pident_revista $=6 \&$ ty $=60 \&$ accion $=$ L\&origen $=$ bronco $\& w e b=w w w . a r c h$ bronconeumol.org\&lan $=$ es\&fichero $=6 \mathrm{v} 41 \mathrm{nSupl} .3 \mathrm{a} 13084296 \mathrm{pdf001} . \mathrm{pdf}$

173. Wang R, Ma X. Clarification on the categorization of comorbidities. Leuk Res [Internet]. 2010 Feb [cited $2015 \mathrm{Jul}$ 6];34(2):e74. Available from: http://www.pubmedcentral.nih.gov/articlerender.fcgi?artid=2815216\&tool=pmcentrez\&rend ertype $=$ abstract 
174. Vallejo MA, Rivera J, Esteve-Vives J, Rodríguez-Muñoz MF. [Use of the Hospital Anxiety and Depression Scale (HADS) to evaluate anxiety and depression in fibromyalgia patients]. Rev Psiquiatr y salud Ment [Internet]. Elsevier; 2012 Jan 1 [cited 2015 May 5];5(2):107-14. Available from: http://www.elsevier.es/es-revista-revista-psiquiatria-salud-mental-286articulo-uso-del-cuestionario-ihospital-anxiety-90123496

175. Cid-Ruzafa J, Damián-Moreno J. Valoración de la discapacidad física: el indice de Barthel. Rev Esp Salud Publica [Internet]. MSSSI; [cited 2015 Jul 6];71(2):127-37. Available from: http://scielo.isciii.es/scielo.php?script=sci_arttext\&pid=S1135$57271997000200004 \& \operatorname{lng}=$ es\&nrm=iso\&tlng=es

176. Carlos Andréu Matéu; Félix Encinas García; Isabel Pérez-Salinas; María Ramos-Trujillo; Victoria Andréu-Guillamón. Creación de una herramienta informática para la integración primaria-especializada en atención domiciliaria [Internet]. Papeles Médicos. 2009 [cited 2015 Apr 22]. p. VOL.8 NUM. 2. Available from: http://sedom.es/wpcontent/themes/sedom/pdf/4cbd592e6a98218_2_articulo3.pdf

177. Casey D, Murphy K, Devane D, Cooney A, McCarthy B, Mee L, et al. The effectiveness of a structured education pulmonary rehabilitation programme for improving the health status of people with moderate and severe chronic obstructive pulmonary disease in primary care: the PRINCE cluster randomised trial. Thorax [Internet]. 2013 Oct [cited 2014 May 27];68(10):922-8. Available from:

http://www.pubmedcentral.nih.gov/articlerender.fcgi?artid=3786654\&tool=pmcentrez\&rend ertype $=$ abstract

178. Parker DR, Eaton CB, Ahern DK, Roberts MB, Rafferty C, Goldman RE, et al. The study design and rationale of the randomized controlled trial: translating COPD guidelines into primary care practice. BMC Fam Pract [Internet]. 2013 Jan [cited 2014 Jun 10];14:56. Available from:

http://www.pubmedcentral.nih.gov/articlerender.fcgi?artid=3651367\&tool=pmcentrez\&rend ertype $=$ abstract

179. Leiva-Fernández F, Leiva-Fernández J, Zubeldia-Santoyo F, García-Ruiz A, Prados-Torres D, Barnestein-Fonseca P. Efficacy of two educational interventions about inhalation techniques in patients with chronic obstructive pulmonary disease (COPD). TECEPOC: study protocol for a partially randomized controlled trial (preference trial). Trials [Internet]. 2012 Jan [cited 2014 Jun 5];13:64. Available from:

http://www.pubmedcentral.nih.gov/articlerender.fcgi?artid=3404981\&tool=pmcentrez\&rend ertype $=$ abstract

180. Bourbeau J, Nault D, Dang-Tan T. Self-management and behaviour modification in COPD . Patient Educ Couns [Internet]. 2004 Mar [cited 2014 May 25];52(3):271-7. Available from: http://www.ncbi.nlm.nih.gov/pubmed/14998597

181. Ashmore J, Russo R, Peoples J, Sloan J, Jackson BE, Bae S, et al. Chronic obstructive pulmonary disease self-management activation research trial (COPD-SMART): design and methods. Contemp Clin Trials [Internet]. 2013 Jul [cited 2014 Jun 10];35(2):77-86. Available from: http://www.ncbi.nlm.nih.gov/pubmed/23680985

182. Casey D, Murphy K, Cooney A, Mee L. Developing a structured education programme for clients with COPD. Br J Community Nurs [Internet]. 2011 May [cited 2014 Jun 10];16(5):231-7. Available from: http://www.ncbi.nlm.nih.gov/pubmed/21642927 
183. Valero C, Monteagudo M, Llagostera M, Bayona X, Granollers S, Acedo M, et al. Evaluation of a combined strategy directed towards health-care professionals and patients with chronic obstructive pulmonary disease (COPD): information and health education feedback for improving clinical monitoring and quality-of-life. BMC Public Health [Internet]. 2009 Jan [cited 2014 May 27];9:442. Available from: http://www.pubmedcentral.nih.gov/articlerender.fcgi?artid=2799410\&tool=pmcentrez\&rend ertype $=$ abstract

184. Paneroni M, Clini E, Crisafulli E, Guffanti E, Fumagalli A, Bernasconi A, et al. Feasibility and effectiveness of an educational program in Italian COPD patients undergoing rehabilitation. Respir Care [Internet]. 2013 Feb [cited 2014 Jun 10];58(2):327-33. Available from: http://www.ncbi.nlm.nih.gov/pubmed/22782190

185. Zhou Y, Hu G, Wang D, Wang S, Wang Y, Liu Z, et al. Community based integrated intervention for prevention and management of chronic obstructive pulmonary disease (COPD) in Guangdong, China: cluster randomised controlled trial. BMJ [Internet]. 2010 Jan [cited 2014 Jun 10];341:c6387. Available from:

http://www.pubmedcentral.nih.gov/articlerender.fcgi?artid=2995286\&tool=pmcentrez\&rend ertype $=$ abstract

186. Carré PC, Roche N, Neukirch F, Radeau T, Perez T, Terrioux P, et al. The effect of an information leaflet upon knowledge and awareness of COPD in potential sufferers. A randomized controlled study. Respiration [Internet]. 2008 Jan [cited 2014 Jun 10];76(1):5360. Available from: http://www.ncbi.nlm.nih.gov/pubmed/18253024

187. Van Zeller M, Vaz AP, Soares Pires F, Neves I, Drummond M, Carvalho AM, et al. Efficacy evaluation of educational sessions for patients with asthma and COPD. Rev Port Pneumol [Internet]. 2012 [cited 2014 Jun 10];18(1):29-33. Available from: http://www.ncbi.nlm.nih.gov/pubmed/22177939

188. Davis AHT, Carrieri-Kohlman V, Janson SL, Gold WM, Stulbarg MS. Effects of treatment on two types of self-efficacy in people with chronic obstructive pulmonary disease. J Pain Symptom Manage [Internet]. 2006 Jul [cited 2014 Jun 10];32(1):60-70. Available from: http://www.ncbi.nlm.nih.gov/pubmed/16824986

189. Nguyen HQ, Carrieri-Kohlman V. Dyspnea self-management in patients with chronic obstructive pulmonary disease: moderating effects of depressed mood. Psychosomatics [Internet]. 2005 [cited 2014 Jun 10];46(5):402-10. Available from:

http://www.ncbi.nlm.nih.gov/pubmed/16145184

190. Finnerty JP, Keeping I, Bullough I, Jones J. The effectiveness of outpatient pulmonary rehabilitation in chronic lung disease: a randomized controlled trial. Chest [Internet]. 2001 Jun [cited 2014 Jun 10];119(6):1705-10. Available from:

http://www.ncbi.nlm.nih.gov/pubmed/11399694

191. Kunik ME, Veazey C, Cully JA, Souchek J, Graham DP, Hopko D, et al. COPD education and cognitive behavioral therapy group treatment for clinically significant symptoms of depression and anxiety in COPD patients: a randomized controlled trial. Psychol Med [Internet]. 2008 Mar [cited 2014 Nov 13];38(3):385-96. Available from:

http://www.ncbi.nlm.nih.gov/pubmed/17922939 
192. Scherer YK, Schmieder LE, Shimmel S. The effects of education alone and in combination with pulmonary rehabilitation on self-efficacy in patients with COPD. Rehabil Nurs [Internet]. 1998 [cited 2014 Nov 13];23(2):71-7. Available from: http://www.ncbi.nlm.nih.gov/pubmed/9668868

193. Lainscak M, Kadivec S, Kosnik M, Benedik B, Bratkovic M, Jakhel T, et al. Discharge coordinator intervention prevents hospitalizations in patients with COPD: a randomized controlled trial. J Am Med Dir Assoc [Internet]. 2013 Jun [cited 2014 Jun 10];14(6):450.e16. Available from: http://www.ncbi.nlm.nih.gov/pubmed/23623520

194. Gallefoss F. The effects of patient education in COPD in a 1-year follow-up randomised, controlled trial. Patient Educ Couns [Internet]. 2004 Mar [cited 2014 Jun 11];52(3):259-66. Available from: http://www.ncbi.nlm.nih.gov/pubmed/14998595

195. Gallefoss F, Bakke PS. Impact of patient education and self-management on morbidity in asthmatics and patients with chronic obstructive pulmonary disease. Respir Med [Internet]. 2000 Mar [cited 2014 Jun 11];94(3):279-87. Available from: http://www.ncbi.nlm.nih.gov/pubmed/10783940

196. Gallefoss F, Bakke PS. How does patient education and self-management among asthmatics and patients with chronic obstructive pulmonary disease affect medication? Am J Respir Crit Care Med [Internet]. 1999 Dec [cited 2014 Jun 11];160(6):2000-5. Available from: http://www.ncbi.nlm.nih.gov/pubmed/10588620

197. Gallefoss F, Bakke PS, Rsgaard PK. Quality of life assessment after patient education in a randomized controlled study on asthma and chronic obstructive pulmonary disease. Am J Respir Crit Care Med [Internet]. 1999 Mar [cited 2014 Jun 11];159(3):812-7. Available from: http://www.ncbi.nlm.nih.gov/pubmed/10051255

198. Nguyen HQ, Donesky D, Reinke LF, Wolpin S, Chyall L, Benditt JO, et al. Internet-based dyspnea self-management support for patients with chronic obstructive pulmonary disease. $\mathrm{J}$ Pain Symptom Manage [Internet]. 2013 Jul [cited 2014 Jun 11];46(1):43-55. Available from: http://www.ncbi.nlm.nih.gov/pubmed/23073395

199. Lord VM, Cave P, Hume VJ, Flude EJ, Evans A, Kelly JL, et al. Singing teaching as a therapy for chronic respiratory disease--a randomised controlled trial and qualitative evaluation. BMC Pulm Med [Internet]. 2010 Jan [cited 2014 Jun 11];10:41. Available from: http://www.pubmedcentral.nih.gov/articlerender.fcgi?artid=2920262\&tool=pmcentrez\&rend ertype $=$ abstract

200. Osterlund Efraimsson E, Osterlund Eraimsson E, Eva OE, Klang B, Birgitta K, Larsson K, et al. Communication and self-management education at nurse-led COPD clinics in primary health care. Patient Educ Couns [Internet]. 2009 Nov [cited 2014 Jun 11];77(2):209-17. Available from: http://www.ncbi.nlm.nih.gov/pubmed/19414234

201. Kim J, Kim S, Kim H-C, Kim K-H, Yang S-C, Lee C-T, et al. Effects of consumer-centered u-health service for the knowledge, skill, and attitude of the patients with chronic obstructive pulmonary disease. Comput Inform Nurs [Internet]. 2012 Dec [cited 2014 Jun 10];30(12):661-71. Available from: http://www.ncbi.nlm.nih.gov/pubmed/23266537 
202. Kara M, Aşti T. Effect of education on self-efficacy of Turkish patients with chronic obstructive pulmonary disease. Patient Educ Couns [Internet]. 2004 Oct [cited 2014 Jun 11];55(1):114-20. Available from: http://www.ncbi.nlm.nih.gov/pubmed/15476998

203. Boxall A-M, Barclay L, Sayers A, Caplan GA. Managing chronic obstructive pulmonary disease in the community. A randomized controlled trial of home-based pulmonary rehabilitation for elderly housebound patients. J Cardiopulm Rehabil [Internet]. 2005 [cited 2014 Jun 10];25(6):378-85. Available from: http://www.ncbi.nlm.nih.gov/pubmed/16327534

204. Carrieri-Kohlman V, Nguyen HQ, Donesky-Cuenco D, Demir-Deviren S, Neuhaus J, Stulbarg MS. Impact of brief or extended exercise training on the benefit of a dyspnea selfmanagement program in COPD. J Cardiopulm Rehabil [Internet]. 2005 [cited 2014 May 29];25(5):275-84. Available from: http://www.ncbi.nlm.nih.gov/pubmed/16217231

205. McGlone S, Wood-Baker R WE. The effect of a written action plan in COPD [Abstract]. Respirology 2004;9(2 Suppl):A46. Respirology [Internet]. 2004 Mar [cited 2014 Sep 23];9(s2):A1-A75. Available from: http://doi.wiley.com/10.1111/j.1440-1843.2004.00553.x

206. Field SK, Conley DP, Thawer AM, Leigh R, Cowie RL. Effect of the management of patients with chronic cough by pulmonologists and certified respiratory educators on quality of life: a randomized trial. Chest [Internet]. 2009 Oct [cited 2014 Jun 11];136(4):1021-8. Available from: http://www.ncbi.nlm.nih.gov/pubmed/19349387

207. Soler JJ, Martínez-García MA, Román P, Orero R, Terrazas S, Martínez-Pechuán A. [Effectiveness of a specific program for patients with chronic obstructive pulmonary disease and frequent exacerbations]. Arch Bronconeumol [Internet]. 2006 Oct [cited 2014 Jun 11];42(10):501-8. Available from: http://www.ncbi.nlm.nih.gov/pubmed/17067516

208. Koff PB, Jones RH, Cashman JM, Voelkel NF, Vandivier RW. Proactive integrated care improves quality of life in patients with COPD. Eur Respir J [Internet]. 2009 May [cited 2014 Jun 11];33(5):1031-8. Available from: http:/www.ncbi.nlm.nih.gov/pubmed/19129289

209. Chavannes NH, Grijsen M, van den Akker M, Schepers H, Nijdam M, Tiep B, et al. Integrated disease management improves one-year quality of life in primary care COPD patients: a controlled clinical trial. Prim Care Respir J [Internet]. 2009 Sep [cited 2014 Jun 11];18(3):171-6. Available from: http://www.ncbi.nlm.nih.gov/pubmed/19142557

210. Watson PB, Town GI, Holbrook N, Dwan C, Toop LJ, Drennan CJ. Evaluation of a selfmanagement plan for chronic obstructive pulmonary disease. Eur Respir J [Internet]. 1997 Jun [cited 2014 Jun 11];10(6):1267-71. Available from: http://www.ncbi.nlm.nih.gov/pubmed/9192927

211. Monninkhof E, van der Valk P, Schermer T, van der Palen J, van Herwaarden C, Zielhuis G. Economic evaluation of a comprehensive self-management programme in patients with moderate to severe chronic obstructive pulmonary disease. Chron Respir Dis [Internet]. 2004 Jan [cited 2014 Jun 11];1(1):7-16. Available from:

http://www.ncbi.nlm.nih.gov/pubmed/16281663

212. Kiser K, Jonas D, Warner Z, Scanlon K, Shilliday BB, DeWalt DA. A randomized controlled trial of a literacy-sensitive self-management intervention for chronic obstructive pulmonary disease patients. J Gen Intern Med [Internet]. 2012 Feb [cited 2014 Jun 11];27(2):190-5. Available from: 
http://www.pubmedcentral.nih.gov/articlerender.fcgi?artid=3270237\&tool=pmcentrez\&rend ertype $=$ abstract

213. Monteagudo M, Rodriguez-Blanco T, Llagostera M, Valero C, Bayona X, Granollers S, et al. Effect of health professional education on outcomes of chronic obstructive pulmonary disease in primary care: a non-randomized clinical trial. Respirology [Internet]. 2013 May [cited 2014 Jun 11];18(4):718-27. Available from: http://www.ncbi.nlm.nih.gov/pubmed/23438203

214. Rice KL, Dewan N, Bloomfield HE, Grill J, Schult TM, Nelson DB, et al. Disease management program for chronic obstructive pulmonary disease: a randomized controlled trial. Am J Respir Crit Care Med [Internet]. 2010 Oct 1 [cited 2014 Jun 11];182(7):890-6. Available from: http://www.ncbi.nlm.nih.gov/pubmed/20075385

215. Sridhar M, Taylor R, Dawson S, Roberts NJ, Partridge MR. A nurse led intermediate care package in patients who have been hospitalised with an acute exacerbation of chronic obstructive pulmonary disease. Thorax [Internet]. 2008 Mar [cited 2014 Jun 11];63(3):194200. Available from: http://www.ncbi.nlm.nih.gov/pubmed/17901162

216. Gadoury M-A, Schwartzman K, Rouleau M, Maltais F, Julien M, Beaupré A, et al. Selfmanagement reduces both short- and long-term hospitalisation in COPD. Eur Respir J [Internet]. 2005 Nov [cited 2014 Jun 11];26(5):853-7. Available from: http://www.ncbi.nlm.nih.gov/pubmed/16264046

217. Hesselink AE, Penninx BWJH, van der Windt DAWM, van Duin BJ, de Vries P, Twisk JWR, et al. Effectiveness of an education programme by a general practice assistant for asthma and COPD patients: results from a randomised controlled trial. Patient Educ Couns [Internet]. 2004 Oct [cited 2014 Jun 11];55(1):121-8. Available from: http://www.ncbi.nlm.nih.gov/pubmed/15476999

218. Bischoff EWMA, Akkermans R, Bourbeau J, van Weel C, Vercoulen JH, Schermer TRJ. Comprehensive self management and routine monitoring in chronic obstructive pulmonary disease patients in general practice: randomised controlled trial. BMJ [Internet]. 2012 Jan 28 [cited 2014 Jun 24];345(nov28_1):e7642. Available from: http://www.bmj.com/content/345/bmj.e7642.full.pdf+html

219. McGeoch GRB, Willsman KJ, Dowson CA, Town GI, Frampton CM, McCartin FJ, et al. Self-management plans in the primary care of patients with chronic obstructive pulmonary disease. Respirology [Internet]. 2006 Sep [cited 2014 Jun 10];11(5):611-8. Available from: http://www.ncbi.nlm.nih.gov/pubmed/16916335

220. Labrecque M, Rabhi K, Laurin C, Favreau H, Moullec G, Lavoie K, et al. Can a selfmanagement education program for patients with chronic obstructive pulmonary disease improve quality of life? Can Respir J [Internet]. 2011 [cited 2014 Jun 11];18(5):e77-81. Available from:

http://www.pubmedcentral.nih.gov/articlerender.fcgi?artid=3267612\&tool=pmcentrez\&rend ertype $=$ abstract

221. Cockcroft A, Bagnall P, Heslop A, Andersson N, Heaton R, Batstone J, et al. Controlled trial of respiratory health worker visiting patients with chronic respiratory disability. Br Med J (Clin Res Ed) [Internet]. 1987 Jan 24 [cited 2014 Jun 11];294(6566):225-8. Available from: 
http://www.pubmedcentral.nih.gov/articlerender.fcgi?artid=1245234\&tool=pmcentrez\&rend ertype $=$ abstract

222. Littlejohns P, Baveystock CM, Parnell H, Jones PW. Randomised controlled trial of the effectiveness of a respiratory health worker in reducing impairment, disability, and handicap due to chronic airflow limitation. Thorax [Internet]. 1991 Aug [cited 2014 Jun 11];46(8):559-64. Available from:

http://www.pubmedcentral.nih.gov/articlerender.fcgi?artid=463273\&tool=pmcentrez\&render type $=$ abstract

223. De los Santos Izquierdo JM, Peña Molinero C, Ortega Barriuso R, Manso Melgosa AB. Revisión de evidencias sobre la influencia de la dieta en la evolución de la EPOC. Enfermería Glob [Internet]. 2012 Oct 1 [cited 2014 Jul 16];11(4). Available from: http://revistas.um.es/eglobal/article/view/eglobal.11.4.132491

224. Cochrane Data Base Of Systematic Reviews. Autocuidado para pacientes con enfermedad obstructiva crónica (Revisión Cochrane traducida). [Internet]. 2011 [cited 2014 Jul 16]. Available from: http://www.update-software.com/PDF-ES/CD002990.pdf

225. Ferreira IM, Brooks D, White J, Goldstein R. Nutritional supplementation for stable chronic obstructive pulmonary disease. Cochrane database Syst Rev [Internet]. 2012 Jan [cited 2014 Aug 25];12:CD000998. Available from: http://www.ncbi.nlm.nih.gov/pubmed/23235577

226. Van der Meer RM, Wagena EJ, Ostelo RWJG, Jacobs JE, van Schayck CP. Smoking cessation for chronic obstructive pulmonary disease. Cochrane database Syst Rev [Internet]. 2003 Jan [cited 2014 Aug 25];(2):CD002999. Available from: http://www.ncbi.nlm.nih.gov/pubmed/12804448

227. Casas A, Troosters T, Garcia-Aymerich J, Roca J, Hernández C, Alonso A, et al. Integrated care prevents hospitalisations for exacerbations in COPD patients. Eur Respir J [Internet]. 2006 Jul 1 [cited $2015 \mathrm{Jul}$ 20];28(1):123-30. Available from: http://erj.ersjournals.com/content/28/1/123.full

228. Hernandez C, Casas A, Escarrabill J, Alonso J, Puig-Junoy J, Farrero E, et al. Home hospitalisation of exacerbated chronic obstructive pulmonary disease patients. Eur Respir J [Internet]. 2003 Jan [cited 2014 Jun 16];21(1):58-67. Available from: http://www.ncbi.nlm.nih.gov/pubmed/12570110

229. Kunik ME, Veazey C, Cully JA, Souchek J, Graham DP, Hopko D, et al. COPD education and cognitive behavioral therapy group treatment for clinically significant symptoms of depression and anxiety in COPD patients: a randomized controlled trial. Psychol Med [Internet]. 2008 Mar [cited 2014 Jun 10];38(3):385-96. Available from: http://www.ncbi.nlm.nih.gov/pubmed/17922939

230. Taylor SJC, Candy B, Bryar RM, Ramsay J, Vrijhoef HJM, Esmond G, et al. Effectiveness of innovations in nurse led chronic disease management for patients with chronic obstructive pulmonary disease: systematic review of evidence. BMJ [Internet]. 2005 Sep 3 [cited 2014 Jul 17];331(7515):485. Available from: http://www.bmj.com/content/331/7515/485

231. Rühle K-H. [COPD: Living better with telehealthcare?]. Dtsch Med Wochenschr [Internet]. 2012 Apr [cited 2014 Aug 10];137(16):827. Available from:

http://www.ncbi.nlm.nih.gov/pubmed/22495916 
232. Jansà M, Hernández C, Vidal M, Nuñez M, Bertran MJ, Sanz S, et al. Multidimensional analysis of treatment adherence in patients with multiple chronic conditions. A crosssectional study in a tertiary hospital. Patient Educ Couns [Internet]. Elsevier; 2010 Nov 11 [cited 2015 Jul 20];81(2):161-8. Available from: http://www.pecjournal.com/article/S0738399110000078/fulltext

233. Scherer YK, Schmieder LE, Shimmel S. The effects of education alone and in combination with pulmonary rehabilitation on self-efficacy in patients with COPD. Rehabil Nurs [Internet]. 1998 [cited 2014 Jun 10];23(2):71-7. Available from: http://www.ncbi.nlm.nih.gov/pubmed/9668868

234. Paul Galdas; Jennifer Fell; Peter Bower; Lisa Kidd. The effectiveness of self-management support interventions for men with long-term conditions: a systematic review and metaanalysis [Internet]. 2014 [cited 2015 Mar 21]. Available from: file:///C:/Users/Usuario 1/Downloads/BMJ Open-2015-Galdas-.pdf

235. Octubre G de MB en la EHU 12 de O. EFICACIA DE LOS PROGRAMAS DE TRATAMIENTO INTEGRAL DE LA EPOC. REVISIÓN SISTEMÁTICA Y METAANÁLISIS DE ARTÍCULOS [Internet]. Evidence Based Medicine Neumología. 2014 [cited 2014 Jul 16]. Available from:

$\mathrm{http}: / / \mathrm{mbeneumologia}$. org $/ \mathrm{mbe} / \mathrm{docsMBE} / \mathrm{cat} \cdot \mathrm{aspx} ? \mathrm{sec}=\operatorname{tra} \& \mathrm{id}=87 \& \mathrm{p}=\mathrm{e}$

236. Sohanpal R, Hooper R, Hames R, Priebe S, Taylor S. Reporting participation rates in studies of non-pharmacological interventions for patients with chronic obstructive pulmonary disease: a systematic review. Syst Rev [Internet]. BioMed Central Ltd; 2012 Jan 29 [cited 2014 Jul 16];1(1):66. Available from:

http://www.systematicreviewsjournal.com/content/1/1/66

237. Ancochea J, Badiola C, Duran-Tauleria E, Garcia Rio F, Miravitlles M, Muñoz L, et al. [The EPI-SCAN survey to assess the prevalence of chronic obstructive pulmonary disease in Spanish 40-to-80-year-olds: protocol summary]. Arch Bronconeumol [Internet]. Elsevier; 2009 Jan 1 [cited 2015 Jul 23];45(1):41-7. Available from:

http://www.archbronconeumol.org/es/estudio-epi-scan-resumen-delprotocolo/articulo/13132352/

238. Raluy-Callado M, Lambrelli D, MacLachlan S, Khalid JM. Epidemiology, severity, and treatment of chronic obstructive pulmonary disease in the United Kingdom by GOLD 2013. Int J Chron Obstruct Pulmon Dis [Internet]. 2015 Jan [cited 2015 Jun 17];10:925-37. Available from: http://www.pubmedcentral.nih.gov/articlerender.fcgi?artid=4437524\&tool=pmcentrez\&rend ertype $=$ abstract

239. Navarro A, Costa R, Rodriguez-Carballeira M, Yun S, Lapuente A, Barrera A, et al. Prognostic assessment of mortality and hospitalizations of outpatients with advanced chronic obstructive pulmonary disease. Usefulness of the CODEX index. Rev Clin Esp [Internet]. 2015 Jul 13 [cited 2015 Jul 23]; Available from: http://www.ncbi.nlm.nih.gov/pubmed/26183602

240. Otero González I, Blanco Aparicio M, Montero Martínez C, Valiño López P, Verea Hernando H. Características epidemiológicas de las exacerbaciones por EPOC y asma en un hospital general. Arch Bronconeumol [Internet]. Elsevier; 2002 Jun 1 [cited 2015 Jul 
23];38(06):256-62. Available from: http://www.archbronconeumol.org/es/caracteristicasepidemiologicas-las-exacerbaciones-por/articulo/13032777/

241. Valdes M, Muedra R, Tirado J, Ufer E, Hernandez M. [Epidemiological studies of bronchitis, empysema and asthma in the Province of Castellón]. Rev Sanid Hig Publica (Madr) [Internet]. 1973 Oct [cited $2015 \mathrm{Jul} 23$ ];47(10):907-27. Available from: http://www.ncbi.nlm.nih.gov/pubmed/4794381

242. Sullivan SD, Ramsey SC T AL. The economic burder in COPD. Chest. 2000;117: S5-S9.

243. Soler J, Sánchez L, Latorre M, Alamar J, Román P, Perpiñá M. Impacto asistencial hospitalario de la EPOC. Peso específico del paciente con EPOC de alto consumo sanitario. Arch Bronconeumol [Internet]. Elsevier; 2001 Oct 1 [cited 2015 Jul 24];37(09):375-81. Available from: http:/www.archbronconeumol.org/es/impacto-asistencial-hospitalario-epocpeso/articulo/13020101/

244. Weiss KB. Seasonal trends in US asthma hospitalizations and mortality. JAMA [Internet]. 1990 May 2 [cited 2015 Jul 23];263(17):2323-8. Available from:

http://www.ncbi.nlm.nih.gov/pubmed/2325233

245. Khot A, Burn R, Evans N, Lenney C, Lenney W. Seasonal variation and time trends in childhood asthma in England and Wales 1975-81. Br Med J (Clin Res Ed) [Internet]. 1984 Jul 28 [cited 2015 Jul 23];289(6439):235-7. Available from:

http:/www.pubmedcentral.nih.gov/articlerender.fcgi?artid=1442312\&tool=pmcentrez\&rend ertype $=$ abstract

246. Connors AF, Dawson N V, Thomas C, Harrell FE, Desbiens N, Fulkerson WJ, et al. Outcomes following acute exacerbation of severe chronic obstructive lung disease. The SUPPORT investigators (Study to Understand Prognoses and Preferences for Outcomes and Risks of Treatments). Am J Respir Crit Care Med [Internet]. 1996 Oct [cited 2014 Jun 16];154(4 Pt 1):959-67. Available from: http://www.ncbi.nlm.nih.gov/pubmed/8887592

247. Mushlin AI, Black ER, Connolly CA, Buonaccorso KM, Eberly SW. The necessary length of hospital stay for chronic pulmonary disease. JAMA [Internet]. 1991 Jul 3 [cited 2015 Jul 24];266(1):80-3. Available from: http://www.ncbi.nlm.nih.gov/pubmed/1904506

248. Soriano JB, Visick GT, Muellerova H, Payvandi N, Hansell AL. Patterns of comorbidities in newly diagnosed COPD and asthma in primary care. Chest [Internet]. 2005 Oct [cited 2014 Nov 23];128(4):2099-107. Available from: http://www.ncbi.nlm.nih.gov/pubmed/16236861

249. Mapel DW, Hurley JS, Frost FJ, Petersen H V., Picchi MA, Coultas DB. Health Care Utilization in Chronic Obstructive Pulmonary Disease. Arch Intern Med [Internet]. American Medical Association; 2000 Sep 25 [cited 2015 Jul 24];160(17):2653. Available from: http://archinte.jamanetwork.com/article.aspx?articleid=485446

250. Van Manen J., Bindels PJ., IJzermans C., van der Zee J., Bottema BJA., Schadé E. Prevalence of comorbidity in patients with a chronic airway obstruction and controls over the age of 40. J Clin Epidemiol [Internet]. 2001 Mar [cited 2015 Jul 24];54(3):287-93. Available from: http://www.sciencedirect.com/science/article/pii/S0895435601003468

251. De Miguel Díez J, Izquierdo Alonso JL, Molina París J, Bellón Cano JM, Rodríguez González-Moro JM, de Lucas Ramos P. Factores determinantes de la prescripción 
farmacológica en los pacientes con EPOC estable. Resultados de un estudio multicéntrico español (IDENTEPOC). Arch Bronconeumol [Internet]. 2005 Feb [cited 2015 Jul 24];41(2):63-70. Available from: http://www.sciencedirect.com/science/article/pii/S0300289605705895

252. Sidney S, Sorel M, Quesenberry CP, DeLuise C, Lanes S, Eisner MD. COPD and incident cardiovascular disease hospitalizations and mortality: Kaiser Permanente Medical Care Program. Chest [Internet]. American College of Chest Physicians; 2005 Oct 1 [cited 2015 Jul 24];128(4):2068-75. Available from:

http://journal.publications.chestnet.org/article.aspx?articleid=1083861

253. Carrasco Garrido P, de Miguel Díez J, Rejas Gutiérrez J, Centeno AM, Gobartt Vázquez E, Gil de Miguel A, et al. Negative impact of chronic obstructive pulmonary disease on the health-related quality of life of patients. Results of the EPIDEPOC study. Health Qual Life Outcomes [Internet]. 2006 Jan [cited 2015 Jul 24];4(1):31. Available from: http://www.hqlo.com/content/4/1/31

254. Curkendall SM, DeLuise C, Jones JK, Lanes S, Stang MR, Goehring E, et al. Cardiovascular disease in patients with chronic obstructive pulmonary disease, Saskatchewan Canada cardiovascular disease in COPD patients. Ann Epidemiol [Internet]. 2006 Jan [cited 2015 Jul 27];16(1):63-70. Available from: http://www.ncbi.nlm.nih.gov/pubmed/16039877

255. Salpeter SR, Ormiston TM, Salpeter EE. Cardiovascular effects of beta-agonists in patients with asthma and COPD: a meta-analysis. Chest [Internet]. 2004 Jun [cited $2015 \mathrm{Jul}$ 27];125(6):2309-21. Available from: http://www.ncbi.nlm.nih.gov/pubmed/15189956

256. Souverein PC, Berard A, Van Staa TP, Cooper C, Egberts ACG, Leufkens HGM, et al. Use of oral glucocorticoids and risk of cardiovascular and cerebrovascular disease in a population based case-control study. Heart [Internet]. 2004 Aug 1 [cited 2015 Jul 27];90(8):859-65. Available from: http://www.research.ed.ac.uk/portal/en/publications/use-of-oralglucocorticoids-and-risk-of-cardiovascular-and-cerebrovascular-disease-in-a-populationbased-casecontrol-study(7a748dea-ae25-4539-a73c-d27ce0b24ac7)/export.html

257. Verdaguer Munujos A, Peiró S, Librero J. Variabilidad en la utilización de recursos hospitalarios en pacientes con enfermedad pulmonar obstructivav crónica (EPOC). Arch Bronconeumol [Internet]. 2003 Jan [cited 2015 Jul 24];39(10):442-8. Available from: http://www.sciencedirect.com/science/article/pii/S030028960375426X

258. Miravitlles M, Figueras M. El coste de la enfermedad pulmonar obstructiva crónica en España. Opciones para una optimización de recursos. Arch Bronconeumol [Internet]. 2001 Jan [cited 2015 Jul 24];37(9):388-93. Available from: http://www.sciencedirect.com/science/article/pii/S0300289601788205

259. Fernández Vargas AM, Bujalance Zafra MJ, Leiva Fernández F, Martos Crespo F, García Ruíz AJ, Sánchez de la Cuesta y Alarcón F. Salud autopercibida, apoyo social y familiar de los pacientes con enfermedad pulmonar obstructiva crónica. Medifam [Internet]. Arán Ediciones, S. L.; [cited 2015 Jul 27];11(9):44-53. Available from: http://scielo.isciii.es/scielo.php?script=sci_arttext\&pid=S1131$57682001000900003 \& \operatorname{lng}=$ es\&nrm=iso\&tlng=e

260. Vinaccia S, Quiceno JM. Calidad de Vida Relacionada con la Salud y Factores Psicológicos: Un Estudio desde la Enfermedad Pulmonar Obstructiva Crónica - EPOC. Ter psicológica 
[Internet]. Sociedad Chilena de Psicología Clínica; 2011 Jul [cited 2015 May 16];29(1):6575. Available from: http://www.scielo.cl/scielo.php?script=sci_arttext\&pid=S0718$48082011000100007 \& \operatorname{lng}=\mathrm{es} \& n r m=\mathrm{iso} \& \operatorname{lng}=\mathrm{es}$

261. Amigo C H, Erazo B M, Oyarzún G M, Bello S S, Peruga U A. Tabaquismo y enfermedad pulmonar obstructiva crónica: determinación de fracciones atribuibles. Rev Med Chil [Internet]. Sociedad Médica de Santiago; 2006 Oct [cited 2015 Jul 30];134(10):1275-82. Available from: http://www.scielo.cl/scielo.php?script=sci_arttext\&pid=S0034$98872006001000009 \& \operatorname{lng}=\mathrm{es} \& n r m=\mathrm{iso} \& \operatorname{tn} \mathrm{ln}=\mathrm{es}$

262. Soriano JB, Calle M, Montemayor T, Alvarez-Sala JL, Ruiz-Manzano J, Miravitlles M. The general public's knowledge of chronic obstructive pulmonary disease and its determinants: current situation and recent changes. Arch Bronconeumol [Internet]. 2012 Oct [cited $2015 \mathrm{Jul}$ 31];48(9):308-15. Available from:

http://www.sciencedirect.com/science/article/pii/S0300289612001226

263. Kovacic P, Somanathan R. Pulmonary toxicity and environmental contamination: radicals, electron transfer, and protection by antioxidants. Rev Environ Contam Toxicol [Internet]. 2009 Jan [cited 2014 Dec 17];201:41-69. Available from:

http://www.ncbi.nlm.nih.gov/pubmed/19484588

264. Greene CC, Bradley KA, Bryson CL, Blough DK, Evans LE, Udris EM, et al. The association between alcohol consumption and risk of COPD exacerbation in a veteran population. Chest [Internet]. 2008 Oct [cited 2015 Jul 29];134(4):761-7. Available from: http://www.ncbi.nlm.nih.gov/pubmed/18625671

265. Hoth KF, Ford DW, Sandhaus RA, Strange C, Wamboldt FS, Holm KE. Alcohol use predicts ER visits in individuals with alpha-1 antitrypsin deficiency (AATD) associated COPD. COPD [Internet]. 2012 Aug [cited 2015 Jul 29];9(4):417-25. Available from: http://www.pubmedcentral.nih.gov/articlerender.fcgi?artid=3603142\&tool=pmcentrez\&rend ertype $=$ abstract

266. Hirayama F, Lee AH, Binns CW, Oga T, Nishimura K. Alcohol consumption in patients with chronic obstructive pulmonary disease in Japan. Asia Pac J Public Health [Internet]. 2008 Oct [cited 2015 Jul 29];20 Suppl:87-94. Available from: http://www.ncbi.nlm.nih.gov/pubmed/19533866

267. Nallely Sustaita Soto. índice de Masa Corporal de Pacientes con Enfermedad Pulmonar Obstructiva Crónica del Hospital de Concentración Toluca, Juan Férnandez Alabrrán Issemym [Internet]. Tesis Doctoral de la Universidad Autonómica del Estado de México. 2014 [cited 2015 Oct 16]. Available from: http://ri.uaemex.mx/bitstream/123456789/14934/1/Tesis.419175.pdf

268. Ciro Casanova Macario a; Juan Pablo de Torres. EPOC y maulnutrición [Internet]. Archivos de Bronconeumología. 2009 [cited 2015 Aug 4]. p. 45(Suplemento 4):31-35. Available from: http://apps.elsevier.es/watermark/ctl_servlet?_f=10\&pident_articulo=13148380\&pident_usu ario $=0 \&$ pcontactid $=\&$ pident_revista $=6 \&$ ty $=19 \&$ accion $=$ L\&origen $=$ bronco $\& w e b=w w w . a r c h$ bronconeumol.org\&lan $=$ es\&fichero $=6 \mathrm{v} 45 \mathrm{nSupl} .4 \mathrm{a} 13148380 \mathrm{pdf001} . \mathrm{pdf}$

269. Garcia-Aymerich J, Farrero E, Félez MA, Izquierdo J, Marrades RM, Antó JM. Risk factors of readmission to hospital for a COPD exacerbation: a prospective study. Thorax [Internet]. 
2003 Mar [cited 2015 Jul 29];58(2):100-5. Available from:

http://www.pubmedcentral.nih.gov/articlerender.fcgi?artid=1746561\&tool=pmcentrez\&rend ertype $=$ abstract

270. Hernández Barrera V, Ariñez Fernández M del C, García Carballo MM, Gil de Miguel Á, Carrasco Garrido P, Jiménez García R. Compliance with influenza and pneumococcal vaccination among patients with chronic obstructive pulmonary disease consulting primary care centers in Galicia (Spain) [Internet]. Vacunas: investigación y práctica. Doyma; 2006 [cited $2015 \mathrm{Jul}$ 29]. p. 57-63. Available from:

http://dialnet.unirioja.es/servlet/articulo? $\operatorname{codigo}=4562103 \&$ info $=$ resumen\&idioma $=\mathrm{ENG}$

271. Alfageme I, Vazquez R, Reyes N, Muñoz J, Fernández A, Hernandez M, et al. Clinical efficacy of anti-pneumococcal vaccination in patients with COPD. Thorax [Internet]. 2006 Mar [cited $2015 \mathrm{Jul}$ 30];61(3):189-95. Available from:

http://www.pubmedcentral.nih.gov/articlerender.fcgi?artid=2080738\&tool=pmcentrez\&rend ertype $=$ abstract

272. Melegaro A, Edmunds WJ. The 23-valent pneumococcal polysaccharide vaccine. Part I. Efficacy of PPV in the elderly: a comparison of meta-analyses. Eur J Epidemiol [Internet]. 2004 Jan [cited 2015 Jul 30];19(4):353-63. Available from:

http://www.ncbi.nlm.nih.gov/pubmed/15180106

273. Alfageme Michavila; N. Reyes Núñez; M. Merino Sánc. Vacunación en el enfermo respiratorio [Internet]. Neumosur. 2005 [cited 2015 Jul 29]. p. 17; 4: 259-264. Available from: http://www.neumosur.net/files/NS2005.17.4.A06.pdf

274. Myriam Calle Rubio; Juan Luis Rodríguez Hermosa. Ansiedad y EPOC [Internet]. Archivos de Bronconeumología. 2009 [cited 2015 Aug 4]. p. 45(Supl 4):51-53. Available from: http://apps.elsevier.es/watermark/ctl_servlet?_f=10\&pident_articulo=13148384\&pident_usu ario $=0 \&$ pcontactid $=\&$ pident_revista $=6 \&$ ty $=23$ \&accion $=$ L\&origen $=$ bronco\&web $=w w w$. arch bronconeumol.org\&lan $=$ es $\&$ fichero $=6 \mathrm{v} 45 \mathrm{nSupl} .4 \mathrm{a} 13148384 \mathrm{pdf001} . \mathrm{pdf}$

275. Wei L, Yang X, Li J, Liu L, Luo H, Zheng Z, et al. Effect of pharmaceutical care on medication adherence and hospital admission in patients with chronic obstructive pulmonary disease (COPD): a randomized controlled study. J Thorac Dis [Internet]. 2014 Jun [cited 2015 Jun 23];6(6):656-62. Available from:

http://www.pubmedcentral.nih.gov/articlerender.fcgi?artid=4073386\&tool=pmcentrez\&rend ertype $=$ abstract

276. Stefano Vinaccia; Japcy Margarita Quiceno; Carla Z. Calidad de vida relacionada con la salud y emociones negativas en pacientes con diagnóstico de EPOC [Internet]. Psicología desde el Caribe. Universidad del Norte. 2006 [cited 2015 Aug 4]. Available from: http://ciruelo.uninorte.edu.co/pdf/psicologia_caribe/18/4_Calidad de vida.pdf

277. Álvarez-Gutiérrez FJ, Miravitlles M, Calle M, Gobartt E, López F, Martín A. Impacto de la EPOC en la vida diaria de los pacientes. Resultados del estudio multicéntrico EIME. Arch Bronconeumol [Internet]. $2007 \mathrm{Feb}$ [cited 2015 Aug 4];43(2):64-72. Available from: http://www.sciencedirect.com/science/article/pii/S030028960771030X

278. De Miguel Díez J, Izquierdo Alonso JL, Rodríguez González-Moro JM, de Lucas Ramos P, Bellón Cano JM, Molina París J. Calidad de vida en la enfermedad pulmonar obstructiva crónica. Influencia del nivel de asistencia de los pacientes. Arch Bronconeumol [Internet]. 
2004 Jan [cited 2015 Aug 4];40(10):431-7. Available from:

http://www.sciencedirect.com/science/article/pii/S0300289604755672

279. Ágh T, Dömötör P, Bártfai Z, Inotai A, Fujsz E, Mészáros Á. Relationship Between Medication Adherence and Health-Related Quality of Life in Subjects With COPD: A Systematic Review. Respir Care [Internet]. 2015 Feb [cited 2015 Jun 27];60(2):297-303. Available from: http://www.ncbi.nlm.nih.gov/pubmed/25185152

280. Joan B. Soriano; Myriam Calle b; Teodoro Montem. Opinión pública y patología respiratoria y cirugía torácica. Comité de asuntos profesionales de SEPAR. Encuesta DEMOSCOPIA. 1999 [Internet]. Archivos de bronconeumología. 2012 [cited 2015 Jul 31]. p. 48(9):3083015. Available from:

http://apps.elsevier.es/watermark/ctl_servlet?_f=10\&pident_articulo=90149864\&pident_usu ario $=0 \&$ pcontactid $=\&$ pident_revista $=6 \&$ ty $=32 \&$ accion $=$ L\&origen $=$ bronco $\& w e b=w w w . a r c h$ bronconeumol.org\&lan $=$ es\&fichero $=6 v 48$ n09a90149864pdf001.pdf

281. Cabedo García VR, Garcés Asemany CR, Cortes Berti A, Oteo Elso JT, Ballester Salvador FJ. [Effectiveness of the correct use of inhalation devices in patients with COPD: randomized clinical trial]. Med Clin (Barc) [Internet]. Elsevier; 2010 Nov 6 [cited $2015 \mathrm{Jul}$ 28];135(13):586-91. Available from: http://www.elsevier.es/es-revista-medicina-clinica-2articulo-eficacia-utilizacion-correcta-los-dispositivos-13160695

282. Liam CK, Lo YL, Yap BH, Low SH, Ariwalagam M. Use of pressurised aerosol inhalers among patients attending the Chest Clinic and Primary Care Department of University Hospital, Kuala Lumpur. Med J Malaysia [Internet]. 1993 Sep [cited 2015 Jul 28];48(3):2739. Available from: http://www.ncbi.nlm.nih.gov/pubmed/8183138

283. Golpe Gómez R, Mateos Colino A, Soto Franco I. Técnica inadecuada en el empleo de inhaladores en pacientes atendidos en una consulta de neumología. An Med Interna [Internet]. Arán Ediciones, S. L.; [cited 2015 Jul 28];18(2):25-9. Available from: http://scielo.isciii.es/scielo.php?script=sci_arttext\&pid=S0212$71992001000200004 \& \operatorname{lng}=$ es\&nrm=iso\&tlng=es

284. De las salas R, Mendoza Ballesteros SP, Montenegro Hernández N, Hernández Cantillo MM, Saavedra Jiménez A, Díaz Agudelo D. Uso de inhaladores de dosis medida en pacientes adultos: Necesidad de educación dirigida por enfermería [Internet]. Revista Científica Salud Uninorte. [cited $2015 \mathrm{Jul} 28$ ]. Available from:

http://rcientificas.uninorte.edu.co/index.php/salud/article/view/6004

285. Carrión Valero F, Maya Martínez M, Fontana Sanchis I, Díaz López J, Marín Pardo J. Técnica de inhalación en los pacientes con enfermedades respiratorias crónicas. Arch Bronconeumol [Internet]. Elsevier; 2000 May 1 [cited 2015 Jul 28];36(5):236-40. Available from: http:/www.archbronconeumol.org/es/tecnica-inhalacion-los-pacientescon/articulo/10183/

286. Benito Ortiz L, Pérez Sánchez FC, Nieto Sánchez MP, Saiz Monzón ML, Crespo Fidalgo P, Aldecoa Alvarez-Santullano C. [Use of inhaled bronchodilators by primary care patients]. Aten Primaria [Internet]. 1996 Nov 30 [cited 2015 Jul 28];18(9):497-501. Available from: http://www.ncbi.nlm.nih.gov/pubmed/9280445 
287. Hueto J, Borderias L, Eguia VM, González-Moya JE, Colomo A, Vidal MJ et al. Evaluación del uso de los inhaladores. Importancia de una correcta instrucción. Arch Bronconeumol. 1990;26:235-8.

288. Oğuzülgen IK, Köktürk N, Işikdoğan Z. [Turkish validation study of Morisky 8-item medication adherence questionnaire (MMAS-8) in patients with asthma and chronic obstructive pulmonary disease]. Tuberk Toraks [Internet]. 2014 Jan [cited $2015 \mathrm{Jul}$ 29];62(2):101-7. Available from: http://www.ncbi.nlm.nih.gov/pubmed/25038378

289. Blee J, Roux RK, Gautreaux S, Sherer JT, Garey KW. Dispensing inhalers to patients with chronic obstructive pulmonary disease on hospital discharge: Effects on prescription filling and readmission. Am J Health Syst Pharm [Internet]. 2015 Jul 15 [cited 2015 Jul 29];72(14):1204-8. Available from: http://www.ncbi.nlm.nih.gov/pubmed/26150570

290. Bourbeau J, Bartlett SJ. Patient adherence in COPD. Thorax [Internet]. 2008 Sep 1 [cited 2015 Jul 29];63(9):831-8. Available from: http://thorax.bmj.com/content/63/9/831.long

291. Dolce JJ, Crisp C, Manzella B, Richards JM, Hardin JM, Bailey WC. Medication adherence patterns in chronic obstructive pulmonary disease. Chest [Internet]. 1991 Apr [cited $2015 \mathrm{Jul}$ 29];99(4):837-41. Available from: http://www.ncbi.nlm.nih.gov/pubmed/2009784 


\section{ANEXOS}




\section{ANEXO I . Programa educativo}

\section{Sesión I}

\section{1a Diapositiva}

La primera diapositiva de presentación de las responsables de la docencia del programa educativo, así como los contenido que se van a dar en cada una de las sesiones de educación, así como indicar que el proyecto está subvencionado por la Sociedad Española de Enfermedades respiratorias. Dichas sesiones están basadas en el libro Controlando la EPOC facilitado al inicio de la sesión. Al final de cada sesión de una duración estimada de 40 minutos, los pacientes podrán efectuar preguntas en caso de dudas y podrán interactuar con el resto de compañeros de los

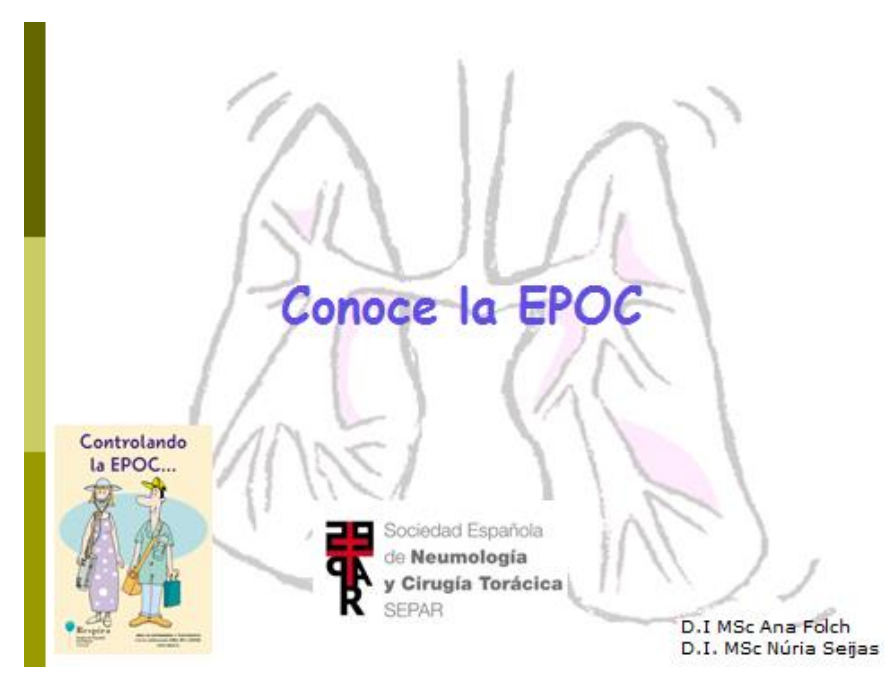
aspectos que les han llamado la atención.

\section{2a Diapositiva}

En esta diapositiva se repasa la anatomía del sistema respiratorio, explicando qué son los pulmones y su finalidad. Desde la entrada del aire por la nariz, su paso por la tráquea, bronquios principales y hasta los alveolos, donde se produce el intercambio de gases: aporte de oxigeno (O2), que se convertirá en energía para el organismo, a través de la inspiración y la eliminación del anhídrido carbónico (CO2) hacia el exterior con la expiración.

Además la vía aérea es la de elección para tratar los problemas respiratorios ya que los ¿Para que sirven los pulmones?

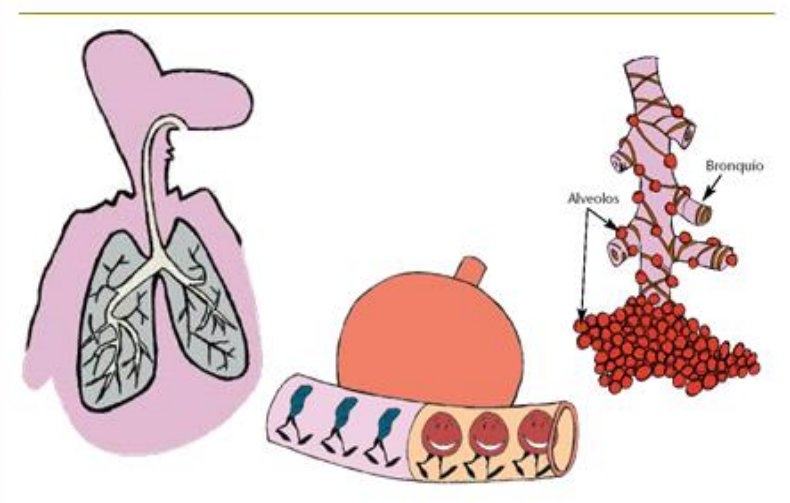
medicamentos administrados por esta vía llegan directamente al órgano afectado, los pulmones, se precisa menos cantidad de fármaco, su acción es más rápida y apenas hay efectos secundarios, pero por el contrario requieren de una técnica correcta de administración para ser efectivos. 


\section{3a Diapositiva}

En esta diapositiva se explica cómo se llama la enfermedad que padecen todas las personas que están en esa sesión informativa. EPOC significa

Enfermedad Pulmonar Obstructiva Crónica, es una enfermedad que está

fundamentalmente asociada al tabaco y se caracteriza por una dificultad del paso del aire por los bronquios, lo que provoca ahogo al andar o al hacer alguna actividad, tos y expectoración. Haciendo incidencia en por que se producen sus crisis respiratorias, como consecuencia de una reducción en el diámetro del alveolo, situación que explicaría la mayor facilidad de contraer infecciones a causa de una mayor dificultad de expulsión de los mocos.

\section{¿Qué es la EPOC?}
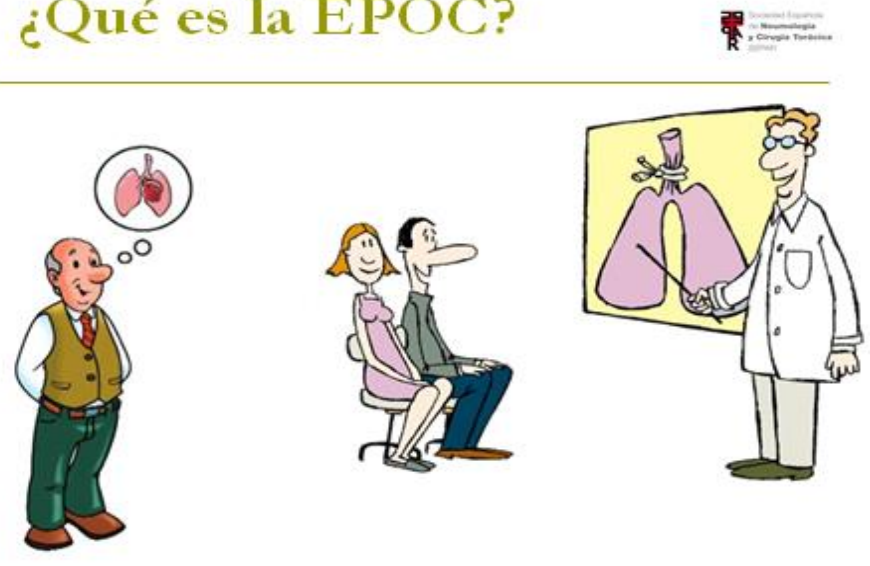

A esta enfermedad también se le puede llamar bronquitis crónica o enfisema pulmonar. Es importante remarcar al paciente que la EPOC es una enfermedad de aparición lenta.

\section{4 a Diapositiva}

El tabaco es un irritante que provoca la inflamación de las paredes de los bronquios y un aumento de secreciones, todo ello causa un estrechamiento y una obstrucción que impide el paso del aire

El primer paso para el tratamiento eficaz en el epoc es dejar de fumar, es importante remarcar que el tratamiento farmacológico será mucho menos efectivo si no se elimina el hábito del tabaco. Dejar de fumar es DIFÍCIL, pero NO IMPOSIBLE.

\section{5a Diapositiva}

En este dibujo muestra la capacidad respiratoria de tres personas, la curva más alta representa a un paciente que no ha fumado nunca, observando que tiene una mayor capacidad pulmonar que el resto pero que con el tiempo como consecuencia del paso de la edad esta capacidad pulmonar se va viendo disminuida, la segunda línea más alta representa a un paciente que era fumador y a los 50 años de edad se ha dejado el hábito

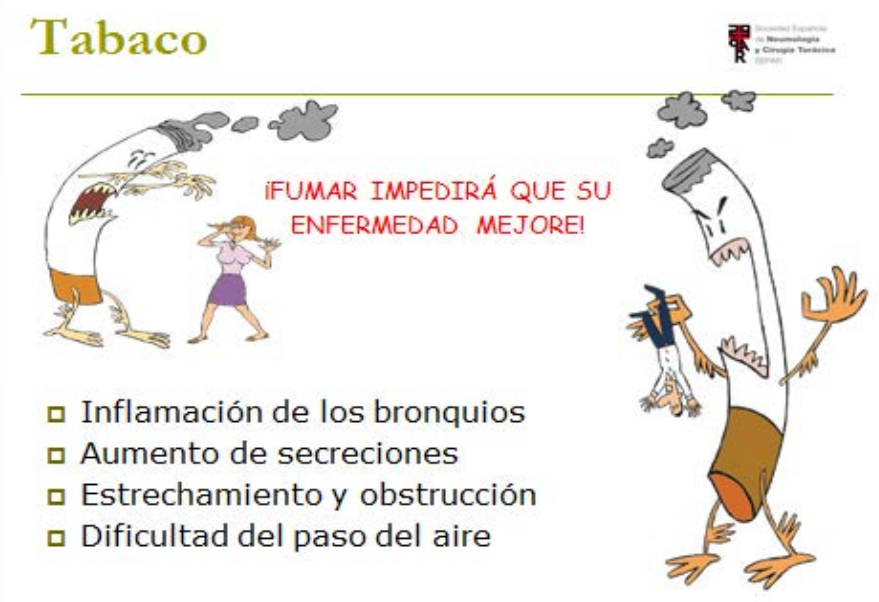

Curva de la EPOC
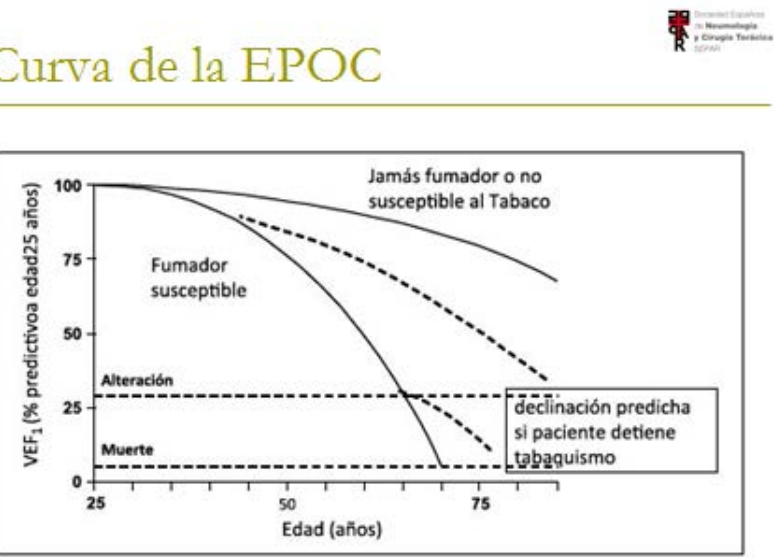

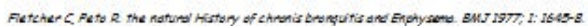


tabáquico, mejorando considerablemente esta capacidad pulmonar del paciente desde el momento en que se deja de fumar, pero nunca tendrá la capacidad pulmonar del paciente que nunca ha fumado. Y por último representa a un paciente que nunca ha dejado de fumar y sigue fumando hasta su muerte, donde se observa que la capacidad respiratoria se ve afectada en gran medida con respecto al resto de personas no fumadoras o que se han dejado el hábito tabáquico. Esta diapositiva se debe de explicar sin ánimo de juzgar a ningún paciente que siga fumando, alentando la necesidad de dejar dicho habito y a aquellos que no han dejado de fumar a seguir en su lucha.

\section{6a Diapositiva}

En esta diapositiva se muestran las aberturas alveolares de tres tipos de pacientes, la primera imagen hace referencia a un alveolo de un paciente no fumador con un alveolo normal, la segunda hace referencia a la abertura alveolar inflamada, siendo esta la situación alveolar de un paciente con EPOC en situación estable, donde como consecuencia de la exposición principalmente al consumo de tabaco se ve inflamado de forma crónica. Y por último el alveolo obstruido hace referencia al alveolo de un paciente EPOC con una exacerbación.

Siendo destacable la reducción tanto en el inflamatorio como en el obstructivo de la capacidad de albergar aire para producir el intercambio gaseoso.

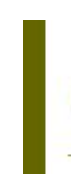

\section{Características}
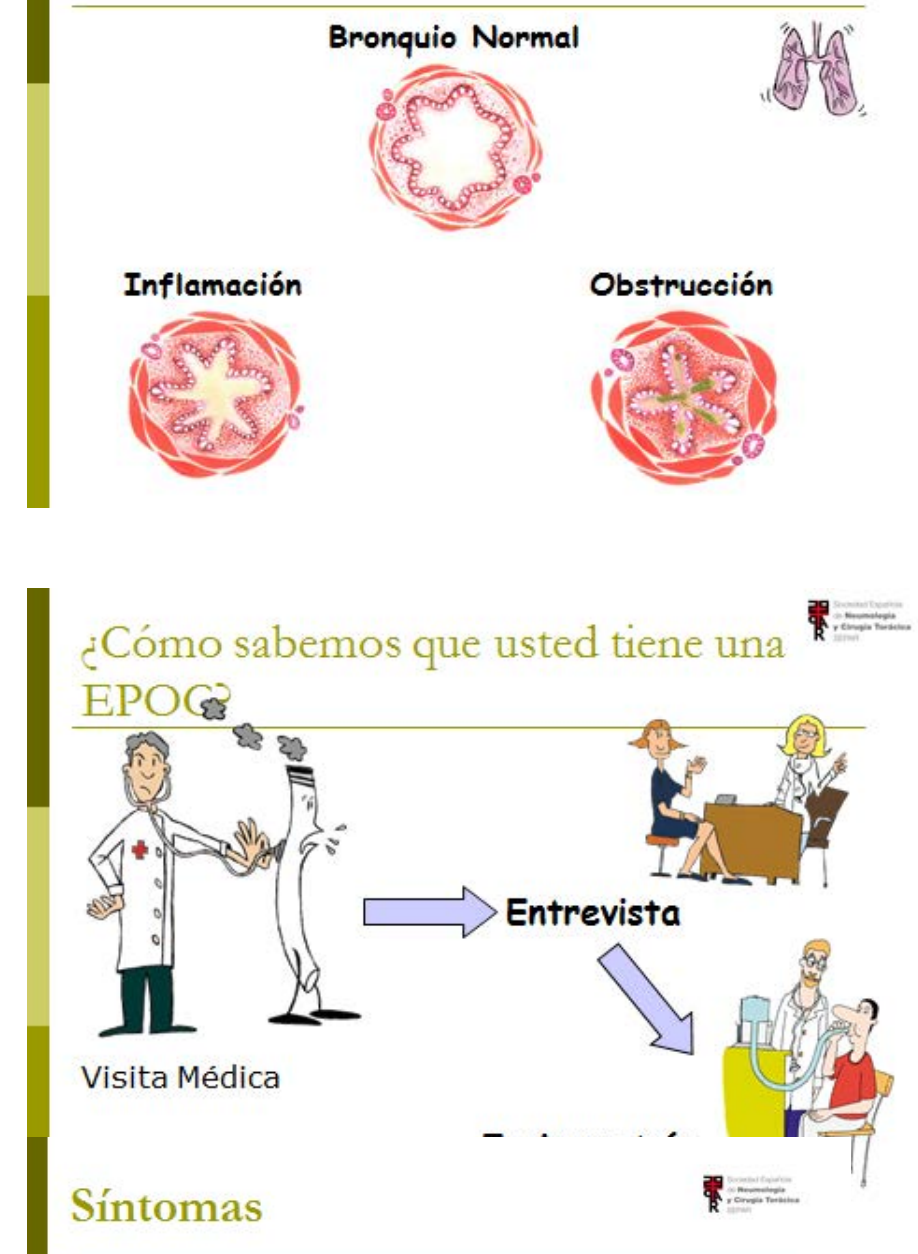

\section{7a Diapositiva}

Esta diapositiva intenta transmitir el mensaje de un diagnostico precoz y de los método de diagnósticos y criterios diagnósticos que se utilizan. Si la persona es fumadora activa, presenta disnea (ahogo), tos y expectoración especialmente por las mañanas y se resfría fácilmente, aproximadamente unas 3 veces al año debe acudir a su Centro de Atención Primaria.

Cuando acuda a la consulta, le preguntaran sobre el consumo de tabaco y los síntomas.

Para confirmar el diagnóstico se le practicará una espirometría forzada (prueba de soplar) que es la prueba imprescindible para diagnosticar la EPOC.

Una vez elaborada la prueba se comprobara primeramente a través de la primera espirometría de una reducción del volumen respiratorio por debajo del $70 \%$, para descartar entre las dos enfermedades crónicas obstructivas que existentes (asma y EPOC) se realizara una segunda espirometria tras haber hecho una 
inhalación de un broncodilatador de corta duración (ventolin o atroven) si no se produce una mejora significativa se confirmara el diagnóstico de EPOC.

\section{8a Diapositiva}

En esta dispositiva se muestran los signos y síntomas más comunes que presentan los pacientes con EPOC, como consecuencia lo dicho anteriormente, explicaría la presencia de tos y expectoración, que producirá la disminución de la abertura alveolar y la inflamación crónica. La disnea y ahogo fruto de un menor volumen pulmonar para hacer el intercambio gaseoso. Que se producirá en una disminución de la tolerancia al ejercicio y una afectación de la calidad de vida.

\section{9 a Diapositiva}

En esta dispositiva se presentan los signos y síntomas de alarma del inicio de una agudización o exacerbación de la EPOC. Siendo el cambio del color del esputo un gran predictor del empeoramiento de la situación respiratoria, donde el color blanco o trasparente será el color normal, y otros colores como marrón o verde predictores claro de inicio de un empeoramiento respiratorio. El dolor de cabeza matutino nos haría pensar en problemas de oxigenación respiratoria o la somnolencia diurna.

Siendo los aspectos más conocidos por todos

\section{Saber actuar de forma temprana}

Ahogo:

$\square$ Relajarse y moverse lo menos posible

- Tomar medicación rescate

(broncodilatadores)

$\checkmark$ Colocarse en posición que facilite la respiración

$\square$ Respirar con los labios fruncidos

口 Utilizar el oxígeno si lo lleva

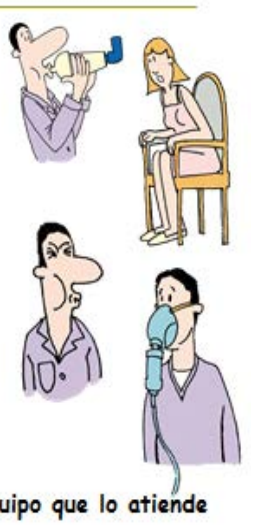

todo

para

final

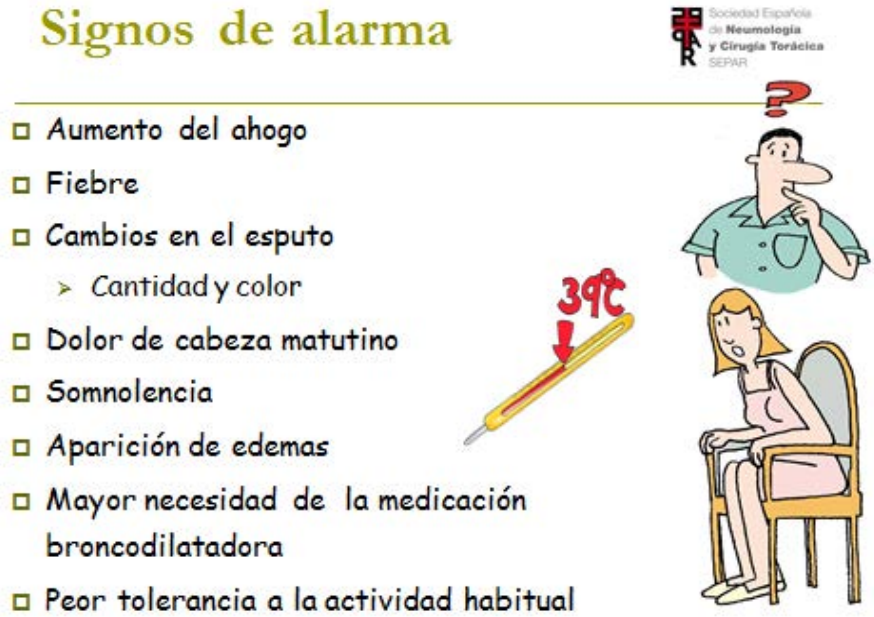
los pacientes el aumento del ahogo, la mayor necesidad de broncodilatadores de corta duración o una peor tolerancia a la actividad normal.

Es importante incidir en esta diapositiva que conseguir un mejor conocimiento del paciente en cuanto a su enfermedad y los síntomas y signos de alarma a tener en cuenta hará que las descompensaciones se detecten de forma precoz y podamos actuar antes que la situación se complique. Un mejor conocimiento de la enfermedad junto a un cumplimiento del tratamiento son nuestras mejores armas para combatir el avance de la enfermedad.

LOS SÍNTOMAS SON UNA ALERTA DE QUE ALGO NO ESTA FUNCIONANDO Y HAY QUE ACTUAR DE FORMA TEMPRANA. 
10므 Diapositiva

Recomendaciones ante el ahogo en situaciones de agudizamiento

\section{1aㅡ Diapositiva}

Recomendaciones en situaciones de exacerbación con el aumento de la expectoración.

\section{2a Diapositiva}

Recomendaciones en pacientes con edemas

\section{3 a Diapositiva}

Se debe de avisar al médico cuando el tratamiento habitual para la EPOC no está resultando efectivo, cada vez se presenta un mayor nivel de ahogo y asfixia siendo necesaria toda la musculatura pectoral y abdominal para la expansión del tórax, signos de mala oxigenación como tener los labios o los dedos azulados, fruto de una retención del carbónico o incluso dolor torácico.

\section{Saber actuar de forma temprana}

Cambios en la expectoración:

$\square$ Aumento de líquidos

$\square$ Limpieza de secreciones

口 Observar cambios de aspecto

$\checkmark$ Control de la temperatura

aparece fiebre ir médico)

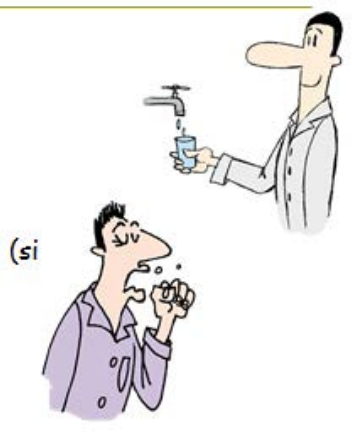

Si el problema no mejora llame al equipo que lo atiende

\section{Saber actuar de forma tempranà}

Aparieión de hinchazón en las piernas:

口 Disminuya la ingesta de líquidos

$\square$ Eleve los pies

$\checkmark$ Compruebe el color de las piernas

Si el problema no mejora llame al equipo que lo atiende
¿Cuándo tengo que avisar?
口 Mala respuesta al tratamiento
$\checkmark$ Presencia de ahogo en reposo
口 Uso de la musculatura accesoria
口 Fiebre muy alta
口 Labios y dedos azulados
$\checkmark$ Irritabilidad, confusión, etc.
口 Dolor torácico

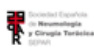




\section{4 a Diapositiva}

Seguir fumando, no realizar el tratamiento tal como se le ha prescrito, no realizar la técnica inhalatoria correctamente, mal control de posibles enfermedades "añadidas", trastornos de ansiedad y depresión. La ansiedad se caracteriza por sensaciones como tensión, miedo, angustia, opresión en el pecho, etc. La depresión se caracteriza por tristeza, apatía, fatiga, etc. Estos, pueden producirse por la propia enfermedad y se deben buscar formas para solucionar el problema, no acudir a las visitas programadas, problemas sociales y familiares, ambientes contaminados.

\section{5 a Diapositiva}

Es importante incidir en esta diapositiva que el tratamiento es para siempre y que no debe automedicarse ni abandonar el tratamiento. Siendo los fármacos habituales, los siguientes, que los veremos en mayor profundidad en la siguiente sesión.

- Broncodilatadores, para eliminar la contracción de los músculos bronquiales

- Anticolinérgicos, para mantener el tono muscular de los bronquios.

- Antiinflamatorios, para eliminar la inflamación bronquial.

- Antibióticos, para tratar las infecciones.

- Vacunas, antigripal para prevenir la gripe u otras infecciones bronquiales (vacuna antineumococica) Es destacable seguir las recomendaciones de pauta especial sobre corticoides inhalados, cuya retirada es muy progresiva, puesto que si se realiza la retirada de forma inmediata dicha medicación produce un efecto revote y en vez de reducir la inflamación aumentaremos la misma.

\section{6 a Diapositiva}

La última diapositiva de la primera sesión hace referencia a los hábitos que no deben de seguir los pacientes con EPOC puesto que se produciría un empeoramiento de su enfermedad. Ya que por haber sido diagnosticado de EPOC no debe dejar de realizar todas aquellas actividades que habitualmente hacía. $Y$ una vez compensada la enfermedad debe intentar reincorporarse a las rutinas habituales de su vida.
¿Que factores pueden influir negativamente en mi enfermedad?

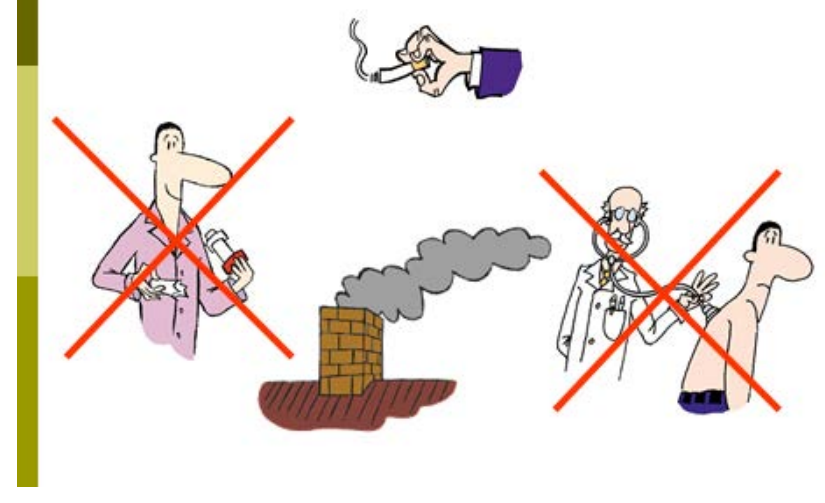

Tratamiento Farmacológico

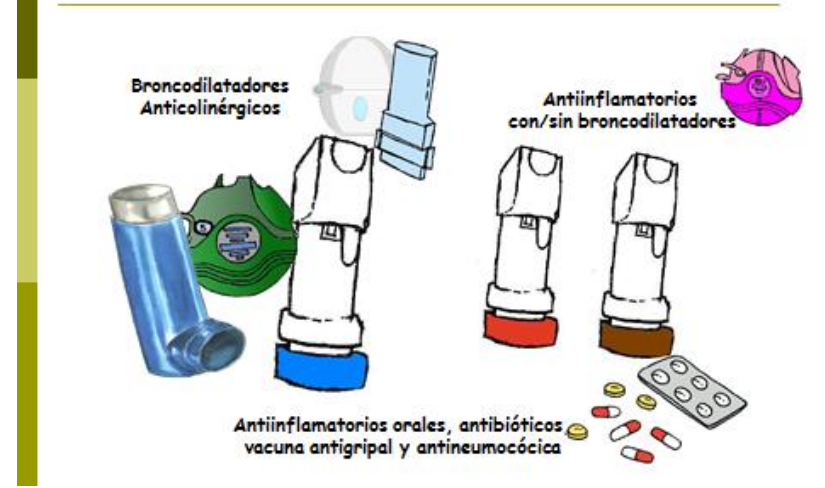




\section{Sesión II}

\section{1a Diapositiva, 2a Diapositiva,}

Presentar que vamos a hacer en esta segunda sesión de información a los pacientes, haciendo incidencia en la importancia del correcto uso de los medicamentos inhalados ya que su enfermedad reside en el pulmón. Siendo destacable la gran variedad de dispositivos que existen en el mercado donde posiblemente muchos de los pacientes han utilizado muchos de los mismos y

\section{Dispositivos de inhalación}

donde cada dispositivo tiene una técnica correcta de inhalación que suele tener determinados puntos que se cometen más errores por los pacientes y es importante destacar.

\section{3a Diapositiva}

En esta diapositiva, de gran utilidad puesto que muchos de los pacientes llevan muchos años utilizando ese dispositivo y consideran que ellos siempre han realizado el inhalador de forma correcta.

\section{4a Diapositiva}

El objeto de esta diapositiva es remarcar la importancia del correcto uso de los inhaladores, ya que la vía inhalatoria tiene una serie de ventajas con respecto a otras vías de administración de fármacos tal y como se puede apreciar en la diapositiva.

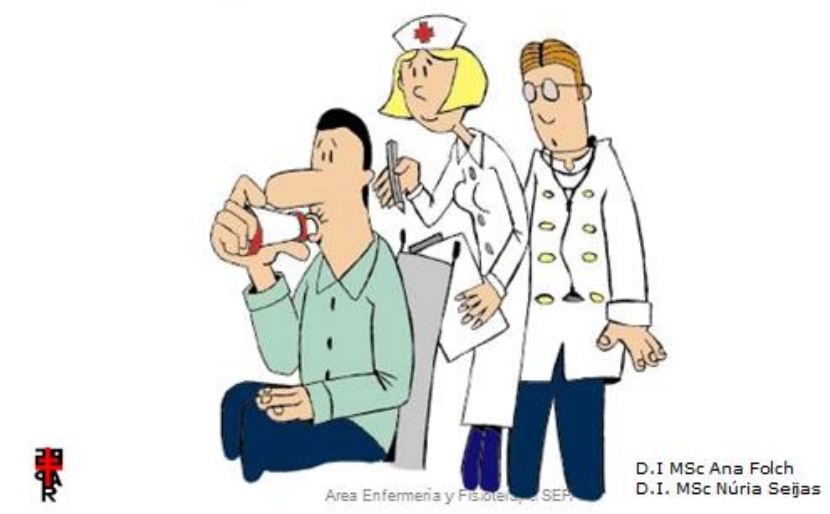




\section{5a Diapositiva}

Un aerosol es una suspensión de partículas sólidas o liquidas en un gas. Un ejemplo de suspensión de partículas sólidas es el humo y el de partículas liquidas es la nube.

\section{6a Diapositiva}

La medicación administrada por vía inhalatoria se suele utilizar entre otros dispositivos los aerosoles, que consisten en dispositivos, que liberan, al accionar el sistema, partículas se debe principalmente al efecto de la gravedad o de sedimentación, las partículas suelen ser higroscópicas y por lo tanto sensibles a la humedad, es por esto que una vez en el interior del pulmón captan humedad y aumentan de tamaño sedimentando y depositándose en el punto que alcanzaron, recordar que en el interior del pulmón el aire está saturado de humedad. Su tamaño debe ser inferior a 5 micras ya que así alcanzaran los alvéolos de las últimas generaciones.

Un efecto poco deseable es el de la impactación inercial, la aspiración se debe realizar lentamente precisamente para evitar que por impactación el fármaco se deposite en la orofaringe siendo este un lugar no deseado y motivo de alteraciones como la afonía, irritación o la candidiasis en el uso de corticoides o picor que desencadena tos tras la inhalación.

El movimiento Browniano (solo para educadores) es aquel por el que las partículas chocan entre sí, si estas son inferiores a 0,5 micras se corre el peligro de ser expulsadas sin depositarse en los alvéolos en la espiración posterior a la inhalación.

\section{7a Diapositiva}

Dentro de los fármacos broncodilatadores existen diversos tipos, que se clasifican dependiendo de la duración de su efecto, por ejemplo tenemos:

\section{¿Qué es un aerosol?}
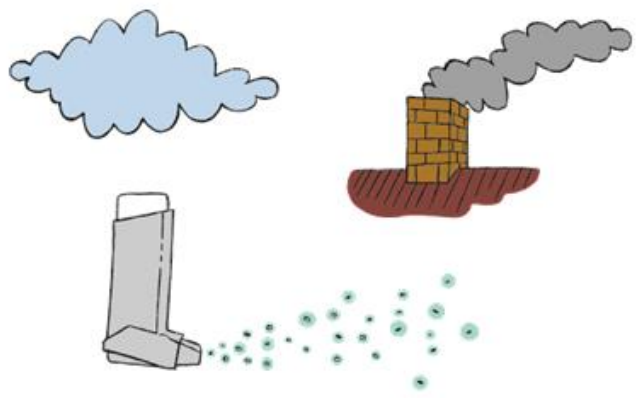

Area Enfermeria y Fisioterapia SEPAR

\section{Distribución y deposito de las partículas}
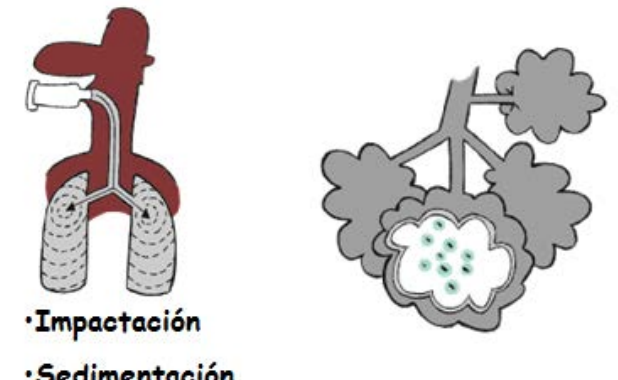

-Sedimentación

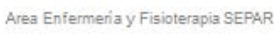

\section{Acción Broncodilatadora}

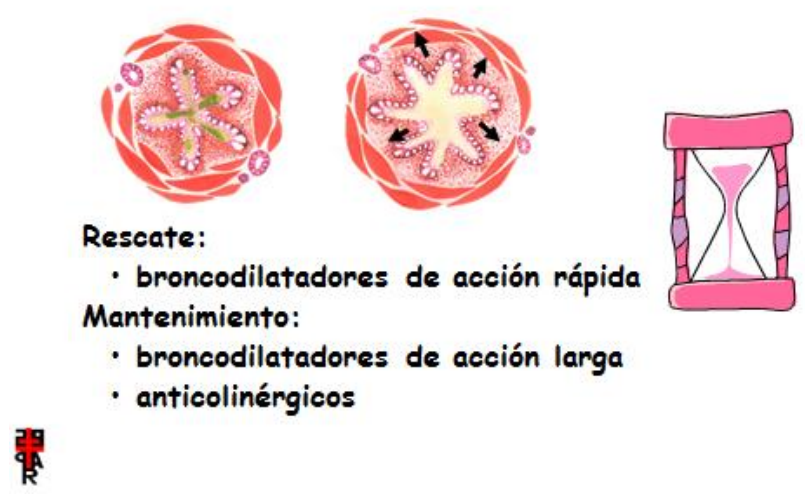

Broncodilatadores:

Acción corta y rápida (4-6 horas) (Salbutamol y Terbutalina) 
Acción prolongada ((12 horas) dentro de este grupo además tenemos según la rapidez que actúen:

Inicio rápido (Formoterol)

Inicio lento (Salmeterol)

\section{8a Diapositiva}

Indicaremos al paciente que en primer lugar siempre debe tomar los fármacos broncodilatadores, a continuación, si los toma, los anticolinérgicos y finalmente los antinflamatorios. Siendo recomendable esperar 10 minutos entre cada toma, por ejemplo se recomienda que si los toma en la hora del desayuno, que realice la primera inhalación desayune y posteriormente se realice el otros inhalador que tenga.

La explicación del orden reside en que es aconsejable primero los broncodilatadores para favorecer la entrada de la medicación y posteriormente los anticolinérgico o los antiinflamatorios para que estos tenga un mayor efecto al tener la entrada al bronquio más accesible.

\section{9a Diapositiva}

A parte de clasificarlos según el tipo de medicamento que contienen también los podemos clasificar según el sistema que utilizan, como los sistemas de inhalación con dosis controlada, que disponen de una válvula dosificadora. $Y$ otros que no tienen esa dosis controlada como los sistemas automáticos, que funcionan con el impulso de la inspiración, liberando una dosis de fármaco contenido. Y el último tipo de dispositivo son las cámaras de inhalación, que mejoran la llegada de partículas en suspensión de los dispositivos automáticos a pacientes con su capacidad pulmonar más disminuida.

Además también es destacable los inhaladores que no son aerosoles, con los cual no tienen gas para favorecer la llegada a los pulmones, como son los dispositivos en polvo, (fármaco depósito (Turbuhaler), en alvéolos (Accuhaler), en monodosis (Aerolizer y HandiHaler), Teniendo como ventaja, que proporcionan un mayor depósito pulmonar y tienen una mayor cumplimiento terapéutico ya que su técnica es más sencilla.

\section{Esquema de los sistemas de inhalación}

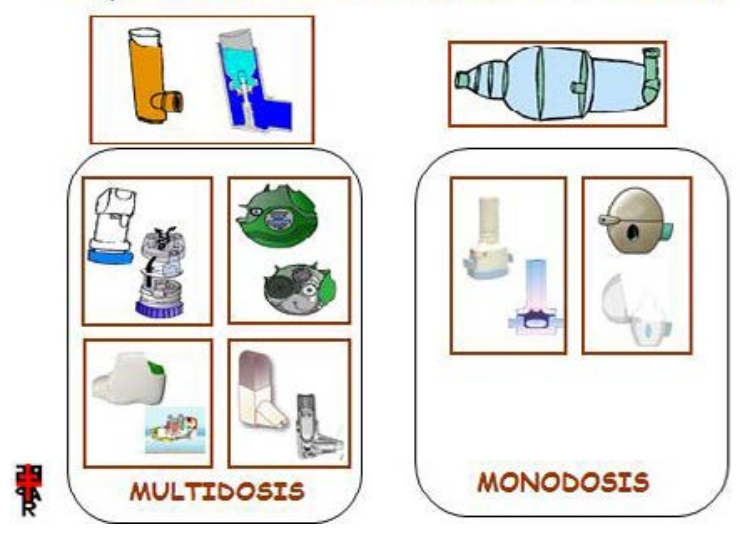

\section{0 a Diapositiva}

Por las razones anteriormente mencionadas existen investigaciones que nos indican que los dispositivos que mayor deposito pulmonar tiene, con lo cual llegan dichas partículas a las zonas más distales del pulmón son los dispositivos en polvo, seguidos de las cámaras de inhalación y los cartuchos presurizados o aerosoles. 


\section{1a Diapositiva}

El cartucho presurizado es uno de los dispositivos más utilizados por los pacientes con EPOC, las recomendaciones de la Sociedad Española de Enfermedades Respiratorias aconsejan realizar los siguientes pasos, siendo destacables los pasos de soplar todo el aire de los pulmones antes de iniciar la inhalación, empezar a coger el aire y coordinar la recogida de aire con el disparo del inhalador. También cabe destacar no abrir la boca inmediatamente ya que la inhalación se debe de aguantar 10 minutos, así como enjugarse la boca sobre todo en aquellos fármacos que llevan corticoides por el riesgo de padecer mayor índice de infecciones.

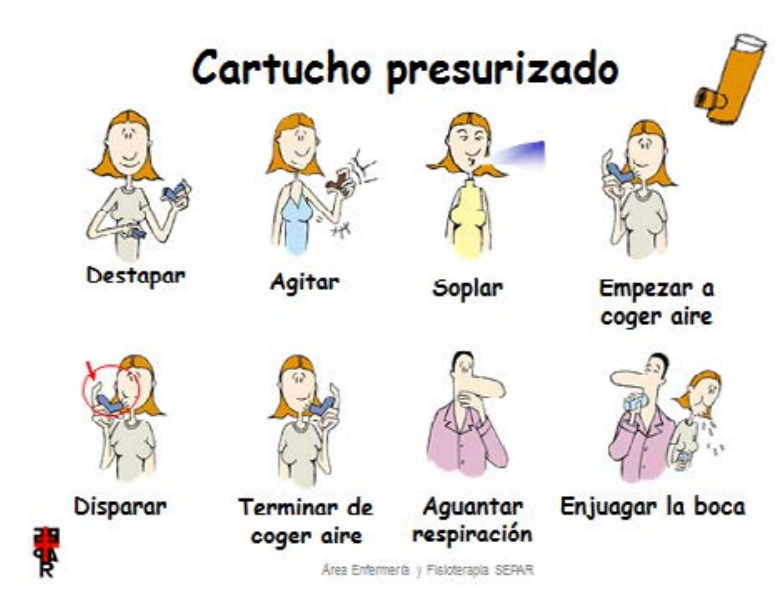

\section{2 a Diapositiva}

De forma frecuente se debe de limpiar el cartucho presurizado, ya que en un número considerable de los pacientes solo los utilizan en momentos de mayor ahogo. La limpieza se debe de quitar el cartucho, limpiar la boquilla, secarla y volver a introducir el cartucho con la boquilla de inhalación, así como asegurarse de no tener caducado el dispositivo como consecuencia del uso poco frecuente.

\section{3a Diapositiva, 14 a Diapositiva}

Otro de los dispositivos alternativos de uso de los aerosoles o cartucho presurizado son las cámaras de inhalación, donde su técnica es muy similar a la del cartucho, siendo como única diferencia que no es necesaria la coordinación entre el disparo y la inhalación, además también es destacable que es igual de efectiva la realización de una inhalación profunda que 4 o 5 inhalaciones lentas.

La cámara de inhalación se aconseja limpiarla con frecuencia con agua y jabón, bien enjuagado y

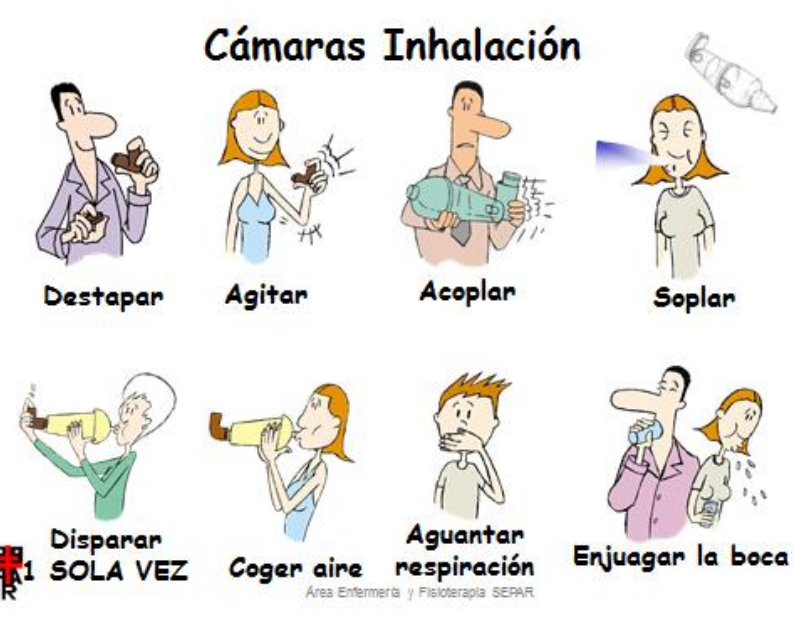
escurrido, secándola al aire, ya que nunca se debe de frotara con paños (electricidad estática). 


\section{6a Diapositiva}

Sistemas de administración de polvo en formato monodósis o multidósis. El sistema Turbuhaler puede proporcionar fármaco puro o junto a un excipiente, la lactosa, que es como lo utilizan los demás dispositivos de polvo, los otros sistemas utilizan lactosa asociada al fármaco.

-Ventajas: Buena dosificación, Buen aporte pulmonar de fármaco (30\%), Buen control de dosis usadas o disponibles, Ausencia de gases contaminantes, Pequeño, ligero y fácil de manejar, Discretos, Mayor porcentaje de corrección

-Inconvenientes: Requiere inspiración voluntaria (30 L/min.), Mayor depósito orofaríngeo, Sensible a la humedad ambiente. Posible sensibilización a la lactosa presente en algunos fármacos.

\section{7ạ Diapositiva}

Uno de los dispositivos de polvo seco es el sistema turbuhaler, dicho sistema es diferente al resto por que a la hora de cargar la dosis es necesario girar una rueda que tiene en la parte inferior, una vez se escucha un "click" significara que se ha cargado el medicamento, siendo siempre el giro en el sentido de las agujas del reloj. El resto de pasos son iguales al resto de inhaladores. También es importante destacar que a aquellos pacientes que tengan dos inhalaciones seguidas de este dispositivo deben de realizar el proceso dos veces.

\section{8a Diapositiva}

Este otro dispositivo de polvo seco, a diferencia del anterior se debe de cargar la medicación destapando el medicamento y bajando hasta el límite una palanca que tiene ubicada en el lateral del dispositivo. Dicho dispositivo presenta una serie de problemas, como no cerrar el dispositivo una vez finalizada la inhalación, con lo cual la palanca se queda en posición cargada cuando realmente no está cargada si no que ya ha sido utilizada en la anterior inhalación.
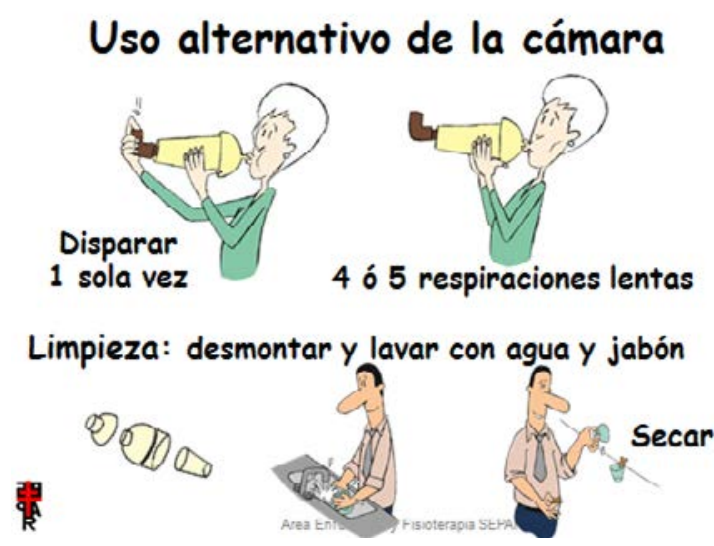

Dispositivos de Polvo
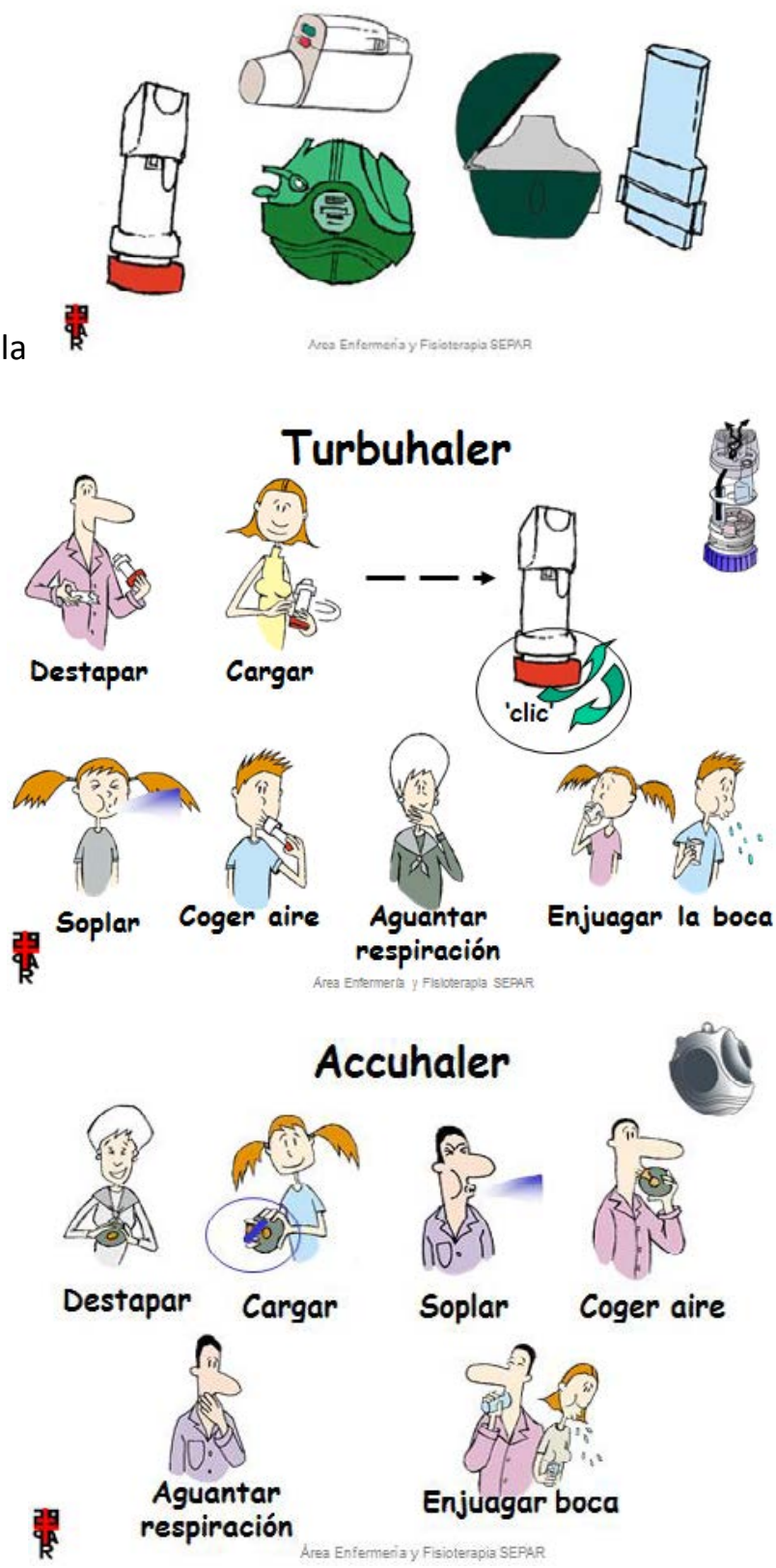


\section{9a Diapositiva}

Este dispositivo lo podéis encontrar como aerolizer, handihaler o inhaletas, dependiendo de la empresa farmacéutica. Dicho dispositivo hace referencia a aquellos inhaladores que tienen una capsula y deben de colocarla en el dispositivo para inhalar el contenido. Esta técnica se realiza del mismo modo que todas las anteriores pero con la diferencia que cada vez que realizas la inhalación debes de colocar la capsula en la cazoleta, pincharla misma y realizar la inhalación. Los principales problemas residen en mantener presionado

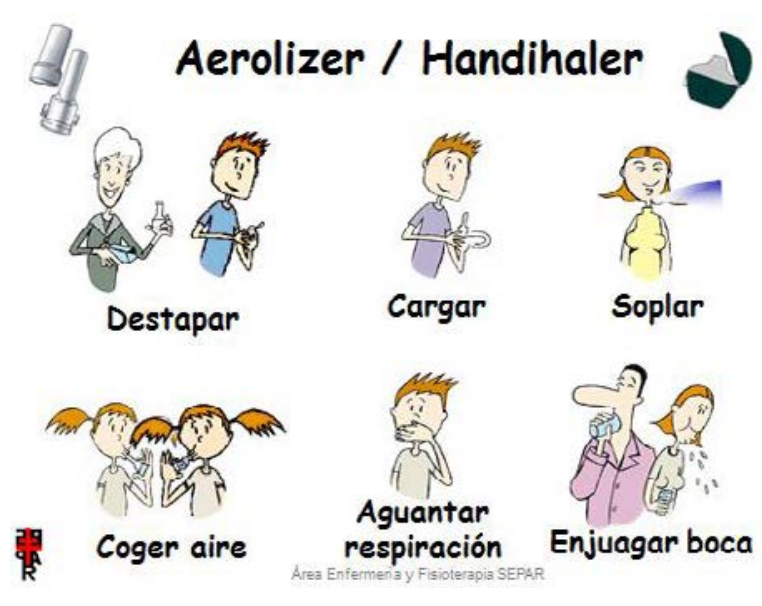
el dispositivo mientras se realiza la inhalación, con lo cual el punzón que atraviesa la capsula no deja pasar todo el contenido de la misma en la inhalación. Otros pacientes cometen errores como perforar varias veces el dispositivo probocando la inhalación de microparticulas de plástico.

\section{0a Diapositiva}

Por tanto es destacable que los dispositivos en polvo, tienen mayoritariamente control de dosis, cada dispositivo tiene un sistema de control o bien de las dosis utilizadas. Así como la limpieza de los dispositivos en polvo, a diferencia de los aerosoles, debe realizarse sin desmontar los dispositivos, al ser equipos de uso individual para su limpieza emplearemos un paño seco, nunca sumergir en líquidos limpiadores ni usar paños húmedos.

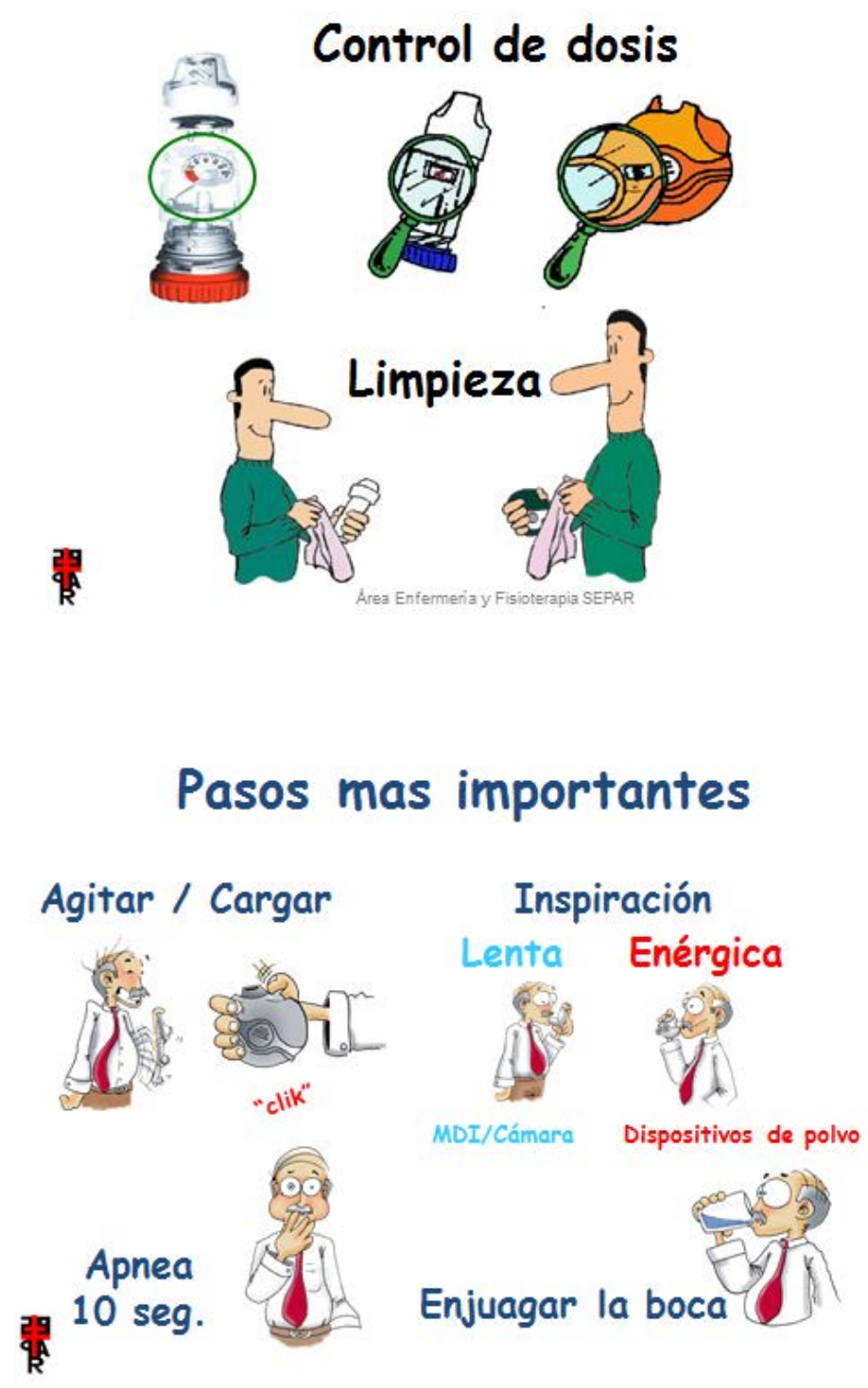

\section{1a Diapositiva}

De todos los inhaladores los puntos más importantes que hemos visto son, agitar en la cartucho y cargar en los dispositivos en polvo, realizar una inspiración lenta en los dispositivos de cartucho y fuerte en los dispositivos de polvo seco, así como aguantar la respiración segundo después de hacer la inhalación y enjuagarse la boca. 


\begin{abstract}
22a Diapositiva
Otro de los dispositivos que normalmente utilizáis o bien en el hospital o bien en casa cuando tenéis periodos de agudización es el nebulizador. La medicación que debéis de utilizar normalmente esta precargada y los pasos son los siguientes.
\end{abstract}

\section{3a Diapositiva}

Se debe de llevar un control periódico de la técnica de inhalación en caso de dudas pregunten al personal sanitario, ya que está en sus manos que la medicación administrada le surta el mayor efecto posible.

\section{Nebulizadores}

- Lavado higiénico de las manos

- Preparar el fármaco tal como se lo han indicado

- Introducir el fármaco dentro de la cazoleta

- Posición sentado o incorporado

- Colocar la mascarilla en la cara

a Si precisa oxígeno en casa, debe realizar la nebulización con el oxígeno conectado

- Nebulizar el fármaco. Comprobar que se produce una nube de aerosol

- Respirar lentamente hasta su finalización

- Si después de la nebulización siente usted: nerviosismo, pulso rápido. nauseas, vómito, comuníquelo al equipo que lo atiende

- Mantener piel facial limpia y seca

- Higiene bucal

踤

Area Enfermeria y Fisioterapia SEPAR.

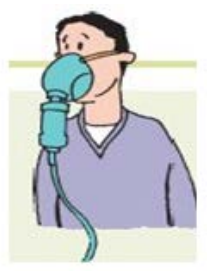

\section{Control periódico de la técnica}

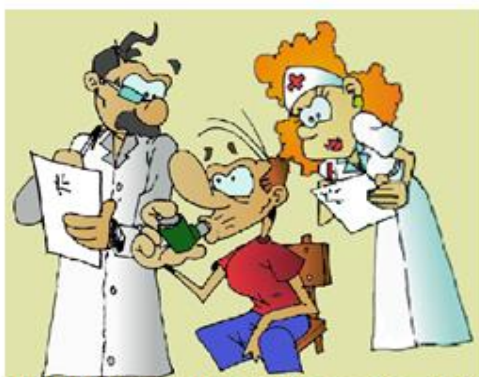

Es un proceso continuo, cada visita es una oportunidad para revisar, reforzar y aumentar los conocimientos y habilidades, 踏 por lo que es imprescindible consensuar entre todo el equipo

EDUCA Y ENSEÑA, SISTEMAS DE INHALACTÓN.J.Giner, V.Mocion " 


\section{SESIÓN III}

\section{1a Diapositiva}

Mediante la sesión de hoy, aprenderemos diferentes estrategias que pueden ser de gran utilidad para el afrontamiento de las actividades diarias o el afrontamiento de situaciones de agudización. Toda la información que os voy a explicar hoy está disponible de forma más ampliada en el libro que os facilite el primer día de controlando la EPOC.

\section{2a Diapositiva}

Las diferentes técnicas que vamos a ver hoy se van a basar en ejercicios que podéis hacer en nuestra casa y favorecen la función pulmonar, la vacunación, el ejercicio físico, técnicas de limpieza de secreciones y que dieta es recomendable para un pacientes con EPOC y que cambios en la dieta se deben de realizar en caso de agudizaciones.

\section{3a Diapositiva}

La gripe es una infección que afecta al aparato respiratorio, es distinta a los catarros y puede ser grave en las personas que como usted, presentan una mayor sensibilidad de las vías respiratorias, por ello todos los años debe vacunarse contra la gripe. La neumonía puede deteriorar su enfermedad respiratoria, por ello es importante que le administren la vacuna de la neumonía cada 5 años si tiene más de 65 años. No hay problema si se la administran conjunta con la de la gripe.

\section{4a Diapositiva}

Todo esto a través de la optimización del patrón ventilatorio y el entrenamiento con los ejercicios respiratorios para prevenir las disfunciones respiratorias, restituir la función pulmonar y mejorar la calidad de vida. La respiración significa vida, pero cuando tenemos un problema respiratorio, esto tan

\section{Tratamiento no farmacológico}

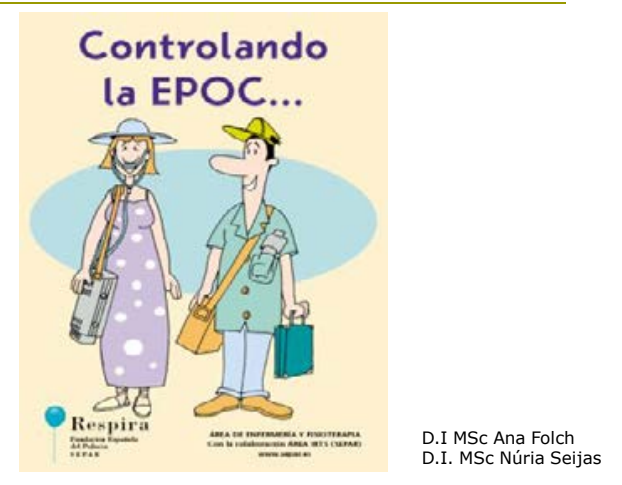

Tratamiento No Farmacológico

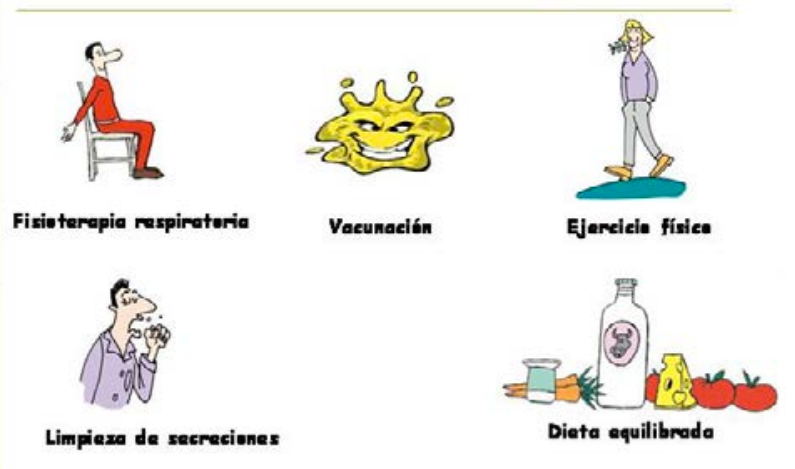

Vacunas

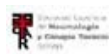

$\square$ Debe vacunarse cada año contra la gripe

- Es importante que le administren la vacuna de la neumonía cada 5 años si tiene más de 65 años

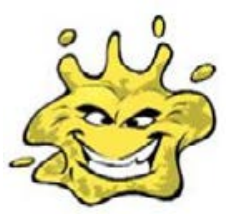

Objetivos de la fisioterapia en la EPOC

․ Eliminar secreciones

- Optimizar la función respiratoria

- Aliviar la sensación de ahogo

- Mejorar la capacidad de ejercicio

- Facilitar las actividades de la vida diaria

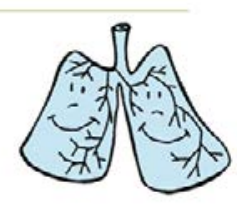


natural se hace muy complicado, por tanto para aliviar este ahogo, le vamos a dar una serie de recomendaciones que le ayudarán a vivir mejor.

\section{5a Diapositiva}

En este enlace perteneciente a la página web de forum clinic, podéis acceder para visualizar diferentes ejercicios que podéis hacer en vuestra casa y favorecerán vuestra capacidad respiratoria.

Como ejercicios de expansión del tórax, sobre una camilla o ejercicios de subir escaleras, como ahora veremos a continuación.

\section{6a Diapositiva}

Para subir escaleras: póngase delante del primer peldaño y tome aire por la nariz, suba soplando los peldaños que pueda. Pare y tome aire por la nariz, siga subiendo y sople

La falta de actividad es un grave problema. Además de favorecer la obesidad, hace que el paciente 'pierda su forma física'. El ejercicio regular (30 minutos de paseo diario, utilizar las escaleras en lugar del ascensor, etc.), es fácil de realizar y es una parte importante del tratamiento. Debe tenerse en cuenta el estado de cada paciente.

Subir escaleras

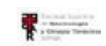
cr\%C3\%B3nica/informaci\%C3\%B3n/tratamiento-nofarmacol\%C3\%B3gico

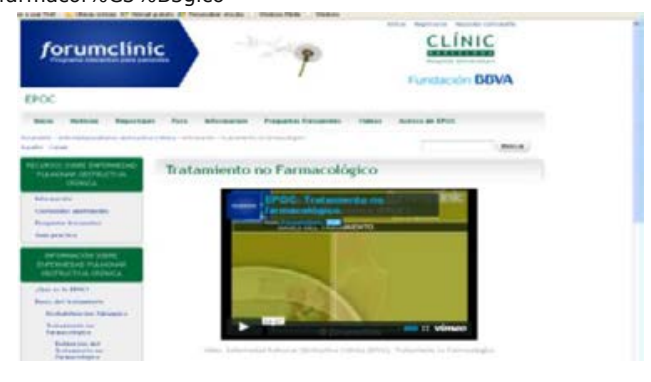

\section{Subir escaleras}

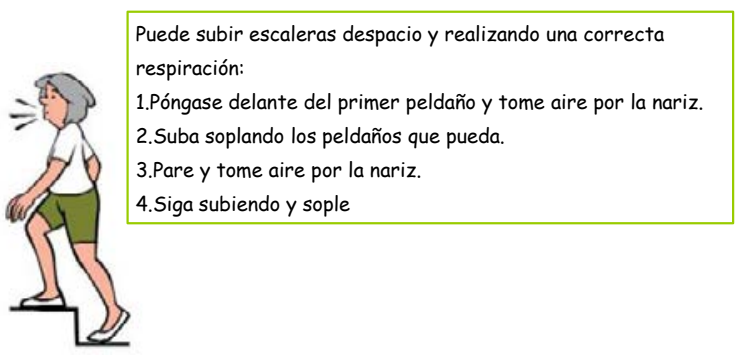

\section{7ạ Diapositiva}

Con la tos se limpian las vías respiratorias. Para que la tos sea eficaz debe coger aire profundo y soltarlo fuerte en uno o dos golpes de tos. ¡Beba 1,5 litros de agua al día! Toser muchas veces seguidas, no provoca irritación de garganta y no es tan eficaz, es mejor llenar los pulmones de aire bien y soltarlo en uno o dos golpes de tos fuertes. Además otras técnicas muy útiles para provocar la tos sobretodo en situaciones de agudización donde de tanto toser tienen las gargantas irritadas, es soltar paulatinamente el aire de los pulmones hasta que no nos quede nada más de aire e inmediatamente se producirá la tos.

\section{Limpieza de secreciones}
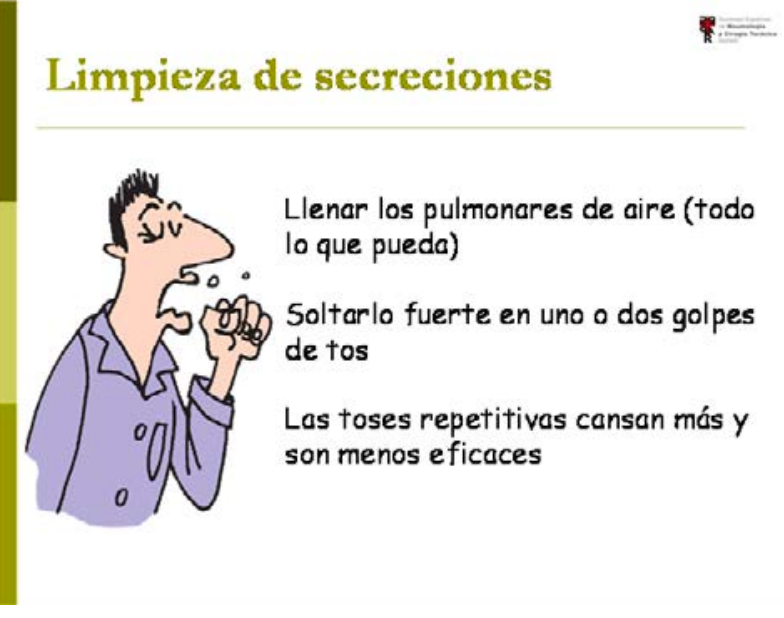


\section{8a Diapositiva}

Por tanto la falta de actividad es un grave problema. Además de favorecer la obesidad, hace que el paciente 'pierda su forma física'. El ejercicio regular (1 hora de paseo diario, utilizar las escaleras en lugar del ascensor, etc.), es fácil de realizar y es una parte importante del tratamiento. Debe tenerse en cuenta el estado de cada paciente.

\section{9a Diapositiva}

Es recomendable que en el día a día aumente la ingesta de líquidos sobre todo agua, para fluidificar le moco y arrancar más fácilmente. Evitar no engordar, ya que mayor peso, mayor fuerza de la caja torácica para expandirse. Así como el estreñimiento y las flatulencias provocan una mayor distensión abdominal.

\section{0aㅡ Diapositiva}

Cuando se encuentre mal...

1. Comidas ligeras y poco abundantes (5-6 tomas de consistencia blanda).

2. Evite digestiones pesadas, alimentos flatulentos (col, coliflor, cebollas, legumbres etc.) y la ingesta excesiva de hidratos de carbono (pan, pastas, patatas, arroz...).

3. Es importante incrementar el aporte de calcio (lácteos y derivados) mientras esté tomando corticoides orales "cortisona".

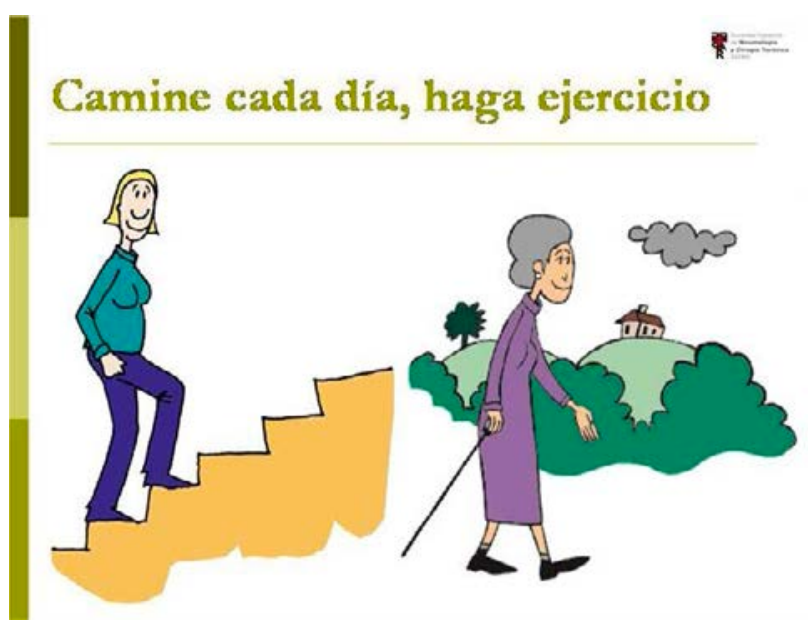

Nutrición

- Dieta equilibrada (3-4 tomas al día)

口 Control periódico del peso

口 Evitar digestiones pesadas

$\checkmark$ Evitar el estreñimiento

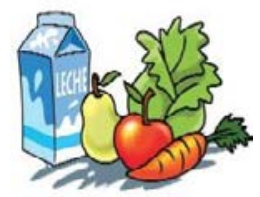

\section{La mejor bebida es el agua}

\section{Alimentación cuando se encuentra mal}

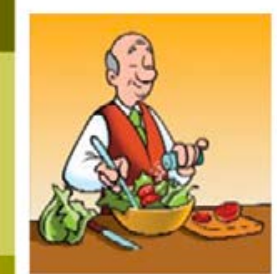

$\square$ Comidas ligeras y poco abundantes (5-6 tomas)

$\checkmark$ Evite digestiones pesadas y alimentos flatulentos

- Aumentar el aporte de lácteos y derivados

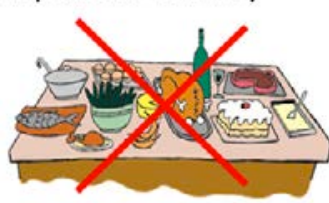




\section{1a Diapositiva}

Modificar algunos hábitos aprendiendo nuevas maneras de hacer las cosas con menor gasto energético. Por ejemplo en el aseo personal, al vestirse, en la realización de las tareas domésticas, etc.

1. Calefacción en casa: Mantenga un ambiente húmedo (la humedad óptima es del 45\% y la temperatura 19-219).

2. Clima: El frío y los cambios de temperatura son enemigos de las enfermedades respiratorias.

\section{Estilo de vida saludable}
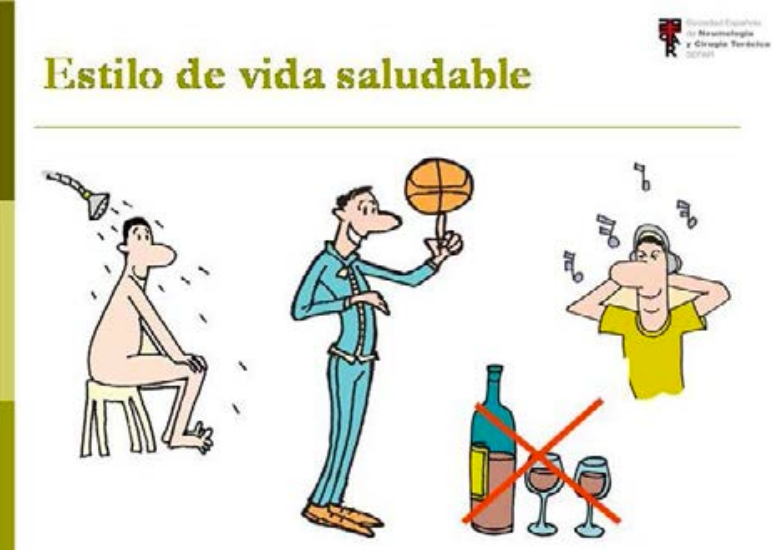

3. Viajes y vacaciones: Planifique sus vacaciones con antelación, deberá tener en cuenta la altura del lugar donde va, se aconseja no superar los 1500 metros. Usted puede viajar en avión, si precisa oxígeno, debe avisar con suficiente antelación a la compañía aérea.

4. Vestirse: La ropa debe ser la adecuada para la época del año, sin exagerar en la cantidad de piezas, holgada y de fácil colocación. No utilice cinturones o fajas que compriman el tórax.

5. Sueño: Establezca rutinas para acostarse, levantarse y descansar. No duerma siestas superiores a 90 minutos. Evite alimentos que contengan cafeína y alcohol.

6. Ocio: Mantenga el interés en realizar actividades sociales. Utilice estrategias de distracción: técnicas de relajación, escuchar música,etc.

7. Baño/ducha: Si realizar esta actividad le produce ahogo, coloque un taburete dentro de la bañera, lávese sentado (un familiar puede ayudarle en las zonas donde le pueda causar más esfuerzo), hágalo despacio, séquese con toallas pequeñas.

8. Polución: Evite los contaminantes como lacas, insecticidas, pinturas, etc., ya que pueden producir irritaciones.

9. Relaciónese: interésese por otros pacientes con su misma enfermedad.

\section{Seguir controles}

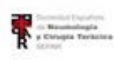

\section{2a Diapositiva}

Es importante recordar al paciente seguir las visitas periódicas con su equipo médico habitual. Así podremos conseguir que el paciente y su entorno tengan una actitud más participativa y positiva frente a la enfermedad. Hay otras pruebas que le pueden hacen para el seguimiento

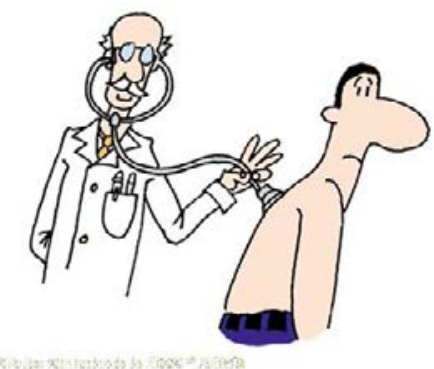
de la enfermedad: Espirometría forzada para control de la evolución de la enfermedad y la eficacia del tratamiento, gasometría arterial, sirve para conocer el nivel de oxígeno y de $\mathrm{CO} 2$ en la sangre. No tiene que 
estar en ayunas y puede tomar toda la medicación. Debe indicar si lleva O2 en caso o no para saber si lo tiene que retirar antes. Radiografía de tórax: no tiene que estar en ayunas Análisis de sangre: debe estar en ayunas pero puede tomarse los inhaladores. Caminata de 6 minutos para conocer si necesita oxígeno durante el ejercicio. No tiene que estar en ayunas y puede tomar la medicación. Lleve la medicación de rescate y ropa y calzado cómodos. Cultivo de secreciones (moco): puede realizarlo en casa y traerlo inmediatamente para analizar. Se recomienda no tomar antibiótico 48h antes de realizar la prueba. Lávese los dientes. El mejor momento para realizarlo es por la mañana. Estudio del sueño: puede tomarse la medicación y llevársela al hospital. Comunique si toma pastillas para dormir. Notifique si tiene 02 en casa o cualquier otro aparato. 


\section{SESIÓN IV}

\section{1a Diapositiva}

La oxigenoterapia es un tratamiento más para los pacientes como vosotros con EPOC, este tratamiento a diferencia de los que todos los pacientes creen no elimina el ahogo, si no que mejora los niveles de oxígeno en sangre. Por ese motivo la cantidad de litros a administrar se basa en la gasometría del paciente. El aumento del volumen de oxígeno en situaciones de agudización es contraproducente en aquellos paciente que no necesitan más oxígeno del que ya les ha pautado el neumólogo.

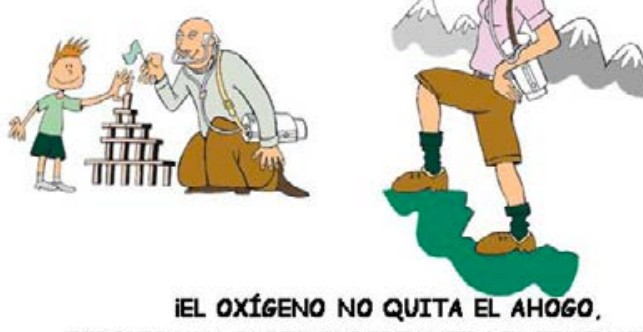

PERO ES UNA PARTE IMPORTANTE DEL TRATAMIENTOI

\section{2a Diapositiva}

Existen en el mercado tres dispositivos básicos, el concentrador, la bomba y la mochila de oxígeno líquido. Tanto el sistema a utilizar, la forma de administración (cánulas nasales "gafas" o mascarilla) y la cantidad de oxígeno dependerá de las necesidades del paciente y estará indicada por el equipo que le atiende. En ningún caso se puede modificar sin la pauta del equipo asistencial

\section{3a Diapositiva}

El oxígeno no es combustible, pero activa la combustión de las materias inflamables. No fumar en el local donde esté almacenado y se esté utilizando el oxígeno. Los depósitos de oxígeno se utilizan y almacenan en un local ventilado y espacioso (no en armarios, maleteros de coche,....). Es necesario ventilar sistemáticamente la habitación donde se utiliza. El depósito de oxígeno debe estar como mínimo a unos 2 m. de fuentes de cualquier llama (cocina, calentador, chimenea, etc.) Tener un extintor en la habitación más

Oxigenoterapia

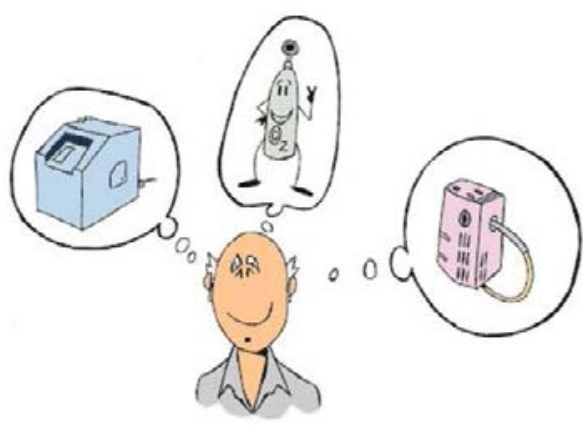

\section{Precauciones generales}

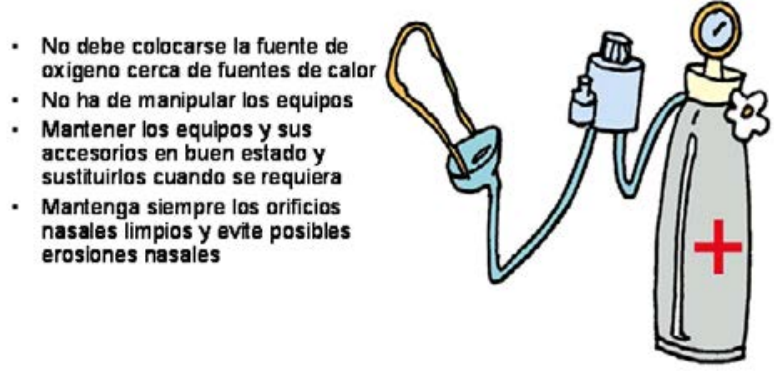
frecuentemente utilizada. Los depósitos deben mantenerse en posición vertical. Se han de tomar las medidas necesarias para evitar su vuelco. No poner productos grasos en presencia del oxígeno (pomadas, cremas, vaselina, etc.). No engrasar ni lubricar las válvulas que sirven para el suministro. No utilizar aerosoles ni disolventes. No transportar los depósitos grandes en vehículos. Mantener el equipo y sus accesorios (máscaras, gafas nasales) en buen estado y sustituirlos por unas nuevas cuando se requiera. Mantenga siempre los orificios nasales limpios y evite 
posibles erosiones nasales. Las alargaderas de los sistemas de administración de oxígeno (gafas o mascarillas) deben ser como máximo de $17 \mathrm{~m}$ y sin empalmes.

\section{4a Diapositiva}

Precauciones con las bombonas, al comenzar a utilizar la bombona se debe abrir la válvula suavemente. Deben mantenerse en posición vertical. Se han de tomar las medidas necesarias para evitar su vuelco.

\section{5a Diapositiva}

Dicho equipo dispone de ruedas y necesita estar conectado a la corriente eléctrica para su funcionamiento. Además, dispone de alarmas y de un contador de horas. La empresa suministradora debe realizar un mantenimiento periódico del aparato le proporcionará una bombona de oxígeno comprimido para emergencias. Sepa que en algunas comunidades autónomas, los gastos en los recibos de la luz ocasionados por el uso del concentrador, le serán abonados a través de la casa suministradora de oxígeno. Precauciones con el concentrador. Debe colocarse al menos a $15 \mathrm{~cm}$. de la pared o de un mueble. Es aconsejable que no lo ponga en la habitación donde duerme porque hace ruido. Debe moverse siempre en posición vertical. Debe esperarse entre 5 y 10 minutos desde la puesta en marcha hasta su utilización. Debe desenchufarse cuando no se utiliza. Se puede colocar una alfombra o manta bajo el aparato para amortiguar el ruido, pero no debe TAPARSE NUNCA. El filtro externo del aparato debe ser retirado para su LIMPIEZA (agua y jabón) UNA VEZ A LA SEMANA

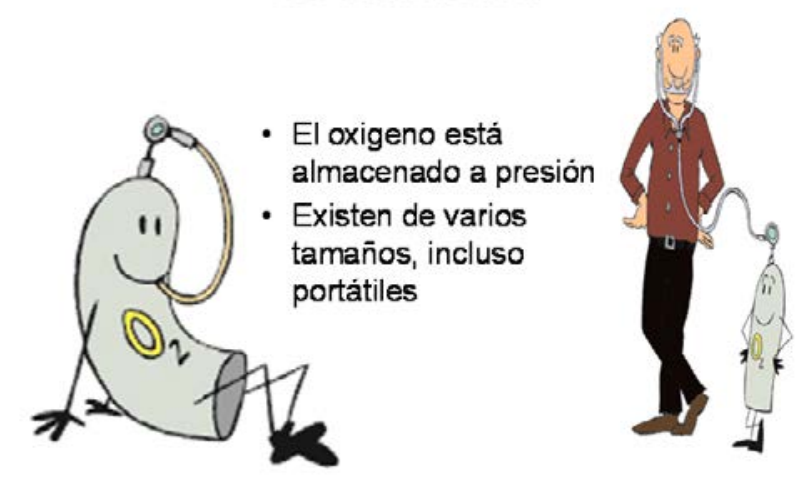

\section{El concentrador}
- Es un equipo que proporciona aire con mayor concentración de oxígeno
- Es el más recomendable para el domicilio

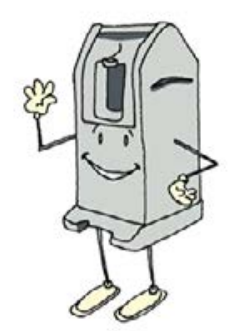

\section{La bombona}

\section{6a Diapositiva}

El oxígeno líquido está almacenado en una reserva fija o "tanque nodriza", que es un cilindro de $40 \mathrm{Kg}$. de peso con ruedas. La "mochila" es la parte portátil del sistema y debe recargarse a partir del tanque nodriza (en una habitación ventilada y en el momento de ser utilizada). Su duración variará según el flujo de oxígeno utilizado, pero suele oscilar entre 6-7 horas si el flujo es de 2 litros por minuto. Precauciones con el oxígeno líquido $\mathrm{EI}$ oxígeno líquido, al estar a bajas temperaturas, puede producir quemaduras al contacto con la piel. Por lo tanto, si se producen fugas, hay que procurar no tocar dicha zona y avisar a la empresa suministradora. Cuando

\section{Oxígeno líquido}

- El oxigeno está almacenado en forma líquida

- Dispondrá de dos depósitos:

- una reserva fija o "tanque nodriza"

- una parte portátil que es la "mochila"
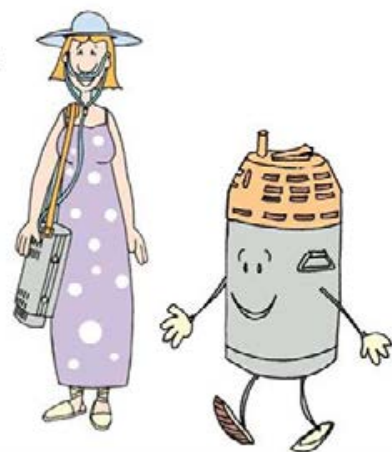
la proyección de oxígeno líquido entra en contacto con los ojos: lavarlos con abundante agua durante más 
de 15 minutos. Avisar al médico. Cuando la proyección de oxígeno líquido entra en contacto con la piel: no frotar, quitar la ropa si es necesario, descongelar las partes afectadas con calor moderado y avisar al médico. Precauciones especiales para la carga de la "mochila": Hacerlo en un local bien ventilado. El suelo debe ser firme. No alejarse del depósito mientras se recarga la mochila. Si hay fugas al separar la mochila del tanque, volver a conectar la mochila, si esto es imposible: ventilar el local, no tocar las fugas, no fumar ni provocar llamas o chispas. 


\section{Anexo II. Definiciones clave}

Definiciones de los conceptos de captación (recogidos en el libro blanco elaborado para el proyecto)

Paciente con EPOC que presenta exacerbaciones frecuentes: Se considera un paciente con EPOC presenta exacerbaciones frecuentes cuando el año previo al estudio el paciente ha presentado dos o más agudizaciones moderadas o graves, separadas al menos de 4 semanas desde la finalización del tratamiento de la agudización (visita a urgencias y / o hospitalización) o 6 semanas desde el inicio de la misma (en los casos que no han recibido tratamiento para diferenciar de aquellos en los que se ha producido un fracaso terapéutico).

Paciente EPOC: Paciente con historia de tabaquismo o historia de exposición a otros agentes tóxicos inhalados en el hogar o en el lugar de trabajo (tabaquismo pasivo, quema de combustibles biomasa), junto con la presencia de una obstrucción al flujo aéreo escasamente reversible, definida como un cociente de FEV1/FVC menor de 70 después de la prueba broncodilatadora.

Exacerbación de la EPOC: aumento mantenido de los síntomas respiratorios respecto a la situación basal y que precisa una modificación en la medicación habitual y que genera necesidades en la asistencia sanitaria.

Ingreso hospitalario: es una decisión médica que recomienda que el paciente quede en el hospital, o en su domicilio pero con responsabilidad asistencial directa del hospital (en el marco de programa de hospitalización a domicilio).

Estancia hospitalaria: periodo mínimo de 24 horas, o bien entre 12 y 24 horas de permanencia en el hospital. Siempre que en este supuesto, la estancia comprenda un mínimo de 12 horas en el horario comprendido entre las 07.00 horas a las 22.00 horas, con independencia de la hora de ingreso.

Alta hospitalaria: un conjunto de actividades y procedimientos que se realizan a un paciente ingresado hasta la finalización de un episodio, durante un periodo continuado de una estancia.

También se consideran altas aquellas que su estancia haya sido inferior a 24 horas, porque su motivo de alta haya sido, una defunción, alta voluntaria o traslado a otros centros, siempre que en este caso el último traslado no provenga de un servicio de urgencias.

En caso de interrupción de su estancia por un periodo igual o inferior a 48 horas el reingreso en un mismo servicio asistencia se contabiliza con una sola alta.

Reingreso: todos los ingresos hospitalarios hechos en el mismo hospital desde el momento del alta (momento del estudio) hasta los 90 días post alta por causas respiratorias y por otras causas.

Visita al Servicio de Urgencias: todas aquellas entradas al servicio de Urgencias del Hospital de estudio que no tengan continuidad con un ingreso en algún servicio del centro. 


\section{Anexo III. Cuestionario al ingreso}

\section{IDENTIFICACIÓN DEL PACIENTE}

1. Fecha: $\square \square . \square \square . \square \square$ (dd/mm/aa)

2. Identificación del profesional $\square \square \square \square$ (ver tabla)

3. Hospital: Clínic $\square$ (1) Castellón $\square$ (2)

4. CIP/SIP $\square \square \square \square \square \square \square \square \square \square \square \square \square \square$ (valor numérico)

5. NHC: $\square \square \square \square \square \square \square \square \square$ (valor numérico)

6. Nombre y Apellidos del paciente:

7. Telèfono:

8. Grupo: Intervención $\square$ (1) Grupo Control $\square$ (2)

9. Código del paciente Este código viene indicado en el sobre de aleatorización

\section{CRITERIOS DE INCLUSIÓN/EXCLUSIÓN}

\begin{tabular}{|c|c|c|}
\hline Enfermedad Pulmonar Obstructiva Crónica* & $\begin{array}{l}\square \mathrm{Si} \\
\square \mathrm{No}\end{array}$ & No continuar \\
\hline Ingreso por exacerbación grave de la EPOC & $\begin{array}{l}\square \mathrm{Si} \\
\square \mathrm{No}\end{array}$ & No continuar \\
\hline Teléfono & $\begin{array}{l}\square \mathrm{Si} \\
\square \mathrm{No}\end{array}$ & No continuar \\
\hline Existe barrera idiomática & $\begin{array}{l}\square \mathrm{Si} \\
\square \mathrm{No}\end{array}$ & No continuar \\
\hline El paciente tiene una esperanza de vida $<6$ meses & $\begin{array}{l}\square \mathrm{Si} \\
\square \mathrm{No}\end{array}$ & No continuar \\
\hline Incapacidad para seguir un programa educativo ** & $\begin{array}{l}\square \mathrm{Si} \\
\square \text { No }\end{array}$ & No continuar \\
\hline Puede ir a las sesiones educativas presencial o telefónicamente & $\begin{array}{l}\square \text { Si } \\
\square \text { No }\end{array}$ & No continuar \\
\hline Seguimiento por el servicio de neumología del hospital o de la RAE & $\begin{array}{l}\square \text { Si } \\
\square \text { No }\end{array}$ & No continuar \\
\hline Aceptación y firma del consentimiento informado & $\begin{array}{l}\square \mathrm{Si} \\
\square \mathrm{No}\end{array}$ & No continuar \\
\hline ¿Se incluye? & \multicolumn{2}{|c|}{$\begin{array}{l}\square \text { Si (inicio del proceso) } \\
\square \text { No (no continuar) }\end{array}$} \\
\hline
\end{tabular}

${ }^{*}(491.1 ; 491.9 ; 492.0 ; 493.2 ; 494 ; 496 ; 518.81 ; 491.2 ; 492.8 ; 493.2 ; 494 ; 496 ; 137.0 ; 518.81 ; 416.8 ; 416.9 ; 500 ; 502 ; 503 ; 504 ; 505 ; 519.8 ; 519.83 ; 714.0 ; 517.8$ con ICD9-CM)

**(209;210;211;213;214;215;216; $217 ; 218 ; 219 ; 220 ; 221 ; 222 ; 223 ; 224 ; 225 ; 226 ; 227 ; 228 ; 229 ; 230 ; 231 ; 232 ; 233 ; 234 ; 235 ; 236 ; 237 ; 238 ; 239 ; 240 ; 241 ; 242 ; 243 ; 244 ; 245$ 246,$247 ; 248 ; 249 ; 250 ; 251 ; 251 ; 253 ; 254 ; 255 ; 256 ; 257 ; 258 ; 259 ; 260 ; 261 ; 262 ; 263 ; 264 ; 265 ; 266 ; 267 ; 268 ; 269 ; 270 ; 271 ; 272 ; 273 ; 274 ; 275 ; 276 ; 277 ; 278 ; 279 ; 280 ; 281 ; 282$ 283; 284; 285; 286; 287; 288; 289; 290; 291; 292; 293; 294; 295; 296; 297; 298; 299; 300; 301; 302; 303; 304; 305; 306; 307; 308; 309; 310; 311; 312; 313; 314; 315; 316; 317; 318; 319 con ICDM9-CM)

$\left(^{*}\right)$ Imprescindible firmar el consentimiento informado previo a la inclusión. 


\section{CUESTIONARIO I. CUESTIONARIO DE REVISIÓN DE LA HISTÒRIA CLÍNICA (12 MESES PREVIOS AL INGRESO)}

IDENTIFICACIÓN DEL PACIENTE : ___ sólo indicar el código del paciente

Fecha de inclusión: $\square \square / \square \square / \square \square$ dd/mm/aa Identificación del personal: $\square \square \square \square$ (ver tabla)

\section{SISTEMA SANITARIO (utilización de los recursos hospitalarios):}

1.1 Ingresos hospitalarios por causa respiratoria en los últimos 12 meses:

$\square$ Sí (1) Número total de ingresos: $\square \square$ (valor numérico) $\square$ No (0)

1.1.1 Estancias en UCl: $\square$ Sí (1) $\square$ No (0)

1.2 Ingresos hospitalarios por causa NO respiratoria en los últimos 12 meses:

$\square$ Sí (1) Número total de ingresos: $\square \square$ (valor numérico) $\square$ No (0) IDENTIFICACIÓN DEL PERSONAL 117 Ma Angeles Redón 118 Noelia Martinavarro 119 Beatriz Cano 120 María Escrig

1.2.1 Estancias en UCl: $\square$ Sí (1) $\square$ No (0)

1.3. Visitas a URGÉNCIAS sin ingreso por causa respiratoria en los últimos 12 meses:

$\square$ Sí (1) Número de visitas: $\square \square$ (valor numérico)

$\square$ No (0)

1.4. Visites a URGĖNCIAS sin ingreso por causa no respiratoria en los últimos 12 meses:

$\square$ Sí (1) Número de visitas: $\square \square$ (valor numérico)

$\square$ No (0)

1. 5. Visitas a Consultas Externas hospitalarias por la EPOC en los últimos 12 meses:

$\square$ Sí (1) Número de visitas: $\square \square$ (valor numérico)

$\square$ No (0)

\section{II.PRUEBAS COMPLEMENTARIAS:}

2.1. Si dispones de resultados de pruebas funcionales respiratorias en los últimos 12 meses?

$\square$ Sí (1) Fecha última medición: $\square \square / \square \square / \square \square$ dd/mm/aa

2.1.1 La prueba ha estado realizada con prueba pre-broncodilatadora?

$\square$ Sí (1) $\square$ No (0) $\square$ No consta (N)

2.1.2 La medida ha estado realizada con prueba post-broncodilatadora?

$\square$ Sí(1) $\square$ No (0) $\square$ No consta (N)

2.1.3 FVC (\%) $\square \square$

2.1.4 FEV 1 (\%) $\square \square$

2.1.5 FEV $1 / \mathrm{FVC}(\%) \square \square . \square \square$

$\square$ No (0)

2.2 Se disponen de resultados de Gasometría arterial de los últimos 12 meses?

$\square$ Si (1) Fecha de la última medición: $\square \square / \square \square / \square \square$ dd/mm/aa

2.2.1pH: $\square . \square \square \square$

2.2.2 $\mathrm{pO}_{2}: \square \square . \square$

2.2.3 $\mathrm{pCO}_{2}: \square \square . \square$

2.2.3 $\mathrm{FiO}_{2}$ : $\square$ Basal (B) $\square$ Cánulas nasales (C) $\square, \square$ litros $\square$ Mascarilla (M) $\square \square \%$

$\square$ No consta la $\mathrm{FiO}_{2}(0)$

No (0)

\section{COMORBILIDAD:}

3.1 Índice de comorbilidad de Charlson. Puntuación total: $\square \square$ (valor numérico) Ver cuestionarios de soporte para la cumplimentación

3.2 Número de comorbilidades (El número de comorbilidades se basa en el número de enfermedades crónicas que tiene el paciente) $\square \square$ (valor numérico) 


\begin{tabular}{|c|c|}
\hline OMORBIDIDAD DE CHARLSON & \\
\hline Diagnóstico: & Puntuación: \\
\hline $\begin{array}{l}\text { Infarto de miocardio: (Tiene que existir evidencia en la historia clínica de que el paciente ha estado } \\
\text { hospitalizado por esto o bien evidencia de que existieron cambios enzimáticos y/o al ECG). }\end{array}$ & 1 \\
\hline $\begin{array}{l}\text { Insuficiencia cardíaca: (Tiene que existir historia de disnea de esfuerzo y/o signos de insuficiencia cardíaca en } \\
\text { la exploración física, que respondieron favorablemente al tratamiento con digital, diuréticos o vasodilatadores. Los } \\
\text { pacientes que estén tomando este tratamiento pero que no pueden constatar que haya existido mejoría clínica de } \\
\text { los signos y/o síntomas NO se incluirá como tal). }\end{array}$ & 1 \\
\hline $\begin{array}{l}\text { Enfermedad arterial periférica: (Incluye claudicación intermitente, intervenidos de bypass arterial periférico, } \\
\text { isquemia arterial aguda y aquellos con aneurisma de aorta -torácica o abdominal- de >6 cm de diámetro). }\end{array}$ & 1 \\
\hline Enfermedad cerebrovascular: (Pacientes con ACV con secuelas mínimas o ACV transitorio). & 1 \\
\hline Demencia: (Pacientes con evidencia en la historia clínica de deterioramento cognitivo crónico). & 1 \\
\hline $\begin{array}{l}\text { Enfermedad respiratoria crónica: (Tiene que existir evidencia en la historia clínica, en la exploración física y en } \\
\text { la exploración complementaria de cualquier enfermedad respiratoria crónica, incluidas la EPOC y el asma). }\end{array}$ & 1 \\
\hline $\begin{array}{l}\text { Enfermedad del tejido conectivo: (Incluye lupus, polimiositis, enfermedad mixta, poli mialgia reumática, arteritis } \\
\text { celular y artritis reumatoide). }\end{array}$ & 1 \\
\hline $\begin{array}{l}\text { Úlcera gastroduodenal: (Incluye aquellos que han rechazado tratamiento por ulcus y aquellos que han tenido } \\
\text { sangrados por úlceras). }\end{array}$ & 1 \\
\hline Hepatopatía crónica leve: (Sin evidencia de hipertensión portal, incluye pacientes con hepatitis crónica). & 1 \\
\hline $\begin{array}{l}\text { Diabetes: (Incluye los tratados con insulina o hipoglucemiantes, pero sin complicaciones tardías. NO se incluirán } \\
\text { los tratados con dieta únicamente). }\end{array}$ & 1 \\
\hline Hemiplejia: (Evidencia de hemiplejia o paraplejia como una consecuencia de un AVC u otra condición). & 2 \\
\hline $\begin{array}{l}\text { Insuficiencia renal crónica moderada/severa: (Incluye pacientes en diálisis, o bien con creatinina }>3 \mathrm{mg} / \mathrm{dl} \\
\text { objetivada de manera repetida y mantenida). }\end{array}$ & 2 \\
\hline $\begin{array}{l}\text { Diabetes con lesión en órganos diana: (Evidencia de retinopatia, neuropatía o nefropatía. Se incluyen también } \\
\text { antecedentes de cetoacidosi o descompensación hiperosmolar). }\end{array}$ & 2 \\
\hline Tumor o neoplasia sólida: (Incluyen pacientes con cáncer, pero sin metástasis documentadas). & 2 \\
\hline $\begin{array}{l}\text { Leucemia: (Incluyen leucemia mieloide crónica, leucemia linfática crónica, policitemia severa, otras leucemias } \\
\text { crónicas y todas las leucemias agudas). }\end{array}$ & 2 \\
\hline Linfoma: (Incluyen todos los linfomas, Waldestrom y mielomas). & 2 \\
\hline $\begin{array}{l}\text { Hepatopatía crónica moderada/severa: (Con evidencia de hipertensión portal (ascitis, varias esofágicas o } \\
\text { encefalopatía). }\end{array}$ & 3 \\
\hline Tumor o neoplasia sólida con metástasis & 6 \\
\hline Sida definido: (No incluye portadores asintomáticos). & 6 \\
\hline
\end{tabular}

Modificado por edad. Añadir 1 punto por cada década a partir de los 40 años. Si el valor del índice es 0 no se añade puntuación por edad. 
X. Anexos

\section{CUESTIONARIO II. ENTREVISTA CON EL PACIENTE}

EVALUACIÓN DEL PACIENTE DURANTE EL INGRESO

IDENTIFICACIÓN DEL PACIENTE :

Fecha de inclusión: $\square \square / \square \square / \square \square$ dd/mm/aa sólo indicar el código del paciente

Telefónica Identificación del personal: $\square \square \square \square$ (ver tabla)

\section{SINTOMAS habituales}

1.1 Disnea $\square$ Si MRC $\square$ (Indique el valor del MCR) $\square$ No (0)

GRADO DE DISNEA: ESCALA DEL MEDICAL RESEARCH COUNCIL (MRC) IDENTIFICACIÓN DEL PERSONAL

117 Ma Angeles Redón

Grado 0 :Ausencia de disnea, excepto al realizar ejercicio intenso.

Grado 1 : Disnea al caminar rápido en plano o subiendo una pendiente poco pronunciada. (1)

Grado 2 : Incapacidad de mantener el paso de otras personas de la misma edad debido a una dificultad respiratoria o a la necesidad

de pararse a descansar al andar en plano siguiendo el propio paso. (2)

Grado 3: Necesidad de pararse a descansar al caminar unos 100 metros o a pocos minutos de caminar en plano. (3)

Grado 4: La disnea impide al paciente salir de casa o aparece en actividades como vestirse y desvestirse. (4)

\begin{tabular}{|c|c|c|c|}
\hline 1.2 Tos & $\square \mathrm{Si}_{(1)}$ & $\square$ No $(0)$ & \\
\hline 1.3 Expectoración & $\square \mathrm{Si}$ (1) Color: $\quad$ (B, A, V, M) & $\square$ No $(0)$ & Color: B: Blanco: A: Amarillo: V: Verde: M: Marrón \\
\hline 1.4 Sibilancias & $\square \mathrm{Si}(1)$ & $\square$ No (0) & \\
\hline 1.5 Somnolencia diurna & $\square \mathrm{Si}_{(1)}$ & $\square$ No (0) & \\
\hline 1.6 Precisa dormir sentado & $\square \mathrm{Si}_{(1)}$ & $\square$ No (0) & \\
\hline 1.7 Edemas & $\square \mathrm{Si}(1)$ & $\square$ No (0) & \\
\hline 1.8 Fiebre & $\square \mathrm{Si}(1)$ & $\square$ No (0) & \\
\hline 1.9 Dolor & $\square$ Si $\quad$ EVA $\square \square(0-10)$ & $\square$ No (0) & \\
\hline
\end{tabular}

\section{DATOS SOCIODEMOGRÀFICOS}

\subsection{Genero $\square$ Hombre (1) $\square$ Mujer (2)}

2.2. Fecha de nacimiento: $\square \square / \square \square / \square \square \square \square$ dd/mm/aa

2.3. ¿Que estudios ha completado?

$\square$ Sin estudios (1)

$\square$ Estudios básicos (2)

$\square$ Estudios de secundaria o formación profesional (3)

$\square$ Estudios universitarios (4)

2.4. ¿Dónde vive en el momento actual?

$\square$ En su casa (1) $\square$ En una residencia (2) $\square$ En un centro sociosanitario (3) $\square$ Otros (4)

2.5. ¿Quién está viviendo con usted (respuesta múltiple)?

$\square$ Marido/esposa (1) $\square$ Hijos (2) $\square$ Otros familiares (3) $\square$ Amigos (4) $\square$ Cuidador externo (5) $\square$ Vivo solo (6) $\square$ Otros (4)

\section{TRATAMIENTO FARMACOLÓGICO}

3.1 ¿Cuántas pastillas toma al día?

3.2 ¿Cuántas inyecciones o pinchazos se realiza al día?

3.3 ¿Cuántas inhalaciones realiza al día?

$\square \square$ total al día (valor numérico) $\square$ ninguna (0)

$\square \square$ total al día (valor numérico) $\square$ ninguna (0)

$\square \square$ total al día (valor numérico) $\square$ ninguna (0)

$\square$ Cartucho (1) $\square$ Cámara (2) $\square$ Turbuhaler (3) $\square$ Accuhaler (4)

$\square$ Inhaletas (5) $\square$ Nebulizador (6) Otros 


\section{BRONCODILATADORES}

Corta duración: Terbasmin, Ventolín, Berodual, Onsukil, Atrovent

Larga duración: Oxis, Serevent, Belglan, Broncora, Foradil, Inaspir, Metamican, Neblik

CORTICOIDES Pulmicort, Becloforte, Becotide, Betsuril, Brioncivent, Flixotide, Flusonal, Inalacor, Quar-Autohaler, Olfex, Pulmictan, Ribujet.

\section{ASOCIACIONES}

Broncodilatador + Anticolinérgico: Combivent

Broncodilatador + Corticoides: Symbicort, Anasma, Butosol, Inalduo, Plusvent, Seretide.

\section{TĖCNICA INHALADA}

Ahora, si le apetece, haga una inhalación con el sistema de inhalación que utiliza tal y como usted lo hace en su casa. Tómese el tiempo que necesite. (SI TOMA MÁS DE UNA PRESENTACIÓ, HAGALO CON TODAS UTILITZANDO PLACEBO, UNA DETRAS DE LA OTRA DEJANDO TIEMPO SUFICIENTE

4.1 Cartucho presurizado (NO rellenar esta opción si el paciente utiliza cámara espaciadora para este sistema)

4.1.1 Medicación que toma con este dispositivo:

$\square \beta 2$ adrenérgico de corta duración $\square \beta 2$ adrenérgico de larga duración $\square$ Anticolinergico $\square$ Corticoide inhalado

$\square$ Sí $\square$ NO $\rightarrow$ saltar a cámara espaciadora

\subsubsection{Sentado y en posición cómoda}

4.1.2. Destapar el cartucho y situarlo en posición vertical (forma de L)

4.1.3. Sujetar el cartucho entre los dedos índice y pulgar. Agitar

4.1.4.Efectuar una espiración lenta y profunda

4.1.5.Poner el boquilla del cartucho a la boca y cerrar completamente

4.1.6. Inspirar lentamente para la boca (la lengua ha de estar de bajo del paladar)

4.1.7. Una vez iniciada la inspiración, presionar una sola vez el cartucho y seguir inspirando lenta y profundamente hasta llenar los pulmones completamente

4.1.8. Retirar el cartucho de la boca (aguantar la respiración durante 10 segundos)

4.1.9.Esperar medio minuto entre cada inhalación

4.1.10.Tapar el inhalador y guardarlo en un lugar seco

\subsection{Cámara espaciadora
4.2.1 Medicación que toma con este dispositivo:}

$\square \beta 2$ adrenérgico de corta duración $\square \beta 2$ adrenérgico de larga duración $\square$ Anticolinergico $\square$ Corticoide inhalado $\square$ SI $\square$ NO $\rightarrow$ saltar a Turbuhaler $\downarrow$

4.2.1. Sentado y en posición cómoda

4.2.2. Destapar el cartucho y situarlo en posición vertical (forma de L)

4.2.3. Acoplar el cartucho al orificio de la cámara

4.2.4.Efectuar una espiración lenta y profunda

4.2.5.Efectuar una pulsación del inhalador

4.2.6. Inspirar profundamente el aire de la cámara

(la lengua tiene que estar debajo del paladar)

4.2.7. Retirar la cámara de la boca y aguantar la respiración 10 segundos

4.2.8. Puede realizar una segunda inhalación lenta y profunda para asegurarse de que vacía bien la cámara.

4.2.9.Esperar 30 segundos entre cada toma.

4.2.10.Limpiar bien la cámara una vez a la semana con agua y jabón

\subsection{Turbuhaler}

4.3.1 Medicación que toma con este dispositivo:

$\square \beta 2$ adrenérgico de corta duración $\square \beta 2$ adrenérgico de larga duración $\quad \square$ Anticolinergico $\square$ Corticoide inhalado $\square$ SI $\square$ NO $\rightarrow$ salta a Accuhaler $\downarrow$

\subsubsection{Sentado y en una posición cómoda}

4.3.2.Desenroscar y retirar la capucha del inhalador

4.3.3.Sostener el inhalador en posición vertical

4.3.4. Girar la rosca de la parte inferior en sentido contrario al de las agujas del reloj

4.3.5. Volver a girar la rosca en sentido de las agujas del reloj. Esperar a escuchar "clic"

4.3.6. Realizar una espiración (sin poner el dispositivo en la boca)

4.3.7.Poner el boquilla entre los dientes y cerrar los labios

4.3.8.Aspirar enérgicamente y mantener la respiración durante 10 segundos

\begin{tabular}{|c}
$\square$ \\
$\square$ \\
$\square$ \\
$\square$ \\
$\square$ \\
$\square$ \\
$\square$ \\
$\square$ \\
$\square$ \\
$\square$
\end{tabular}

\begin{tabular}{|c|c|}
\hline SI & NO \\
$\square(1)$ & $\square(0)$ \\
\hline$\square(1)$ & $\square(0)$ \\
$\square(1)$ & $\square(0)$ \\
\hline$\square(1)$ & $\square(0)$ \\
$\square(1)$ & $\square(0)$ \\
\hline$\square(1)$ & $\square(0)$ \\
$\square(1)$ & $\square(0)$ \\
$\square(1)$ & $\square(0)$ \\
$\square(1)$ & $\square(0)$ \\
$\square(1)$ & $\square(0)$ \\
\hline
\end{tabular}

(0)

\begin{tabular}{|c|c|}
\hline SI & $\mathrm{NO}$ \\
\hline$\square$ (1) & $\square_{(0)}$ \\
\hline$\square$ (1) & $\square_{(0)}$ \\
\hline$\square$ (1) & $\square_{(0)}$ \\
\hline$\square$ (1) & $\square_{(0)}$ \\
\hline$\square$ (1) & $\square(0)$ \\
\hline$\square$ (1) & $\square(0)$ \\
\hline$\square$ (1) & $\square(0)$ \\
\hline$\square$ (1) & $\square(0)$ \\
\hline$\square$ (1) & $\square(0)$ \\
\hline$\square$ (1) & $\square(0)$ \\
\hline
\end{tabular}




\begin{tabular}{|c|c|c|}
\hline 4.3.9.Esperar medio minuto entre cada toma & $\square(1)$ & $\square(0)$ \\
\hline \multicolumn{3}{|l|}{$\begin{array}{l}\text { 4.4 Accuhaler } \\
\text { 4.4.1 Medicación que toma con este dispositivo: } \\
\square \text { B2 adrenérgico de corta duración } \square \text { B2 adrenérgico de larga duración } \square \text { Anticolin }\end{array}$} \\
\hline \multicolumn{3}{|l|}{$\square \mathrm{SI} \quad \square \mathrm{NO} \rightarrow$ saltar a Inhaletes $\downarrow$} \\
\hline & $\mathrm{SI}$ & NO \\
\hline 4.4.1. Sentado y en posición cómoda & $\square$ (1) & $\square(0)$ \\
\hline 4.4.2. Bajar el protector de la pieza bucal & $\square(1)$ & $\square(0)$ \\
\hline 4.4.3. Apretar la pestaña lateral hacia abajo hasta el límite & $\square(1)$ & $\square(0)$ \\
\hline 4.4.4. Efectuar una espiración lenta y profunda & $\square(1)$ & $\square(0)$ \\
\hline $\begin{array}{l}\text { 4.4.5.Poner los labios alrededor } \\
\text { de la pieza bucal. }\end{array}$ & $\square(1)$ & $\square(0)$ \\
\hline 4.4.6.Aspirar profundamente y enérgicamente & $\square(1)$ & $\square(0)$ \\
\hline 4.4.7.Mantener la respiración durante 10 segundos & $\square(1)$ & $\square(0)$ \\
\hline 4.4.8.Esperar medio minuto entre cada toma & $\square(1)$ & $\square(0)$ \\
\hline 4.4.9.Tapar la pieza bucal y guardarlo & $\square(1)$ & $\square(0)$ \\
\hline \multirow{2}{*}{\multicolumn{3}{|c|}{$\begin{array}{l}\text { 4.5 Inhaletes } \\
\text { 4.5.1 Medicación que toma con este dispositivo: } \\
\square \text { B2 adrenérgico de corta duración } \square \text { 及2 adrenérgico de larga duración } \square \text { Anticolinergico } \square \text { Corticoide inhalado } \\
\square \mathrm{SI} \quad \square \text { NO salta a Nebulitzador } \downarrow\end{array}$}} \\
\hline & & \\
\hline & $\mathrm{SI}$ & NO \\
\hline 4.5.1.Abrir el inhalador y levantar la boquilla & $\square(1)$ & $\square(0)$ \\
\hline 4.5.2.Poner la cápsula al orificio correspondiente y cerrar el inhalador & $\square(1)$ & $\square(0)$ \\
\hline 4.5.3.Con la boquilla hacia arriba, presione el pulsados hasta el límite & $\square(1)$ & $\square(0)$ \\
\hline 4.54.Realizar una espiración lenta y profunda & $\square(1)$ & $\square(0)$ \\
\hline 4.5.5.Poner la boquilla entre los dientes y cerrar los labios alrededor de este & $\square(1)$ & $\square(0)$ \\
\hline 4.5.6.Aspirar profundamente y enérgicamente & $\square(1)$ & $\square(0)$ \\
\hline $\begin{array}{l}\text { 4.5.7. Levantar la boquilla, girar el inhalador y agitar hasta conseguir que salga la } \\
\text { cápsula }\end{array}$ & $\square(1)$ & $\square(0)$ \\
\hline 4.5.8.Cerrar el inhalador y guardarlo en un sitio seco & $\square(1)$ & $\square(0)$ \\
\hline \multirow{2}{*}{\multicolumn{3}{|c|}{$\begin{array}{l}\text { 4.6 Nebulizador } \\
\text { 4.6.1 Medicación que toma con este dispositivo: } \\
\square \beta 2 \text { adrenérgico de corta duración } \square \text { 及2 adrenérgico de larga duración } \square \text { Anticolinergico } \square \text { Corticoide inhalado } \\
\square \mathrm{SI} \quad \square \mathrm{NO} \rightarrow \text { saltar al siguiente apartado }\end{array}$}} \\
\hline & & \\
\hline & $\mathrm{SI}$ & NO \\
\hline 4.6.1.Lavarse las manos & $\square(1)$ & $\square(0)$ \\
\hline 4.6.2. El paciente sentado & $\square(1)$ & $\square(0)$ \\
\hline 4.6.3.Preparación del fármaco y preparación del nebulizador & $\square(1)$ & $\square(0)$ \\
\hline 4.6.4.Poner la cánula nasal si el paciente precisa oxigenoterapia & $\square(1)$ & $\square(0)$ \\
\hline 4.6.5.Poner el nebulizador en posición vertical & $\square(1)$ & $\square(0)$ \\
\hline 4.6.6.Nebulizar el fármaco & $\square(1)$ & $\square(0)$ \\
\hline 4.6.7. Limpiar la cazoleta del nebulizador después de cada uso. Guardarla limpia y seca & $\square(1)$ & $\square(0)$ \\
\hline 4.6.8.Revisión periódica de la casa suministradora & $\square(1)$ & $\square(0)$ \\
\hline
\end{tabular}




\section{ADHERÈNCIA FARMACOLÒGICA (Morisky-Green)}

Realizar estas preguntas durante la conversación NO directamente. Muchas persones pueden tener dificultades o barreras para seguir el tratamiento, como poß ejemplo.X゚OS entender bien la pauta, haber de tomar mucha medicación, pensar que la que ie va bien para una cosa le va mal para otra, o por problemas económicos o sociales, etc.

5.1 ¿Olvida alguna vez tomar sus medicamentos para tratar su enfermedad?

$\square \mathrm{Si}$ (1)

$\square$ No (0)

5.2 ¿Toma los medicamentos a las horas indicadas?

5.3 Cuando se encuentra bien, ¿deja de tomar la medicación?

$5.4 \mathrm{Si}$ alguna vez se encuentra mal, ¿deja usted de tomarlas?

Paciente cumplidor: Se acepta si contesta correctamente a las 4 preguntas (No/Si/No/No) $\square \mathrm{Si}(1) \square \mathrm{No}(0)$

\section{FACTORES DE RIESGO}

\subsection{TABACO}

$\square$ No (0)

$\square$ Si (1)

$\square$ Exfumador (2)

\section{Si el paciente es fumador pasar cuestionario autoadministrado Fagerström}

Si fumador o exfumador calcular la dosis acumulada de paquetes/año

6.1.1Paq/año $\square \square \square$ (valor numérico)

\subsection{ALCOHOL.}

$\square \mathrm{Si} \square \square$ Vasos (valor numérico)

$\square$ No $(0)$

\subsection{NUTRICIÓN}

¿Sigue alguna dieta o régimen especial de forma continuada por motivos de salud?
6.3.1 $\square \mathrm{Si}(1)$
$\square$ No (0)

6.3.2 ¿Sabe cuánto pesa? Si el paciente no lo sabe, pesar $\square$ Peso $\square \square \square \mathrm{Kg} . \quad \square$ No se puede valorar (N)

6.3.3 ¿Sabe cuánto mide? Si el paciente no lo sabe, medir $\square$ Talla $\square . \square \square \mathrm{m}$. $\square$ No se puede valorar (N)

INGESTA DE LÍQUIDOS ¿Cuantos vasos de agua/zumo/caldos/leche bebe al día? $\square \square$ vasos ( $\square$, $\square$ litros/día) (valor l/día numérico) Un vaso equivale a $250 \mathrm{cc}$

6.4 ACTIVIDAD FíSICA Ahora le preguntaré sobre la actividad física y ejercicio que usted realiza de forma habitual
6.4.1 Caminar fuera de casa de forma regular 30 minutos diarios
$\square \mathrm{Si}(1)$
$\square \quad \mathrm{No}(0)$

$\square \mathrm{Si}(1)$

6.4.2 Pasa la mayor parte del tempo en la cama o en el sillón

\section{TRATAMIENTO NO FARMACOLOGICO}

\subsection{VACUNA DE LA GRIPE}

$\square$ Sí (1)

$\square$ No (0)

$\square$ No lo sabe (N)

\subsection{VACUNA PNEUMOCOCO:}

$\square$ Sí (1)

$\square$ No (0)

$\square$ No lo sabe (N)

\begin{tabular}{|c|c|c|c|}
\hline \multicolumn{4}{|c|}{ VIII. COMPLEJIDAD DEL TRACTAMIENTO A DOMICILIO PREVIO AL INGRÉSO } \\
\hline 8.1 Oxígeno en el domicilio & $\square \mathrm{Si}(1)$ & $\square$ No (0) & 8.2 Cumple mínimo 16h diarias $\square$ Sí (1) $\square$ No (0) \\
\hline 8.3 Ventilación mecánica no invasiva & $\square$ Si (1) & $\square$ No (0) & 8.4 Cumple mínimo 8h nocturnas $\square$ Sí (1) $\square$ No (0) \\
\hline 8.5 CPAP nocturna & $\square \mathrm{Si}(1)$ & $\square$ No $(0)$ & 8.6 Cumple mínimo 8h nocturnas $\square$ Sí (1) $\square$ No (0) \\
\hline 8.7 Reservorio subcutáneo & $\square \mathrm{Si}(1)$ & $\square$ No (0) & \\
\hline 8.8 Vía Central & $\square \mathrm{Si}(1)$ & $\square$ No (0) & \\
\hline 8.9 Bomba de perfusión de medicación & $\square$ Si (1) & $\square$ No (0) & \\
\hline 8.10 Tensión arterial & $\square \mathrm{Si}(1)$ & $\square$ No $(0)$ & \\
\hline 8.11 Glucemia capilar & $\square \mathrm{Si}(1)$ & $\square$ No (0) & \\
\hline 8.12 Control acenocumarol & $\square \mathrm{Si}_{(1)}$ & $\square$ No $(0)$ & \\
\hline 8.13 Ostomía & $\square \mathrm{Si}_{(1)}$ & $\square$ No $(0)$ & \\
\hline 8.14 Sonda vesical & $\square \mathrm{Si}_{(1)}$ & $\square$ No (0) & \\
\hline 8.15 Sonda gastro-percutània & $\square \mathrm{Si}(1)$ & $\square$ No (0) & \\
\hline 8.16 Nutrición enteral & $\square \mathrm{Si}(1)$ & $\square$ No $(0)$ & \\
\hline 8.17 Suplementos nutricionales & $\square \mathrm{Si}(1)$ & $\square$ No (0) & \\
\hline 8.18 Traqueotomia & $\square \mathrm{Si}_{(1)}$ & $\square$ No $(0)$ & \\
\hline 8.19 Laringuectomia & $\square$ Si (1) & $\square$ No $(0)$ & \\
\hline 8.20 Aspirado de secreciones & $\square \mathrm{Si}_{(1)}$ & $\square$ No $(0)$ & \\
\hline 8.21 Enemas & $\square$ Si (1) & $\square$ No $(0)$ & \\
\hline 8.22 Curas (heridas, úlceras...) & $\square$ Si (1) & $\square$ No $(0)$ & \\
\hline 8.23 Control de peso & $\square \mathrm{Si}(1)$ & $\square$ No (0) & \\
\hline
\end{tabular}


IX. CONOCIMIENTO DE LA/LAS PATOLOGIA/AS CRÓNICA/AS

9.1 ¿Tiene usted una enfermedad respiratoria?

¿Cómo se llama su enfermedad respiratoria crónica. Anotar palabras que dice el paciente:

X. Anexos

Respuesta correcta: se aceptará una respuesta correcta si el paciente dice EPOC, bronquitis crónica o enfisema pulmonar

Entrevistador: $\square$ respuesta correcta (1) $\square$ respuesta incorrecta (2)

No (0)

9.2 ¿Conoce usted los síntomas de alarma que tiene que tener cuando sus problemas respiratorios empeoran? ¿Qué le pasa cuando sus problemas respiratorios empeoran?

Respuesta correcta: se aceptará una respuesta correcta si el paciente menciona como mínimo dos de les siguientes situaciones: (aumento del ahogo, aumento del esputo, cambio del color de las secreciones, fiebre, aparición de tos, edemas en los pies, somnolencia y cianosis)

Entrevistador: $\square$ respuesta correcta (1) $\square$ respuesta incorrecta (2)

$\square$ No $(0)$

9.3 ¿Conoce cuál es la primera medicación que tiene que tomar o qué tiene que hacer cuando su enfermedad respiratoria le hace empeorar?

$\square \mathrm{Si}$

Respuesta correcta: se aceptará una respuesta correcta si el paciente dice $\beta_{2}$ corta duración, salbutamol, ventolín ${ }$

Entrevistador: $\square$ respuesta correcta (1) $\square$ respuesta incorrecta (2)

No (0)

\section{ATENCIÓN SANITARIA:}

10.1 Debido a los problemas de salud respiratorios, tiene visitas frecuentes con un profesional sanitario?

(si es "No" pasar a la pregunta 10.4)

$\square$ Sí (1) $\square$ No (0)

10.2 En el caso de que haya contestado "Si" a la pregunta anterior, dónde se visita por su problema respiratorio? (Respuesta múltiple)

$\square$ Centro de Atención primaria (1)

$\square$ Hospital (2)

$\square$ Ninguno (3)

$\square$ No lo sé (N)

10.3 Se realiza controles de forma periódica por su problema respiratorio?

$\square \mathrm{Si}$, una vez cada 3-6 meses (3)

$\square \mathrm{Si}$, una vez al año (1)

$\square$ Sí, pero no me acuerdo (2)

$\square$ No (0)

Para el entrevistador: se entiende por programa de educación terapéutica como un proceso de aprendizaje estructurado durante un período de tiempo determinado que sigue el paciente y su familia con el soporte de un profesional de la salud con unos objetivos concretos y resultados medibles. Generalmente,se trata de sesiones individuales o en grupos donde se tratan temas específicos de la enfermedad con el objetivo de conocer mejor la patología y mejorar el cumplimento terapéutico.

10. 4 Ha participado alguna vez en algún programa de educación terapéutica por sus enfermedades crónicas? (Si es "No" pasar a la pregunta 10.7, si es "Si" contestar les preguntes de la 10.5 y 10.6) $\square$ Si (1) $\square$ No (0)

10.5 Para que enfermedad estaban indicadas estas sesiones? Escriba literalmente

10.6 Le proporcionaron algún tipo de documentación (libros, vídeos, etc)? $\square \mathrm{Si}$ (1) $\square$ No (0)

10.7 Cuando usted se encuentra mal (su enfermedad respiratoria ha empeorado), ¿a quién llama o dónde acude?

$\square$ Atención Primaria(1) $\square$ Hospital(2) $\square$ Urgencias hospital(3) $\square$ Hospital de día(4) $\square$ A nadie(5) $\square$ Otros (incluyendo web)(6)

No lo he precisado (7)

XII. ESCALA CANADIENSE SOBRE SALUD Y ENVEJECIMIENTO, como te considerarías de las siguientes opciones:

12.1 Muy en forma- robusto, activo, energético, motivado y en forma.

12.2 Bien- sin enfermedad activa, pero menos en forma que las personas de la categoría 1.

$\square$ 12.3 Bien- con comorbilidad tratada-síntomas de enfermedades controladas en comparación con la categoría 4.

$\square$ 12.4 Aparente vulnerable- no es dependiente pero se queja de problemas de enlentecimiento, tiene síntomas de enfermedad

$\square$ 12.5 Un poco frágil-depende de otros para realizar las actividades instrumendas de la vida diaria.

$\square$ 12.6 Moderadamente frágil- completamente dependiente de los otros por las actividades de la vida diaria.

$\square$ 12.7 Enfermo terminal 


\section{I. ÍNDICE DE BARTHEL}

\section{Comer}

(0) Incapaz

$\square$ (5) Necesita ayuda para cortar y utilizar los cubiertos

$\square$ (10) Independiente

\section{Bañarse/ducharse}

(0) Dependiente

(5) Independiente

\section{Higiene personal}

$\square$ (0) Necesita ayuda con la higiene personal

$\square$ (5) Independiente para lavarse la cara, les manos y los dientes, peinarse y afeitarse.

\section{Vestirse y desvestirse}

(0) Dependiente

$\square$ (5) Necesita ayuda pero puede hacer la mitad, aproximadamente sin ayuda.

$\square$ (10) Independiente, hasta con los botones, cremalleras, cordones, etc.

\section{Control de las heces}

$\square$ (0) Incontinente

$\square$ (5) Accidente excepcional (una/semana)

$\square$ (10) Continente

\section{Control de la orina}

(0) Incontinente (o con sonda incapaz de cambiarse la bolsa)

$\square$ (5) Accidente excepcional (máximo unas/24 horas)

$\square$ (10) Continente

\section{Úso del W.C.}

$\square$ (0) Dependiente

$\square$ (5) Necesita algún tipo de ayuda, pero puede hacer cosas solo/a

$\square$ (10) Independiente (entrar y salir, limpiarse y vestirse)

\section{Desplazarse de la silla a la cama y al revés}

$\square$ (0) Incapaz, no se mantiene sentado

$\square$ (5) Necesita ayuda importante (una persona entrenada o dos personas)

$\square$ (10) Necesita alguna ayuda (una pequeña ayuda física o ayuda verbal)

$\square$ (15) Independiente

\section{Desplazarse}

(0) Inmóvil o $<40$ metros

(5) Independiente con silla de ruedas, rincones incluidos $>40$ metros

$\square$ (10) Camina con ayuda de otra persona (ayuda verbal o física $>40$ metros)

$\square$ (15) Independiente

\section{Subir y bajar escaleras}

$\square$ (0) Incapaz

$\square$ (5) Necesita ayuda (física o verbal, para llevar cualquier tipo de muleta)

$\square$ (10) Independiente para subir y bajar.

2. VALOR TOTAL ÍNDICE DE BARTHEL $\square \square \square$ (Indique el valor numérico) 


\section{CUESTIONARIO III. CUESTIONARIO DE AUTOCUMPLIMEANTACIÓN EN BASE A LOS 12 ÚLTIMOS MESES}

IDENTIFICACIÓN DEL PACIENTE:

Fecha de inclusión en el programa: $\square \square / \square \square / \square \square$ dd/mm/aa solo indicar código del paciente

Cuestionario elaborado de forma: $\square$ Presencial $\square$ Telefónica

\section{ASPECTOS PSICOLÓGICO. HAD}

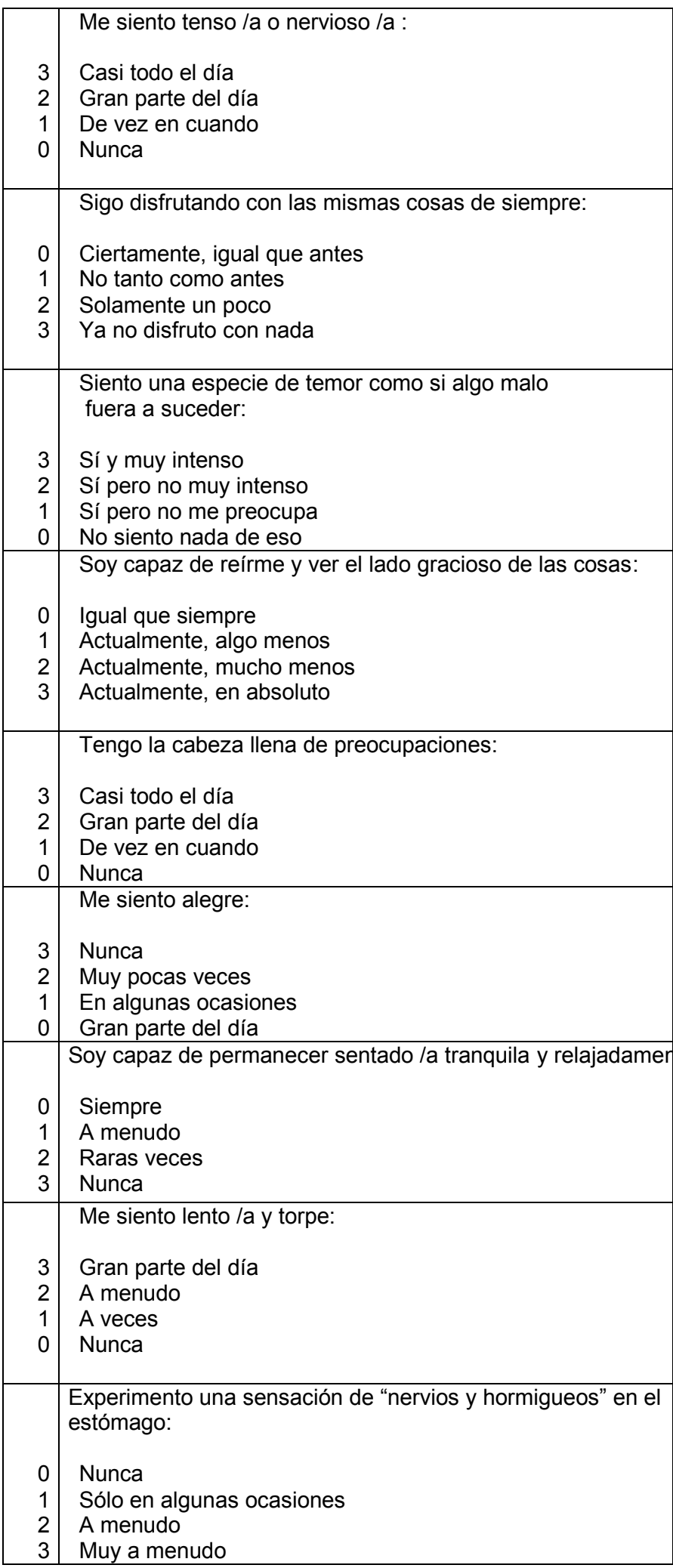

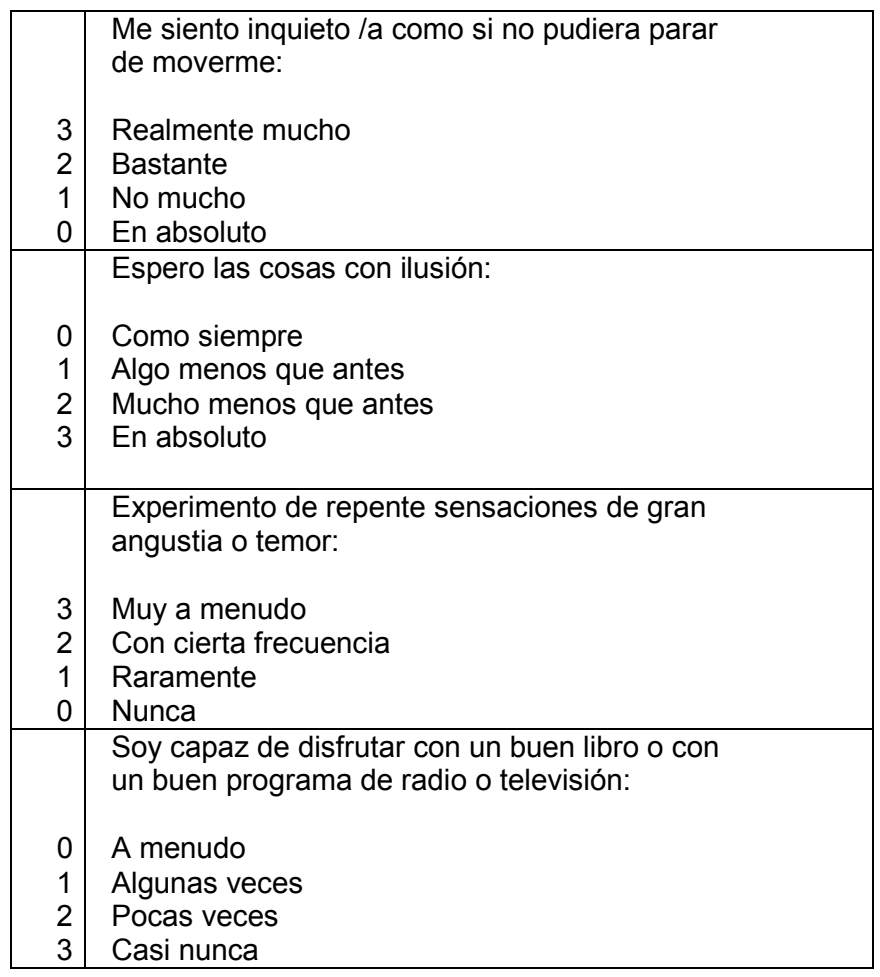


Indique la casilla que mejor describa su estado actual:

Este cuestionario les ayudará a usted y al profesional del cuidado de la salud a medir el impacto que la EPOC (enfermedad pulmonar obstructiva crónica) está teniendo en su bienestar y su vida diaria. Sus respuestas y la puntuación de la prueba pueden ser utilizadas por usted y por el profesional del cuidado de la salud para ayudar a mejorar el manejo de la EPOC y obtener el máximo beneficio del tratamiento.

En cada uno de los siguientes enunciados, ponga una $X$ en la casilla que mejor describa su estado actual.Asegúrese de seleccionar sólo una respuesta para cada pregunta.

Ejemplo: Estoy muy contento

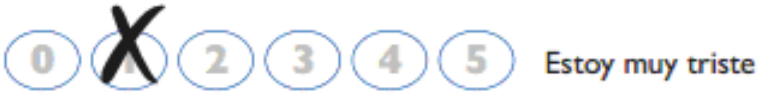

Nunca toso

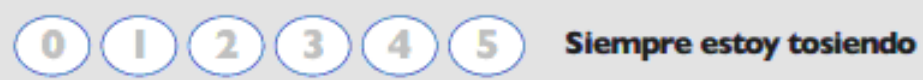

No tengo flema

(mucosidad) en el pecho

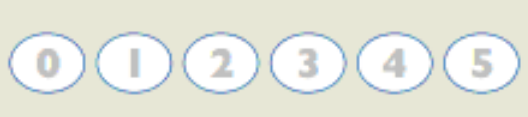

Tengo el pecho

completamente lleno de

flema (mucosidad)

\section{No siento ninguna opresión en el pecho \\ (0) 13 Siento mucha opresión en el pecho}

Cuando subo una pendiente o un tramo de escaleras, no me falta el aire
Cuando subo una pendiente o un tramo de escaleras, me falta mucho el aire
No me siento limitado para realizar actividades domésticas

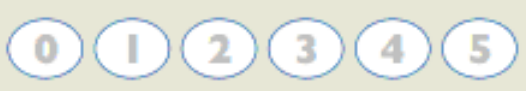

Me siento seguro al salir de casa a pesar de la enfermedad pulmonar que padezco

\section{Duermo sin problemas}

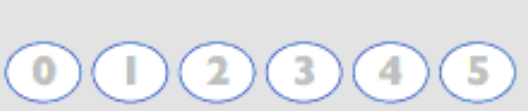

Me siento muy limitado para realizar actividades domésticas

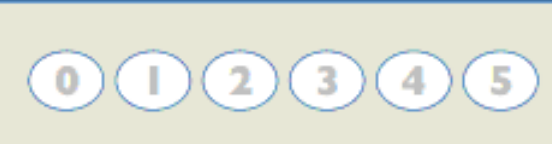

No me siento nada seguro al salir de casa debido a la enfermedad pulmonar que padezco

Tengo problemas para dormir debido a la enfermedad pulmonar que padezco 
INSTRUCCIONES: Este cuestionario está hecho para ayudarnos a saber mucho más sobre sus problemas respiratorios y cómo le afectan a su vida. Usamos el cuestionario, no tanto para conocer los problemas que los médicos y las enfermeras piensan que usted tiene, sino para saber qué aspectos de su enfermedad son los que le causan más problemas. Por favor, lea atentamente las instrucciones y pregunte lo que no entienda. No se entretenga demasiado en decidir las respuestas.

Conteste cada pregunta señalando con una cruz el cuadro correspondiente a la respuesta elegida, (ASÍ $X$ ).

Toda la información será confidencial.

A continuación algunas preguntas para saber cuántos problemas respiratorios ha tenido durante el último año. Por favor, para cada pregunta marque la respuesta que corresponda.

$\begin{array}{lcccc}\text { Casi todos } & \text { Varios } & \text { Unos } & \begin{array}{c}\text { Sólo cuando } \\ \text { tuve infección }\end{array} & \text { Nada en } \\ \text { los días de } & \text { días a la } & \text { pocos días } & \text { en los } & \text { absoluto } \\ \text { la semana } & \text { semana } & \text { al mes } & \text { pulmones } & \end{array}$

1. Durante el último año, cha tenido tos?

2<smiles>CCCCC</smiles>

$4 \square \quad---$<smiles>C1CCC1</smiles>

2. Durante el último año, cha arrancado? (sacar esputos) 1 2<smiles>C1CCCC1</smiles>
4 $5 \square$

3. Durante el último año, cha tenido ataques de falta de respiración? 1<smiles>C1CCC2CCC2CC1</smiles>
2<smiles>C1CCC1</smiles>
$5 \square$

4. Durante el último año, cha tenido ataques de pitos o silbidos en los pulmones? 2 3 $\square$-.-5 
5. Durante el último año, ¿cuántos ataques tuvo por problemas respiratorios que fueran graves o muy desagradables?

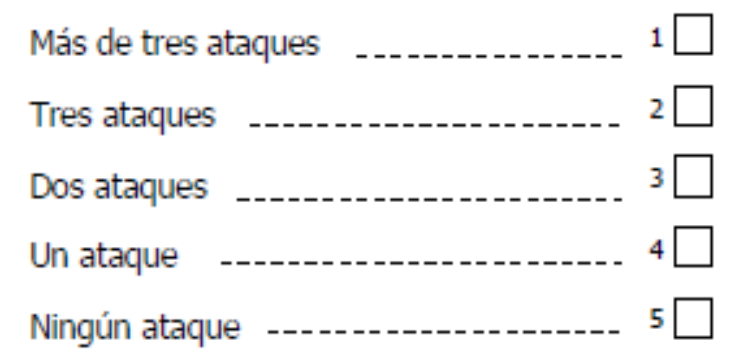

6. ¿Cuánto le duró el peor de los ataques que tuvo por problemas respiratorios?

\section{(SI NO TUVO NINGÚN ATAQUE SERIO VAYA A LA PREGUNTA 7)}

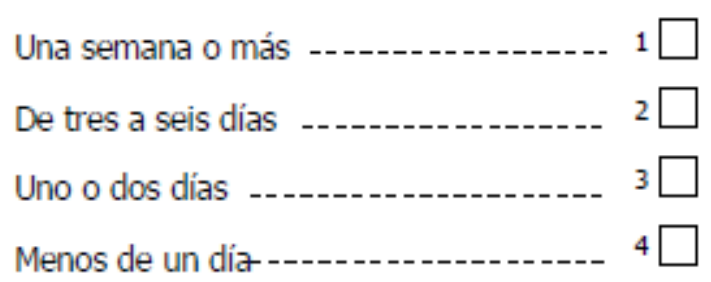

7. Durante el último año, ¿cuántos días buenos (con pocos problemas respiratorios) pasaba en una semana habitual?

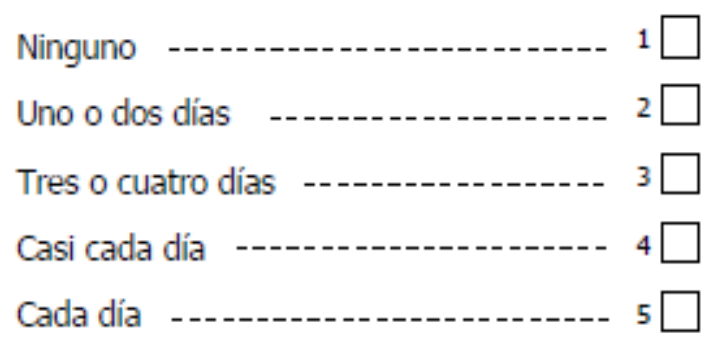

8. Si tiene pitos o silbidos en los pulmones, ¿son peores por la mañana?

(SI NO TIENE PITOS O SILBIDOS EN LOS PULMONES VAYA A LA PREGUNTA 9)

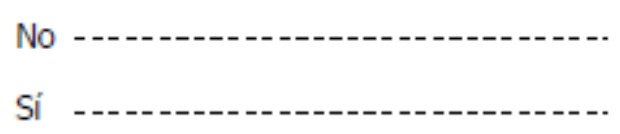


9. ¿Cómo diría usted que está de los pulmones?, Por favor, marque una sola de las siguientes frases:

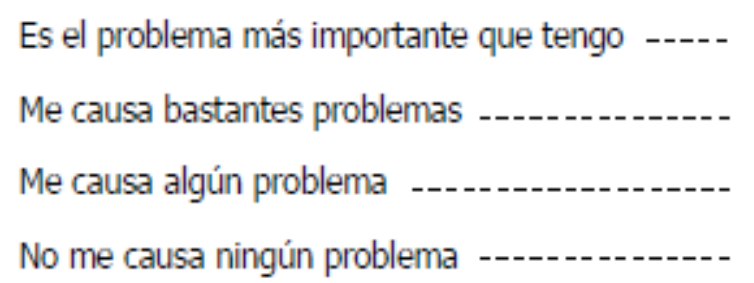

10. Si ha tenido algún trabajo remunerado, por favor marque una sola de las siguientes frases:

(SI NO HA TENIDO UN TRABAJO REMUNERADO VAYA A LA PREGUNTA 11)

Mis problemas respiratorios me obligaron a dejar de trabajar 1

Mis problemas respiratorios me dificultan en mi trabajo o me obligaron a cambiar de trabajo 2

Mis problemas respiratorios no me afectan (o no me afectaron) en mi trabajo

11. A continuación algunas preguntas sobre las actividades que últimamente le pueden hacer sentir que le falta la respiración. Por favor, para cada pregunta marque la respuesta que corresponda:

Me falta la respiración estando sentado o incluso estirado

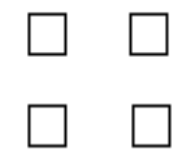

Me falta la respiración cuando me lavo o me visto

Me falta la respiración al caminar por dentro de casa

Me falta la respiración al caminar por fuera de casa, en terreno llano

Me falta la respiración al subir un tramo de escaleras

Me falta la respiración al subir una cuesta

Me falta la respiración al hacer deporte o al jugar 
12. Algunas preguntas más sobre la tos y la falta de respiración que tiene últimamente. Por favor, para cada pregunta marque la respuesta que corresponda:

Tengo dolor cuando toso

Me canso cuando toso

Me falta la respiración cuando hablo

Me falta la respiración cuando me agacho

La tos o la respiración me molestan cuando duermo

Enseguida me agoto
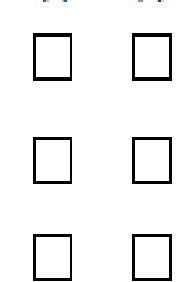

13. A continuación algunas preguntas sobre otras consecuencias que sus problemas respiratorios le pueden causar últimamente. Por favor, para cada pregunta marque la respuesta que corresponda:

La tos o la respiración me dan vergüenza en público

Mis problemas respiratorios son una molestia para mi familia, mis amigos o mis vecinos 然

Me asusto o me alarmo cuando no puedo respirar

Siento que no puedo controlar mis problemas respiratorios

Creo que mis problemas respiratorios no van a mejorar<smiles></smiles>

Por culpa de mis problemas respiratorios me he convertido en una persona débil o inválida

Hacer ejercicio es peligroso para mi $-$ 
14. A continuación algunas preguntas sobre su medicación.

\section{(SÍ NO ESTÁ TOMANDO NINGUNA MEDICACIÓN, VAYA A LA PREGUNTA 15)}

Sí NO

(1) (0)

Creo que la medicación me sirve de poco

Me da vergüenza tomar la medicación en público

La medicación me produce efectos desagradables

La medicación me altera mucho la vida

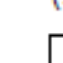

$\square$

15. Estas preguntas se refieren a cómo sus problemas respiratorios pueden afectar sus actividades. Por favor, para cada pregunta marque la respuesta que corresponda:

Tardo mucho para lavarme o vestirme

Me resulta imposible ducharme o bañarme o tardo mucho rato

Camino más despacio que los demás, o tengo que pararme a descansar

Tardo mucho para hacer trabajos como las tareas domésticas, o tengo que parar a descansar

Para subir un tramo de escaleras, tengo que ir despacio o parar

Si he de correr o caminar rápido, tengo que parar o ir más despacio

Mis problemas respiratorios me dificultan hacer cosas tales como subir una cuesta, llevar cosas por las escaleras, caminar durante un buen rato, arreglar un poco el jardín, bailar, o jugar a los bolos

\section{un}

Mis problemas respiratorios me dificultan hacer cosas tales como llevar cosas pesadas, caminar a unos $7 \mathrm{kms}$ por hora, hacer "jogging", nadar, jugar a tenis, cavar en el jardín o quitar la nieve con una pala

Mis problemas respiratorios me dificultan hacer cosas tales como un trabajo manual muy pesado, correr, ir en bicicleta, nadar rápido o practicar deportes de competición 
16. Nos gustaría saber ahora como sus problemas respiratorios le afectan normalmente en su vida diaria. Por favor, para cada pregunta marque la respuesta que corresponda: Sí NO

Puedo hacer deportes o jugar

(1) (0)

Puedo salir a distraerme o divertirme

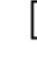

$\square$

Puedo salir de casa para ir a comprar

Puedo hacer el trabajo de la casa

Puedo alejarme mucho de la cama o de la silla

17. A continuación, ¿podría marcar la frase (sólo una) que usted crea que describe mejor como le afectan sus problemas respiratorios?

No me impiden hacer nada de lo que quisiera hacer 1

Me impiden hacer 1 o 2 cosas de las que quisiera hacer 2

Me impiden hacer la mayoría de cosas que quisiera hacer $3 \square$

Me impiden hacer todo lo que quisiera hacer $.4 \square$

Gracias por contestar a estas preguntas 


\section{Anexo IV. Cuestionario a los 3 meses}

\section{CUESTIONARIO II. ENTREVISTA CON EL PACIENTE EVALUACIÓN DEL PACIENTE A LOS 3 MESES POST ALTA}

IDENTIFICACIÓN DEL PACIENTE:

Fecha de inclusión en el programa: $\square \square / \square \square / \square \square$ dd/mm/aa

Fecha de revisión 3 meses $\square \square / \square \square / \square \square$ dd/mm/aa

Cuestionario elaborado de forma: $\square$ Presencial $\square$ Telefónica

Para el entrevistador: es importante explicar al paciente que todas las preguntas guardan relación con los últimos 3 meses.

\begin{tabular}{|c|c|c|}
\hline \multicolumn{3}{|l|}{ I. SINTOMAS habituales } \\
\hline 1.1 Disnea & MRC $\square$ (Índique el valor del MRC) & $\square$ No (0) \\
\hline \multicolumn{3}{|c|}{ GRADO DE DISNEA: ESCALA DEL MEDICAL RESEARCH COUNCIL (MRC) } \\
\hline \multicolumn{3}{|c|}{ Grado 0 : Ausencia de disnea, excepto al realizar ejercicio intenso $(0)$} \\
\hline \multicolumn{3}{|c|}{ Grado 1 : Disnea al caminar rápido en plano o subir una pendiente poco pronunciada (1) } \\
\hline \multicolumn{3}{|c|}{$\begin{array}{l}\text { Grado } 2 \text { : Incapacidad de mantener el paso de otras personas de la misma edad debido a una dificultad respiratoria o a la necesidad } \\
\text { de pararse a descansar al andar en plano siguiendo el propio paso. (2) }\end{array}$} \\
\hline \multicolumn{3}{|c|}{ Grado 3: Necesidad de pararse a descansar al caminar unos 100 metros o a pocos minutos de caminar en plano (3) } \\
\hline \multicolumn{3}{|c|}{ Grado 4: La disnea impide al paciente salir de casa o aparece en actividades como vestirse y desvestirse (4) } \\
\hline 1.2 Tos & $\square \mathrm{Si} \quad(1)$ & $\square$ No (0) \\
\hline \multirow{2}{*}{ 1.3 Expectoración } & \multirow{2}{*}{$\square \mathrm{Si}$ (1) Color: _ } & $\square$ No (0) \\
\hline & & Color: B: Blanco; A: Amarillo; V: Verde ; M: Marrón \\
\hline 1.4 Sibilancias & $\square \mathrm{Si}(1)$ & $\square$ No (0) \\
\hline 1.5 Somnolencia diurna & $\square \mathrm{Si}_{(1)}$ & $\square$ No (0) \\
\hline 1.6 Precisa dormir sentado & $\square S_{i}(1)$ & $\square$ No (0) \\
\hline 1.7 Edemas & $\square \mathrm{Si}_{\text {(1) }}$ & $\square$ No (0) \\
\hline 1.8 Fiebre & $\square \mathrm{Si}_{(1)}$ & $\square$ No (0) \\
\hline 1.9 Dolor & $\square \mathrm{Si}_{\text {(1) }}$ EVA $\square \square(0-10)$ & $\square$ No (0) \\
\hline
\end{tabular}

\section{DATOS SOCIODEMOGRȦFICOS}

2.1. ¿Dónde ha vivido el paciente durante los últimos 3 meses? (A identificar por el entrevistador/a)

$\square$ A su casa (1) $\square$ En una residencia (2) $\square$ En un centro sociosanitario (3)

2.2 ¿Con quién ha estado viviendo durante estos 3 meses? (Respuesta múltiple)

$\square$ Marido/Esposa (1) $\square$ Hijos (2) $\square$ Otros familiares (3) $\square$ Amigos/alojamiento compartido (4) $\square$ Cuidador externo (5) $\square$ Solo (6)

2.3. Apoyo que ha recibido por la sociedad durante estos últimos 3 meses (a rellenar por el entrevistado).

$\square$ No necesita ningún apoyo. (0)

$\square$ Tiene apoyo por parte de los vecinos. (1)

$\square$ Tiene apoyo social formal suficiente (centro de día, trabajadora social, institución) (2)

$\square$ Tiene soporte social pero no es suficiente (3)

$\square$ No tiene ningún soporte social y no lo necesita. (4)

\begin{tabular}{|l|l|}
\hline III. TRATAMIENTO FARMACOLÓGICO & \\
\hline 3.1 ¿Cuantas pastillas toma al día? & $\square \square$ total al día (valor numérico) $\square$ ninguna (0) \\
\hline 3.2 ¿Cuantas inyecciones o pinchazos es realiza al día? & $\square \square$ total al día (valor numérico) $\square$ ninguna (0) \\
\hline
\end{tabular}




$\square \square$ total al día (valor numérico) $\quad \square$ ninguna (0)
$\square$ Cartucho (1) $\square$ Cámara (2) $\square$ Turbuhaler (3) $\square$ Accuhaler (4)
$\square$ Inhaletas (5) $\square$ Nebulizador (6) $\square$ Otros....................(7)

\section{TĖCNICA INHALADA.}

Ahora, si le apetece, haga una inhalación con el sistema de inhalación que utiliza tal y como usted lo hace en su casa. Tómese el tiempo que necesite. (SI TOMA MÁS DE UNA PRESENTACIÓ, HAGALO CON TODAS UTILITZANDO PLACEBO, UNA DETRAS DE LA OTRA DEJANDO TIEMPO SUFICIENTE)

4.1 Cartucho presurizado (NO rellenar esta opción si el paciente utiliza cámara espaciadora para este sistema)

4.1.1 Medicación que toma con este dispositivo:

$\square \beta 2$ adrenérgico de corta duración $\square$ 及2 adrenérgico de larga duración $\square$ Anticolinergico $\square$ Corticoide inhalado

$\square$ Sí $\square \mathrm{NO} \rightarrow$ saltar a cámara espaciadora $\downarrow$

\begin{tabular}{|c|c|c|}
\hline & SI & NO \\
\hline 4.1.1 Sentado y en posición cómoda & $\square(1)$ & $\square(0)$ \\
\hline 4.1.2 Destapar el cartucho y situarlo en posición vertical (forma de $L$ ) & $\square(1)$ & $\square(0)$ \\
\hline 4.1.3 Sujetas el cartucho entre los dedos índice y pulgar. Agitar & $\square(1)$ & $\square(0)$ \\
\hline 4.1.4 Efectuar una espiración lenta y profunda & $\square(1)$ & $\square(0)$ \\
\hline 4.1.5 Poner el boquilla del cartucho a la boca y cerrar completamente & $\square(1)$ & $\square(0)$ \\
\hline 4.1.6 Inspirar lentamente para la boca (la lengua ha de estar de bajo del paladar) & $\square(1)$ & $\square(0)$ \\
\hline $\begin{array}{l}\text { 4.1.7 Una vez iniciada la inspiración, presionar una sola vez el cartucho y seguir } \\
\text { inspirando lenta i profundamente hasta llenar los pulmones completamente }\end{array}$ & $\square(1)$ & $\square(0)$ \\
\hline 4.1.8 Retirar el cartucho de la boca (aguantar la respiración durante 10 segundos) & $\square(1)$ & $\square(0)$ \\
\hline 4.1.9 Esperar medio minuto entre cada inhalación & $\square(1)$ & $\square(0)$ \\
\hline 4.1.10 Tapar el inhalador y guardarlo en un lugar seco & $\square(1)$ & $\square(0)$ \\
\hline
\end{tabular}

\subsection{Cámara espaciadora}

4.2.1 Medicación que toma con este dispositivo:

$\square$ B2 adrenérgico de corta duración $\square$ 及2 adrenérgico de larga duración $\square$ Anticolinergico $\square$ Corticoide inhalado $\square$ SI $\square$ NO $\rightarrow$ saltar a Turbuhaler $\downarrow$

\begin{tabular}{|c|c|c|}
\hline & $\mathrm{SI}$ & NO \\
\hline 4.2.1 Sentado y en posición cómoda & $\square(1)$ & $\square(0)$ \\
\hline 4.2.2 Destapar el cartucho y situarlo en posición vertical (forma de L) & $\square(1)$ & $\square(0)$ \\
\hline 4.2.3 Acoplar el cartucho al orificio de la cámara & $\square(1)$ & $\square(0)$ \\
\hline 4.2.4 Efectuar una espiración lenta y profunda & $\square(1)$ & $\square(0)$ \\
\hline 4.2.5 Efectuar una pulsación del inhalador & $\square(1)$ & $\square(0)$ \\
\hline $\begin{array}{l}\text { 4.2.6 Inspirar profundamente el aire de la cámara } \\
\text { (La lengua tiene que estar al debajo del paladar) }\end{array}$ & $\square(1)$ & $\square(0)$ \\
\hline 4.2.7 Retirar la cámara de la boca y aguantar la respiración 10 segundos & $\square(1)$ & $\square(0)$ \\
\hline $\begin{array}{l}\text { 4.2.8 Puede realizar una segunda inhalación lenta y profunda para asegurarse de que } \\
\text { vacía bien la cámara. }\end{array}$ & $\square(1)$ & $\square(0)$ \\
\hline 4.2.9 Esperar 30 segundos entre cada toma. & $\square(1)$ & $\square(0)$ \\
\hline 4.2.10 Limpiar bien la cambra una vez a la semana con agua y jabón & $\square(1)$ & $\square(0)$ \\
\hline \multirow{2}{*}{\multicolumn{3}{|c|}{$\begin{array}{l}\text { 4.3 Turbuhaler } \\
\text { 4.3.1 Medicación que toma con este dispositivo: } \\
\square \text { B2 adrenérgico de corta duración } \square \text { 及2 adrenérgico de larga duración } \square \text { Anticolinergico } \square \text { Corticoide inhalado } \\
\square \mathrm{SI} \quad \square \text { NO } \rightarrow \text { salta a Accuhaler } \downarrow\end{array}$}} \\
\hline & & \\
\hline & $\mathrm{SI}$ & NO \\
\hline 4.3.1 Sentado y en una posición cómoda & $\square(1)$ & $\square(0)$ \\
\hline 4.3.2 Desenroscar y retirar la capucha del inhalador & $\square(1)$ & $\square(0)$ \\
\hline 4.3.3 Sostener el inhalador en posición vertical & $\square(1)$ & $\square(0)$ \\
\hline 4.3.4 Girar la rosca de la parte inferior en sentido contrario al de las agujas del reloj & $\square(1)$ & $\square(0)$ \\
\hline 4.3.5 Volver a girar la rosca en sentido de les agujas del reloj. Esperar a escuchar "clic" & $\square(1)$ & $\square(0)$ \\
\hline 4.3.6 Realizar una espiración (sin poner el dispositivo en la boca) & $\square(1)$ & $\square(0)$ \\
\hline 4.3.7 Posar el boquilla entre los dientes y cerrar los labios & $\square(1)$ & $\square(0)$ \\
\hline 4.3.8 Aspirar enérgicamente y mantener la respiración durante 10 segundos & $\square(1)$ & $\square(0)$ \\
\hline 4.3.9 Esperar medio minuto entre cada toma & $\square(1)$ & $\square(0)$ \\
\hline
\end{tabular}


4.4 Accuhaler

4.4.1 Medicación que toma con este dispositivo:

$\square \beta 2$ adrenérgico de corta duración $\square$ 及2 adrenérgico de larga duración $\square$ Anticolinergico $\square$ Corticoide inhalado $\square$ SI $\square$ NO $\rightarrow$ saltar a Inhaletes $\downarrow$

\begin{tabular}{|l|l|l|}
\hline & SI & NO \\
\hline 4.4.1 Sentado y en posición cómoda & $\square(1)$ & $\square(0)$ \\
\hline 4.4.2 Bajar el protector de la pieza bucal & $\square(1)$ & $\square(0)$ \\
\hline 4.4.3 Apretar la pestaña lateral hacia abajo hasta el límite & $\square(1)$ & $\square(0)$ \\
\hline 4.4.4 Efectúa una espiración lenta i profunda & $\square(1)$ & $\square(0)$ \\
\hline 4.4.5 Poner los labios alrededor de la pieza bucal. & $\square(1)$ & $\square(0)$ \\
\hline 4.4.6 Aspirar profundamente y enérgicamente & $\square(1)$ & $\square(1)$ \\
\hline 4.4.7 Mantener la respiración durante 10 segundos & $\square(1)$ & $\square(0)$ \\
\hline 4.4.8 Esperar medio minuto entre cada toma & $\square(1)$ & $\square(0)$ \\
\hline 4.4.9 Tapar la pieza bucal y guardarlo & $\square(0)$ \\
\hline 4.5
\end{tabular}

\subsection{Inhaletes}

4.5.1 Medicación que toma con este dispositivo:

$\square \beta 2$ adrenérgico de corta duración $\square \beta 2$ adrenérgico de larga duración $\square$ Anticolinergico $\square$ Corticoide inhalado $\square$ SI $\square$ NO $\rightarrow$ salta a Nebulizador $\downarrow$

\begin{tabular}{|c|c|c|}
\hline & $\mathrm{SI}$ & NO \\
\hline 4.5.1 Abrir el inhalador levantar la boquilla & $\square(1)$ & $\square(0)$ \\
\hline 4.5.2 Poner la capsula al orificio correspondiente y cerrar el inhalador & $\square(1)$ & $\square(0)$ \\
\hline 4.5.3 Con la boquilla hacia arriba, presione el pulsados hasta el límite & $\square(1)$ & $\square(0)$ \\
\hline 4.5.4 Realizar una espiración lenta y profunda & $\square(1)$ & $\square(0)$ \\
\hline 4.5.5 Poner la boquilla entre los dientes y cerrar los labios alrededor de este & $\square(1)$ & $\square(0)$ \\
\hline 4.5.6 Aspirar profundamente y enérgicamente & $\square(1)$ & $\square(0)$ \\
\hline 4.5.7 Levantar la boquilla, girar el inhalador y agitar hasta conseguir que salga la capsula & $\square(1)$ & $\square(0)$ \\
\hline 4.5.8 Cerrar el inhalador y guardarlo en un sitio seco & $\square(1)$ & $\square(0)$ \\
\hline \multirow{2}{*}{\multicolumn{3}{|c|}{$\begin{array}{l}\text { 4.6 Nebulizador } \\
\text { 4.6.1 Medicación que toma con este dispositivo: } \\
\square \text { 及2 adrenérgico de corta duración } \square \text { 及2 adrenérgico de larga duración } \square \text { Anticolinergico } \square \text { Corticoide inhalado } \\
\square \mathrm{SI} \quad \square \mathrm{NO} \rightarrow \text { saltar al siguiente apartado }\end{array}$}} \\
\hline & & \\
\hline & $\mathrm{SI}$ & NO \\
\hline 4.6.1 Lavarse las manos & $\square(1)$ & $\square(0)$ \\
\hline 4.6.2 Paciente sentado & $\square(1)$ & $\square(0)$ \\
\hline 4.6.3 Preparación del fármaco y preparación del nebulizador & $\square(1)$ & $\square(0)$ \\
\hline 4.6.4 Poner la cánula nasal si el paciente precisa oxigenoterapia & $\square(1)$ & $\square(0)$ \\
\hline 4.6.5 Poner el nebulizador en posición vertical & $\square(1)$ & $\square(0)$ \\
\hline 4.6.6 Nebulizar el fármaco & $\square(1)$ & $\square(0)$ \\
\hline 4.6.7 Limpiar la cazoleta del nebulizador después de cada uso. Guardarla limpia y seca & $\square(1)$ & $\square(0)$ \\
\hline 4.6.8 Revisión periódica de la casa suministradora & $\square(1)$ & $\square(0)$ \\
\hline
\end{tabular}

\section{ADHERĖNCIA FARMACOLÒGICA (Morisky-Green) Este cuestionario debe ser administrado como una conversación no como preguntas concretas}

Realizar estas preguntas durante la conversación NO directamente. Muchas persones pueden tener dificultades o barreras para seguir el tratamiento, como por ejemplo: No entender bien la pauta, haber de tomar mucha medicación, pensar que la que li va bien para una cosa le va mal para otra, o por problemas económicos o sociales, etc

5.1 ¿Olvida alguna vez tomar los medicamentos para tratar su enfermedad?

5.2 ¿Toma los medicamentos a las horas indicadas?

$\begin{array}{ll}\square \mathrm{Si}_{(1)} & \square \text { No (0) } \\ \square \mathrm{Si}_{(1)} & \square \mathrm{No}(0) \\ \square \mathrm{Si}_{(1)} & \square \mathrm{No}_{(0)} \\ \square \mathrm{Si}_{(1)} & \square \mathrm{No}_{(0)} \\ \square \mathrm{Si}_{(1)} & \square \mathrm{No}(0)\end{array}$

5.3 Cuantos se encuentra bien ¿deja de tomar la medicación?

5.4 Si alguna vez se encuentra más, ¿deja usted de tomar la medicación?

Paciente cumplidor: Se acepta si contesta correctamente a las 4 preguntes (No/Si/No/No) 


6.1 TABACO
$\square$ No (0)
$\square$ Si $_{(0)}$
$\square$ Exfumador (2)

6.1 TABACO

$\square \mathrm{Si}(0)$

$\square$ Exfumador (2)
Si el paciente es fumador pasar cuestionario autoadministrado Fagerström

Si fumador o exfumador calcular la dosis acumulada de paquetes/año

Paq/año $\square \square \square$ (valor numérico) ((cigarrillos día (.........) x Años de fumador $(. . . \ldots . . .) /$.20 )

(Pipa $=3$ cigarrillos, puro pequeño $=3$ cigarrillos, puro grande $=5$ cigarrillos)

\subsection{ALCOHOL.}

$\square \mathrm{Si}_{\text {No) }}^{\square} \square$ Vasos (valor numérico)

\subsection{NUTRICIÓN}

¿Sigue alguna dieta o régimen especial de forma continuada por motivos de salud?
6.3.1 $\square \mathrm{Si}(1)$
$\square$ No (0)

6.3.2 ¿Sabe cuánto pesa? Si el paciente no lo sabe, pesar $\square$ Peso $\square \square \square \mathrm{Kg}$. $\square$ No se puede valorar (N)

6.3.3 ¿Sabe cuánto mide? Si el paciente no lo sabe, medir $\square$ Talla $\square . \square \square \mathrm{m}$. $\square$ No se puede valorar (N)

6.3.4 IMC (peso/altura ${ }^{2}$ ): $\square \square \square . \square \square$ (valor numérico)

INGESTA DE LÍQUIDOS ¿Cuantos vasos de agua/zumo/caldos/leche bebe al dla? $\square \square$ vasos ( $\square, \square$ litros/dila) (valor l/día numérico) Un vaso equivale a $250 \mathrm{cc}$

6.4 ACTIVIDAD FíSICA Ahora le preguntaré sobre la actividad física y ejercicio que usted realiza de forma habitual
6.4.1 Caminar fuera de casa de forma regular 30 minutos diarios
$\square \mathrm{Si}(1)$
$\square \quad$ No $(0)$
6.4.2 Pasa la mayor parte del tempo en la cama o en el sillón
$\square$ Si (1)
$\square \quad$ No $(0)$

\section{TRATAMIENTO NO FARMACOLOGICO}

\subsection{VACUNA DE LA GRIPE}

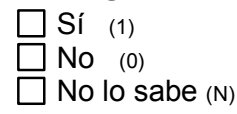

\subsection{VACUNA PNEUMOCOCO}
$\square$ Sí (1)
$\square$ No (0)
$\square$ No lo sabe (N)

VIII. COMPLEJIDAD DEL TRACTAMIENTO A DOMICILIO PREVIO AL INGRÉSO

\begin{tabular}{|c|c|c|c|}
\hline 8.1 Oxígeno en el domicilio & $\square$ Si (1) & $\square$ No (0) & 8.2 Cumple mínimo $16 \mathrm{~h}$ diarias $\square$ Sí (1) $\square$ No (0) \\
\hline 8.3 Ventilación mecánica no invasiva & $\square \mathrm{Si}(1)$ & $\square$ No (0) & 8.4 Cumple mínimo 8h nocturnas $\square$ Sí (1) $\square$ No (0) \\
\hline 8.5 CPAP nocturna & $\square$ Si (1) & $\square$ No (0) & 8.6 Cumple mínimo 8h nocturnas $\square$ Sí (1) $\square$ No (0) \\
\hline 8.7 Reservorio subcutaneo & $\square \mathrm{Si}(1)$ & $\square$ No $(0)$ & \\
\hline 8.8 Via Central & $\square \mathrm{Si}_{(1)}$ & $\square$ No (0) & \\
\hline 8.9 Bomba de perfusión de medicación & $\square \mathrm{Si}_{(1)}$ & $\square$ No (0) & \\
\hline 8.10 Tensión arterial & $\square \mathrm{Si}(1)$ & $\square$ No $(0)$ & \\
\hline 8.11 Glicèmia capilar & $\square \mathrm{Si}(1)$ & $\square$ No $(0)$ & \\
\hline 8.12 Control acenocumarol & $\square \mathrm{Si}_{(1)}$ & $\square$ No $(0)$ & \\
\hline 8.13 Ostomía & $\square \mathrm{Si}(1)$ & $\square$ No $(0)$ & \\
\hline 8.14 Sonda vesical & $\square \mathrm{Si}(1)$ & $\square$ No (0) & \\
\hline 8.15 Sonda gastro-percutània & $\square \mathrm{Si}(1)$ & $\square$ No $(0)$ & \\
\hline 8.16 Nutrición enteral & $\square \mathrm{Si}(1)$ & $\square$ No (0) & \\
\hline 8.17 Suplementos nutricionales & $\square \mathrm{Si}_{(1)}$ & $\square$ No (0) & \\
\hline 8.18 Traqueotomia & $\square \mathrm{Si}(1)$ & $\square$ No (0) & \\
\hline 8.19 Laringuectomia & $\square$ Si (1) & $\square$ No $(0)$ & \\
\hline 8.20 Aspirado de secreciones & $\square \mathrm{Si}(1)$ & $\square$ No (0) & \\
\hline 8.21 Enemas & $\square \mathrm{Si}_{(1)}$ & $\square$ No (0) & \\
\hline 8.22 Curas (heridas, úlceras...) & $\square \mathrm{Si}(1)$ & $\square$ No (0) & \\
\hline 8.23 Control de peso & $\square \mathrm{Si}_{(1)}$ & $\square$ No (0) & \\
\hline
\end{tabular}

\section{CONOCIMIENTO DE LA/LAS PATOLOGIA/AS CRÒNICA/AS}

\section{1 ¿Tiene usted una enfermedad respiratoria?}

¿Cómo se llama su enfermedad respiratoria crónica. Anotar palabras que dice el paciente:

Respuesta correcta: se aceptará una respuesta correcta si el paciente dice EPOC, bronquitis crónica o enfisema pulmonar

Entrevistador: $\square$ respuesta correcta (1) $\square$ respuesta incorrecta (2)

$\square$ No (0) 
9.2 ¿Conoce usted los síntomas de alarma que tiene que tener cuando sus problemas respiratorios empeoran? ¿Qué le pasa cuando sus problemas respiratorios empeoran?

Respuesta correcta: se aceptará una respuesta correcta si el paciente menciona como mínimo dos de les siguientes situaciones: (aumento del ahogo, aumento del esputo, cambio del color de las secreciones, fiebre, aparición de tos, edemas en los pies, somnolencia y cianosis)

Entrevistador:

$\square$ respuesta correcta (1)

$\square$ respuesta incorrecta (2)

$\square$ No $(0)$

9.3 ¿Conoce cual és la primera medicación que tiene que tomar o qué tiene que hacer cuando su enfermedad respiratoria le hace empeorar?

$\square \mathrm{Si}$

Respuesta correcta: se aceptará una respuesta correcta si el paciente dice $\beta_{2}$ corta duración, salbutamol, ventolín® Entrevistador: $\square$ respuesta correcta (1) $\square$ respuesta incorrecta (2)

$\square$ No (0)

\section{ATENCIÓN SANITARIA:}

10.1 Debido a los problemas de salud respiratòrias, se ha visita con un profesional sanitario en los últimos 3 meses?

(si es "No" pasar a la pregunta 10.3)

$\square$ Sí (1) $\square$ No (0)

10.2 En el caso de que haya contestado "Si" a la pregunta anterior, con que lugar se visita por su problema respiratorio? (Respuesta multiple)

$\square$ Centro de Atención primaria (1)

$\square$ Hospital (2)

$\square$ Ningúno (3)

$\square$ No lo sé (N)

10.3 Tiene cita para los controles de forma periòdica por su problema respiratorio?

$\square \mathrm{Si}$, una vez cada 3-6 meses (3)

$\square \mathrm{Si}$, una vez al año (1)

$\square$ Sí, però no me acuerdo (2)

$\square$ No (0) 
Para el entrevistador: se entiende por programa de educación terapéutica como un proceso de aprenendizaje estructurado durante un período de tiempo determinado que sigue el paciente y su família con el soporte de un profesional de la salud con unos objetivos concretos y resultados medibles. Generalmente,se trata de sesiones individuales o en grupos donde se tratan temas especificos de la enfermedad con el objetivo de conocer mejor la patología y mejorar el cumplimento terapèutico.

10.4 Cuando usted se ha encontrado mal (su enfermedad respiratoria ha empeorado), a quien ha llamado o a donde ha ido para recibir esta atención?

$\square$ Atenció primaria (1) $\square$ Hospital (2) $\square$ Urgencias hospitalarias (3) $\square$ Hospital de día (4) $\square$ A nadie (5) $\square$ Otros (incluyendo web) (6) $\square$ No lo he precisado (7)

\section{DEPENDENCIA DE LAS ACTIVIDADES DE LA VIDA DIARIA}

11.1. Valor total índice de Barthel $\square \square \square$ (Indique el valor numérico) Ver cuestionarios de soporte para la cumplimentación

\section{ESCALA CANADIENSE SOBRE SALUD Y ENVEJECIMIENTO}

$\square$ 12.1 Muy en forma- robusto, activo, energético, motivado y en forma.

12.2 Bien- sin enfermedad activa, pero menos en forma que las personas de la categoría 1.

12.3 Bien- con comorbilidad tratada-síntomas de enfermedades controladas en comparación con la categoría 4.

12.4 Aparentemente vulnerable-no es dependiente pero se queja de problemas de enlentecimiento y tiene síntomas de enfermedad

12.5 Un poco frágil-depende de otros para realizar las actividades instrumentas de la vida diaria.

12.6 Moderadamente frágil- completamente dependiente de los otros por las actividades de la vida diaria. 12.7 Enfermo terminal 
CUESTIONARIO III. CUESTIONARIO DE AUTOCUMPLIMENTACIÓN EN BASE A LOS 3 ÚLTIMOS MESES

IDENTIFICACIÓN DEL PACIENTE:

Fecha de inclusión en el programa: $\square \square / \square \square / \square \square$ dd/mm/aa

Fecha de revisión 3 meses $\square \square / \square \square / \square \square$ dd/mm/aa

Cuestionario elaborado de forma: $\square$ Presencial $\square$ Telefónica

\section{ASPECTES PSICOLÒGICS. HAD}

LEER A continuación le preguntaré por cómo usted se ha encontrado de ánimos en la última semana. Leeré cada pregunta y usted me contestará la respuesta que considere que coincida con su propio estado emocional en la última semana. Espere a que yo le lea las respuestas posibles. No es necesario que piense mucho tiempo cada respuesta; en este cuestionario las respuestas espontáneas son de mayor valor que las que se piensan mucho.

\begin{tabular}{|c|c|c|}
\hline & $\begin{array}{l}\text { A } \\
3 \\
2 \\
1 \\
0\end{array}$ & $\begin{array}{l}\text { Me siento tenso /a o nervioso /a: } \\
\text { Casi todo el día } \\
\text { Gran parte del día } \\
\text { De vez en cuando } \\
\text { Nunca }\end{array}$ \\
\hline $\begin{array}{l}\mathrm{D} \\
0 \\
1 \\
2 \\
3\end{array}$ & & $\begin{array}{l}\text { Sigo disfrutando con las mismas cosas de siempre: } \\
\text { Ciertamente, igual que antes } \\
\text { No tanto como antes } \\
\text { Solamente un poco } \\
\text { Ya no disfruto con nada }\end{array}$ \\
\hline & $\begin{array}{l}\text { A } \\
3 \\
2 \\
1 \\
0\end{array}$ & $\begin{array}{l}\text { Siento una especie de temor como si algo malo fuera a suceder: } \\
\text { Sí y muy intenso } \\
\text { Sí pero no muy intenso } \\
\text { Sí pero no me preocupa } \\
\text { No siento nada de eso }\end{array}$ \\
\hline $\begin{array}{l}0 \\
1 \\
2 \\
3\end{array}$ & & $\begin{array}{l}\text { Soy capaz de reírme y ver el lado gracioso de las cosas: } \\
\text { lgual que siempre } \\
\text { Actualmente, algo menos } \\
\text { Actualmente, mucho menos } \\
\text { Actualmente, en absoluto }\end{array}$ \\
\hline & $\begin{array}{l}\text { A } \\
3 \\
2 \\
1 \\
0\end{array}$ & $\begin{array}{l}\text { Tengo la cabeza llena de preocupaciones: } \\
\text { Casi todo el día } \\
\text { Gran parte del día } \\
\text { De vez en cuando } \\
\text { Nunca }\end{array}$ \\
\hline $\begin{array}{l}\mathrm{D} \\
3 \\
2 \\
1 \\
1 \\
0\end{array}$ & & $\begin{array}{l}\text { Me siento alegre: } \\
\text { Nunca } \\
\text { Muy pocas veces } \\
\text { En algunas ocasiones } \\
\text { Gran parte del día }\end{array}$ \\
\hline & $\begin{array}{l}\text { A } \\
0 \\
1 \\
2 \\
3\end{array}$ & $\begin{array}{l}\text { Soy capaz de permanecer sentado /a tranquila y relajadamente: } \\
\text { Siempre } \\
\text { A menudo } \\
\text { Raras veces } \\
\text { Nunca }\end{array}$ \\
\hline $\begin{array}{l}3 \\
2 \\
1 \\
0\end{array}$ & & $\begin{array}{l}\text { Me siento lento la y torpe: } \\
\text { Gran parte del día } \\
\text { A menudo } \\
\text { A veces } \\
\text { Nunca }\end{array}$ \\
\hline & $\begin{array}{l}\text { A } \\
0 \\
1 \\
2 \\
3\end{array}$ & $\begin{array}{l}\text { Experimento una sensación de "nervios y hormigueos" en el estómago: } \\
\text { Nunca } \\
\text { Sólo en algunas ocasiones } \\
\text { A menudo } \\
\text { Muy a menudo }\end{array}$ \\
\hline $\begin{array}{l}3 \\
2\end{array}$ & & $\begin{array}{l}\text { He perdido el interés por mi aspecto personal: } \\
\text { Completamente } \\
\text { No me cuido como debería hacerlo }\end{array}$ \\
\hline
\end{tabular}




\begin{tabular}{|c|c|c|}
\hline $\begin{array}{l}1 \\
0\end{array}$ & & $\begin{array}{l}\text { Es posible que no me cuide como debiera } \\
\text { Me cuido como siempre lo he hecho }\end{array}$ \\
\hline & $\begin{array}{l}\text { A } \\
3 \\
2 \\
1 \\
0\end{array}$ & $\begin{array}{l}\text { Me siento inquieto /a como si no pudiera parar de moverme: } \\
\text { Realmente mucho } \\
\text { Bastante } \\
\text { No mucho } \\
\text { En absoluto }\end{array}$ \\
\hline $\begin{array}{l}0 \\
1 \\
2 \\
3\end{array}$ & & $\begin{array}{l}\text { Espero las cosas con ilusión: } \\
\text { Como siempre } \\
\text { Algo menos que antes } \\
\text { Mucho menos que antes } \\
\text { En absoluto }\end{array}$ \\
\hline & $\begin{array}{l}\text { A } \\
3 \\
2 \\
1 \\
0\end{array}$ & $\begin{array}{l}\text { Experimento de repente sensaciones de gran angustia o temor: } \\
\text { Muy a menudo } \\
\text { Con cierta frecuencia } \\
\text { Raramente } \\
\text { Nunca }\end{array}$ \\
\hline $\begin{array}{l}0 \\
1 \\
2 \\
3\end{array}$ & & $\begin{array}{l}\text { Soy capaz de disfrutar con un buen libro o con un buen programa de radio o televisión: } \\
\text { A menudo } \\
\text { Algunas veces } \\
\text { Pocas veces } \\
\text { Casi nunca }\end{array}$ \\
\hline
\end{tabular}

1.Puntuació total: 1.1 Ansiedad

(Indique el valor numérico)

1.2 Depresión

(Indique el valor numérico) 


\section{CAT (calidad de vida)}

Indique la casilla que mejor describa su estado actual:

Este cuestionario les ayudará a usted y al profesional del cuidado de la salud a medir el impacto que la EPOC (enfermedad pulmonar obstructiva crónica) está teniendo en su bienestar y su vida diaria. Sus respuestas y la puntuación de la prueba pueden ser utilizadas por usted y por el profesional del cuidado de la salud para ayudar a mejorar el manejo de la EPOC y obtener el máximo beneficio del tratamiento.

En cada uno de los siguientes enunciados, ponga una $X$ en la casilla que mejor describa su estado actual.Asegúrese de seleccionar sólo una respuesta para cada pregunta.

Ejemplo: Estoy muy contento

PUNTUACIÓN

Nunca toso (0) (1) (2) Siempre estoy tosiendo

No tengo flema

(mucosidad) en el pecho

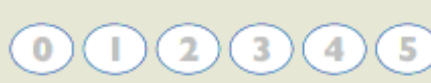

Tengo el pecho

completamente lleno de

flema (mucosidad)

No siento ninguna opresión

en el pecho

(0) (1) (2) (3) (4) (5)

Siento mucha opresión

en el pecho

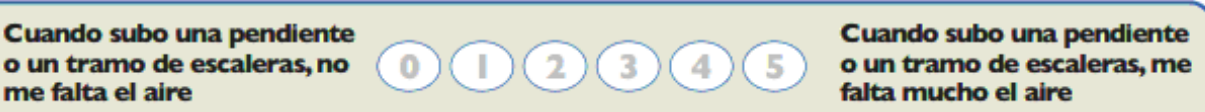

me falta el aire

falta mucho el aire

\section{No me siento limitado para \\ realizar actividades \\ domésticas \\ Me siento muy limitado \\ para realizar actividades \\ domésticas}

\begin{tabular}{lll}
\hline $\begin{array}{l}\text { Me siento seguro al salir } \\
\text { de casa a pesar de la } \\
\text { enfermedad pulmonar } \\
\text { que padezco }\end{array}$ & $\begin{array}{l}\text { No me siento nada seguro } \\
\text { al salir de casa debido a la } \\
\text { enfermedad pulmonar que } \\
\text { padezco }\end{array}$ \\
\hline
\end{tabular}

Duermo sin problemas (1) (2) (3) (5) $\begin{aligned} & \text { Tengo problemas para } \\ & \text { debido a la enfermedad }\end{aligned}$ pulmonar que padezco

Tengo mucha energía (1) (2) (3) No tengo ninguna energía 
INSTRUCCIONES: Este cuestionario está hecho para ayudarnos a saber mucho más sobre sus problemas respiratorios y cómo le afectan a su vida. Usamos el cuestionario, no tanto para conocer los problemas que los médicos y las enfermeras piensan que usted tiene, sino para saber qué aspectos de su enfermedad son los que le causan más problemas. Por favor, lea atentamente las instrucciones y pregunte lo que no entienda. No se entretenga demasiado en decidir las respuestas.

Conteste cada pregunta señalando con una cruz el cuadro correspondiente a la respuesta elegida, (ASÍ $\mathrm{X}$ ).

Toda la información será confidencial.

A continuación algunas preguntas para saber cuántos problemas respiratorios ha tenido durante el último año. Por favor, para cada pregunta marque la respuesta que corresponda.

$\begin{array}{lcccc}\text { Casi todos } & \text { Varios } & \text { Unos } & \begin{array}{c}\text { Sólo cuando } \\ \text { tuve infección }\end{array} & \text { Nada en } \\ \text { los días de } & \text { días a la } & \text { pocos días } & \text { en los } & \text { absoluto } \\ \text { la semana } & \text { semana } & \text { al mes } & \text { pulmones } & \end{array}$

1. Durante el último año, cha tenido tos?

$2 \square \quad \ldots 3 \square \quad \ldots$

$4 \square$

$5 \square$

2. Durante el último año,

¿ha arrancado?

(sacar esputos)

2

$3 \square$

$4 \square$

$5 \square$

3. Durante el último año, cha tenido ataques de falta de respiración?

$1 \square$ 2 $3 \square$ $4 \square \quad$--- $5 \square$

4. Durante el último año, cha tenido ataques de pitos o silbidos en los pulmones? (1)
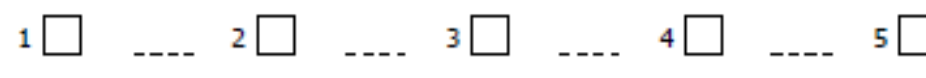
5. Durante el último año, ¿cuántos ataques tuvo por problemas respiratorios que fueran graves o muy desagradables?

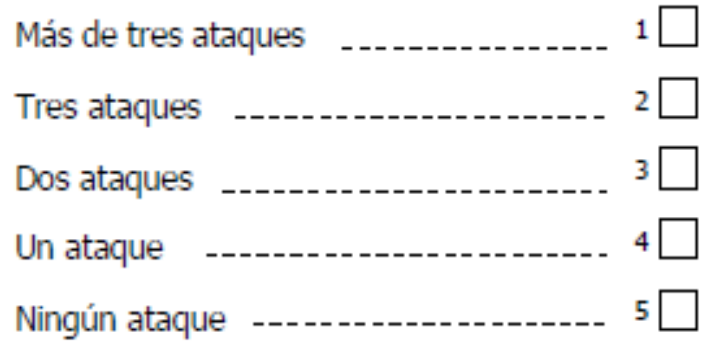

6. ¿Cuánto le duró el peor de los ataques que tuvo por problemas respiratorios?

(SI NO TUVO NINGÚN ATAQUE SERIO VAYA A LA PREGUNTA 7)

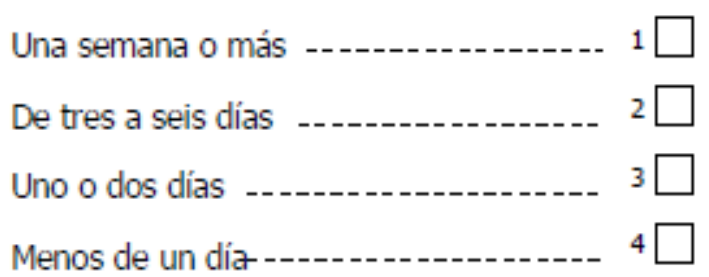

7. Durante el último año, ¿cuántos días buenos (con pocos problemas respiratorios) pasaba en una semana habitual?

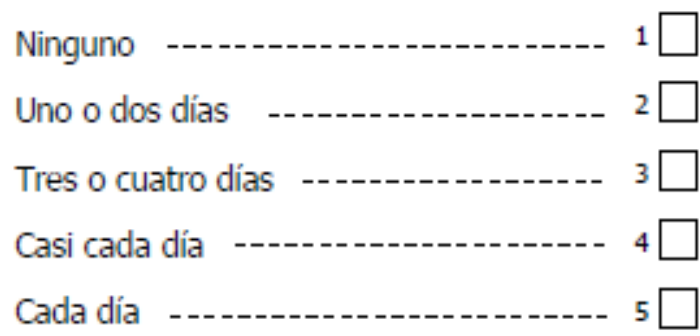

8. Si tiene pitos o silbidos en los pulmones, ¿son peores por la mañana?

(SI NO TIENE PITOS O SILBIDOS EN LOS PULMONES VAYA A LA PREGUNTA 9)

No

1

Sí

2 
9. ¿Cómo diría usted que está de los pulmones?, Por favor, marque una sola de las siguientes frases:

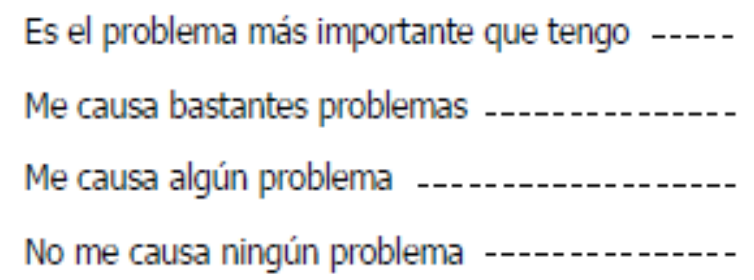

1

$2 \square$

$3 \square$

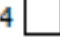

10. Si ha tenido algún trabajo remunerado, por favor marque una sola de las siguientes frases:

(SI NO HA TENIDO UN TRABAJO REMUNERADO VAYA A LA PREGUNTA 11)

Mis problemas respiratorios me obligaron a dejar de trabajar 1

Mis problemas respiratorios me dificultan en mi trabajo o me obligaron a cambiar de trabajo

Mis problemas respiratorios no me afectan (o no me afectaron) en mi trabajo

11. A continuación algunas preguntas sobre las actividades que últimamente le pueden hacer sentir que le falta la respiración. Por favor, para cada pregunta marque la respuesta que corresponda:

Me falta la respiración estando sentado o incluso estirado

Me falta la respiración cuando me lavo o me visto

Me falta la respiración al caminar por dentro de casa

Me falta la respiración al caminar por fuera de casa, en terreno llano

Me falta la respiración al subir un tramo de escaleras

Me falta la respiración al subir una cuesta

Me falta la respiración al hacer deporte 0 al jugar 
12. Algunas preguntas más sobre la tos y la falta de respiración que tiene últimamente. Por favor, para cada pregunta marque la respuesta que corresponda:

Tengo dolor cuando toso

Me canso cuando toso

Me falta la respiración cuando hablo

Me falta la respiración cuando me agacho

La tos o la respiración me molestan cuando duermo

13. A continuación algunas preguntas sobre otras consecuencias que sus problemas respiratorios le pueden causar últimamente. Por favor, para cada pregunta marque la respuesta que corresponda:

La tos o la respiración me dan vergüenza en público

Mis problemas respiratorios son una molestia para mi familia,

mis amigos o mis vecinos

Me asusto o me alarmo cuando no puedo respirar ---.-------------.-

Siento que no puedo controlar mis problemas respiratorios

Creo que mis problemas respiratorios no van a mejorar

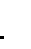

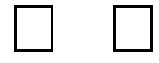

Por culpa de mis problemas respiratorios me he convertido en una persona débil o inválida

Hacer ejercicio es peligroso para mi 
14. A continuación algunas preguntas sobre su medicación.

(SÍ NO ESTÁ TOMANDO NINGUNA MEDICACIÓN, VAYA A LA PREGUNTA 15)

Creo que la medicación me sirve de poco

Me da vergüenza tomar la medicación en público

La medicación me produce efectos desagradables

La medicación me altera mucho la vida

(1)

)

15. Estas preguntas se refieren a cómo sus problemas respiratorios pueden afectar sus actividades. Por favor, para cada pregunta marque la respuesta que corresponda:

Tardo mucho para lavarme o vestirme

Me resulta imposible ducharme o bañarme o tardo mucho rato<smiles>[CH]</smiles>

Camino más despacio que los demás, o tengo que pararme a descansar

Tardo mucho para hacer trabajos como las tareas domésticas, o tengo que parar a descansar

Para subir un tramo de escaleras, tengo que ir despacio o parar

Si he de correr o caminar rápido, tengo que parar o ir más despacio

Mis problemas respiratorios me dificultan hacer cosas tales como subir una cuesta, llevar cosas por las escaleras, caminar durante un buen rato, arreglar un poco el jardín, bailar, o jugar a los bolos

(0) (1)

Mis problemas respiratorios me dificultan hacer cosas tales como llevar cosas pesadas, caminar a unos $7 \mathrm{kms}$ por hora, hacer "jogging", nadar, jugar a tenis, cavar en el jardín o quitar la nieve con una pala

Mis problemas respiratorios me dificultan hacer cosas tales como un trabajo manual muy pesado, correr, ir en bicicleta, nadar rápido o practicar deportes de competición 
16. Nos gustaría saber ahora como sus problemas respiratorios le afectan normalmente en su vida diaria. Por favor, para cada pregunta marque la respuesta que corresponda:

Puedo hacer deportes o jugar

Puedo salir a distraerme o divertirme

Puedo salir de casa para ir a comprar

Puedo hacer el trabajo de la casa

Puedo alejarme mucho de la cama o de la silla

A continuación hay una lista de otras actividades que sus problemas respiratorios pueden impedirle hacer. No tiene que marcarlas, sólo son para recordarle la manera como sus problemas respiratorios pueden afectarle.

- Ir a pasear o sacar a pasear el perro.

- Hacer el amor.

- Visitar a la familia o a los amigos, o jugar con los niños.
- Hacer cosas en la casa o en el jardín.

- Ir a la iglesia, al bar, al club o a su lugar de distracción.

- Salir cuando hace mal tiempo o estar en habitaciones llenas de humo.

Por favor, escriba aqui cualquier otra actividad importante que sus problemas respiratorios le impidan hacer:

17. A continuación, ¿podría marcar la frase (sólo una) que usted crea que describe mejor como le afectan sus problemas respiratorios?

No me impiden hacer nada de lo que quisiera hacer $-1$

Me impiden hacer 1 o 2 cosas de las que quisiera hacer 2

Me impiden hacer la mayoría de cosas que quisiera hacer .... 3

Me impiden hacer todo lo que quisiera hacer $4 \square$

\section{Gracias por contestar a estas preguntas}




\section{CUESTIONARIOS DE SOPORTE}

I. ÍNDICE DE BARTHEL
Comer
$\square$ (0) Incapaz
$\square$ (5) Necesita ayuda para cortar y utilizar los cubiertos
$\square$ (10) Independente

\section{Bañarse/ducharse}

(0) Dependente

$\square$ (5) Independente

Higiene personal

$\square(0)$ Necesita ayuda con la higiene personal

$\square$ (5) Independente para lavarse la cara, les manos y los dientes, peinarse y afeitarse.

\section{Vestirse y desvestirse}

$\square$ (0) Dependente

$\square$ (5) Necesita ayuda però puede hacer la mitad, aproximadamente sin ayuda.

$\square$ (10) Independente, hasta con los botones, cremalleras, cordones, etc.

\section{Control de las heces}

$\square$ (0) Incontinente

$\square$ (5) Accidente excepcional (una/semana)

$\square$ (10) Continente

Control de la orina

(0) Incontinente (o con sonda incapaz de cambiarse la bolsa)

$\square$ (5) Accidente excepcional (màximo unas/24 horas)

$\square$ (10) Continente

Úso del W.C.
$\square$ (0) Dependente
$\square$ (5) Necesita algun tipo de ayuda, però puede hacer cosas solo/a
$\square$ (10) Independente (entrar y salir, limpiarse y vestirse)

\section{Desplazarse de la silla a la cama y al revés}

$\square$ (0) Incapaz, no se mantiene sentado

$\square$ (5) Necesita ayuda importante (una persona entrenada o dos personas)

$\square$ (10) Necesita alguna ayuda (una pequeña ajuda física o ayuda verbal)

$\square$ (15) Independente
Desplaçarse
(0) Immòbil o < 40 metros
$\square$ (5) Independente con silla de ruedas, rincones incluidos $>40$ metros
$\square$ (10) Camina con ayuda de otra persona (ayuda verbal o física $>40$ metros)
$\square$ (15) Independente

\section{Subir y bajar escaleras}

$\square$ (0) Incapaz

$\square$ (5) Necesita ayuda (física o verbal, para llevar cualquier tipo de muleta)

$\square$ (10) Independente para subir y bajar.

2. VALOR TOTAL ÍNDICE DE BARTHEL $\square \square \square$ (Indique el valor numérico) 


\begin{tabular}{|c|c|}
\hline E COMORBIDIDAD DE CHARLSON & \\
\hline Diagnòstico: & Puntuación: \\
\hline $\begin{array}{l}\text { Infarto de miocardio: (Tiene que existir evidència en la història clínica de que el paciente ha estado } \\
\text { hospitalizado por esto o bien evidència de que existieron cambios enzimàticos y/o al ECG). }\end{array}$ & 1 \\
\hline $\begin{array}{l}\text { Insuficiència cardíaca: (Tiene que existir història de disnea de esfuerzo y/o signos de insuficiència cardíaca en } \\
\text { la exploració física, que respondieron favorablement al tratamienot con digital, diurèticos o vasodilatadores. Los } \\
\text { pacientes que esten tomando este tratamiento però que no pueden constatar que haya existido mejoria clínica } \\
\text { de los signos y/o síntomas NO se incluira como tal). }\end{array}$ & 1 \\
\hline $\begin{array}{l}\text { Enfermedad arterial perifèrica: (Incluye claudicación intermitente, intervenidos de by-pass arterial perifèrico, } \\
\text { isquèmia arterial aguda y aquellos con aneurisma de aorta -toràcica o abdominal- de >6 cm de diàmetro). }\end{array}$ & 1 \\
\hline Enfermedad cerebrovascular: (Pacientes con ACV con secuelas mínimas o ACV transitorio). & 1 \\
\hline Demència: (Pacientes con evidència en la història clínica de deterioramento cognitivo crònico). & 1 \\
\hline $\begin{array}{l}\text { Enfermedad respiratòria crònica: (Tiene que existir evidència en la història clínica, en la exploración física y } \\
\text { en la exploración complementària de cualquier enfermedad respiratòria crònica, incluidas la EPOC y el asma). }\end{array}$ & 1 \\
\hline $\begin{array}{l}\text { Enfermedad del tejido conectivo: (Incluye lupus, polimiositis, enfermedad mixta, polimiàlgia reumàtica, arteritis } \\
\text { celular y artritis reumatoide). }\end{array}$ & 1 \\
\hline $\begin{array}{l}\text { Úlcera gastroduodenal: (Incluye aquellos que han rechazado tratamiento por ulcus y aquellos que han tenido } \\
\text { sangrados por úlceras). }\end{array}$ & 1 \\
\hline Hepatopatia crònica lleu: (Sin evidència de hipertensión portal, incluye pacientes con hepatitis crònica). & 1 \\
\hline $\begin{array}{l}\text { Diabetes: (Incluye los tratados con insulina o hipoglucemiantes, però sin complicaciones tardias. NO se incluiran } \\
\text { los tratados con dieta únicamente). }\end{array}$ & 1 \\
\hline Hemiplegia: (Evidència de hemiplegia o paraplegia como una conseqüència de un AVC u otra condición). & 2 \\
\hline $\begin{array}{l}\text { Insuficiència renal crònica moderada/severa: (Incluye pacientes en diàlisis, o bien con creatinina > } 3 \mathrm{mg} / \mathrm{dl} \\
\text { objectivada de manera repetida y mantenida). }\end{array}$ & 2 \\
\hline $\begin{array}{l}\text { Diabetes con lesión en òrganos diana: (Evidència de retinopatia, neuropatia o nefropatia. Se incluyen también } \\
\text { antecedentes de cetoacidosi o descompensación hiperosmolar). }\end{array}$ & 2 \\
\hline Tumor o neoplàsia sòlida: (Incuyen pacientes con càncer, però sin metàstasis documentadas). & 2 \\
\hline $\begin{array}{l}\text { Leucèmia: (Incluyen leucèmia mieloide crònica, leucèmia linfàtica crònica, policitèmia severa, otras leucèmias } \\
\text { cronicas y todas las leucèmias agudas). }\end{array}$ & 2 \\
\hline Linfoma: (Incluyen todos los linfomas, Waldestrom y mielomas). & 2 \\
\hline $\begin{array}{l}\text { Hepatopatia crònica moderada/severa: (Con evidència de hipertensión portal (ascitis, varias esofàgicas o } \\
\text { encefalopatia). }\end{array}$ & 3 \\
\hline Tumor o neoplàsia sòlida con metàstasis & 6 \\
\hline Sida definido: (No incluye portadores asintomaticos). & 6 \\
\hline
\end{tabular}

Modificado por edad. Añadir 1 punto por cada década a partir de los 40 años. Si el valor del índice es 0 no se añade puntuación por edad. 


\section{Anexo V. Recomendaciones para implementar los cuestionarios}

\section{El cuestionario I. Cuestionarios de revisión de la historia clínica (12 meses} previos al ingreso)

En la identificación del paciente en los cuestionarios no es necesario cumplimentar este ítem hasta no haber obtenido la aleatorización del paciente con la identificación del código generado. Este cuestionario debe implementarse con los datos de la historia clínica de los últimos 12 meses previos. Las pruebas funcionales si no han estado realizadas en los últimos 12 meses previos quedaran registradas como No consta.

El apartado de comorbilidad únicamente aparece en los cuestionarios un apartado de resultado pudiendo tener el cuestionario completo en lo cuestionarios de soporte que constan en este libro blanco.

El número de comorbilidades se basa en el número de enfermedades crónicas que tiene el paciente cuantificadas con un valor numérico.

\section{El cuestionario II. Entrevista con el paciente. Evaluación del paciente durante el ingreso.}

\section{Síntomas:}

En la identificación del paciente en los cuestionarios no es necesario cumplimentar este ítem hasta no haber obtenido la aleatorización del paciente con la identificación del código generado.

En el apartado de síntomas habituales, se recogen los síntomas que normalmente el paciente tiene no en su estado actual de agudización, el grado de disnea recogido en este cuestionario esta como (MRC) según la escala que se indica en las siguientes filas. La valoración del dolor se realiza según intensidad a través de la escala EVA, donde el valor numérico 0 se identifica como nada de dolor y el valor 10 el máximo dolor.

\section{Datos sociodemograficos:}

En el apartado 2.5 de quien está viviendo con usted, la respuesta puede ser múltiple ya que el paciente puede estar viviendo con más de una persona, en caso de vivir con otras personas que no están indicadas en este cuestionario es necesario registrarlas en otros escribiendo el tipo de relación.

\section{Tratamiento farmacológico:}

En este apartado si el paciente no recuerda el número de pastillas, inyecciones o inhaladores, se puede solicitar la última receta electrónica para recoger estas variables.

\section{Técnica inhalada:}

En este apartado es necesario realizar una valoración de la técnica inhalatoria, de los dispositivo utilizados por el paciente, tantas valoraciones como dispositivos tenga el paciente, utilizando los placebos que existen en la unidad. La no realización de alguno de los pasos indicados se valorara como una mala realización de la práctica inhalatoria.

\section{Adherencia farmacológica (Morisky-Green)}

Este cuestionario es necesario realizarlo como una conversación, se recomienda iniciar este cuestionario como :

"Hay muchas personas que le cuesta seguir el tratamiento por el médico ya que son muchas las pastillas que tienen que tomar y es normal que los olvidos estén presentes o se olvide de tomarse esa medicación en las horas indicadas ya que se encuentra bien o no le hace ningún efecto cuando se encuentra mal". 
Se considera que el paciente es cumplidos cuando contesta de forma correcta a las 4 preguntas del cuestionario registrándose en la parte inferior como $\mathrm{Si}$, pero si el paciente solo contesta de forma correcta a tres o menos preguntas se valorara como no cumplidos No.

\section{$\underline{\text { VI. Factores de riesgo }}$}

En este apartado si el paciente es fumador se entregara al paciente el cuestionario autoadministrado de Fagerström. La dosis acumulada de paquetes de tabaco se calcula ((cigarrillos fumados al día por el paciente $\mathrm{x}$ años que el paciente fuma o a fumado) / 20) El cálculo de cigarrillos al día en pacientes fumadores de pipa equivale a 3 cigarros, si el paciente fuma puros pequeños equivale a 3 cigarros y si el paciente fuma puros grandes equivalen a 5 cigarros.

El índice de masa corporal $(\mathrm{IMC})$ se calcula $=$ peso/altura ${ }^{2}$

La ingesta de líquidos se considera un vaso $250 \mathrm{cc}$

IX. Conocimiento de la/las patología/as crónica/s

Se debe escribir lo que dice el paciente y posteriormente clasificarlo si es correcta o incorrecta la respuesta.

En el apartado 9.1 se consideran como correctas las respuestas si el paciente dice, EPOC, bronquitos crónica o enfisema pulmonar.

En el apartado 9.2 se consideran como correctas las respuestas si el paciente dice, aumento del ahogo, aumento del esputo, cambio del color de las secreciones, fiebre, aparición de tos, edemas en los pies, somnolencia y cianosis.

En el aparatado 9.3 se consideran como correctas las respuestas si el paciente dice, $\beta_{2}$ corta duración, salbutamol, ventolinß.

X. Atención sanitaria:

Un programa de educación terapéutica se considera como un proceso de aprendizaje estructurado durante un período de tiempo determinado que sigue el paciente y su familia con el soporte de un profesional de la salud con unos objetivos concretos y resultados medibles. Generalmente, se trata de sesiones individuales o en grupos donde se tratan temas específicos de la enfermedad con el objetivo de conocer mejor la patología y mejorar el cumplimiento terapéutico.

Si el paciente contesta que "si" a acudido a un programa de educación terapéutica debe de contestar a las preguntas 10.5 y 10.6. Pero si por contra el paciente contesta que "no" a acudido a ningún programa de educación terapéutica debe de pasar a la pregunta 10.7 .

$\underline{\text { XI Dependencia de las actividades de la vida diaria }}$

Este ítem se valora a través del índice de Barthel, disponible el cuestionario completo en el apartado de material de soporte del libro blanco.

XII. Escala Canadiense sobre salud y envejecimiento

Este cuestionario debe de realizarse a través de la emisión de un juicio del entrevistador y el paciente debe de corroborar o en caso contrario pactar junto con el paciente el estado de salud del mismo.

"Creo que usted esta aparentemente vulnerable ya que no depende de otros para hacer las cosa pero por lo que me comenta las realiza de forma más enlentecidas que antes por su enfermedad, es esto correcto".

\section{Cuestionario III. Cuestionario de autocumplimentación en base a los 12 últimos} $\underline{\text { meses }}$

En la identificación del paciente en los cuestionarios no es necesario cumplimentar este ítem hasta no haber obtenido la aleatorización del paciente con la identificación del código generado.

I. Aspecto psicológico. HAD 
Es necesario en el momento de dar el cuestionario al paciente explicar cómo se cumplimenta el mismo, para que el paciente lo puede elaborar de forma satisfactoria. Bien puede realizar una cruz o un circulo según tenga una mayor conformidad con los ítem que hay se indican, seleccionando solo un ítem de los indicados en cada apartado.

II. CAT (Calidad de vida)

Este cuestionario refleja el estado actual en el ingreso no el habitual que ya se había preguntado anteriormente. Indicándose solo un valor de los posibles, que van de menos a más. 


\section{INFORMACIÓN SOBRE EL PROYECTO Estudio de intervención para la prevención de la exacerbación por EPOC}

Nos dirigimos a usted para informarle de que estamos realizando un programa sobre su enfermedad respiratoria crónica (EPOC). En el Hospital Universitario General de Castellón.

Los pacientes con EPOC, sufren frecuentes agudizaciones de su enfermedad lo que hace que deban acudir en numerosas ocasiones a los servicios de urgencias de los hospitales, ya sea por indicación del médico o por voluntad propia y esto genera un empeoramiento de su estado de salud.

El objetivo de este proyecto que le proponemos es conocer mejor al paciente con EPOC y si a través de un programa de prevención de las exacerbaciones basados en la guía de práctica clínica de GesEPOC, somos capaces de proporcionar una mejor atención socio-sanitaria. Por tanto, el estudio plantea dos estrategias de tratamiento, programa convencional (tratamiento actual) y de programa específico de intervención (seguimiento actual +educación sanitaria). Los conocimientos generados pueden ser muy útiles para decidir qué tratamientos o qué tipo de seguimiento son los más adecuados para mejorar el pronóstico de cada paciente.

Usted ha sido escogido para ser incluido en este ensayo clínico. Dicho programa no pretende sustituir ningún tipo de seguimiento que usted está realizando sino todo lo contrario. Es por esta razón que le pedimos su colaboración, que consistirá en contestar una serie de cuestionarios durante el ingreso hospitalario, a las 3 semanas y a los 3 meses del alta.

Su participación en el estudio es voluntaria pero necesaria, no sólo para mejorar los conocimientos actuales sobre las enfermedades respiratorias crónicas, sino también porque con estos conocimientos podremos atender mejor a usted y otras personas con las mismas molestias. Además de solicitarle su colaboración en el programa, nos gustaría que nos diera su consentimiento para que estos datos se puedan almacenar y analizar para los fines del proyecto en los próximos 10 años.

El proyecto está abierto a todas aquellas personas con EPOC seleccionadas previamente por el equipo clínico especializado que haya presenta exacerbaciones frecuentes (dos o más agudizaciones moderadas o graves) durante el periodo de estudio.

Si decide participar en el proyecto debe cumplimentar la siguiente declaración de consentimiento informado una vez sea informado por el equipo de profesionales que participan en el estudio.

Si usted ha firmado la declaración de consentimiento informado será asignado aleatoriamente a un grupo de estudio o de control. Las personas asignadas al Grupo de Estudio se incluirán en un programa de educación respiratoria que se compone estrategias para dejar de fumar, entrenamiento para facilitar la eliminación de las secreciones bronquiales, manejo de la medicación, consejo nutricional y estrategias de motivación. Aquellos pacientes asignados a un Grupo de Control seguirán recibiendo la misma calidad de asistencia sanitaria que reciben actualmente. Sin embargo, al inicio, a los 3 meses de su incorporación en el estudio se les pedirá que rellenen algunos cuestionarios.

Las personas asignadas al grupo de control jugarán un papel esencial, ya que al comparar su evolución con la del grupo de estudio, podremos establecer de una manera científica si el uso de la tecnología tiene un efecto positivo o simplemente neutro en la frecuencia de exacerbaciones de su enfermedad respiratoria crónica, y consecutivamente, en la frecuencia del uso de servicios sanitarios. 


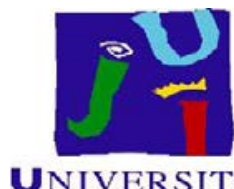

UNIVERSITAT

JAUME•I

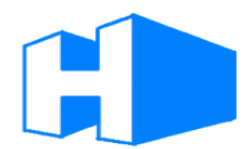

HOSPITAL UNIVERSITARI

GENERAL DE CASTELLó

\section{CONSENTIMIENTO INFORMADO POR ESCRITO}

Estudio de intervención para la prevención de la exacerbación por EPOC.

Yo,

- He leído la hoja de información que me han entregado en la que me han informado suficientemente de las pruebas y tratamientos que recibiré como consecuencia de la investigación que se practica.

- He podido hacer preguntas sobre el estudio.

- Estoy de acuerdo y acepto libre y voluntariamente recibir única y exclusivamente este tratamiento y me comprometo a seguir las prescripciones y a formalizar los cuestionarios que se presenten.

- Puedo abandonar el tratamiento/colaboración en el momento que lo desee, sin tener que dar explicaciones y sin que esto repercuta en mis cuidados médicos.

- El terapeuta puede decidir la finalización del tratamiento si no cumplo un mínimo de las pautas establecidas que posibilite un tratamiento adecuado.

- Salvaguardando siempre el derecho a la intimidad, acepto que los datos que se puedan derivar de esta investigación puedan ser utilizados para la divulgación científica

Firma del paciente

Nombre y apellidos:

Fecha:
Firma de la investigadora:

Nombre y apellidos 